\title{
Pain-related fear in acute low back pain : the prognostic impact on performance, disability, and participation
}

Citation for published version (APA):

Swinkels-Meewisse, I. E. (2006). Pain-related fear in acute low back pain : the prognostic impact on performance, disability, and participation. [Doctoral Thesis, Maastricht University]. Universitaire Pers Maastricht. https://doi.org/10.26481/dis.20060622is

Document status and date:

Published: 01/01/2006

DOI:

10.26481/dis.20060622is

Document Version:

Publisher's PDF, also known as Version of record

Please check the document version of this publication:

- A submitted manuscript is the version of the article upon submission and before peer-review. There can be important differences between the submitted version and the official published version of record.

People interested in the research are advised to contact the author for the final version of the publication, or visit the DOI to the publisher's website.

- The final author version and the galley proof are versions of the publication after peer review.

- The final published version features the final layout of the paper including the volume, issue and page numbers.

Link to publication

\footnotetext{
General rights rights.

- You may freely distribute the URL identifying the publication in the public portal. please follow below link for the End User Agreement:

www.umlib.nl/taverne-license

Take down policy

If you believe that this document breaches copyright please contact us at:

repository@maastrichtuniversity.nl

providing details and we will investigate your claim.
}

Copyright and moral rights for the publications made accessible in the public portal are retained by the authors and/or other copyright owners and it is a condition of accessing publications that users recognise and abide by the legal requirements associated with these

- Users may download and print one copy of any publication from the public portal for the purpose of private study or research.

- You may not further distribute the material or use it for any profit-making activity or commercial gain

If the publication is distributed under the terms of Article $25 \mathrm{fa}$ of the Dutch Copyright Act, indicated by the "Taverne" license above, 


\section{Pain-related fear in acute low back pain}

The prognostic impact on performance, disability, and participation 
All rights reserved. No part of this book may be reproduced, stored in a retrieval system or transmitted in any form or by any means, without written permission of the copyright owner.

() 2006 E.J.C.M. Swinkels-Meewisse, Eindhoven, the Netherlands.

ISBN-10: 905278-536-8

ISBN-13: $978-905278-536-3$

Photography Cover: Koppelmans fotografie

Coverdesign: Datawyse

Printed by Datawyse / Universitaire Pers Maastricht

Part of the studies presented in this thesis have been supported by the Royal Dutch Association of Physiotherapists.

Financial support for the printing of this thesis has been kindly provided by the Royal Dutch Association of Physiotherapists (KNGF), the Dutch Association for Manual Therapy (NVMT), and the Anna Fonds. 


\title{
Pain-related fear in acute low back pain
}

\author{
The prognostic impact on performance, \\ disability, and participation
}

\author{
PROEFSCHRIFT \\ ter verkrijging van de graad van doctor \\ aan de Universiteit Maastricht, \\ op gezag van de Rector Magnificus, \\ Prof. mr. G.P.M.F. Mols \\ volgens het besluit van het College van Decanen, \\ in het openbaar te verdedigen \\ op donderdag 22 juni 2006 om 16.00 uur
}

door

Ilse (Elisabeth, Jacoba, Cornelia, Maria) Swinkels-Meewisse

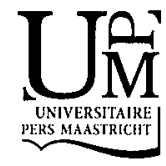




\section{Promotores}

Prof. dr. J.W.S. Vlaeyen

Prof. dr. R.A.B. Oostendorp (Radboud Universiteit Nijmegen)

Prof. dr. A.L.M. Verbeek (Radboud Universiteit Nijmegen)

\section{Copromotor}

Dr. J. Roelofs

\section{Beoordelingscommissie}

Prof. dr. R.A. de Bie (voorzitter)

Prof. dr. L..M. Bouter (Vrije Universiteit, Amsterdam)

Prof. dr. S.J. Linton (Örebrö University, Sweden)

Prof. dr. J.F.M. Metsemakers

Dra. M.L. Peters 


\section{Contents}

\section{Chapter 1}

Introduction

\section{Chapter 2}

Psychometric properties of the Tampa Scale for Kinesiophobia and the

Fear-Avoidance Beliefs Questionnaire in acute low back pain

Reply to Letter to the Editor

\section{Chapter 3}

Assessing pain and pain-related fear in acute low back pain: what is the minimal detectable change?

\section{Chapter 4}

Fear-avoidance beliefs, disability and participation in workers and nonworkers with acute low back pain

\section{Chapter 5}

Fear of movement/(re)injury, disability and participation in acute low

back pain

\section{Chapter 6}

Fear of movement/(re)injury predicting chronic disabling low back pain:

a prospective inception cohort study

\section{Chapter 7}

Acute low back pain: pain-related fear and pain catastrophizing influence physical performance and perceived disability

\section{Chapter 8}

Prediction of pain by acute back pain patients: effects of exposure to physical activity

\section{Chapter 9}

General discussion 
Samenvatting

Dankwoord

About the author

Publications 


\section{Chapter 1}

Introduction 


\section{General introduction}

Low Back Pain (LBP) is a common health complaint, which causes not only a significant public health problem but also a great personal burden for those affected. In industrial countries, lifetime prevalences of LBP vary between $60 \%$ and $90 \%$, with the peak prevalence occurring between ages 35 and $55(2)$. In The Netherlands, the incidence of patients reporting LBP to general practitioners is 3239 per 1000 personyears (36). However, despite an immense investment of research concerning LBP, societal costs are still augmenting $(14,88)$. Particularly the group of patients with chronic LBP accounts for $75-90 \%$ of the costs of LBP $(50,74,82)$. About $15 \%$ of primary care LBP patients experience moderate to severe chronic back pain and a considerable impact on daily functioning has frequently been reported $(54,84,85)$.

LBP has long been thought to have a favourable course (63). However, recent reviews show that LBP does not always resolve itself when left untreated $(25,51)$. The first four weeks after onset of LBP, pain intensity and disability decrease rapidly (58\% mean reduction of initial scores) and $82 \%$ of the persons on sick leave return to work (51). Three months after onset a small further decrease is notable, but after 6 months no further decline in pain complaints were reported. After 12 months, the reported proportion of patients who still experienced pain and/or disability was $62 \%$ on average (range $42-75 \%$ ) and $20 \%$, respectively $(25,85)$. LBP is a typical recurrent disorder. In The Netherlands, van den Hoogen et al. (27) found that almost $75 \%$ of the individuals with LBP experienced a relapse of LBP within one year after onset. This is in line with epidemiological studies in other countries (25). There is much discussion regarding the definitions of acute, subacute, and chronic LBP in particular. LBP is usually classified according to the duration of the episode. Most clinical guidelines define LBP as acute when it persists for less than 6 weeks, subacute between 6 weeks and 3 months and chronic when it lasts for longer than 3 months (73). However, many authors find this definition questionable in the light of the recurrent and fluctuating course LBP often takes $(24,83,85)$. Nevertheless, this thesis follows the Dutch guidelines for low back pain, that define chronic LBP as LBP with a duration of more than 3 months $(4,9)$.

Regarding its aetiology, LBP might roughly be categorised into specific and nonspecific LBP. In specific LBP a specific cause of the disorder is present and can be medically identified. Waddell describes a reliable clinical approach to diagnosing LBP using a simple diagnostic triage, dividing LBP into simple backache (nonspecific LBP), nerve root pain and possible serious spinal pathology, both the latter are considered specific LBP (88). Nerve root pain and possible serious spinal pathology have a pathological basis, such as radicular syndrome $(1-3 \%$ lifetime prevalence), spinal stenosis, inflammatory disease $(<1 \%)$, compression fracture $(<4 \%)$, tumour $(<1 \%)$ or infection $(13,88)$. The majority of LBP is nonspecific (simple) backache (85-90\%) with an unknown aetiology other than those mentioned above $(1,88)$. LBP in this thesis concerns nonspecific LBP. 
The immense costs and the impact of chronic LBP on the patients' physical and psychological well being should make the prevention of chronic LBP a major issue in public health decision making. Identifying predicting/prognostic factors for chronic LBP and developing effective preventive interventions and actions there upon are major issues in lowering this societal and individual burden.

In the introduction of this thesis, a short summary of underlying assumptions of prognostic factors of chronic LBP is given. The biopsychosocial model, painrelated fear models, and instruments measuring pain-related fear will be discussed. Lastly, the outline of the thesis is presented.

\section{The biopsychosocial model}

With the unknown aetiology of nonspecific LBP, the less favourable course, and the importance of preventing chronic LBP, the question what factors are important in the prognosis of chronic LBP emerges. Acute and chronic pain diverge fundamentally $(34,87)$. Conceptually, a difference exists in the relationship between nociception, pain perception, pain experience (suffering), and pain behaviour. In chronic pain, biomedical findings that can sufficiently explain the ongoing pain and disability as experienced by patients cannot be substantiated $(22,71,72,75,86,88)$. The roles of pain experience and pain behaviour have increased and have become more important $(38,75)$. Components of pain reports (reflecting the experience of pain) are inseparably entangled with social variables controlling overt behaviour, independent from actual pain perception (26). For example, laburatory experiments have shown that pain reports may not be due to degree of noxious input alone, but may be learned and maintained by operant conditioning paradigms $(17,26,28)$.

Until 1960, pain was considered an inevitable sensory response to tissue damage. There was little room for the affective dimension of the pain experience (39). The introduction of Melzack and Wall's "Gate-Control Theory" (47), distinguishing sensory, affective and cognitive dimensions of pain, and Fordyce's application of learning processes in chronic pain, in which the consequences of pain behaviour result in reinforcement of pain behaviour (18), resulted in a breakpoint with traditional biomedical thinking. A new paradigm on health and health problems was introduced: the biopsychosocial model (15). The introduction of the biopsychosocial model has integrated physical and physiological processes as well as the influence of psychological and social-contextual variables. The biopsychosocial model aims at describing all relevant variables and it assumes that these variables may interact and influence each other. in recent years, research has demonstrated that the influence of psychological factors and elements of pain perception and pain behaviour are important in the transition from acute to chronic $\operatorname{LBP}(5,10,23,31,33,55,90)$. In the last decennium, research has indicated that pain catastrophizing and pain-related fear are two psychological factors that are hypothesized to make individuals vulnerable to increased pain perception and/or 
disability placing them at risk for chronic pain syndrome developing $(66,81)$. These two factors are integrated in some contemporary fear-avoidance models that propose an explanation for ongoing pain and disability that occur in the absence of identifiable injury or organic pathology (3).

\section{Pain catastrophizing}

Although the definition for pain catastrophizing is still not explicitly stated, it is generally accepted that pain catastrophizing refers to an exaggerated negative "mental set", which might occur during actual or anticipated pain experience $(66,67)$. Severeijns proposes a definition that summarizes the research findings concerning pain catastrophizing: "a negative orientation to pain itself or its possible consequences which is expressed in rumination about pain, cognitions reflecting a subjectively experienced inability to deal with pain, and cognitions reflecting a tendency to magnify or exaggerate possible outcomes of pain" (58). Catastrophizing about pain is associated with increased levels of pain intensity, disability, and distress, independent of pain localisation $(16,32,59,66-68)$. The influence of catastrophizing on pain intensity is partly mediated by pain expectancy levels $(19,30,69,70)$. Concerning levels of disability, pain-related fear might be viewed as a mediator between pain catastrophizing and disability $(11,42,49,80)$. Studies investigating cognitive-behavioural interventions attempting to modify pain-related fear and/or pain catastrophizing are generally in favour of this hypothesis $(62,65,77)$. However, most studies regarding pain catastrophizing used samples of patients with chronic pain problems. To date there is only one prognostic study, using a sample of acute low back pain patients, that corroborates the predictive power of pain catastrophizing as shown in chronic pain samples (7).

In conclusion, pain catastrophizing might influence the levels of pain intensity and disability through pain expectancy levels and pain-related fear. Studies concerning the association between pain catastrophizing and pain-related fear have mainly focused on chronic pain samples. Validity of this hypothesis in acute pain remains to be investigated. Identification of pain catastrophizing as a prognostic factor for chronic LBP may guide the development of effective preventive strategies.

\section{Models of pain-related fear}

Pain-related fear and its subsequent avoidance behaviour are viewed as influencing activity levels in various pain syndromes. The following paragraphs present influential fear-avoidance models that have been developed in the last three decennia, trying to explain the perpetuation of pain beyond the time of expected healing to occur. 
In the eighties, Lethem et al. and Slade et al. developed a fear-avoidance model of exaggerated pain perception, trying to explain the persistence of LBP in some patients from a more multidimensional point of view $(35,61)$. Lethem et al. defined exaggerated pain perception as: "Pain experience and/or pain behaviour (and/or physiological responses to pain stimulation) which is out of all proportion to demonstrable organic pathology or current levels of nociceptive stimulation" (p. 402). This model is an attempt to explain the development of chronic LBP by the process whereby the emotional aspect of pain and its subsequent pain behaviour is in desynchrony with the sensory aspect of pain or nociception in that way enhancing exaggerated pain perception. Lethem, Slade and their colleagues considered fear of pain as the most important feature of the emotional component, with confrontation and avoidance as two opposite reactions to this pain-related fear. LBP patients who confront themselves with their pain, testing the reality of their pain sensation, will maintain synchrony between pain perception and pain behaviour, on the one hand and actual pain sensation on the other. However, avoidance behaviour is considered a dysfunctional response, where patients reduce the opportunities to calibrate the pain sensation against actual pain experience and nociception $(35,61)$ in this way enhancing the development of chronic LBP.

\section{KINESIOPHOBIA}

Applying the fear-avoidance concept of Lethem and Slade to chronic pain and activities, Kori et al. postulated that fear of movement was an important behavioural factor influencing the maintenance of LBP (34). In comparing chronic pain behaviour with phobic behaviour, they found the major features to be similar with one exception: Individuals with chronic pain behaviour are usually not aware that their fear and avoidance behaviour are extreme or irrational (box 1.1). Patients with chronic benign pain are convinced that their pain really indicates danger or injury, despite lacking medical evidence. Kori et al. introduced the term "Kinesiophobia", which they defined as: "an excessive, irrational and debilitating fear of physical movement and activity resulting from a feeling of vulnerability to painful injury or reinjury" (34).

\section{COGNITIVE-BEHAVIOURAL MODEL}

Drawing on the above-mentioned models, new frameworks of pain have been developed to explain the maintenance and initiation of chronic (low back) pain. Vlaeyen et al. developed a new model (figure 1.1), integrating research concerning pain-related fear (fear-avoidance model of exaggerated pain perception), avoidance behaviour (fear of movement = kinesiophobia) and pain catastrophizing into a cognitive-behavioural model of fear of movement/ (re)injury (12,79-81). This new model conceptualises the process of maintaining and developing chronic disabling pain, ascribing a major role to pain-related fear. When, in the acute 
Box 1.1 Comparison of major features of phobic behaviour and chronic pain behaviour (from: Kori et al., 1990)

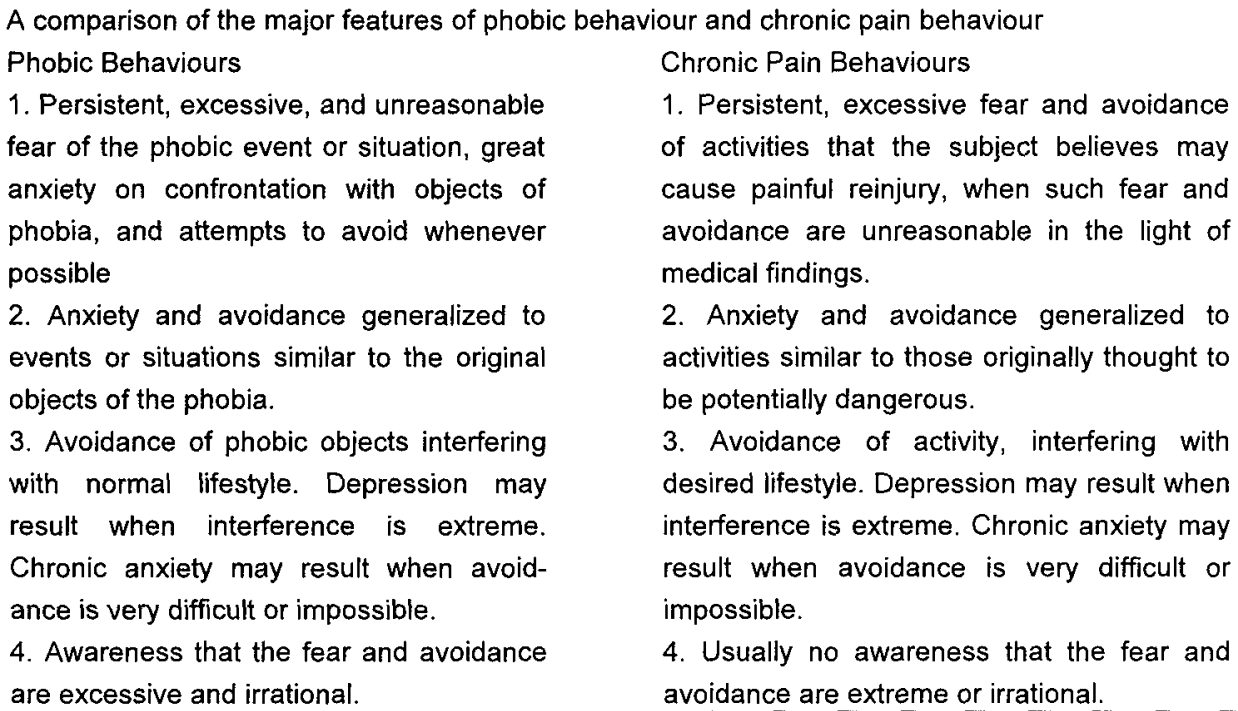

phase of an injury or nociception, the pain is interpreted as threatening, painrelated fear, or the more specific fear that physical activity will cause (re)injury, may evolve. Increased pain-related fear may lead to avoidance behaviour depriving the person of the necessary feedback, followed by disability, disuse and depressive feelings. The latter are associated with decreasing pain tolerance levels $(45,46,57)$. Repeated pain experiences will close the cycle of pain, increasing fear and avoidance behaviour, eventually resulting in and maintaining chronic pain. It should be noted, however, that many of the studies investigating pain-related fear were cross-sectional in nature, excluding causal inferences, used chronic (LBP) samples or investigated the effects of an intervention. The validity of pain-related fear as a predicting factor in the maintenance of disabling LBP needed to be investigated in prospective studies, using sufficiently large samples of individuals with acute LBP and following them a sufficiently long time. Besides that, investigation whether pain-related fear also affects participation in a range of home, work, sports, social, and leisure activities is warranted, thus extending the disability concept to participation problems.

\section{Instruments measuring pain-related fear}

In the last decades, a number of questionnaires have been developed to quantify specific aspects of pain-related fear. For example, the Pain Anxiety Symptom Scale (43), the Fear of Pain Questionnaire (44), the Fear-Avoidance Beliefs Questionnaire (89), and the Tampa Scale for Kinesiophobia (TSK)(48). Because the 
Figure 1.1 Cognitive-behavioural model of disability in low back pain

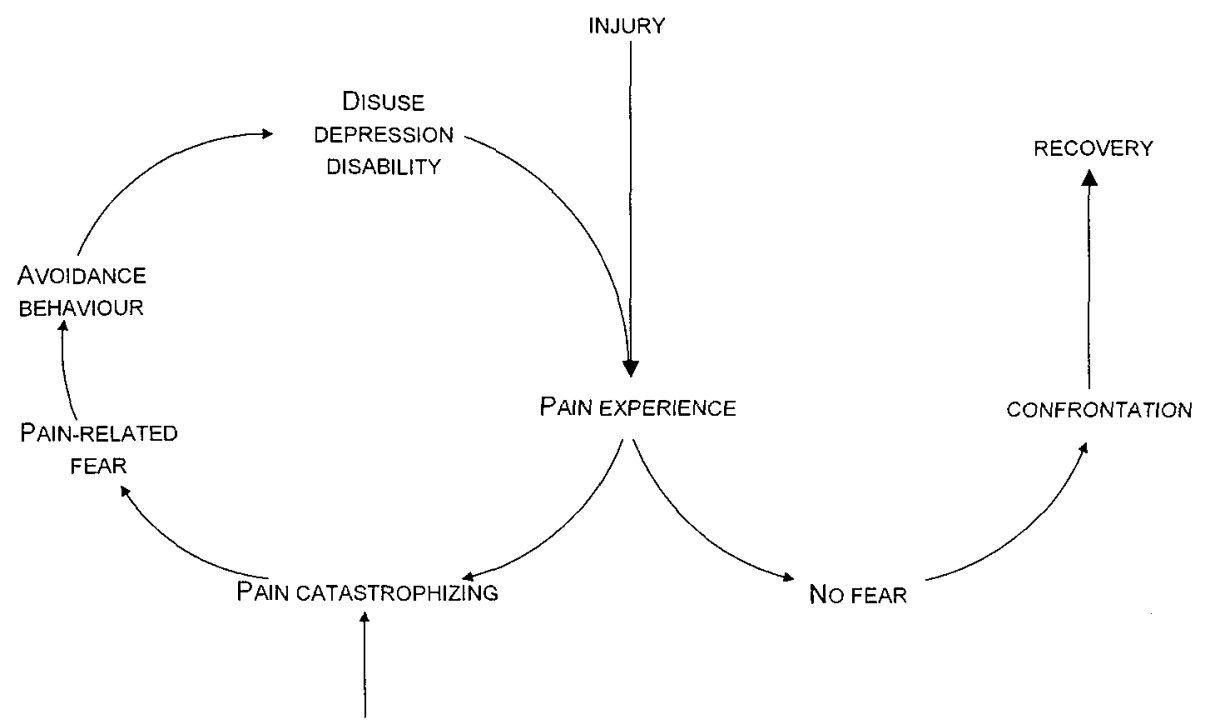

Negative AfFectivity THREATENING ILLNESS INFORMATION

Reprinted from: Vlaeyen, J.W.S. and Linton, S.J. Fear-avoidance and its consequences in chronic musculoskeletal pain: a state of the art. Pain, 2000; 85: 317-332 (Reproduced with permission)

FABQ and the TSK were developed specifically for back pain patients, addressing best the concerns of individuals with LBP, the studies in this thesis use the TSK or $F A B Q$ for investigating pain-related fear.The Fear-Avoidance Beliefs Questionnaire (FABQ) (89) assesses the level of fear-avoidance beliefs of patients with LBP. Items of the FABQ are scored on a 7-point Likert-scale $(0=$ strongly disagree to $6=$ strongly agree) and two subscale scores (one for work and one for physical activity) can be obtained. The FABQ was found to be reproducible, valid, and to have acceptable responsiveness in chronic LBP samples $(8,12,89)$.

Another measure of fear of pain was developed by Miller et al. (48). The Tampa Scale for Kinesiophobia (TSK) specifically focuses on fear of movement/ (re)injury. The 17-item questionnaire is scored on a 4-point Likert-scale ranging from 1 (=highly disagree) to 4 (=highly agree). Total scores are obtained by summing the scores on the individual items after reversing the scores on items 4,8 , 12 , and 16. The Dutch version of the TSK has been shown to have adequate psychometric properties, validity and predictive value for disability in chronic LBP patients $(12,20,21,41,56,79,80,91)$. English and Swedish versions have been examined with similar results $(40,91)$. Woby et al. recommended a short version of the TSK because 'reverse' items showed low item total correlations. However, 
although both questionnaires seem to have good psychometric properties in chronic LBP samples, these qualities remain to be investigated in persons with episodes of acute LBP.

\section{Clinical management of pain-related fear}

The increasing numbers of patients with (chronic) LBP, the integration of the biopsychosocial framework in clinical practice, and the fear-avoidance-models emerging from it necessitate the development of novel treatment modalities. Viewing the resemblance between phobias and chronic pain, and the positive results in the treatment of phobias by exposure techniques, exposure-based interventions might be as well applicable in persons with elevated pain-related fear. Gradually exposing patients to those movements the patient is most afraid of might be effective in readjusting incorrect cognitions towards pain and movement $(53,76)$. A graded exposure intervention consists of three basic elements: (1) the identification of patients whose level of disability may be mainly determined by pain-related fear and the determination of the feared stimuli and their hierarchy (screening); (2) education directed at the patient's specific situation and history; and (3) the graded exposure to situations and/or activities the patient has identified as 'dangerous' or 'threatening'. The graded exposure approach specifically addresses maladaptive beliefs of patients and gives them the opportunity to correct inaccurate predictions about the relationship between activities and harm (81). The aim of graded exposure, as developed and tested by Vlaeyen et al. (76) is to enhance function by directly addressing these pain-related fears. Although investigations testing the efficacy of graded exposure in chronic LBP using RCT methodology is still needed, there are indications that graded exposure techniques are effective in the treatment of persons with chronic LBP who have increased levels of pain-related fear $(6,29,76-78)$. So far, there is one study focussing on exposure-based treatment in individuals with acute LBP scoring high on pain-related fear measures (60). The results of this study suggest that fear-reducing treatment might be effective as a preventive measure for chronic LBP (60). However, due to the low sample size and possible selection bias, this conclusion should be drawn with caution. It is likely that exposure-therapy might well be applicable to patients with acute LBP. If pain-related fear is a risk factor for chronic LBP, and if this heightened fear can be modified by exposure-based treatment, the next logical step is to test graded exposure in the acute phase using larger sample sizes. Customizing an intervention on the supposed mechanism underlying the transition from acute to chronic pain disability might be effective in preventing chronic disability to develop (78). Preventing chronic pain to develop from acute pain might be easier and more cost-effective than trying to positively influence chronic benign pain syndromes with settled dysfunctional cognitions and behaviour patterns (37). 


\section{Outline of this thesis}

The societal and personal burden of LBP is augmenting despite the development and application of various treatment strategies, e.g. medication, chirurgical treatment, manual therapy, chiropractics, physiotherapy, behavioural, cognitive and cognitive-behavioural treatment, etc. $(14,88)$. The body of research concerning prognostic and predictive factors of chronic LBP is immense and is still increasing. The successful prevention of chronic LBP depends on two main factors: 1 . The identification of prognostic/predictive factors of long-term LBP. 2. The development and timely implementation of effective preventive actions. Although there are indications in the literature that pain-related fear might be viewed as a prognostic factor for the development of chronic LBP, this has yet to be confirmed in welldesigned studies. In fearful patients with chronic LBP, a graded exposure-based treatment might be an effective intervention. Whether exposure-therapy might be effective in persons with acute LBP has yet to be investigated.

The main research question addressed in this thesis concerns the prognostic influence of pain-related fear in the transition of acute LBP to chronic LBP. The current thesis has been divided in three sections: (I) the psychometric investigation of two pain-related fear measures in acute LBP(chapter 2 and 3); (II) an inception cohort investigation regarding the association of pain-related fear with (future) perceived disability and participation (chapters 4, 5, and 6); finally (III), an experimental examination concerning the associations of pain-related, pain catastrophizing, and (repeated) exposure with performance and pain expectancies (chapters 7 and 8$)$.

\section{PSYCHOMETRIC INVESTIGATION}

To date, the reliability of the Fear-Avoidance Beliefs questionnaire (FABQ) has been investigated in heterogeneous samples of LBP patients, i.e. patients with acute, subacute or chronic LBP, and patients working or not working $(8,52,64,89)$. However, in acute LBP patients, these clinimetric parameters have yet to be investigated. Regarding the Tampa Scale for Kinesiophobia (TSK), investigations of its psychometric qualities have been studied only in chronic LBP samples. Prior to using measurement instruments in research or clinical practice, the psychometric properties should be investigated in the target population. In chapters 2 and 3 the reliability, i.e. test-retest accuracy and internal consistency, standard error of measurement (SEM), and minimal detectable change (MDC) of the TSK and $F A B Q$ in patients with acute LBP are studied.

In chapter 4, a cross-sectional study in a sample of acute LBP patients is presented, divided in two sections. First, the factor structure of the TSK is investigated. Efforts are made to confirm former results of factor structures of the TSK 
(These factors concern activity avoidance and pathological somatic focus) by using confirmatory factor analysis. Second, the predictive value of the TSK for selfreported disability and participation is examined. Furthermore, it is hypothesized that disability plays a mediating role between pain and pain-related fear and participation.

Chapter 5 reports the results of a cross-sectional study, using a large sample of persons with acute LBP. Here, the factor structure of the FABQ was investigated with confirmatory factor analysis. Additionally, the value of the $F A B Q /$ work and FABQ/physical activities subscales in predicting perceived disability and participation were investigated. Because validation of the work subscale of the FABQ has been shown only for working populations, the sample of the current study was divided in a working and not-working subset.

Chapter 6 focuses on the prediction of long-lasting disabling LBP. A longitudinal design with a follow up period of six months was chosen to prospectively investigate pain-related fear as a predictor of self-report disability and participation in a large inception cohort of acute LBP patients.

\section{EXPERIMENTAL STUDY}

Chapter 7 reports on an experimental study investigating the influence of catastrophizing, and pain-related fear on the performance of a functional physical task in patients with acute LBP. The second aim of this investigation was to examine which factors are associated with a more general measure of perceived disability. In line with similar studies in chronic pain, it was hypothesized that both catastrophizing and pain-related fear are stronger predictors of performance and perceived disability than pain severity or socio-demographics.

Chapter 8 reports the results of an experimental study concerning the repeated exposure to a physical task. The first goal of the current study was to investigate if high fearful individuals or high catastrophizers in a sample of acute LBP patients overpredict pain intensity associated with a back stressing movement. Furthermore, we expected low catastrophizers or low fearful persons to correct this overprediction more rapidly in the consecutive movements than would high catastrophizers or low fearful persons. A second aim of the current investigation was to examine whether repeated exposure resulted in a better performance of the task in persons with acute LBP.

Finally, in chapter 9 , the results of the different studies are critically appraised. This chapter includes a general discussion concerning the role of pain-related fear in acute low back pain, its role in the transition from acute to chronic disabling LBP, and the role of catastrophizing and pain-related fear in physical task per- 
Introduction

formance. Furthermore some methodological considerations are made and lastly the clinical implications and suggestions for future research are discussed. 


\section{References}

1. Abenhaim,L., Rossignol,M., Gobeille,D., Bonvalot,Y., Fines,P., and Scott,S. The Prognostic Consequences in the Making of the Initial Medical Diagnosis of Work-Related Back injuries. Spine 1995; 20 (7): 791-795.

2. Andersson,G.B.J. Epidemiology of low back pain. Acta Orthop Scand Suppl 1998; $28128-$ 31.

3. Asmundson,G.J.G., Norton,P.J., and Vlaeyen,J.W.S. Fear-avoidance models of chronic pain: An overview. In Asmundson,G.J.G., Vlaeyen,J.W.S., Crombez,G. (Eds) Understanding and treating fear of pain. (pp.3-24). New York: Oxford University Press, 2004

4. Bekkering,G.E., Hendriks,H.J.M., Koes,B.W., Oostendorp,R.A.B., Ostelo,R.W.J.G., Thomassen,J., and Tulder,M.W.v. Dutch physiotherapy guideline for low back pain. Physiotherapy 2003; 89 (2): 82-96.

5. Bigos,S.J., Battie,M.C., Spengler,D.M., Fisher,L.D., Fordyce,W.E., Hansson,T.H., Nachemson,A.L., and Wortley,M.D. A prospective study of work perceptions and psychosocial factors affecting the report of back injury. Spine $1991 ; 16(1): 1-6$.

6. Boersma,K., Linton,S., Overmeer,T., Jansson,M., Vlaeyen,J.W.S., and de Jong,J. Lowering fear-avoidance and enhancing function through exposure in vivo. A multiple baseline study across six patients with back pain. Pain 2004; 108 (1-2): 8-16.

7. Burton,A.K., Tillotson,K.M., Main,C.J., and Hollis,S. Psychosocial Predictors of Outcome in Acute and Subchronic Low Back Trouble. Spine 1995; 20 (6): 722-728.

8. Chaory,K., Fayad,F., Rannou,F., Lefevre-Colau,M.M., Fermanian,J., Revel,M., and Poiraudeau,S. Validation of the French version of the fear avoidance belief questionnaire. Spine 2004; 29 (8): 908-913.

9. Chavannes,A.W., Mens,J.M.A., Koes,B.W., Lubbers,M.A.I., Ostelo,R.W., Spinnewijn, W.F.M., and Kolenaar,B.G.M. NHG-Standaard Aspecifieke lagerugpijn. Huisarts en Wetenschap 2005; 48 (3): 113-123.

10. Croft,P.R., Papageorgiou,A.C., Ferry,S., Thomas,E., Jayson,M.I.V., and Silman,A.J. Psychologic Distress and Low Back Pain: Evidence from a prospective study in the general population. Spine 1995; 20 (24): 2731-2737.

11. Crombez,G., Eccleston,C., Baeyens,F., and Eelen,P. When somatic information threatens, catastrophic thinking enhances attentional interference. Pain 1998; 75 (2-3): 187-198.

12. Crombez,G., Vlaeyen,J.W.S., Heuts,P.H.T.G., and Lysens,R. Pain-related fear is more disabling than pain itself. Evidence on the role of pain-related fear in chronic back pain disability. Pain 1999; 80 (1,2): 329-339.

13. Deyo,R.A. and Tsui-wu,Y.J. Descriptive Epidemiology of Low-Back Pain and Its Related Medical Care in the US. Spine 1987; 12 (3): 264-268.

14. Dionne,C.E. Low back pain. In Crombie, I.K. (Ed.) Epidemiology of pain (pp. 283-298). Seatle.: IASP Press, 1999

15. Engel,G.L. The clinical application of the biopsychosocial model. Am.J Psychiatry 1980; 137 (5): 535-544.

16. Flor,H., Behle,D.J., and Birbaumer,N. Assessment of pain-related cognitions in chronic pain patients. Behav Res Ther 1993; 31 (1): 63-73.

17. Flor, H., Knost,B., and Birbaumer,N. The role of operant conditioning in chronic pain: an experimental investigation. Pain 2002; 95 (1-2): 111-118.

18. Fordyce,W.E., Shelton,J.L., and Dundore,D.E. The Modification of Avoidance Learning Pain Behaviors. J Behav Med 1982; 5 (4): 405-414.

19. Geisser,M.E., Robinson,M.E., Keefe,F.J., and Weiner,M.L. Catastrophizing, depression and the sensory, affective and evaluative aspects of chronic pain. Pain 1994; 59: 79-83.

20. Goubert,L., Crombez,G., Van Damme,S., Vlaeyen,J.W.S., Bijttebier,P., and Roelofs,J. Confirmatory factor analysis of the Tampa Scale for Kinesiophobia: invariant two-factor model across low back pain patients and fibromyalgia patients. Clin J Pain 2004; 20 (2): 103-110.

21. Goubert,L., Crombez,G., Vlaeyen,J.W.S., Van Damme,S., Van den Broeck,A., and van Houdenhove,B. De Tampaschaal voor Kinesiofobie. Psychometrische karakteristieken en normering. Gedrag \& Gezondheid 2000; 28 54-62. 
22. Grönblad,M., Hurri,H., and Kouri,J.-P. Relationship between spinal mobility, physical performance tests, pain intensity and disability assessment in chronic low back pain patients. Scand J Rehab Med 1997; 29 17-24.

23. Grossi,G., Soares,J.J.F., Angesleva,J., and Perski,A. Psychosocial correlates of long-term sick-leave among patients with musculoskeletal pain. Pain 1999; 80 (3): 607-619.

24. Hestbaek,L., Leboeuf-Yde,C., Engberg,M., Lauritzen,T., Bruun,N.H., and Manniche,C. The course of low back pain in a general population. Results from a 5-year prospective study. J Manipulative Physiol Ther. 2003; 26 (4): 213-219.

25. Hestbaek,L., Leboeuf-Yde,C., and Manniche,C. Low back pain: what is the long-term course? A review of studies of general patient populations. Eur Spine J 2003;12: 149-165.

26. Holzl,R., Kleinbohl,D., and Huse,E. Implicit operant learning of pain sensitization. Pain 2005; $115(1-2): 12-20$.

27. Hoogen,H.M.M.v.d., Koes,B.W., Deville,W., Eijk,J.Th.M.v., and Bouter,L.M. The prognosis of low back pain in general practice. Spine 1997; 22 (13): 1515-1521.

28. Jolliffe,C.D. and Nicholas,M.K. Verbally reinforcing pain reports: an experimental test of the operant model of chronic pain. Pain 2004; 107 (1-2): 167-175.

29. Jong,J.R.d., Vlaeyen,J.W.S., Onghena,P., Goossens,M.E., Geilen,M., and Mulder,H. Fear of movement/(re)injury in chronic low back pain: education or exposure in vivo as mediator to fear reduction? Clin J Pain 2005; 21 (1): 9-17.

30. Keefe,F.J., Lefebvre,J.C., Egert,J.R., Affleck,G., Sullivan,M.J., and Caldwell,D.S. The relationship of gender to pain, pain behavior, and disability in osteoarthritis patients: the role of catastrophizing. Pain 2000; 87 (3): 325-334.

31. Keefe,F.J., Rumble,M.E., Scipio,C.D., Giordano,L.A., and Perri,L.M. Psychological aspects of persistent pain: Current state of the science. J Pain 2004; 5 (4): 195-211.

32. Keefe,F.J., Wallston,K.A., and Caldwell,D.S. Coping with rheumatoid arthritis pain: catastrophising as a maladaptive strategy. Pain 1989; 37 51-56.

33. Klenerman,L., Slade,P.D., Stanley,I.M., Pennie,B., Reilly,J.P., Atchison,L.E., Troup,J.D.G., and Rose,M.J. The prediction of chronicity in patients with an acute attack of low back pain in a general practice setting. Spine $1995 ; 20(4): 478-484$.

34. Kori,S.H., Miller,R.P., and Todd,D.D. Kinesophobia: a new view of chronic pain behavior. Pain Management 1990; (1): 35-43.

35. Lethem,J., Slade,P.D., Troup,J.D.G., and Bentley,G. Outline of a fear-avoidance model of exaggerated pain perception - I. Behav Res Ther 1983; 21 (4): 401-408.

36. Linden,M.W.v.d., Westert,G.P., Bakker,D.H.d., and Schellevis,F.G. Tweede Nationale Studie naar ziekten en verrichtingen in de huisartsenpraktijk: klachten en aandoeningen in de bevolking $\in \mathrm{n}$ in de huisartsenpraktijk. 2004; 1-139.

37. Linton,S.J. and Skevington,S.M. Psychological factors. In Crombie, I.K. (Ed.) Epidemiology of pain (pp. 25-43). Seatle.: IASP Press, 1999

38. Loeser,J.D. Disability, Pain, and Suffering. Clinical Neurosurgery 1989; 35 398-408.

39. Loeser,J.D. and Melzack,R. Pain: an overview. Lancet 1999; 353 (9164): 1607-1609

40. Lundberg,M.K.E., Styf,J., and Carlsson, S.G. A psychometric evaluation of the Tampa Scale for Kinesiophobia - from a physiotherapeutic perspective. Physiotherapy Theory and Practice $2004 ; 20121-133$.

41. Lundberg,M.K.E., Styf,J., and Carlsson,S.G. A psychometric evaluation og the Tampa Scale for Kinesiophobia - from a physiotherapeutic perspective. Physiotherapy Theory and Practice $2004 ; 20121-133$.

42. McCracken,L.M. and Gross,R.T. Does anxiety affect coping with chronic pain? Clin J Pain 1993; 9 (4): 253-259.

43. McCracken,L.M., Zayfert,C., and Gross,R.T. The pain anxiety symptoms scale: development and validation of a scale to measure fear of pain. Pain 1992; 50:67-73.

44. McNeil,D.W. and Rainwater,A.J., III Development of the Fear of Pain Questionnaire-III. J Behav Med 1998; 21 (4): 389-410.

45. McQuade,K.J., Turner,J.A., and Buchner,D.M. Physical fitness and chronic low back pain. An analysis of the relationship among fitness, functional limitations and depression. Clin Orthop Rel Research 1988; 233: 198-204. 
46. McQuade,K.J., Turner,J.A., and Buchner,D.M. Physical fitness and chronic low back pain. An analysis of the relationships among fitness, functional limitations, and depression. Clin Orthop 1988; (233): 198-204.

47. Melzack,R. and Wall,P.D. Pain mechanisms: a new theory. Science 1965; 150 971-979.

48. Miller,R.P., Kori,S.H., and Todd,D.D. The Tampa Scale. 1991;

49. Murphy,D., Lindsay,S., and Williams,A.C. Chronic low back pain: predictions of pain and relationship to anxiety and avoidance. Behav Res Ther 1997; 35 (3): 231-238.

50. Nachemson,A.L. Newest knowledge of low back pain. Clin Orthop Rel Res. 1992; (279): 820.

51. Pengel,L.H., Herbert,R.D., Maher,C.G., and Refshauge,K.M. Acute low back pain: systematic review of its prognosis. BMJ 2003; $327(7410): 323-327$.

52. Pfingsten,M., Kroner-Herwig,B., Leibing,E., Kronshage,U., and Hildebrandt,J. Validation of the German version of the Fear-Avoidance Beliefs Questionnaire (FABQ). Eur J Pain 2000; 4 (3): 259-266.

53. Philips,H.C. Avoidance Behaviour and its role in sustaining chronic pain. Behav Res Ther 1987; 25 (4): 273-279.

54. Picavet,H.S. and Schouten,J.S. Musculoskeletal pain in the Netherlands: prevalences, consequences and risk groups, the DMC(3)-study. Pain 2003; 102 (1-2): 167-178.

55. Pincus,T., Burton,A.K., Vogel,S., and Field,A.P. A systematic review of psychological factors as predictors of chronicity/disability in prospective cohorts of low back pain. Spine 2002; 27 (5): E109-E120.

56. Roelofs,J., Goubert,L., Peters,M.L., Vlaeyen,J.W.S., and Crombez,G. The Tampa Scale for Kinesiophobia: further examination of psychometric properties in patients with chronic low back pain and fibromyalgia. Eur J Pain 2004; 8 (5): 495-502.

57. Romano,J.M. and Turner,J.A. Chronic pain and depression: does the evidence support a relationship? Psychol Bull 1985; 97 (1): 18-34.

58. Severeijns, R. Thinking the worst about pain. Thesis 2005.

59. Severeijns,R., Vlaeyen,J.W.S., van den Hout,M.A., and Weber,W.E. Pain catastrophizing predicts pain intensity, disability, and psychological distress independent of the level of physical impairment. Clin J Pain 2001; 17 (2): 165-172.

60. Sieben,J.M. Pain-related fear in acute low back pain: towards understanding and prevention of chronicity. Thesis 2005.

61. Slade,P.D., Troup,J.D.G., Lethem,J., and Bentley,G. The Fear-Avoidance model of exaggerated pain perception - II. Preliminary studies of coping strategies for pain. Behav Res Ther 1983; 21 (4): 409-416.

62. Spinhoven,P., Ter Kuile,M., Kole-Snijders,A.M., Hutten,M.M., Den Ouden,D.J., and Vlaeyen,J.W.S. Catastrophizing and internal pain control as mediators of outcome in the multidisciplinary treatment of chronic low back pain. Eur J Pain 2004; 8 (3): 211-219.

63. Spitzer,W.O. and Quebec Task Force Scientific approach to the assessment and management of activity-related spinal disorders. A monograph for clinicians. Spine 1987; 12 (7): S6S59.

64. Staerkle,R., Mannion,A.F., Elfering,A., Junge,A., Semmer,N.K., Jacobshagen,N., Grob,D., Dvorak,J., and Boos,N. Longitudinal validation of the fear-avoidance beliefs questionnaire $(F A B Q)$ in a Swiss-German sample of low back pain patients. Eur Spine J 2004; 13 (4): 332340.

65. Sullivan,M.J. and Stanish,W.D. Psychologically based occupational rehabilitation: the PainDisability Prevention Program. Clin J Pain 2003; 19 (2): 97-104.

66. Sullivan,M.J., Thorn,B., Haythornthwaite,J.A., Keefe,F., Martin,M., Bradley,L.A., and Lefebvre,J.C. Theoretical perspectives on the relation between catastrophizing and pain. Clin $J$ Pain 2001; 17 (1): 52-64.

67. Sullivan,M.J.L. and Bishop,S.R. The Pain Catastrophizing Scale: Development and validation. Psychol Assess 1995; 7 (4): 524-532.

68. Sullivan,M.J.L. and D'Eon,J.L. Relation Between Catastrophizing and Depression in Chronic Pain Patients. Journal of Abnormal Psychology 1990; 99 (3): 260-263.

69. Sullivan,M.J.L., Rodgers,W.M., and Kirsch,I. Catastrophizing, depression and expectancies for pain and emotional distress. Pain 2001; 91 (1-2): 147-154. 
70. Sullivan,M.J.L., Stanish,W., Waite,H., Sullivan,M., and Tripp,D.A. Catastrophizing, pain, and disability in patients with soft-tissue injuries. Pain 1998; 77 (3): 253-260.

71. Turk,D.C. and Okifuji,A. Assessment of patients' reporting of pain: an integrated perspective. Lancet 1999; 353 (9166): 1784-1788.

72. Turk,D.C. and Okifuji,A. Psychological factors in chronic pain: evolution and revolution. $J$ Consult Clin Psychol. 2002; 70 (3): 678-690.

73. van Tulder,M., Koes,B., and Bombardier,C. Low back pain. Best Pract Res Clin Rheumatol 2002; 16 (5): 761-775.

74. van Tulder,M.W., Koes,B.W., and Bouter,L.M. A cost-of-illness study of back pain in The Netherlands. Pain 1995; 62 (2): 233-240.

75. Verhaak,P.F.M., Kerssens,J.J., Dekker,J., Sorbi,M.J., and Bensing,J.M. Prevalence of chronic benign pain disorder among adults: a review of the literature. Pain 1998; 77 (3): 231239.

76. Vlaeyen,J.W.S., de Jong,J., Geilen,M., Heuts,P.H.T.G., and van Breukelen,G. Graded exposure in vivo in the treatment of pain-related fear: a replicated single-case experimental design in four patients with chronic low back pain. Behav Res Ther 2001; 39 (2): 151-166.

77. Vlaeyen,J.W.S., Jong,J.R.d., Geilen,M., Heuts,P.H.T.G., and Breukelen,G.v. The treatment of fear of movement/(re)injury in chronic low back pain: further evidence on the effectiveness of exposure in vivo. Clin J Pain 2002; 18 (4): 251-261.

78. Vlaeyen,J.W.S., Jong,J.R.d., Onghena,P., Kerckhoffs-Hanssen,M., and Kole-Snijders,A.M. Can pain-related fear be reduces? The application of cognitive-behavioural exposure in vivo. Pain Res Manag 2002; 7 (3): 144-153.

79. Vlaeyen,J.W.S., Kole-Snijders,A.M.J., Boeren,R.G.B., and Eek,H.v. Fear of movement/(re)injury in chronic low back pain and its relation to behavioral performance. Pain $1995 ; 62$ 363-372.

80. Vlaeyen,J.W.S., Kole-Snijders,A.M.J., Rotteveel,A.M., Ruesink,R., and Heuts,P.H.T.G. The role of fear of movement/(re)injury in pain disability. J Occup Rehabil 1995; 5 (4): 235-252.

81. Vlaeyen,J.W.S. and Linton,S.J. Fear-avoidance and its consequences in chronic musculoskeletal pain: a state of the art. Pain 2000; 85 (3): 317-332.

82. Volinn,E., Koevering,D.v., and Loeser,J.D. Back Sprain in Industry. The role of socioeconomic factors in chronicity. Spine 1991; 16 (5): 542-548.

83. Von Korff,M. Studying the natural history of back pain. Spine 1994; 19 (18S): 2041S-2046S.

84. Von Korff,M. Acute low back pain improves rapidly, however recovery is not complete and recurrence is common. Aust J Physiother 2004; 50 (1): 58

85. Von Korff,M. and Saunders, K. The Course of Back Pain in Primary Care. Spine 1996; 21 (24): 2833-2839.

86. Waddell,G. Biopsychosocial analysis of low back pain. Bailliere's Clinical Rheumatology 1992; 6 (3): 523-551.

87. Waddell,G. Low back Pain: A Twentieth Century Health Care Enigma. Spine 1996; 21 (24): 2820-2825.

88. Waddell,G. The back pain revolution. Edinburgh: Churchill Livingstone, 1998

89. Waddell,G., Newton,M., Henderson,I., Somerville,D., and Main,C.J. A fear avoidance beliefs questionnaire (FABQ) and the role of fear-avoidance beliefs in chronic low back pain and disability. Pain 1993; 52 157-168.

90. Williams,R.A., Pruitt,S.D., Doctor,J.N., Epping-Jordan,J., Wahlgren,D.R., Grant,I., Patterson,T.L., Webster,J.S., Slater,M.A., and Atkinson,J.H. The contribution of job satisfaction to the transition from acute to chronic low back pain. Arch of Physical Med and Rehab. 1998; 79 (4): 366-374.

91. Woby,S.R., Roach,N.K., Urmston,M., and Watson,P.J. Psychometric properties of the TSK11: A shortened version of the Tampa Scale for Kinesiophobia. Pain 2005; 117 (1-2): $137-$ 144. 


\section{Chapter 2}

\section{Psychometric Properties of the Tampa Scale for Kinesiophobia and the Fear-Avoidance Beliefs Questionniare in acute low back pain}

Ilse E.J.C.M. Swinkels-Meewisse, Raymond A.H.M. Swinkels, André L.M. Verbeek, Johan W.S. Vlaeyen, Rob A.B. Oostendorp

Published as:

E.J.C.M. Swinkels-Meewisse, R.A.H.M. Swinkels, A.L.M. Verbeek, J.W.S. Vlaeyen, R.A.B. Oostendorp. Psychometric properties of the Tampa Scale for Kinesiophobia and the Fear-Avoidance beliefs Questionnaire in acute low back pain. Man Ther 2003; 8 (1): 29-36. 


\section{Abstract}

Introduction: The transition from acute to chronic low back pain (LBP) is influenced by many interacting factors. Pain-related fear, as measured by the Tampa Scale for Kinesiophobia (TSK) and the Fear-Avoidance Beliefs Questionnaire (FABQ), is one of these factors.

Objectives: To investigate, in a population with acute LBP, the reliability of TSK and $F A B Q$ through evaluation of the internal consistency, the test-retest reliability, and the concurrent validity between TSK and FABQ.

Methods: 176 Patients suffering LBP for no longer than four weeks completed a Visual Analogue Scale for pain (VAS), the TSK, the FABQ, and a sociodemographic questionnaire. Each patient completed the VAS, TSK, and FABQ twice within 24 hours. Results: Internal consistency of TSK and FABQ scores range from $\alpha=0.70$ to $\alpha=0.83$. Test-retest reliability ranges from $r_{s}=0.64$ to $r_{s}=0.80$ $(p<0.01)$. Concurrent validity is moderate, ranging from $r_{s}=0.33$ to $r_{s}=0.59$ $(p<0.01)$.

Conclusions: It may be concluded that in a population with acute LBP, both the TSK and the FABQ are reliable measures of pain-related fear. In the clinical setting they may provide the practitioner a means of identifying pain-related fear in a patient with acute LBP. 


\section{Introduction}

Low Back Pain (LBP) is one of the major reasons patients with musculoskeletal disorders visit their general practitioners (12). The total annual cost of LBP in The Netherlands amounts to $\$ 4.9$ billion (38). 75 to $90 \%$ of these costs are accounted for by the relatively small group of patients with chronic LBP $(14,29,36,48)$. The prevalence and costs of LBP are still increasing $(25,51)$. Early identification of LBP patients at risk of becoming chronic is needed in order to focus early optimal intervention and possibly prevent chronicity, thus reducing the personal, social and economic consequences.

The transition of acute to chronic LBP is influenced by many factors, and these prognostic factors probably interact $(11,37)$. There is growing evidence that the persistence of pain is not explained by objective clinical findings $(29,34,51,52)$ but that it depends as much on cognitive, affective, behavioural and social factors as on the underlying physical disorder $(3,6,20,32)$. There is increasing evidence that LBP and disability are better understood and managed according to the biopsychosocial model $(4,51)$. The same development is reflected in the implementation of the biopsychosocial model in clinical settings in manual therapy (18). The last decade there has been a shift from the biomedical model to the biopsychosocial approach in manual therapy, and within the framework of this model the utilization of questionnaires is essential to objectify patient characteristics, in particular personal factors.

There are some theoretical avoidance-based models, which attempt to explain the perpetuation of pain and pain behaviour, although evidence of the role of fearavoidance is scarce $(1,32,47)$. Two models are outlined below.

Lethem et al. (1983) tried to explain the persistence of LBP by introducing the 'Fear-Avoidance Model of Exaggerated Pain Perception'. Central to this model is the idea that fear is the most important affective dimension of pain with two possible coping responses; 'confrontation' and 'avoidance' $(23,33)$. Chronic LBP patients may be classified as confronters or as avoiders $(7,31)$. Avoidance is being enhanced by fear. Kori et al. (1990) use the term 'kinesiophobia'. They defined 'kinesiophobia' as: "an excessive, irrational, and debilitating fear of physical movement and activity resulting from a feeling of vulnerability to painful injury or reinjury" (21). In LBP patients, the resulting inactivity may lead to a deterioration of physical and mental health, i.e. decreased muscle strength, and mobility, an increased fear of pain, somatic preoccupation, and depressive symptoms $(2,21,46)$.

Vlaeyen et al. developed a cognitive-behavioural model of fear of movement and (re)injury as a possible explanation of chronic pain (44-47) (Figure 2.1). In this theoretical model, pain catastrophizing influences fear of (re)injury, which in its turn enhances avoidance behaviour, in the long run resulting in disuse, depression and disability. In their model, Vlaeyen et al. emphasize the influence of attributional 
Figure 2.1 Cognitive-behavioural model of fear of movement/(re)injury

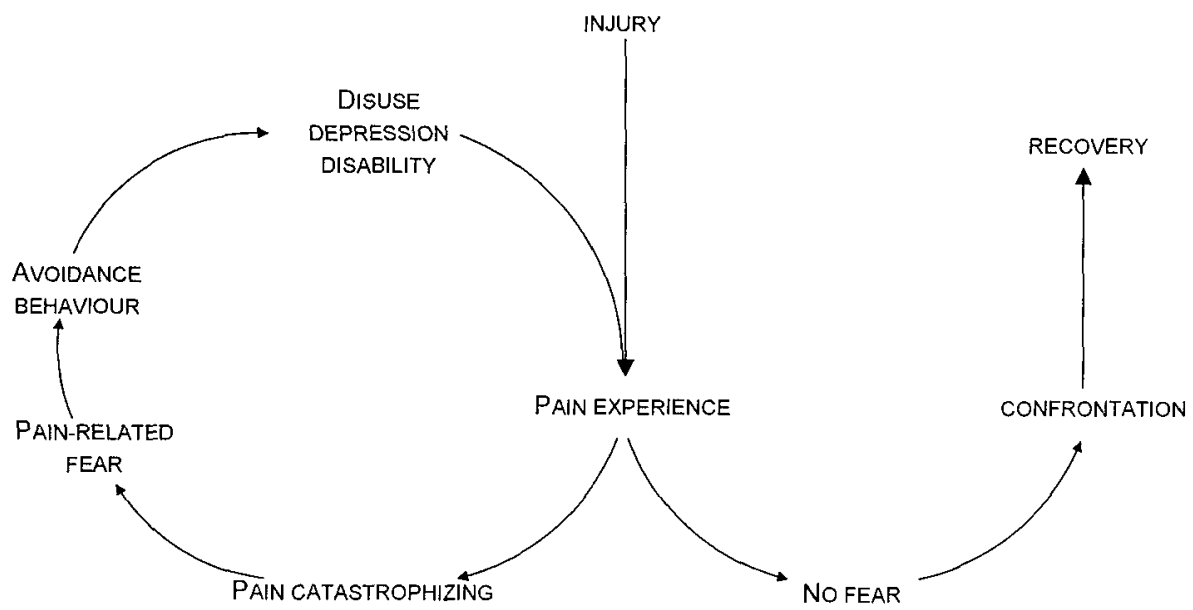

Reprinted from: JWS Vlaeyen, AMJ Kole-Snijders, RGB Boeren and $H$ van Eek. Fear of movement/(re)injury in chronic low back pain and its relation to behavioural performance. Pain, 1995; 62: 363-372. (Reproduced with permission)

factors, especially pain catastrophizing, on pain-related fear. Founded on the avoidance-based models two questionnaires were developed to measure painrelated fear or fear-avoidance beliefs. The first is the Tampa Scale for Kinesiophobia (TSK) (28) and the second is the Fear-Avoidance Beliefs Questionnaire (FABQ) (52). The FABQ consists of two subscales, one regarding physical activities (FABQ/pa) and one concerning work related items (FABQ/w). At the time of writing no published studies are known to the authors that investigate the psychometric properties of the TSK and FABQ in populations of acute LBP patients. In a population of chronic LBP patients the TSK is a reliable instrument with internal consistency ranging from $\alpha=0.68$ to $\alpha=0.80(8,45,46)$. At the time of writing testretest reliability is not investigated before.

The two $F A B Q$ subscales, the $F A B Q / w$ and $F A B Q / p a$, have good internal consistency ranging from $\alpha=0.84$ to $\alpha=0.92$ on the work subscale and $\alpha=0.52$ to $a=0.77$ on the physical activity subscale $(8,35,41,52)$. The two subscales interact significantly with correlations varying from $r=0.39$ to $r=0.60(8,52)$. The relationship between TSK and subscales of the FABQ shows moderate correlations with Pearson's $r=0.57$ and $r=0.76(p<0.001$ ) for the physical activity subscale and $r=0.53$ and $r=0.56(p<0.001)$ for the FABQ/w (8). The questionnaire has good test-retest 
stability $(30,52)$. With the exception of the study by Fritz et al. (2001) the abovementioned studies used prevalent cases of LBP or chronic LBP patients. In the study by Fritz et al. patients with work-related, acute LBP were used. The patterns of correlation between FABQ and concurrently measured variables were similar to those reported in patients with chronic LBP (13).

\section{Study objectives}

Some of the psychometric properties of the TSK and FABQ have been investigated in chronic pain populations $(8,45,46)$. However, before being eligible to use the questionnaires in cases with acute low back pain and draw valid conclusions, the psychometric qualities of the TSK and FABQ in a population with acute LBP must be examined. The objectives of this study are threefold: (1) to investigate the internal consistency of the Dutch version of the TSK and FABQ; (2) to investigate the test-retest reliability of the above-mentioned questionnaires; and (3) to examine the concurrent validity between the TSK and FABQ.

\section{Methods}

\section{SUBJECTS}

Patients with LBP were recruited by general practitioners and physiotherapists in the southeast region of The Netherlands between April 1998 and January 1999. Patients were included who were aged between 18 and 65 years and who had non-specific low back pain independent of radiation for no longer than a maximum of four weeks with a pain free period of at least three months preceding this episode of LBP. Criteria for exclusion were: LBP with a specific underlying pathology (e.g. tumours, trauma, infection, inflammatory disorders); presence of malignancies; operations in the lumbar area; or pregnancy.

\section{Procedure}

At the first consultation with their GP or physiotherapist patients were asked if they would be willing to cooperate with the study and they were given written information about it. After written informed consent was obtained, a battery of questionnaires was completed twice by each patient: the first time at the first consultation with the health-care provider (t1); and the second time (t2) at home the same evening or with a maximum of 24 hours after the questionnaires were first completed. This time interval was chosen to minimise clinical or cognitive change. It was also unlikely that patients would remember their previous answers given the number and length of the questionnaires. 


\section{MEASURES}

Socio-demographic variables

A questionnaire was completed covering different socio-demographical elements and biographical data (age, gender, education level, pain onset, sick-leave, time since onset and preceding episodes).

\section{Current Pain intensity}

A Visual Analogue Scale for pain was used (17). A VAS is a standardised instrument to measure pain intensity with high test-retest reliability $(r>0.95)$ and criterion-related validity with established instruments (e.g. Numerical rating scale, and McGill Pain Questionnaire) ranging from $r=0.42$ to $r=0.91(9,54)$.

\section{Pain-related Fear Measures}

The Dutch versions of the Tampa Scale for Kinesiophobia (TSK) $(28,45)$ and the Fear-Avoidance Beliefs Questionnaire (FABQ) $(8,52)$ were used. The Tampa Scale for Kinesiophobia is a 17-item questionnaire developed to identify fear of (re)injury due to movement or activities. Items are scored on a 4-point Likert scale with scoring possibilities ranging from 'strongly disagree' (score=1) to 'strongly agree' (score=4). The scores on items $4,8,12$, and 16 are to be reversed. Total score ranges from 17 to 68 .

The Fear-Avoidance Beliefs Questionnaire is a 16-item measure comprising two subscales: a seven-item subscale of fear-avoidance beliefs about work-related activities (FABQ/w), and a four-item subscale regarding fear-avoidance beliefs about physical activities (FABQ/pa). Items are scored on a 7-point Likert scale ranging from 0 (strongly disagree) to 6 (strongly agree). Total score of the $F A B Q / p a$ ranges from 0 to 24 , the total score of the $F A B Q / w$ subscale ranges between 0 and 42 .

\section{STATISTICAL PROCEDURE}

The statistical analysis only includes results for those patients who fully completed the battery of questionnaires twice within the 24-hours period. The statistical analyses use the subscales FABQ/w and FABQ/pa. Pearson's correlation coefficients are calculated in order to investigate the test-retest stability, and the relationship between the questionnaires. It was decided before the analysis was undertaken that the correlational criteria according to Landis and Koch should be used (22). Cronbach's alpha is used to calculate the internal consistency of the two questionnaires and Feinstein's criteria for internal consistency are applied (10). The criterion for significance was set at $\alpha=0.05$. For all statistical analyses the Statistical Package for Social Science (SPSS/PC+, version 8.0) was used. 


\section{Results}

212 Patients were entered in the study, of which $36(17 \%)$ were omitted from the analysis, leaving 176 patients for whom there are complete data. Patients were excluded because of incomplete questionnaires $(n=28)$, missing sociodemographic data $(n=5)$, and by being above the age of $65(n=3)$. There are no statistical differences between the excluded cases and the analysed cases regarding age $(t=1.22, p=0.22)$, gender $\left(x^{2}=0.21, d f=1, p=0.65\right)$, sick-leave $\left(x^{2}=1.1, d f=2, p=0.58\right)$, pain onset $\left(x^{2}=0.92, d f=1, p=0.34\right)$ or educational level $\left(x^{2}=0.33, d f=2, p=0.85\right)$.

The patient's mean age is 42.7 years $(S D=11.5)$. Of the sample $60 \%$ are male $(n=105), 40 \%$ are female $(n=71) .55 .7 \%$ of the patients are employed, in $37.5 \%$ the employment status is not applicable (e.g. students, early retirement, house wives, unemployment), and $6.8 \%$ regarding employment status are missing data (Table 2.1).

\section{Tampa Scale for Kinesiophobia}

The total scores of the TSK on the first measurement (TSK-t1) and the second measurement (TSK-t2) range from 18 to 55 and 17 to 55 , respectively. The mean of TSK-t1 and TSK-t2 is $36.3(\mathrm{sd}=6.8)$ and $36.0(\mathrm{sd}=7.4)$. The median for both measurements is 36 (Table 2.2). Total scores are normally distributed for TSK-t1 as well as for TSK-t2 (Kolmogorov-Smirnov goodness-of-fit test, $p>0.05$ ). The internal consistency of TSK is $\alpha_{t_{1}}=0.70$ on $t 1$ and $\alpha_{t_{2}}=0.76$ on $\mathrm{t} 2$. The items $4,8,12$, and 16 (the 'reverse' items) reduce the internal consistency. If these items are deleted the alpha increases to $\alpha_{t 1}=0.76$ and $\alpha_{12}=0.80$, respectively. The test-retest reliability is 'substantial' with Pearson's $r=0.78$ ( $p \leq 0.01$ ) (Table 2.3). If the reverse items are deleted test-retest reliability slightly increases to $r=0.79$.

\section{Fear-Avoidance Beliefs Questionnaire}

The total scores of the $F A B Q / p a$ on $t 1$ and $t 2$ both range from 0 to 24 . The means on $\mathrm{t} 1$ and $\mathrm{t} 2$ are $14.1(\mathrm{sd}=5.5)$ and $13.3(\mathrm{sd}=5.8)$ respectively; with medians of 15 and 14 respectively. Total scores of $\mathrm{FABQ} / \mathrm{w}$ are positively skewed $\left(\mathrm{Sk}_{\mathrm{t} 1}=0.256\right.$, $S_{\mathrm{t} 2}=0.209$, Kolmogorov-Smirnov goodness-of-fit test, $p<0.05$ ). The internal consistency of the $F A B Q / p a$ on $t 1$ and $t 2$ are $\alpha_{t 1}=0.70$ and $\alpha_{t 2}=0.72$, and of the $F A B Q / w$ are $\alpha_{t 1}=0.82$, and $\alpha_{t 2}=0.83$. Test-retest reliability of $F A B Q / p a$ and $F A B Q / w$ is 'substantial' $(r=0.64$ and $r=0.80 ; p \leq 0.01)$ (Table 2.3). The two subscales are significantly intercorrelated $\left(r_{t 1}=0.33\right.$, and $\left.r_{t_{2}}=0.47 ; p \leq 0.01\right)$.

\section{Visual Analogue Scale for pain}

The mean scores for the VAS on $\mathrm{t} 1$ and $\mathrm{t} 2$ are $49 \mathrm{~mm}(\mathrm{SD}=25.7)$ and $45 \mathrm{~mm}$ $(S D=25.3)$ respectively, with medians of $49 \mathrm{~mm}$ and $45 \mathrm{~mm}$. 
Table 2.1 Patient characteristics on $\mathrm{t} 1(\mathrm{n}=176)$

\begin{tabular}{lc}
\hline Variable & percentage \\
\hline Age (mean years \pm sd) & \\
Gender (\% male) & $42.7( \pm 11.5)$ \\
education level & \\
less than secondary education & 38.1 \\
secondary education & 26.7 \\
higher education/university & 33.5 \\
missing & 1.7 \\
Pain onset (\% sudden) & 61.9 \\
Sick-leave & \\
on sick-leave & 38.1 \\
no sick-leave & 17.6 \\
not applicable & 37.5 \\
missing & 6.8 \\
Time since onset & \\
$<7$ days & 36.9 \\
$7-14$ days & 29.5 \\
$14-21$ days & 16.5 \\
$21-28$ days & 17.0 \\
Preceding episodes & \\
first episode & 15.3 \\
1 - 5 episodes & 59.7 \\
6 - 10 episodes & 13.6 \\
missing & 6.3 \\
\hline
\end{tabular}

Table 2.2 Mean (standard deviation), range and median of the TSK en FABQ on time $\mathrm{t} 1$ and $\mathrm{t} 2$ $(n=176)$

\begin{tabular}{llll}
\hline & mean $(\mathrm{sd})$ & range & median \\
\hline TSK-t1 & $36.3(6.8)$ & $18-55$ & 36 \\
TSK-t2 & $36.0(7.4)$ & $17-55$ & 36 \\
FABQ/pa-t1 & $14.1(5.5)$ & 0 & 15 \\
FABQ/pa-t2 & $13.4(5.8)$ & 0 & 14 \\
FABQ/w-t1 & $14.4(10.1)$ & $0-38$ & 14 \\
FABQ/w-t2 & $14.7(10.3)$ & $0-38$ & 14 \\
\hline
\end{tabular}

Fear-Avoidance Beliefs Questionnaire physical activity subscale: FABQ/pa.; Fear-Avoidance Beliefs Questionnaire work subscale: FABQ/w; Tampa Scale for Kinesiophobia: TSK

Concurrent validity between TSK and FABQ

Pearson's rho between TSK and FABQ/w on $\mathrm{t} 1$ and $\mathrm{t} 2$ is 'weak' to 'moderately strong' ( $r_{11}=0.33$ and $r_{12}=0.38$ respectively, $p \leq 0.01$ ) (Table 2.3). With the reverseitems of the TSK deleted the correlation coefficients increase to $r_{t 1}=0.37$ and 
$r_{t_{2}}=0.41$ respectively $(p \leq 0.01)$. The correlation between TSK and FABQ/pa on $t 1$ and $t 2$ is 'moderately strong' to 'strong' with $r_{t 1}=0.39$ and $r_{t 2}=0.59$ ( $p \leq 0.01$ ) (Table 2.3). After deletion of the items $4,8,12$, and 16 of the TSK Pearson's tho is $r_{t 1}=0.38$ and $r_{t 2}=0.59(p \leq 0.01)$.

Table 2.3 Pearson correlation coefficients between TSK and FABQ on time $t 1$ and $t 2 . \quad(n=176)$

\begin{tabular}{llllll}
\hline & TSK-t2 & FABQ/pa-t1 & FABQ/pa-t2 & FABQ/w-t1 & FABQ/w-t2 \\
\hline TSK-t1 & $0.78^{\star \star}$ & $0.39^{\star \star}$ & - & $0.33^{\star \star}$ & - \\
TSK-t2 & & & $0.59^{\star \star}$ & - & $0.39^{\star \star}$ \\
FABQ/pa-t1 & & & $0.64^{\star \star}$ & $0.33^{\star \star}$ & - \\
FABQ/pa-t2 & & & & & $0.47^{\star \star}$ \\
FABQ/w-t1 & & & & & $0.80^{\star \star}$ \\
\hline
\end{tabular}

Fear-Avoidance Beliefs Questionnaire physical activity subscale: FABQ/pa; Fear-Avoidance Beliefs Questionnaire work subscale: FABQ/w; Tampa Scale for Kinesiophobia: TSK

\section{Discussion}

This study was carried out to investigate the psychometric properties (i.c. internal consistency, test-retest stability and concurrent validity) of the pain-related fear measures TSK and FABQ in a population of acute LBP patients. With the exception of the study of Fritz et al. (13) there have been no published studies that investigate these qualities in acute LBP, only with chronic LBP, and therefore comparisons will be made with studies that used populations with chronic LBP patients.

\section{Tampa Scale for Kinesiophobia.}

The internal consistency of the TSK equals the values found by Vlaeyen et al. and Crombez et al. $(8,45,46)$. If the reverse items $(4,8,12$, and 16) are deleted, the internal consistency increases slightly. Up to date there are no studies published investigating the test-retest reliability in either the acute or chronic stages of LBP. The test-retest reliability is 'substantial', and increases slightly if the reverse items are deleted. The items that are responsible for this decrease, (items $4,8,12$, and $16)$, are those where the score should be reversed. Goubert et al. found the reverse-items $4,8,12$, and 16 most frequently to be missing (15). In our experience the difficulties encountered by patients in interpreting the structure and content of these items is caused by their formulation.

\section{Fear-Avoidance Beliefs Questionnaire.}

The reported positive skewness of the $F A B Q / w$ is mainly caused by a high frequency of zero total scores, which may have been responsible for an eventual floor-effect. The test-retest reliability of both the $F A B Q / w$ and $F A B Q / p a$ subscales 
is 'substantial'. The higher retest stability of the $F A B Q / w$ versus the $F A B Q / p a$ $(r=0.80$ vs. $r=0.64$ ) may be caused by the relatively high frequency of zero total scores thus making it easier for the patient to remember which answers were given on the first occasion. Waddell et al. found higher correlation coefficients for the two scales $(0.95$ and 0.88$)$ in testing the reproducibility, but the major part $(75 \%)$ of the population they studied existed of chronic LBP patients and the reproducibility was tested in a small population of 26 patients (52). Pfingsten et al. calculated the test-retest stability of the total FABQ, that is of all 16 items, and found a Pearson's rho of 0.87 . In this study a small group of chronic LBP patient was used $(n=30)(30)$.

The internal consistency of both the $F A B Q / w$ and $F A B Q / p a$ resemble previous studies $(8,35,52)$, although the internal consistency of the $F A B Q / p a$ subscale in the studies by Crombez et al. is lower.

In the statistical analyses it is not taken into account whether patients are employed, although modified instructions were given (e.g. housewives were given instructions to regard their household duties as their work), or whether they were absent from work due to back pain. Repeating the analyses, excluding patients absent due to their LBP (38.1\%), internal consistency and test-retest reliability of both the $F A B Q / p a$ and $F A B Q / w$ are comparable with the results of the total group ( $F A B Q / p a:$ Cronbach's alpha is 0.75 ; test-retest $r=0.64, p<0.01$, and $F A B Q / w$ : Cronbach's alpha is $\alpha=0.82$; test-retest $r=0.80, p<0.01$ ). This means that, although a point of concern to Waddell and colleagues (1993), the FABQ can be used in cases of unemployment or absence due to LBP, with the restriction that modified instructions are given.

As expected, in this study a significant correlation is found between the two subscales of the $F A B Q$, which corroborates previous findings $(8,13,52)$. This raises questions about the orthogonality of the two subscales.

\section{Relationship between the measures}

The intercorrelations between the $\mathrm{FABQ} / \mathrm{pa}$ and $\mathrm{TSK}$ or $\mathrm{FABQ} / \mathrm{w}$ on $\mathrm{t} 2$ are higher than on 1 . Looking at the test-retest correlations of the measures, this difference may be caused by the only 'moderate' test-retest reliability of the FABQ/pa. One study investigated the concurrent validity of the TSK and FABQ. Crombez et al. reported higher correlations between TSK and FABQ (8). The fact that the calculated correlation between the two questionnaires does not exceed 'moderate' might mean that the theoretical constructs are not completely the same (although they show an empirical 'moderate' overlap), or it might mean that the validity of each questionnaire is only moderate. The TSK may be aimed more at measuring a fear of (re)injury, whereas the FABQ measures more a fear of pain directly caused by physical activities or work. This might explain the difference as well as it explains the correlation of the two measures. On the other hand the high percentage of zero total scores of the $\mathrm{FABQ} / \mathrm{w}$ may influence the correlational analyses with TSK and FABQ/pa. The high percentage of zero scores may be explained by 
the fact that, in the statistical analysis, it is not taken into account whether patients are working or on sick leave. This may also explain the contrast with the findings of Crombez et al. who found higher significant correlational values between TSK, $F A B Q / p a$ and $F A B Q / w$, ranging from $r=0.53$ to $r=0.76$, but who gave no information about the work status of their patients (8). It is unclear to what extent the study of acute LBP patients is responsible for the different findings in our study and that of Crombez et al.

We are not aware of studies reporting normative scores of the TSK and FABQ. It would be interesting to know whether scores on TSK and FABQ differ if measured in a general population without LBP as compared to a population with LBP: this might give an insight into the interpretation of the scores of TSK and FABQ.

\section{Limitations of the study}

There are some methodological aspects of this study that need considering. First, 212 patients were included during a 9-month period. The incidence of patients reporting LBP to GPS in The Netherlands (40) indicates that more patients could have been included. The researchers learned by asking GPs and physiotherapists that they often forgot to ask for patients' cooperation in the study. The number of non-responders and their characteristics are therefore unknown and no insight is provided into a possible selection bias. Second, the population included in the study is in fact heterogeneous: it comprises both patients who make a quick recovery from their back pain episode and those who don't. Much discussion exists regarding the definition of chronicity $(27,42)$. Although one of the inclusion criteria for this study was having had a period of at least three month free of back pain before the current LBP episode, there is a chance the population is biased with patients already having a chronic condition if the definition of chronic LBP is characterised by an episodic, recurrent course $(27,49,50)$. Third, in investigating the test-retest reliability a maximum interval of 24 hours was chosen, because patients with LBP of short duration are likely to show true change from one day to another (5). It is possible that recall played a role, although patients had to complete four questionnaires and they were not told that in the second battery three out of four questionnaires were the same as in the first battery. If memory had played an important role one might expect the correlation to be higher than the results show. The second reason for choosing this short interval was to minimize the influence of interventions, such as medication and activity-related instructions or advices (4). These factors may have affected the scores on $\mathrm{t} 2$.

Practical implications of the current findings in the examination or treatment of patients with acute $L B P$

During the last five decades it has increasingly become clear that pain is multidimensional, and this is confirmed by the IASP definition of pain (16). The biopsychosocial model as a new paradigm in the diagnostics and treatment of patients with benign pain (e.g. low back pain) is gradually winning acceptance by manual 
therapists (18). In applying this new model, it is important to obtain an overview of all relevant patient characteristics, so treatment or advice can be tailored (19). Pain-related fear, as part of the cognitive dimension of pain $(31,45,46)$ may be a precursor of chronic LBP $(13,20)$. Early identification of patients who have an abnormal pain-related fear is of the utmost importance in order to focus intervention on those beliefs in stead of focusing treatment on impairments in anatomical structures of the lumbar and sacral region, and possibly prevent acute patients becoming chronic. A more cognitive-behaviourally oriented treatment combined with manual therapeutic treatment on the level of impairments in physiological functions, in the early stage, may be very effective in reducing pain-related fear and hence the development of chronic disability (24,26,39). A cognitive-behavioural intervention based on exposure in vivo treatment has shown to be quite effective in patients with chronic LBP reporting elevated scores on the TSK (43). Focusing on patients' beliefs can have a positive affect on those beliefs and on disability $(4,53)$. Similar studies with a slightly modified intervention adapted to the primary care setting with acute LBP patients are badly needed, and are likely to be promising. Both the TSK and the FABQ have the potential to distinguish patients with abnormal pain-related fear $(8,28,45,46,52)$.

\section{Conclusions}

Before using the TSK and FABQ in the assessment of acute LBP patients the reliability in the acute phase needed to be examined. From this study it may be concluded that both the TSK and the FABQ are reliable questionnaires with good internal consistency and substantial test-retest reliability. Internal consistency of both questionnaires is independent of the phase of the LBP. Concurrent validity between TSK and FABQ/pa is 'moderately strong' to 'strong', and higher than between $T S K$ and $F A B Q / w$.

\section{Acknowledgements}

This work was partly supported by a grant from the Royal Dutch Association of Physiotherapists. Much gratitude is extended to William Duquet PhD, for his statistical advice, and to the GPs and physiotherapists for the inclusion of their patients. Without their cooperation this research would not have been possible. 


\section{References}

1. Asmundson,G.J.G., Norton,P.J., and Norton,G.R. Beyond pain: the role of fear and avoidance in chronicity. Clin Psychol Rev 1999; 19 (1): 97-119.

2. Bortz,W.M. The Disuse Syndrome. Western Journal of Medicine 1984; 141 691-694.

3. Burton,A.K., Tillotson,K.M., Main,C.J., and Hollis,S. Psychosocial Predictors of Outcome in Acute and Subchronic Low Back Trouble. Spine 1995; 20 (6): 722-728.

4. Burton,A.K., Waddell,G., Tillotson,K.M., and Summerton,N. Information and advice to patients with back pain can have a positive effect. A randomized controlled trial of a novel educational booklet in primary care. Spine 1999; 24 (23): 2484-2491.

5. Coste,J., Delecoeuillerie,G., Cohen de Lara,A., Le Parc,J.M., and Paolaggi,J.B. Clinical course and prognostic factors in acute low back pain: an inception cohort study in primary care practice. Britisch Medical Journal 1994; 308 577-580.

6. Croft,P.R., Papageorgiou,A.C., Ferry,S., Thomas,E., Jayson,M.I.V., and Silman,A.J. Psychologic Distress and Low Back Pain: Evidence from a prospective study in the general population. Spine 1995; 20 (24): 2731-2737.

7. Crombez,G., Govaerts,K., Vervaet,L., Lysens,R., Eelen,P., and Baeyens,F. Vermijden en volharden van bewegingen bij patienten met chronische lage- rugpijn. Gedragstherapie 1995; 28 (2): 69-84.

8. Crombez,G., Vlaeyen,J.W.S., Heuts,P.H.T.G., and Lysens,R. Pain-related fear is more disabling than pain itself. Evidence on the role of pain-related fear in chronic back pain disability. Pain 1999; $80(1,2)$ : 329-339.

9. Downie,W.W., Leatham,P.A., Rhind,V.M., Wright,V., Branco,J.A., and Anderson,J.A. Studies with pain rating scales. Annals of the Rheumatic Diseases 1978; 37 378-381.

10. Feinstein,A.R. Clinimetrics. New Haven: Yale University Press, 1987

11. Flor,H. and Turk,D.C. Etiological theories and treatments for chronic back pain. I. Somatic Models and Interventions. Pain 1984; 19 105-121.

12. Fordyce,W.E. Back pain in the workplace. Management of disability in nonspecific conditions. $1995 ; 1-72$.

13. Fritz,J.M., George,S.Z., and Delitto,A. The role of fear-avoidance beliefs in acute low back pain: relationships with current and future disability and work status. Pain 2001; 94: 7-15.

14. Frymoyer,J.W., Pope,M.H., Clements,J.H., Wilder,D.G., MacPherson,B., and Ashikaga,T. Risk Factors in Low-Back Pain. An epidemiological Survey. J Bone Joint Surg 1983; 65-A (2): 213-218.

15. Goubert,L., Crombez,G., Vlaeyen,J.W.S., Van Damme,S., Van den Broeck,A., and van Houdenhove,B. De Tampaschaal voor Kinesiofobie. Psychometrische karakteristieken en normering. Gedrag \& Gezondheid 2000; 28 54-62.

16. International Association for the study of Pain,s.o.T. Classification of chronic pain, descriptions, descriptions of chronic pain syndromes and definitions of pain terms. Pain 1986; 1. 225.

17. Jensen,M.P. and Karoly,P. Self-report scales and procedures for assessing pain in adults. In Turk,D.C., Melzack,R. (eds) Handbook of Pain Assessment. The Guilford Press, New York. 1992; 135-151.

18. Jones,M., Edwards,I., and Gifford,L. Conceptual models for implementing biopsychosocial theory in clinical practice. Man Ther 2002; 7 (1): 2-9.

19. Keen,S., Dowell,A.C., Hurst,K., Klaber Moffett,J.A., Tovey,P., and Williams,R. Individuals with low back pain: how do they view physical activity? Fam Pract 1999; 16 (1): 39-45.

20. Klenerman,L., Slade,P.D., Stanley,I.M., Pennie,B., Reilly,J.P., Atchison,L.E., Troup, J.D.G., and Rose,M.J. The prediction of chronicity in patients with an acute attack of low back pain in a general practice setting. Spine 1995; 20 (4): 478-484.

21. Kori,S.H., Miller,R.P., and Todd,D.D. Kinesophobia: a new view of chronic pain behavior. Pain Management 1990; (1): 35-43.

22. Landis,J.R. and Koch,G.G. The measurement of observer agreement for categorical data. Biometrics 1977; 33159-33174.

23. Lethem,J., Slade,P.D., Troup,J.D.G., and Bentley,G. Outline of a fear-avoidance model of exaggerated pain perception - I. Behav Res Ther 1983; 21 (4): 401-408. 
24. Linton,S.J. and Ryberg,M. A cognitive-behavioral group intervention as prevention for persistent neck and back pain in a non-patient population: a randomized controlled trial. Pain 2001; 90 (1-2): 83-90.

25. Maniadakis,N. and Gray,A. The economic burden of back pain in the UK. Pain 2000; 84 (1): 95-103.

26. Marhold,C., Linton,S.J., and Melin,L. A cognitive-behavioral return-to-work program: effects on pain patients with a history of long-term versus short-term sick leave. Pain 2001; 91 (1-2): 155-163.

27. McGorry,R.W., Webster,B.S., Snook,S.H., and Hsiang,S.M. The relation between pain intensity, disability, and the episodic nature of chronic and recurrent low back pain. Spine 2000; 25 (7): 834-841.

28. Miller,R.P., Kori,S.H., and Todd,D.D. The Tampa Scale. 1991;

29. Nachemson,A.L. Newest knowledge of low back pain. Clin Orthop Rel Res. 1992; (279): 820.

30. Pfingsten,M., Kroner-Herwig,B., Leibing,E., Kronshage,U., and Hildebrandt,J. Validation of the German version of the Fear-Avoidance Beliefs Questionnaire (FABQ). Eur J Pain 2000; 4 (3): 259-266.

31. Philips,H.C. and Jahanshahi,M. The components of pain behaviour report. Behav Res Ther 1986; 24 (2): 117-125.

32. Pincus, T., Burton,A.K., Vogel,S., and Field,A.P. A systematic review of psychological factors as predictors of chronicity/disability in prospective cohorts of low back pain. Spine 2002; 27 (5): E109-E120.

33. Slade,P.D., Troup,J.D.G., Lethem,J., and Bentley,G. The Fear-Avoidance model of exaggerated pain perception - II. Preliminary studies of coping strategies for pain. Behav Res Ther 1983; 21 (4): 409-416.

34. Sternbach,R.A. Psychological aspects of chronic pain. Clin Orthop Rel Research $1977 ; 129$ 150-155.

35. Symonds,T.L., Burton,A.K., Tillotson,K.M., and Main,C.J. Do attitudes and beliefs influence work loss due to low back trouble? Occup Med 1996; 46 (1): 25-32.

36. Tulder,M.W.v. Diagnostics and treatment of chronic low back pain in primary care. 1996; 1 164.

37. Turk,D.C. The role of demographic and psychosocial factors in transition from acute to chronic pain: 185-214. Seattle: IASP, 1997

38. van Tulder,M.W., Koes,B.W., and Bouter,L.M. A cost-of-illness study of back pain in The Netherlands. Pain 1995; 62 (2): 233-240.

39. van Tulder,M.W., Koes,B.W., and Bouter,L.M. Conservative treatment of acute and chronic nonspecific low back pain. A systematic review of randomized controlled trials of the most common interventions. Spine 1997; 22 (18): 2128-2156.

40. Velden,J.V.d., De Bakker,D.H., Claessens,A.A.M.C., and Schellevis,F.G. Een nationale studie naar ziekten en verrichtingen in de huisartsenpraktijk. Basisrapport morbiditeit in de huisartsenpraktijk. 1991;

41. Vendrig,A., Deutz,P., and Vink,I. Nederlandse vertaling en bewerking van de FearAvoidance Beliefs Questionnaire. Ned Tijdschrift voor Pijn en Pijnbestrijding 1998; 18 (1): 11-14.

42. Verhaak,P.F.M., Kerssens,J.J., Dekker,J., Sorbi,M.J., and Bensing,J.M. Prevalence of chronic benign pain disorder among adults: a review of the literature. Pain 1998; 77 (3): 231-239.

43. Vlaeyen,J.W.S., de Jong,J., Geilen,M., Heuts,P.H.T.G., and van Breukelen,G. Graded exposure in vivo in the treatment of pain-related fear: a replicated single-case experimental design in four patients with chronic low back pain. Behav Res Ther 2001; 39 (2): 151-166.

44. Vlaeyen,J.W.S. and Crombez,G. Fear of movement/(re)injury, avoidance and pain disability in chronic low back pain patients. Man Ther 1999; 4 (4): 187-195.

45. Vlaeyen,J.W.S., Kole-Snijders,A.M.J., Boeren,R.G.B., and Eek,H.v. Fear of movement/(re)injury in chronic low back pain and its relation to behavioral performance. Pain 1995; 62 363-372.

46. Vlaeyen,J.W.S., Kole-Snijders,A.M.J., Rotteveel,A.M., Ruesink,R., and Heuts,P.H.T.G. The role of fear of movement/(re)injury in pain disability. J Occup Rehabil 1995; 5 (4): 235-252. 
47. Vlaeyen,J.W.S. and Linton,S.J. Fear-avoidance and its consequences in chronic musculoskeletal pain: a state of the art. Pain 2000; 85 (3): 317-332.

48. Volinn,E., Koevering,D.v., and Loeser,J.D. Back Sprain in Industry. The role of socioeconomic factors in chronicity. Spine 1991; 16 (5): 542-548.

49. Von Korff,M. Studying the natural history of back pain. Spine 1994; 19 (18S): 2041S-2046S.

50. Von Korff,M. and Saunders,K. The Course of Back Pain in Primary Care. Spine 1996; 21 (24): 2833-2839.

51. Waddell,G. The back pain revolution. Edinburgh: Churchill Livingstone, 1998

52. Waddell,G., Newton,M., Henderson,I., Somerville,D., and Main,C.J. A fear avoidance beliefs questionnaire $(F A B Q)$ and the role of fear-avoidance beliefs in chronic low back pain and disability. Pain 1993; 52 157-168.

53. Walsh,D.A. and Radcliffe,J.C. Pain beliefs and perceived physical disability of patients with chronic low back pain. Pain 2002; 97 (1-2): 23-31.

54. Wewers,M.E. and Lowe,N.K. A critical review of visual analogue scales in the measurement of clinical phenomena. Res Nurs Health 1990; 13 (4): 227-236. 


$$
\text { , }
$$




\section{Appendix}

Reply to letter to the editor

EJCM Swinkels-Meewisse, J Roelofs, RAHM Swinkels, ALM Verbeek, JWS Vlaeyen, RAB Oostendorp

Published as:

EJCM Swinkels-Meewisse, J Roelofs, RAHM Swinkels, ALM Verbeek, JWS Vlaeyen, RAB Oostendorp. Reply to Letter to the Editor. Man Ther 2004; 9: 47-48 


\section{Author's reply}

We would like to thank Dr. Nijs and Dr. Truyen for their interest in and careful reading of our paper entitled "Psychometric properties of the Tampa Scale for Kinesiophobia and the Fear-Avoidance Beliefs Questionnaire" (4). Dr. Nijs and Dr. Truyen expressed concerns about the statistical analyses that have been used in the study. In this response, we would like to comment on these concerns in a point-by-point reply.

The first concern is that items of the TSK-DV and FABQ are scored on a Likert-scale and individual items as well as total scores should be considered ordinal data. Consequently, a Spearman rank correlation coefficient should have been used to analyse concurrent validity of both measures, rather than a Pearson product-moment correlation, of which the application is only restricted to interval and ratio scales. We agree that individual items of the TSK-DV and the FABQ should be considered ordinal data. Measurement on an ordinal scale involves rankordered categories. An interval scale also has this rank-order characteristic but also assumes equal distances or intervals between units of measurement (2). For an individual item, it would perhaps be difficult to assume that a difference between 1 and 2 is the same as the difference between 3 and 4 . However, none of the analyses have relied on scores on individual items, but all have been conducted on total scores (TSK) or total scores of subscales (FABQ) of these measures. It is not possible to statistically test whether total scores could be considered as interval data, but we can only assume that each item is equally important in the composition of the total score and subsequently assume that we may treat total scores of the TSK-DV and FABQ as continuous variables measured at an interval level. This is a common assumption in examining self-report measures in the behavioural and social sciences. In our opinion, the Pearson product-moment correlation is an appropriate measure for analyzing concurrent validity of both measures.

The second concern relates to the first one: descriptive statistics should comprise the median and the interquartile range as is appropriate for ordinal data. Again, we assume the total scores of the measures are continuous and measured on an interval scale. Thus, we consider the mean as a measure of central tendency and the corresponding standard deviation as appropriate descriptive statistics of the measures. Also, direct comparisons with other studies that have reported means and standard deviations of these measures are possible.

The third concern relates to the analysis of the test-retest reliability. An intraclass correlation coefficient (ICC) or a kappa statistic ( $\mathrm{K}$ ) should have been used to examine test-retest reliability. We fully agree that an ICC is the most preferred index for examining test-retest reliability as it not only accounts for the degree of 
correspondence (i.e., correlation) but also the degree of agreement. If all individuals that complete a self-report measure would score exactly ten points higher on this measure at the second test occasion as compared to the first occasion, then a perfect correlation coefficient (Pearson $r=1.0$ ) would be obtained but agreement is poor. An ICC accounts for both these issues. However, it should be noted that computations of ICC involves the estimation of variance estimates obtained through analysis of variance, which assumes equal intervals between the measurement units of the total scores (2). This is only the case when total scores of the TSK-DV and total scores on the subscales of the FABQ are assumed to be at the interval level. In re-analyzing our data, we obtained an ICC for the TSK-DV of 0.78 (95\% confidence interval: $0.71-0.83$ ). For two total scores on the $\mathrm{FABQ} / \mathrm{w}$ and $\mathrm{FABQ} /$ pa subscales we found an ICC of 0.80 (95\% confidence interval: $0.74-0.85$ ) and 0.64 (95\% confidence interval: $0.55-0.72)$ respectively. The ICC estimates are almost identical to the Pearson product moment correlation coefficient reported in our study.

The fourth concern relates to the internal consistency of the TSK-DV and the FABQ. We agree that measurement instruments with a Cronbach's alpha below 0.80 are considered less reliable. As correctly pointed out by Dr. Nijs and Dr. Truyen, Cronbach's alpha is affected by the number of items in a scale. Future studies could extend these measures with appropriate items.

In the final concern, Dr. Nijs and Dr. Truyen stress the importance of reporting the $95 \%$ confidence intervals of TSK-DV and FABQ scores for evaluating interventions as they may be useful for determining whether a change in the scores on these measures can be considered clinically relevant. We agree with their notion but a greater time interval between both test occasions than used in our study, should be applied to address this concern. Future studies may focus on the responsiveness of the TSK-DV and the subscales of the FABQ. Responsiveness refers to the ability of an instrument to detect change over time, which is important in both clinical practice and research (3). To assess the responsiveness of an instrument an external criterion is necessary to determine whether real change has occurred or not (1). Responsiveness can be quantified by either comparing change scores with the corresponding smallest real difference (SRD) or by receiver operating characteristics curves (ROC curves)(see (1) for more details). We hope that this response sufficiently cleared up the concerns raised by Dr. Nijs and Dr. Truyen. 


\section{References}

1. de Vet,H.C., Bouter,L.M., Bezemer,P.D., and Beurskens,A.J. Reproducibility and responsiveness of evaluative outcome measures. Theoretical considerations illustrated by an empirical example. Int J Technol Assess Health Care 2001; 17 (4): 479-487.

2. Portney,L.G. and Watkins,M.P.Foundations of clinical research. Applications to practice. Appleton and Lange, 2000

3. Sim,J. and Waterfield,J. Validity, reliability and responsiveness in the assessment of pain. Physiotherapy Theory and Practice 1997; 13 23-37.

4. Swinkels-Meewisse,E.J., Swinkels,R.A., Verbeek,A.L., Vlaeyen,J.W.S., and Oostendorp,R.A. Psychometric properties of the Tampa Scale for kinesiophobia and the fearavoidance beliefs questionnaire in acute low back pain. Man Ther 2003; 8 (1): 29-36. 


\section{Chapter 3}

\section{Assessing pain and pain-related fear in acute low back pain: what is the minimal detectable change?}

Raymond W.J.G. Ostelo, Ilse J.C.M. Swinkels-Meewisse, Dirk L. Knol, Johan W.S. Vlaeyen, Henrica C.W. de Vet 


\section{Abstract}

In the last decade there has been an increasing interest in the role that pain and pain-related fear play in the transition from acute to chronic low back pain (LBP). The Tampa Scale for Kinesiophobia (TSK) and the Fear-Avoidance Beliefs Questionnaire (FABQ) are two frequently used questionnaires for pain-related fear. The visual analogue scale (VAS) is frequently used for measuring pain. It has been concluded that, in acute LBP, both the TSK and the FABQ are reliable questionnaires. However, reproducibility encompasses two concepts: reliability and agreement. If the focus is on detecting changes in health status agreement parameters are important. The first objective of this study was to assess the agreement on the individual items of these questionnaires, and, secondly, to determine the minimal detectable change (MDC) of these measures in patients with acute low back pain. Finally, ceiling and/or floor effects were investigated.

A wide range was found in weighted Kappa's of the individual items of the TSK and $F A B Q$, indicating that there are items with good and items with poor testretest agreement. Furthermore, the MDC of the TSK appeared to be $9.2(95 \% \mathrm{Cl}$ : $8.4 ; 10.3)$. The MDC of the FABQ physical activity subscale is 9.4 (95\% Cl: 8.5 ; 10.6) and $12.7(95 \% \mathrm{Cl}: 11.5 ; 14.1)$ for the $\mathrm{FABQ}$ work subscale. For pain (VAS) the change between two measures should be $36.2 \mathrm{~mm}(95 \% \mathrm{Cl}: 32.4 ; .41 .0)$ before it becomes likely that a patient has truly changed. Finally, assessing floor and ceiling effects, the FABQ physical activity subscale and pain (VAS) seem to have considerable problems in detecting improvement and deterioration. The TSK total score appears to be able to detect improvement as well as deterioration. 


\section{Introduction}

In the last decade there has been an increasing interest in the role that pain and pain-related fear play in the transition from acute to chronic low back pain (LBP) and in the maintenance of chronic pain disability $(1,12,19)$. In the literature concerning pain-related fear and fear-avoidance beliefs two questionnaires, based on the theories of fear and avoidance behaviour, are frequently used: the Tampa Scale for Kinesiophobia (11) and the Fear-Avoidance Beliefs Questionnaire (FABQ) (21). The TSK measures one particular aspect of pain related fear, i.e. fear of movement and fear of (re) injury during physical activity and proved to be a reliable and valid questionnaire in patients with chronic low back pain $(8,13,18)$. The FABQ was developed focussing specifically on the patient's beliefs about how physical activity and work affected their low back pain (21). It was recommended to consider the $F A B Q$ in the medical management for $L B P$.

Swinkels-Meewisse (16) concluded that both the TSK and the FABQ are also reliable in a population with acute LBP. Furthermore a two-factor solution consisting of a 'harm' subscale and an 'avoidance-of-activity' subscale was reported but the validity of these subscales needs to be confirmed in future studies (15). However, the concept of reliability is only one side of the reproducibility coin. Reliability coefficients relate the variance due to measurement error to the variation between individuals in a population and thus are dependent on the heterogeneity of the population. Therefore, reliability represents the extent to which individuals can be distinguished from each other, despite measurement errors. If one is more interested in detecting changes in health status agreement parameters are importani (17). Based on the within-subject variance the variation around a single measurement can be estimated: the standard error of measurement (SEM), which is expressed in the same units as the original questionnaire. Based on the SEM the minimal detectable change (MDC) can be estimated. As the MDC is also expressed in the same unit as the questionnaire it improves the interpretation of change scores on a questionnaire.

This study focuses on agreement parameters for the pain (VAS), the Tampa Scale for Kinesiophobia (TSK) and the Fear-Avoidance Beliefs Questionnaire (FABQ) in a population with acute low back pain. The first objective of this study is to assess the agreement on the individual items of these questionnaires. Secondly, this study aims to determine the minimal detectable change (MDC) of the total scores of these questionnaires. Finally, ceiling and/or floor effects are investigated.

\section{Methods}

\section{STUDY POPULATION}

Patients with LBP were recruited by general practitioners (GPS) and physiotherapists in the southeast region of The Netherlands between April 1998 and January 
1999. Patients were included if they were aged between 18 and 65 years and if they suffered had non-specific LBP (with or without radiation) for no longer than 4 weeks with a pain-free period of at least 3 months preceding this episode of LBP. Criteria for exclusion were: LBP with a specific underlying pathology (e.g. tumours, trauma, infection, inflammatory disorders); presence of malignancies; operations in the lumbar area; or pregnancy.

\section{PROCEDURES}

At the first consultation with their GPs and physiotherapists patients were asked if they were willing to participate in the study. If so, they received written information. After written informed consent was obtained, the TSK, the FABQ and, the VAS (Pain) were administered twice by each patient. The first set of questionnaires was completed during the first consultation with their health care provider; the second time at home the same evening or with a maximum of 24 hours after the completion of the first set of questionnaires. This time was chosen to minimize the change, both clinically and cognitively, within subjects. Therefore patients were considered to be 'unchanged', assuming that they had no clinically relevant improvement. It was anticipated that patients would not remember their initial responses given the length of the questionnaires. During the first consultation patients also completed a questionnaire covering their socio-demographic variables.

\section{QUESTIONNAIRES}

In this study the Tampa Scale for Kinesiophobia_Dutch Version (TSK_DV) was used $(11,18)$. The TSK is a 17-item self-reporting questionnaire measuring fear of movement or (re)injury. Each item is scored on a 4-point Likert scale: 'strongly disagree' (score 1), 'somewhat disagree' (score 2), 'somewhat agree' (score 3) and, 'strongly agree' (score 4). There are 4 reverse-keyed items: item 4, 8,12 , and 16 . If the complete TSK_DV is considered, the total score ranges from 17 (no fear avoidance beliefs) to 68 (strong fear avoidance beliefs). Also the two subscales of the TSK_DV (15) were considered in this study. The 'harm' factor consists of the items $3,5,6,9,11$, and 15 , reflecting the beliefs that there is something seriously wrong with the body. The 'activity-avoidance' factor consists of the items $1,2,7,10,13,14$, and 17 , reflecting beliefs that avoiding exercise or activities might prevent an increase of pain.

The Fear-Avoidance Beliefs Questionnaire (FABQ) (21) has 16 items, each scored $0-6$, with higher numbers indicating increased levels of fear-avoidance beliefs. Two subscales within the FABQ have been identified; the FABQ work, a seven-item work subscale scale (score range $0-42$ ), and the $F A B Q$ physical activity, a four-item physical activity subscale (score range 0-24).

One of the most frequently used instruments for measuring current pain intensity is a visual analogue scale (VAS) for assessing current pain intensity consisting 
of a horizontal $100 \mathrm{~mm}$ line, with the anchors 'no pain' $(0 \mathrm{~mm})$ and 'worst imaginable pain' $(100 \mathrm{~mm})(20)$.

\section{DATA ANALYSES}

For each of the individual items weighted kappa's (quadratic weights) were calculated in order to consider the disagreement on each individual item (5).

The standard error of measurement (SEM) defined as the square root of the within-subject variance was calculated in a test-retest design. If systematic errors between test-retest occasions are taken into account the within subject variance consists of the residual variance plus the variance between measures. The $95 \%$ Cls were calculated as described by Brennan (4).

The MDC was calculated as $1.96 \times \sqrt{2} \times$ SEM. In other words, the MDC expresses the magnitude of change that a truly stable patient could undergo. Finding a change score larger than the MDC occurs with a chance of $5 \%$ or less (2). Given this small probability, it is likely that a patient whose score exceeds the MDC has truly changed.

A prerequisite for measuring improvement is an initial score not equal to the best possible score. Vice versa, the same holds true for measuring deterioration. In other words, initial scores at the 'floor' or at the 'ceiling' of the scale affect the ability of the scale to detect a meaningful change. Davidson and Keating (6) have coined the term 'scale width' to indicate the capacity of a scale to have initial scores that are far enough onto the scale to allow detection of change in scores over time. Because we defined the MDC as the minimal detectable change, we defined 'scale width' as $1 \mathrm{MDC}$ from the theoretical minimum or maximum of a particular scale. In line with Davidson and Keating (6) we defined 'floor' and ceiling' effects in terms of not more than $15 \%$ of the respondents within 1 MDC from the theoretical minimum or maximum of a particular scale. The scores of the first set of questionnaires was used for determining floor and ceiling effects. For all statistics SPSS 10.1 for Windows was used, except the weighted kappa's, which were calculated with StatXact 4.0.

\section{Results}

212 Patients were entered in the study. Thirty-six patients $(17 \%)$ were excluded from the analysis because of incomplete questionnaires $(n=28)$, missing sociodemographic data $(n=5)$, and by being above the age of $65(n=3)$. This resulted in 176 patients with complete data. There were no statistical differences between the excluded cases and the analyzed cases regarding age, gender, sick-leave, pain onset or educational level. Table 3.1 presents the information of the characteristics of the 176 patients. 
Table 3.1 Characteristics of patients $(n=176)$

\begin{tabular}{ll}
\hline Variable & \\
\hline Mean age in years (SD) & $52.7(11.5)$ \\
Sex (\% male) & $59.7 \%$ \\
Educational level (\%) & $38.7 \%$ \\
Less than secondary education & $26.7 \%$ \\
Secondary education & $33.5 \%$ \\
Higher education/University & $1.7 \%$ \\
Missing & \\
On sick-leave & $38.1 \%$ \\
Not on sick-leave & $17.6 \%$ \\
Not Applicable & $37.5 \%$ \\
Missing & $6.8 \%$ \\
Pain onset (\%sudden) & $61.9 \%$ \\
Preceding episodes & \\
First episode & $15.3 \%$ \\
1 - 5 episodes & $59.7 \%$ \\
6 - 10 episodes & $13.6 \%$ \\
$>11$ episodes & $6.3 \%$ \\
Missing & $5.1 \%$ \\
< 7 days & \\
7 - 14 days & $36.9 \%$ \\
14 - 21 days 28 days & $29.5 \%$ \\
Duration of this episode & $16.5 \%$ \\
\hline
\end{tabular}

Tables 3.2 and 3.3 present the weighted kappa's of the individual items of the TSK and the FABQ, respectively. The weighted kappa's for the TSK-items range from $0.26(95 \% \mathrm{Cl}: 0.1 ; 0.4)$ for item 16 to $0.70(95 \% \mathrm{Cl}: 0.6 ; 0.8)$ for item 1 and item 5 , respectively. The weighted kappa's of the items of the $F A B Q$ work subscale range from $0.40(95 \% \mathrm{Cl}: 0.2 ; 0.6)$ for items 15 to $0.74(95 \% \mathrm{Cl}: 0.7 ; 0.8)$ for items 7 . The weighted kappa's of the items that comprise FABQ_physical activity subscale range from $0.48(95 \% \mathrm{Cl}: 0.3 ; 0.6)$ for item 4 to $0.59(95 \% \mathrm{Cl}: 0.5 ; 0.7)$ for item 5 .

Table 3.4 presents the between-subject variance and the within-subject variance, the standard error of measurement (SEM) and the minimal detectable change (MDC). In order to make these latter parameters comparable across questionnaires these are also expressed in percentages of corresponding scale. Based on these percentages the results show that the MDC of the complete TSK (theoretical scoring range from 17-68) is the smallest (18.0\%) with a value expressed in TSK-scale points of $9.2(95 \% \mathrm{Cl}: 8.4,10.3)$. The MDC of the FABQ_physical activity subscale (theoretical scoring range from $0-24)$ is the biggest value $(39.6 \%)$ with a value expressed in FABQ subscale points of $9.4(95 \% \mathrm{Cl}: 8.5,10.6)$. 
Table 3.2 Weighted kappa per TSK-item

\begin{tabular}{|c|c|c|}
\hline \# & & $\begin{array}{l}\text { Weighted Kappa } \\
(95 \% \mathrm{Cl})\end{array}$ \\
\hline 1 & I'm afraid I might injure myself if I exercise & $.70(.60, .81)$ \\
\hline 5 & People aren't taking my medical condition seriously enough & $.70(.56, .83)$ \\
\hline 9 & I am afraid I might hurt myself accidentally & $.67(.57, .78)$ \\
\hline 3 & My body is telling I have something dangerously wrong & $.65(.54, .75)$ \\
\hline 10 & $\begin{array}{l}\text { Simply being careful that I do not make unnecessary movements is } \\
\text { the safest }\end{array}$ & $.62(.49, .75)$ \\
\hline $4^{H}$ & My pain would probably be relieved if I were to exercise & $.61(.49, .73)$ \\
\hline 15 & $\begin{array}{l}\text { I can't do all the things normal people do because it's too easy for me } \\
\text { to get injured }\end{array}$ & $.60(.47, .73)$ \\
\hline 14 & $\begin{array}{l}\text { It's really not safe for a person with a condition like mine to be physi- } \\
\text { cally active }\end{array}$ & $.59(.48, .71)$ \\
\hline 2 & If I were to try to overcome it, my pain would increase & $.59(.48, .70)$ \\
\hline 7 & Pain always means I have injured my body & $.57(.45, .69)$ \\
\hline $12^{\#}$ & Although pain, if I were physically active I would be better of & $.51(.39, .64)$ \\
\hline 17 & No one should have to exercise when he/she is in pain & $.51(.38, .63)$ \\
\hline 13 & Pain lets my know when to stop exercising so I don't injure myself & $.47(.32, .62)$ \\
\hline 11 & $\begin{array}{l}\text { I wouldn't have so much pain if there weren't something potentially } \\
\text { dangerously } \\
\text { going on in my body }\end{array}$ & $.47(.31, .63)$ \\
\hline $8^{H}$ & $\begin{array}{l}\text { Just because something aggravates my pain does not mean it is } \\
\text { dangerous }\end{array}$ & $.46(.33, .60)$ \\
\hline 6 & My accident has put my body at risk for the rest of my life & $.45(.29, .60)$ \\
\hline $16^{\#}$ & $\begin{array}{l}\text { Even though something is causing me a lot of pain, I don't think it's } \\
\text { actually dangerous }\end{array}$ & $.26(.11, .41)$ \\
\hline
\end{tabular}

$n=176$; \# item number; \# reverse-keyed items

For pain intensity (as measured on a VAS) the change between two measures should at least be $36.2 \mathrm{~mm}(95 \% \mathrm{Cl}: 32.4, .41 .0)$ before it becomes likely that a patient has truly changed.

Assessing the 'floor' and 'ceiling' effects (table 3.5) revealed that on pain (VAS) and the FABQ_physical activity subscale more than $15 \%$ of the participants had initial scores that hamper detection of improvement and deterioration. The TSK harm subscale and the FABQ work subscale only exceeded the $15 \%$ rule for detection of improvement. The complete TSK and the TSK activity avoidance subscale seem to be able to detect improvement as well as deterioration.

\section{Discussion}

It has been shown that in a population with acute LBP, both the TSK and the FABQ are reliable questionnaires of pain-related fear (16). But as already stated, 
agreement parameters are important if one wants to detect changes in health status over time (17). So, if one wants to assess the course of pain or pain related fear in acute low back pain or the effectiveness of interventions that aim to reduce pain intensity or pain-related fear it is important to know the minimal detectable change (MDC) of these questionnaires. For the TSK, for example, the current study reveals that a change score of 9.2 TSK-points (on the TSK total) or smaller between two measures in a population with acute low back pain is probably due to chance. The 'change' of 9.2 or smaller reflects fluctuations in pain-related fear in the absence of real change. In other words, a patient assumed to be stable can

Table 3.3 Weighted kappa per FABQ-item

\begin{tabular}{cll}
\hline \multicolumn{1}{|c}{} & & $\begin{array}{l}\text { Weighted Kappa } \\
(95 \% \mathrm{Cl})\end{array}$ \\
\hline 8 & I have a claim for compensation for my pain & $.87(.73,1)$ \\
1 & My pain was caused by physical activity & $.77(.69, .85)$ \\
14 & I cannot do my normal work till my pain is treated & $.74(.66, .82)$ \\
$7^{\#}$ & My work aggravated my pain & $.74(.65, .83)$ \\
$11^{\#}$ & My work might harm my back & $.73(.65, .83)$ \\
$6^{\#}$ & My pain was caused by work or by an accident at work & $.73(.63, .83)$ \\
13 & I cannot do my normal work with my present pain & $.70(.61, .79)$ \\
$12^{\#}$ & I should not do my normal work with my present pain & $.69(.60, .79)$ \\
$10^{\#}$ & My work makes or would make my pain worse & $.63(.52, .74)$ \\
$9^{\sharp}$ & My work is too heavy for me & $.61(.46, .76)$ \\
16 & I don not think that I will ever be able to go back to that work & $.61(.35, .86)$ \\
$5^{\phi}$ & I cannot do physical activities which (might) make my pain worse & $.59(.47, .71)$ \\
$3^{\phi}$ & Physical activity might harm my back & $.58(.46, .70)$ \\
$2^{\phi}$ & Physical activity makes my pain worse & $.57(.45, .68)$ \\
$4^{\phi}$ & I should not do physical activities which (might) make my pain & $.48(.33, .62)$ \\
& worse & \\
$15^{\#}$ & I don not think that I will be back to my normal work within 3 months & $.40(.22, .59)$ \\
\hline
\end{tabular}

$\mathrm{n}=176$; \# item number; \# items comprise fear-avoidance beliefs about work-related activities; $\phi$ items comprise fear-avoidance beliefs about physical activity.

Table 3.5 Floor and ceiling effects based on 'scale width' of questionnaires at baseline

\begin{tabular}{lcc}
\hline Questionnaire & $\begin{array}{c}\text { hamper detection of improve- } \\
\text { ment\# }\end{array}$ & $\begin{array}{l}\text { hamper detection of } \\
\text { deterioration\# }\end{array}$ \\
\hline Pain (VAS) & 36.3 & 27.9 \\
TSK total & 6.7 & 0.0 \\
TSK 'harm' & 67.6 & 0.6 \\
TSK 'activity avoidance' & 11.7 & 3.9 \\
FABQ physical activity & 24.0 & 43.0 \\
FABQ work & 49.2 & 3.4 \\
\hline
\end{tabular}

\#Percentage of subjects with initial scores within $1 \mathrm{MDC}$ of end of scale. 


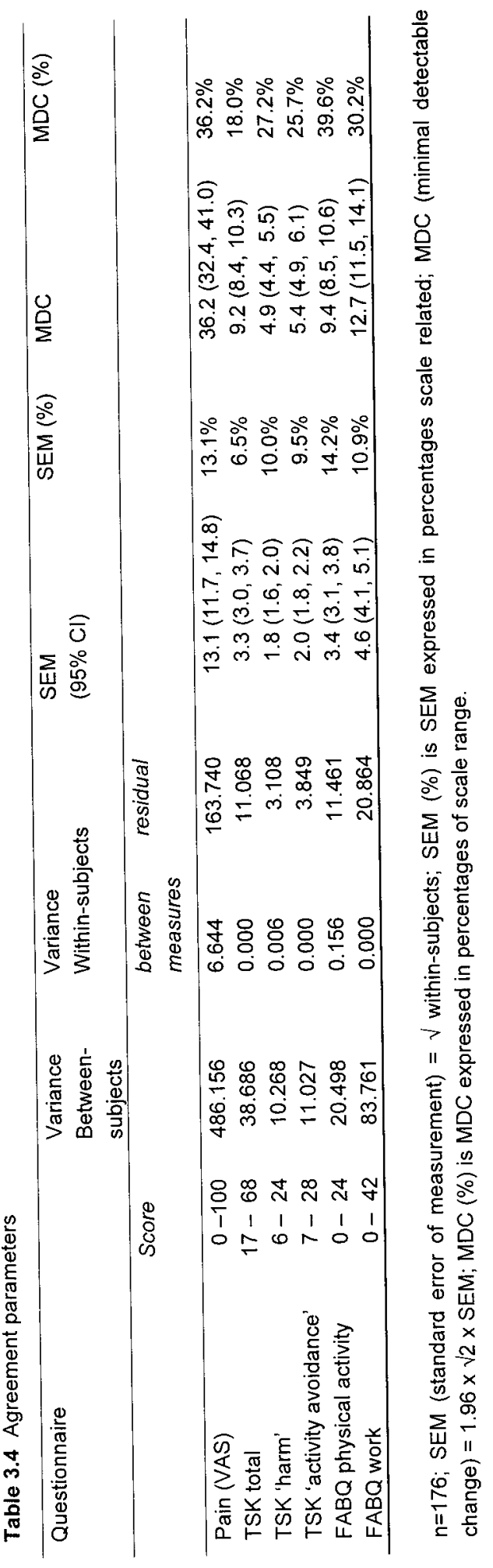


reveal a difference (with a chance of $95 \%$ ) between two occasions of 9.2 (or smaller). There could be several explanations for these fluctuations. The assumption that patients had no clinically relevant improvement regarding pain related fear could be questioned: fear of movement could be reduced both by internal and external factors, e.g. advice to stay active by their GP or PT. However, we think that our assumption of no clinically relevant improvement in pain-related fear was reasonable because of the short interval between measurements. Moreover, the variance between the two measurements moments is 0 on the TSK indicating that no systematic change between the two measurements moments has occurred. In other words, the only fluctuation is random error. Therefore we think that our assumption regarding no clinically relevant improvement regarding pain related fear is reasonable.

Another factor influencing pain-related fear could be the current pain intensity during the two moments of administration. However, there were no significant or relevant correlations between current pain and the scores on the TSK and the two subscales of the FABQ, as calculated for both moments separately. (Data not presented.) Therefore it seems unlikely that current pain has a substantial influence on the responses on the items of th: TSK or FABQ.

Table 3.2 yields some insight in individual items that might be held 'responsible' for the fluctuation. Ten out of the 17 items yield a weighted kappa of 0.6 or lower, 5 of which even lower than 0.5 . There are no standards for when a weighted kappa is 'good enough' (14), but values lower than 0.5 can be considered as rather low. Although current pain status does not seem to influence the responses on the TSK or FABQ it is interesting to notice that 8 out of these 10 items contain the word 'pain'. Moreover, four out of the 5 items with the lowest kappa's contain the word 'dangerous' or 'at risk'. A possible explanation might be that the perception of concepts such as 'pain' or 'dangerous' might be highly contextualized in the experience of the patient. For example on one measurement occasion the patient reflects on the situation in which there are restriction due to low back pain and therefore activities might not be perceived as dangerous. On the other occasion he might reflect on the situation where he is severely restricted in his activities due to LBP. Under such conditions activities might be perceived as dangerous. Indeed, preliminary results of a qualitative study, currently underway, on the meaning and the interpretation of the individual items of the TSK reveal that patients have difficulties with the interpretation of concepts as 'dangerously wrong'. Whether activities are perceived as 'dangerous' could depend on the specific situation a patient reflects on. Moreover some patients report that 'dangerous' is not an appropriate concept for describing low back pain: low back pain is a nuisance but not 'dangerous' (10).

Another source of misconception might be due to erroneous reading. The results on some of these items revealed that patients 'changed' their responses (within 24 hours!) from 'completely agree' to 'completely disagree'. It is highly unlikely that this reflects upon a real change. A more reasonable explanation is 
that some of these items are multi interpretable. In this perspective it is interesting to see that 3 of the 4 reverse items are among the items with low weighted Kappa's. Goubert et al. (9) already reported these items to be most frequently missing. The qualitative study will shed more light on these issues and one of the important challenges for future research on responsiveness of these questionnaires is to examine the feasibility of integrating the results of qualitative studies.

This study also included the two-factors ('harm' and 'avoidance-of-activity'). Determining the MDCs of the two subscales revealed some interesting differences in terms of measurement error. While the TSK total score has a MDC of 9.2 (95\% $\mathrm{Cl}: 8.4 ; 10.3)$ the two MDCs of the TSK harm and the TSK activity avoidance subscales are $4.9(95 \% \mathrm{Cl}: 4.4,5.5)$ and $5.5(95 \% \mathrm{Cl}: 4.9,6.1)$, respectively. This indicates that there should at least be a change of $27.2 \%$ and $25.7 \%$ on TSK 'harm' and the TSK 'activity avoidance -' respectively, before it becomes likely that there is a real change as opposed to $18 \%$ in the TSK-total. Moreover the TSK 'harm' has serious difficulties in detecting improvement: $67.6 \%$ of the patients had initial scores in the low end of the scale. These results support the conclusion of Vlaeyen and Linton (19) that the TSK-total score is to be preferred to the subscales if one is more interested in measuring change.

Comparing the scores of the individual items of the FABQ of the current study with Waddells' results revealed some differences. Waddell et al. (21) concluded that on all 16 items $71 \%$ of the answers were identical on retest. In the current study only on 4 items the answers were identical on the 7-point scale, while on the remaining 12 items this was only $61 \%$ or lower. However, the populations are different as Waddell included patients with chronic low back pain attending an orthopaedic out-patient clinical, whereas the current study included patients with acute low back pain that attended their GP or PT. Table 3.3 reveals that especially the items that comprise the $F A B Q$ physical activity subscale have poor weighted kappa's, which is reflected in a rather large MDC. Moreover, the FABQ_physical activity has problems in detecting deterioration as well as improvement in acute low back pain. Possible explanations are similar then previously discussed regarding the TSK. Because the FABQ specifically focuses on work we performed subgroup analyses on workers and non-workers. This had no substantial influence on the magnitude of the MDC.

The $100 \mathrm{~mm}$ VAS is commonly used for measuring pain intensity and there is much evidence supporting its validity (20). However interpretation of the VASscores remains difficult. The current study indicates that a change smaller that $36.2 \mathrm{~mm}(95 \% \mathrm{Cl}: 32.4 ; 41.0)$ needs to be interpreted with considerable caution because this might reflect the amount of measurement error only. Farrar et al. (7) reported that a reduction of approximately two points or a reduction of approximately $30 \%$ on an 11-point numerical pain rating scale represented a clinically important difference. Beurskens et al (3) concluded that a change score between 10-18 mm on a VAS for the pain was the best cut-off point, based on ROC curve analysis, to discriminate between improved and non-improved patients. These cut- 
off values are smaller than the MDC we calculated but one has to realise when using ROC cut-off values instead of the MDC that a certain proportion of patients false-positively labelled as improved as the scores of these patients fall within the measurement error.

Another important remark that needs to be made is that it is important to recognize that the minimally clinically important change may be smaller than the minimal detectable change as calculated in the current study, because what can be considered as 'clinically important' remains a matter of (arbitrary) judgment. But if the minimally clinically important change as expressed in scale points on a given instrument is smaller than the minimal detectable change of that instrument, distinguishing between real change and fluctuations in the absence of real change remains hazardous or even impossible. It is also important to realise that, in general, single items measures are not very reliable. It has been shown that aggregated pain measures are more reliable and more sensitive to treatment effect than single measures (20). Although it is more time consuming we think that averaging multiple pain measures (of current pain) is preferable especially in acute low back pain. This might also overcome the problems of detecting improvement and/or deterioration in pain intensity as with a single item pain intensity measure.

In conclusion, there was a wide range in weighted kappa's of the individual items of the TSK and the FABQ indicating that there are items with good and items with poor test-retest agreement. Several possible explanations have been discussed. The MDCs of the (subscales of) questionnaires and pain intensity range from $25 \%$ to $40 \%$ of the scale, the TSK total being the exception with a MDC that equals $18 \%$ of the scale. Floor and ceiling effects are expected in most scales, except the TSK-total and the TSK activity avoidance subscale 


\section{References}

1. Asmundson,G.J.G., Norton,P.J., and Norton,G.R. Beyond pain: the role of fear and avoidance in chronicity. Clin Psychol Rev 1999; 19 (1): 97-119.

2. Beckerman,H., Roebroeck,M.E., Lankhorst,G.J., Becher,J.G., Bezemer,P.D., and Verbeek,A.L. Smallest real difference, a link between reproducibility and responsiveness. Qual Life Res 2001; 10 (7): 571-578.

3. Beurskens,A.J.H.M., Vet,H.C.W.d., and Koke,A. Responsiveness of functional status in low back pain: a comparison of different instruments. Pain 1996; 65 71-76.

4. Brennan,J.L.Generalizability theory. New York: Springer, 2001

5. Cohen,J. Weighted Kappa: Nominal scale agreement with provision for scaled disagreement of partial credit. Psychol Bul 1968; 80 213-220.

6. Davidson,M. and Keating,J.L. A comparison of five low back disability questionnaires: reliability and responsiveness. Phys Ther 2002; 82 (1): 8-24.

7. Farrar,J.T., Young,J.P., LaMoreaux,L., Werth,J.L., and Poole,R.M. Clinical importance of changes in chronic pain intensity measured on an 11-point numerical pain rating scale. Pain 2001; 94 (2): 149-158.

8. Goubert,L., Crombez,G., Van Damme,S., Vlaeyen,J.W.S., Bijttebier,P., and Roelofs,J. Confirmatory factor analysis of the Tampa Scale for Kinesiophobia: invariant two-factor model across low back pain patients and fibromyalgia patients. Clin J Pain 2004; 20 (2): 103-110.

9. Goubert,L., Crombez,G., Vlaeyen,J.W.S., Van Damme,S., Van den Broeck,A., and van Houdenhove,B. De Tampaschaal voor Kinesiofobie. Psychometrische karakteristieken en normering. Gedrag \& Gezondheid 2000; 28 54-62.

10. Hiralal,S., Pool,J.J., Ostelo,R.W.J.G., and Vet,H.C.W.de. Measuring psychological factors in the transition form acute to chronic neck pain. Interpretation and meaning of two frequently used questionnaires. 2004

11. Miller,R.P., Kori,S.H., and Todd,D.D. The Tampa Scale. 1991

12. Pincus, T., Burton,A.K., Vogel,S., and Field,A.P. A systematic review of psychological factors as predictors of chronicity/disability in prospective cohorts of low back pain. Spine 2002; 27 (5): E109-E120.

13. Roelofs,J., Goubert,L., Peters,M.L., Vlaeyen,J.W.S., and Crombez,G. The Tampa Scale for Kinesiophobia: further examination of psychometric properties in patients with chronic low back pain and fibromyalgia. Eur J Pain 2004; 8 (5): 495-502.

14. Streiner,D.L. and Norman,G.R.Health Status Measurement Scales. A practical guide to their development and use. Oxford: Oxford University Press, 2003

15. Swinkels-Meewisse,E.J., Roelofs,J., Verbeek,A.L., Oostendorp,R.A., and Vlaeyen,J.W.S. Fear of movement/(re)injury, disability and participation in acute low back pain. Pain 2003; $105(1-2): 371-379$.

16. Swinkels-Meewisse,E.J., Swinkels,R.A., Verbeek,A.L., Vlaeyen,J.W.S., and Oostendorp, R.A. Psychometric properties of the Tampa Scale for kinesiophobia and the fear-avoidance beliefs questionnaire in acute low back pain. Man Ther 2003; 8 (1): 29-36.

17. Vet,H.C.W.d., Terwee,C.B., and Bouter,L.M. Current challenges in clinimetrics. J Clin Epidemiol 2003; 56 (12): 1137-1141.

18. Vlaeyen,J.W.S., Kole-Snijders,A.M.J., Boeren,R.G.B., and Eek,H.v. Fear of movement/(re)injury in chronic low back pain and its relation to behavioral performance. Pain $1995 ; 62$ 363-372.

19. Vlaeyen,J.W.S. and Linton,S.J. Fear-avoidance and its consequences in chronic musculoskeletal pain: a state of the art. Pain 2000; 85 (3): 317-332.

20. Von Korff,M., Jensen,M.P., and Karoly,P. Assessing global pain severity by self-report in clinical and health services research. Spine 2000; 25 (24): 3140-3151.

21. Waddell,G., Newton,M., Henderson,I., Somerville,D., and Main,C.J. A fear avoidance beliefs questionnaire (FABQ) and the role of fear-avoidance beliefs in chronic low back pain and disability. Pain 1993; 52 157-168. 


$$
\text { - }
$$




\section{Chapter 4}

\section{Fear-avoidance beliefs, disability and participation in workers and non-workers with acute low back pain}

Ilse E.J. Swinkels-Meewisse, Jeffrey Roelofs, André L.M. Verbeek, Rob A.B. Oostendorp, Johan W.S. Vlaeyen

Published as:

Ilse E.J. Swinkels-Meewisse, Jeffrey Roelofs, André L.M. Verbeek, Rob A.B. Oostendorp, Johan W.S. Vlaeyen. Fear of movement/(re)injury, disability and participation in acute low back pain. Clin J Pain, 2006; 22 (1): 45-54. 


\section{Abstract}

Objectives: Fear-avoidance beliefs have been shown to be associated with disability and work-status in patients with low back pain (LBP). Especially in acute LBP much research is needed to increase the knowledge concerning the role of fearavoidance beliefs and its associated avoidance behaviour in the influence on disability and the participation in daily and social life activities. The Fear-Avoidance Beliefs Questionnaire (FABQ) is developed to measure such beliefs and has become increasingly popular for use in primary care practice. The aim of the current study was: (1) to investigate the factor structure of the FABQ in a population of acute LBP patients by means of confirmatory factor analysis (CFA); (2) to examine the relationship between fear-avoidance beliefs and perceived disability, as well as participation in daily and social life; (3) to investigate whether perceived disability mediates the association between pain and participation, and between fearavoidance beliefs and participation.

Methods: The study has a cross-sectional design and was performed on a sample of 615 acute LBP patients in primary care settings in The Netherlands. Patients completed a VAS for pain, the Roland Disability Questionnaire, the FABQ, a sociodemographic questionnaire and five participation items.

Results: CFA corroborated the two-factor structure of the FABQ as found by Waddell and colleagues. Investigation of the association between fear-avoidance beliefs and perceived disability or participation was performed for workers and non-workers separately. The two subscales of the FABQ were significantly associated with perceived disability and participation, although there were differences between the samples. Perceived disability was significantly predicted by pain intensity and fear-avoidance beliefs. Perceived disability significantly predicted participation and finally, the mediational role of perceived disability was supported.

Discussion: In the early stage of LBP, .the reduction of pain and fear-avoidance beliefs might increase the level of activity, which might foster increased participation in daily and social life activities. 


\section{Introduction}

Since the late eighties, the contribution of psychological and psychosocial variables influencing the course of low back pain (LBP) has become proliferated $(13,15,21,27,31,40,49)$. An important element of LBP that has received increased attention is fear of pain, which has shown to be associated with avoidance of physical activities. An increasing number of studies have been conducted concerning the influences and consequences of pain-related fear and its associated avoidance behaviour in the development and maintenance of disabling LBP $(3,60)$. In chronic back pain patients, pain-related fear is associated with impaired physical performance $(1,17,51,58)$ and increased self-reported disability $(2,17,59)$. In working populations, fear-avoidance beliefs are related to work loss due to LBP $(19,20,65)$. It has also been shown that, in the open population, fear-avoidance beliefs are related to the onset of a LBP episode (31), and that pain-related fear as well as negative appraisals about pain (pain catastrophizing) predict future disability and health status $(12,39,44)$. Besides that, educational interventions aimed at reducing negative attitudes and beliefs that mediate avoidance behaviour, reduce LBP related absence from work $(11,36,49,64)$. The reduction of pain-related fear as a result of cognitive-behavioural exposure in vivo, is associated with increased activity tolerance and improved functional abilities (55-57).

Several self-report measures have been developed aimed at measuring specific aspects of pain-related fear, such as the Pain Anxiety Symptom Scale (33), the Tampa Scale for Kinesiophobia (TSK; R.P. Miller, S.H. Kori, D.D. Todd, The Tampa Scale for Kinesiophobia, 1991, Unpublished Work), the Fear of Pain Questionnaire (35) (FPQ), and the Fear-Avoidance Beliefs Questionnaire (65) (FABQ). In comparing these measures of specific pain-related fear and measures of general responses of anxiety, such as the trait version of the Spielberger State-Trait Anxiety Inventory (45) (STAI), McCracken et al. (32), concluded specific measures of pain-related fear to be more useful when predicting pain, disability and pain behaviour than more general questionnaires.

One of the major goals of pain management and rehabilitation is to help people participate in their daily activities again. The most recent draft of the 'International Classification of Functioning, Disability and Health' (66), defined 'activity' as: the capacity of executing a task or action that is an inherent or intrinsic feature of the person themselves, without the influences of varying environmental factors. Participation in contrast, is the actual performance of activities in the persons' current environment aimed at engaging in a life situation (e.g. work), encompassing all aspects of the physical, social, and attitudinal world. As such, it elicits information about the effects the environment may have on the persons' action. For example, an activity might be lifting the arm above the head. A participation item might be cleaning windows. When activities are limited, a person may have difficulties in executing activities. When participation is restricted, a person may experience problems in involvement in life situations, such as working as a window 
cleaner. Although related, activity and participation are different theoretical constructs. If they were similar constructs, one would expect an almost perfect correlation between activity and participation, and moreover, one would expect restriction in activity and participation to have the same predictive factors. However, using the TSK as a specific pain-related fear measure (i.e. measuring fear of movement/(re)injury), Swinkels-Meewisse et al. showed that in an acute LBP sample, pain-related fear was significantly associated with self-report perceived disability, and that the association between pain and participation and between fear of movement/(re)injury and participation was mediated by perceived disability (47). Work restriction as a result of LBP is a major and increasing problem. However, except for the $F A B Q$, none of the pain-related fear measures focus on workrelated activities. Besides that, there seems to be a conceptual difference between the TSK, which focuses more on fear of (re)injury, whereas the FABQ is aimed at measuring fear of physical activities including work-related ones. This might explain the moderate correlations found between the two measures $(17,48)$.

The FABQ is a 16-item self-report measure, and has been shown to be a valid and reliable instrument in chronic $\operatorname{LBP}(38,65)$. With respect to the scale structure of the FABQ, Waddell et al. (65) used exploratory principal-components analysis (PCA) with orthogonal rotation on the FABQ scores derived from a population of 210 chronic LBP patients. PCA showed a 2-factor structure, containing 11 out of 16 items. The first factor (items 6,7,9,10,11,12, and 15) concerned fear-avoidance beliefs about work (FABQ/w); the second factor (items 2,3,4, and 5) was related to fear-avoidance beliefs about physical activities (FABQ/pa). Using PCA with varimax rotation, Vendrig et al. (54) successfully replicated the factor structure on a Dutch version of the $F A B Q$ in a sample of sub-acute and chronic LBP patients. However, factor analysis of a German translation of the FABQ in a sample of chronic LBP patients, yielded a three-factor solution, each consisting of five items (38). They also identified a physical activity factor (items 1, 2, 3, 4, and 5), which was almost identical to the FABQ/pa of the English version. The factor 'work' was divided into two factors: one related to 'work as cause of pain' (items $6,7,9,10$, and 11) and one to the patients' assumptions of their 'probable return to work' (items $12,13,14,15$, and 16) (38). The present study offers a first attempt to examine the factor structure of the FABQ in acute LBP patients using confirmatory factor analysis.

The purpose of this study is threefold: First, to further investigate the factor structure of the FABQ in a population of acute LBP patients by means of a confirmatory factor analysis (CFA). Using CFA, the goodness-of-fit of the two factor solution obtained by Waddell et al. (65), and the three-factor solution by Pfingsten et al (38) is examined. We hypothesize that the two-factor solution of Waddell et al. (65) will be replicated in a population with acute LBP patients. Second, to investigate the relationship between specific fear-avoidance beliefs (FABQ), perceived disability, and participation in a population of acute LBP patients. Third, to exam- 
ine whether perceived disability mediates the association between fear-avoidance beliefs and participation. In line with results from previous investigations, in which pain-related fear was a strong predictor of disability $(2,17,19,20,59)$, we hypothesize that fear-avoidance beliefs will predict a substantial proportion of perceived disability and participation in acute LBP. More specifically, we hypothesize that perceived disability mediates the relation between pain and fear-avoidance beliefs, and participation.

\section{Materials and methods}

In the present study, 615 individuals with acute LBP with or without radiation participated in this study. Acute LBP was defined as LBP not longer existing than 4 weeks with the three preceding months free of any back pain. Patients were aloud to have previous episodes. Eligible patients were recruited on the first visit with their general practitioners (GP) and physiotherapists (PT) in the southeast region of The Netherlands. Patients were aged 18 to 65 years on entry with the study. Patients with specific LBP (e.g. tumours, trauma, infection, fractures, inflammatory disorders), presence of malignancies, operations in the lumbar area, pregnancy, and inability to read and write were excluded. Written informed consent was obtained prior to participation in the study. At the first visit with their health-care provider, the patients were requested to complete a set of self-report measures.

MEASURES

\section{Socio-demographic variables}

A questionnaire was completed covering biographical data most of which were dichotomous (i.e.: gender; male/female, civil status; living together/separately, educational level; high/low, sick leave; yes/no, and sport activities; yes/no), data regarding the current LBP episode (duration of current episode; number of weeks, radiation; yes/no, onset; sudden/gradual, and number of disability-days), and regarding any preceding episodes of LBP (number and mean duration of preceding LBP episodes, the mean interval between episodes, and the interventions during these episodes).

\section{Current Pain intensity}

The Visual Analogue Scale (VAS) for pain was used (25). The VAS consists of a $100 \mathrm{~mm}$. horizontal line, with at one end "no pain", and at the other end "worst imaginable pain". Patients were asked to rate the pain they experienced at the moment of completing the questionnaires. 


\section{Functional status}

The Dutch version of the Roland Disability Questionnaire $(8,43)$ (RDQ) was used to measure the functional status in LBP. The RDQ is a 24-items self-report questionnaire that was selected from the Sickness Impact Profile $(6,7)$, after which the phrase "because of my back or back pain" was added (e.g. I get dressed more slowly than usual because of my back). Scoring possibilities are: yes (= item is applicable), or no (= item is not applicable). Total scores range from 0 points (no disability) to 24 points (severe disability). The RDQ is a reliable and valid instrument to measure self-report perceived disability with good responsiveness $(8,29,46)$. Reliability of the RDQ in acute LBP, as calculated by the internal consistency, was good (Cronbach's alpha was 0.87$)(47)$. For logistic reasons, the RDQ was included halfway the study. For this reasons data of functional status of only 337 patients were available in this study.

\section{Participation}

Five questions concerning self-reported level of actual participation were scored on an 11-point Likert scale, ranging from zero (no participation) to 10 (full participation). The participation-items comprised items about participation with home activities, work or house holding activities, sport activities, leisure activities, and social or family activities (e.g. To what extent did you participate in any leisure time activities, besides sports, during this episode of low back pain?). The items are derived from the Chronic Pain Grading Questionnaire(62). The mean of the scores was used to obtain one 'participation' score. In case a person did not engage in sport activities, the participation score was obtained by calculating the mean based on the remaining item scores. The participation items constituted a reliable instrument (47) (Cronbach's alpha was 0.85 ).

\section{Fear-avoidance beliefs}

The Dutch version of the Fear-Avoidance Beliefs Questionnaire $(17,65)$ is a 16 item measure existing fear-avoidance beliefs about work-related activities (e.g. my work aggravated my pain), and fear-avoidance beliefs about physical activities (e.g. physical activities make my pain worse). Items are scored on a 7-point Likert scale ranging from 0 (strongly disagree) to 6 (strongly agree). The reliability of the FABQ in a population with acute LBP patients is good (48).

\section{STATISTICAL PROCEDURE}

The goodness-of-fit of the previously reported factor solutions of the FABQ $(38,65)$ was tested by means of confirmatory factor analyses using LISREL, version 8.30 (26). Direct comparisons between the models cannot be made, because the models contain different variables. Therefore only descriptive measures will be reported and discussed in the light of the corresponding model. The weighted least squares algorithm was used to assess the fit of the solutions for which polychoric 
correlation matrices were used. The goodness-of-fit for the factor solutions was evaluated using multiple criteria: (a) chi square divided by degrees of freedom; (b) the Root Mean Square Error of Approximation (RMSEA); (c) the Comparative Fit Index (CFI); (d) the Non-Normed Fit Index (NNFI); (e) the Goodness of Fit Index (GFI). With regard to the chi-square divided by degrees of freedom, a ratio below 3 is considered acceptable (28). For the RMSEA, values below 0.08 are deemed acceptable whereas for CFI, NNFI, and GFI, values above 0.90 indicate good to very good fit. Results of the CFA were integrated in the correlational analysis of $F A B Q, R D Q, V A S$, and participation.

In case a specific work-factor has been confirmed and because a work-factor was only validated for patients who are or have recently been employed (65), it might be more appropriate to divide the sample in a working and not-working group preventing possible bias as a result of persons not working, but nevertheless completing items concerning work $(38,65)$. Besides that, it might be important to gain insight into the effect of active work on the associations between painrelated fear, perceived disability, and participation. Therefore, correlational and regression analyses were performed separately for patients working (i.e. people with paying jobs or housewives) and patients not working (i.e. individuals being students, being retired, having a disablement payment, or being on sick leave). Analysis of variance was used to investigate differences in measurement scores in the two samples. In cases of dichotomous or categorical variables Chi-square was calculated. The hypothesized mediation, i.e. perceived disability mediating the relation between pain intensity, fear-avoidance beliefs, and participation, was examined by means of regression analyses according to the guidelines provided by Baron and Kenny (4). To establish the mediational model, three subsequent regression equations should meet the following criteria: (1) the independent variables (pain intensity and fear) must affect the mediator (perceived disability), (2) the independent variables (pain intensity and fear) must be shown to affect the dependent variable (participation), and (3) in the third equation the mediating variable (perceived disability) must influence the dependent variable (actual participation). Mediation is confirmed if, in the third equation, the effect of the independent variables on the dependent variable is substantially less than in the second equation. Significance of mediation was tested by means of Sobel's t-test (41).

\section{Results}

The total sample consisted of 615 persons with acute LBP. The mean age was 43.0 years $(S D=11.6), 257(41.8 \%)$ were female, and 358 were male. Statistical analysis was performed on 555 cases. Ten cases were dropped because of age (>65 years). Fifty cases were excluded from analyses because of possible chronicity. The questions concerning preceding episodes are used to identify these possible chronic stages of LBP. In cases of more than 10 preceding episodes or a mean duration of preceding episodes of more than 26 weeks and a 
time interval between episodes of less than 26 weeks, the cases were dropped from the analysis. There were no significant differences between the excluded cases and the analysed cases regarding gender $\left(\chi^{2}=0.087, d f=1, p=0.77\right)$, pain onset $\left(\chi^{2}=2.42, d f=1, p=0.30\right)$, scores on VAS $(t=0.06, p=0.58), F A B Q / w \quad(t=1,51$, $p=0.13), F A B Q / p a(t=0.93, p=0.35)$, and $R D Q(t=0.57, p=0.57)$. In line with the exclusion criterion by age there was a significant difference concerning age $(t=3,81, p<0.001)$. The group of 555 cases included in the analyses existed of 233 women $(42 \%)$ and 322 men $(58 \%)$ with a mean age of 42.4 years $(S D=11.3)$. In $21.4 \%$ of the sample it was the first time ever episode of LBP. Of the individuals participating in the current study, $59.5 \%$ had $1-5$ episodes, $14.4 \%$ had experienced 6-10 episodes, and 4,7\% were missing data. Reliability of the FABQ as reflected by the internal consistency, was good (Cronbach's alpha was 0.85 ).

\section{Confirmatory factor analyses}

In investigating the factor structure of the FABQ by means of CFA, the adequacy of two models were assessed: (a) the two-factor solution by Waddell et al. (65); and (b), the three-factor model by Pfingsten et al. (38). Table 4.1 presents the goodness-of-fit indices for the two and three factor structure models. Direct comparison of the two models is inappropriate because the CFAs were performed with different variables and with different number of items. The results demonstrated an adequate fit of the two-factor model for the 11-item FABQ and an acceptable fit of the three-factor model to the 15-item FABQ. As the two-factor model was the most parsimonious, this model was chosen and used in further analyses in the present study. The two factors 'work' (FABQ/w) and 'physical activity' (FABQ/pa) were moderately intercorrelated $(r=0.37, p<0.01)$, and the internal consistency was $\alpha=0.71$ and $\alpha=0.83$ respectively. Factor loadings of the $F A B Q / w$ and $F A B Q / p a$ varied between $0.42-0.87$ and $0.63-0.75$ respectively (see figure 4.1 ). One remark with regard to the results presented in table 4.1 needs further addressing. In confirmatory factor analysis all items are fixed parameters, which means that each item loads on one subscale and items are not mutually associated. The results from the con-firmatory factor analyses clearly indicated that overall fit improved substantially when allowing for one pair of items to have residual correlation (i.e., item 6 and 7) in both models. In addition, fit of the three-factor model improved substantially when also allowing items 15 and 16 to have residual correlation. When two items have residual correlation, it means that the correlation between these two items is stronger than the correlations between the remaining items of the scale. The fit-indices reported in table 4.1 were estimated while allowing these pairs of items to correlate. This may be theoretically justified as item 6 and 7 load on the same subscale. Similarly, items 15 and 16 also load on the same subscale in the three-factor solution. 


\section{Associations between measures}

Of the sample of 555 persons with acute LBP, $54.6 \%$ was not working $(n=303)$ and $40.2 \%$ was working ( $n=223)$. Twenty-nine individuals $(5.2 \%)$ did not give any information regarding working status. Persons not working had a significantly higher self-reported pain intensity and perceived disability level (Table 4.2). Persons

Table 4.1 Goodness-of-fit indices for FABQ factor solutions as obtained by means of confirmatory factor analysis $(n=547)$.

\begin{tabular}{lccclllll}
\hline & $\mathrm{X}^{2}$ & df & $X^{2 / d f}$ & RMSEA & CFI & NNFI & GFI \\
\hline & & & & Point estimate & $90 \% \mathrm{Cl}$ & & & \\
\hline Three-factor solution & 338 & 85 & 3.97 & 0.074 & $0.066-0.082$ & 0.92 & 0.90 & 0.97 \\
Two-factor solution & 148 & 42 & 3.52 & 0.068 & $0.056-0.080$ & 0.93 & 0.91 & 0.98 \\
\hline
\end{tabular}

Note: RMSEA = Root Mean Square Error of Approximation, CFI = Comparative Fit Index, NNFI = Non-Normed Fit Index, GFI = Goodness of Fit Index. Fit indices are presented while allowing item 6 and 7 to have residual correlation in both the two-factor solution(65) and the three-factor solution(38) and item 15 en 16 to have residual correlation only in the three-factor solution.

not working scored significantly higher on both the physical activity and work subscales of the FABQ. Between patients working and patients not working, there were no significant differences in civil status $\left(\chi^{2}=0.34, d f=1, p=0.56\right)$, educational level $\left(\chi^{2}=3.45, d f=1, p=0.06\right)$, radiation $\left(\chi^{2}=0.23, d f=1, p=0.63\right)$, onset $\left(\chi^{2}=2.35\right.$, $d f=1, p=0.13)$, duration of complaints $\left(\chi^{2}=3.9, d f=3, p=0.27\right)$, or sport activities $\left(\chi^{2}=0.56, d f=1, p=0.45\right)$. There was a significant difference in gender between workers and non-workers $\left(\chi^{2}=17.2, d f=1, p<0.001\right) .46 .6 \%$ of the working persons with acute LBP were male. Of the non-workers, $67.3 \%$ was male. As displayed in table 4.3, correlations between FABQ factors, RDQ, VAS, participation, and socio-

Table 4.2 Mean scores and differences of fear-avoidance beliefs, pain intensity, perceived disability, preceding episodes, and age for working and not working patients subgroups (Mean, standard deviations (SD) and $F$ values for one-way ANOVA).

\begin{tabular}{lccrr}
\hline & Working $(\mathrm{n}=223)$ & Not working $(\mathrm{n}=303)$ & & \\
& Mean (SD) & Mean (SD) & $\mathrm{F}$ & $\mathrm{p}$ \\
\hline FABQ/pa & $12.4(5.7)$ & $14.5(5.6)$ & 16.6 & $<0.000$ \\
FABQ/w & $12.1(9.6)$ & $16.7(10.3)$ & 26.7 & $<0.000$ \\
VAS(pain) & $45.6(24.0)$ & $53.2(23.9)$ & 12.9 & $<0.000$ \\
RDQ & $11.6(5.1)$ & $14.3(4.7)$ & 24.1 & $<0.000$ \\
Participation & $5.5(2.9)$ & $3.0(2.5)$ & 109.3 & $<0.000$ \\
Age (in years) & $42.0(10.7)$ & $43.0(11.8)$ & 0.9 & 0.339 \\
Preceding episodes & $3.1(3.2)$ & $2.7(2.5)$ & 2.1 & 0.153 \\
\hline
\end{tabular}

VAS: Visual Analogue Scale for pain; FABQ/pa: Fear-Avoidance Beliefs Questionnaire/physical activity; FABQ/w: Fear-Avoidance Beliefs Questionnaire/work; RDQ: Roland Disability Questionnaire. 
Figure 4.1 Factor loadings of the Fear avoidance Beliefs Questionnaire as resulting from confirmatory factor analysis of the two-factor model.

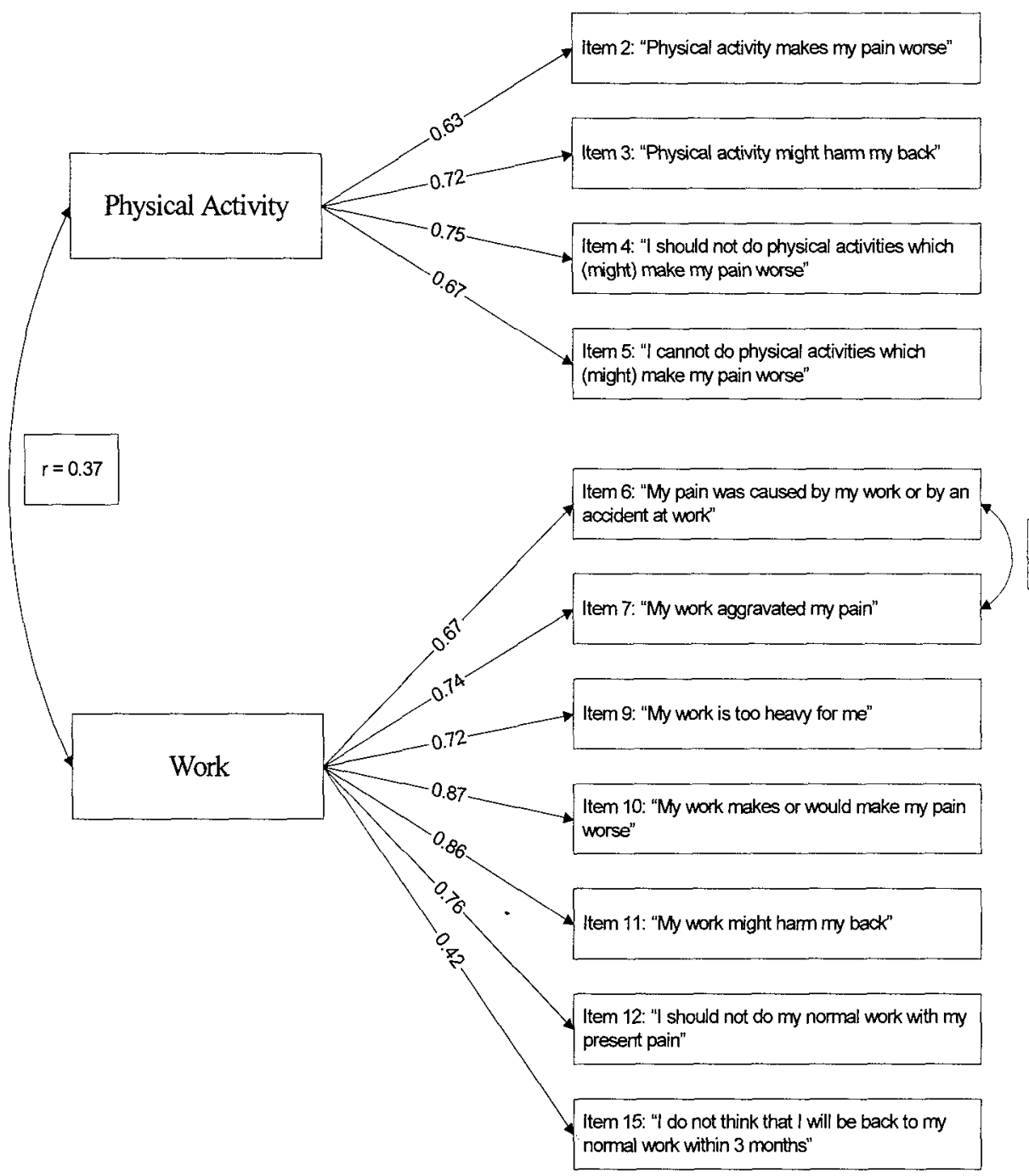

Physical activity: Physical activity factor of the Fear-Avoidance Beliefs Questionnaire; Work: Work factor of the Fear-Avoidance Beliefs Questionnaire. 
demographics are in line with expectations and do not exceed the limits of moderate as defined by Landis and Koch (30). In non-workers, age correlated significantly, though only slightly with $F A B Q / w$, and persons with low educational level scored significantly higher on the $\mathrm{FABQ} / \mathrm{w}$ (table 4.4). In order to adjust the correlational analyses for reliability of each measure, the unattenuated correlation between $F A B Q / w, F A B Q / p a, R D Q$ and participation in workers and non-workers were calculated (between brackets in Table 4.3).

\section{Mediation of perceived disability}

Three models were investigated: (1) mediation of perceived disability between pain intensity, fear-avoidance beliefs of work, and participation; (2) mediation of perceived disability between pain intensity, fear-avoidance beliefs regarding physical activities, and participation (3) a combined model testing mediation of perceived disability between pain intensity, fear-avoidance beliefs, and participation. According to the suggestions of Waddell et al. (65), the three models were investigated for workers and non-workers separately.

In working persons with LBP (Figure 4.2, Table 4.5) pain intensity and fearavoidance beliefs of physical activities and work were significant predictors of perceived disability, with $\beta=0.44 \quad(p<0.001), \beta=0.36 \quad(p<0.001)$, and $\beta=0.21$ $(p<0.05)$ respectively. Regression analyses showed a mediating effect of perceived disability between fear-avoidance beliefs and participation while controlling for pain intensity (Sobel's t-test with $F A B Q / w$ and $F A B Q / p a: t=2.01, p=0.044$ and $t=2.8, p=0.005$ respectively). Perceived disability significantly predicted the level of participation in a group of patients working despite their LBP, $(\beta=-0.38, p<0.001)$. The variables in the equation testing the total model explained $30 \%$ of the total variance of participation.

In not-working patients with acute LBP pain intensity and fear-avoidance beliefs of physical activities and work were significant predictors of perceived disability $^{1}$ with $\beta=0.38(p<0.001), \beta=0.33(p<0.001)$, and $\beta=0.24(p<0.001)$ respectively (Table 4.5).

There was a mediating effect of perceived disability between fear-avoidance beliefs and participation (Sobel's $t$-test with $F A B Q / w$ and $F A B Q / p a: ~ t=3.00$ $p=0.003$ and $t=3.73 p<0.001$ respectively). Results indicated that, in the final model, perceived disability was the only significant predictor of participation $(\beta=-$ $0.41, p<0.001$ ). The variables in the last equation (Figure 4.3 ) explained $34 \%$ of the total variance of participation. Variance Inflating Factors in the two final models were small (range: $1.10-1.60$ ), suggesting that there was no problem of collinearity.

\footnotetext{
${ }^{1}$ Secondary analyses of the not-working group were performed, excluding students, retirees, and persons with disability pension, including only individuals who were absent from work because of their current LBP episode $(n=137)$. The results (data not shown) were almost identical with the former results of the non-working group.
} 
Chapter four

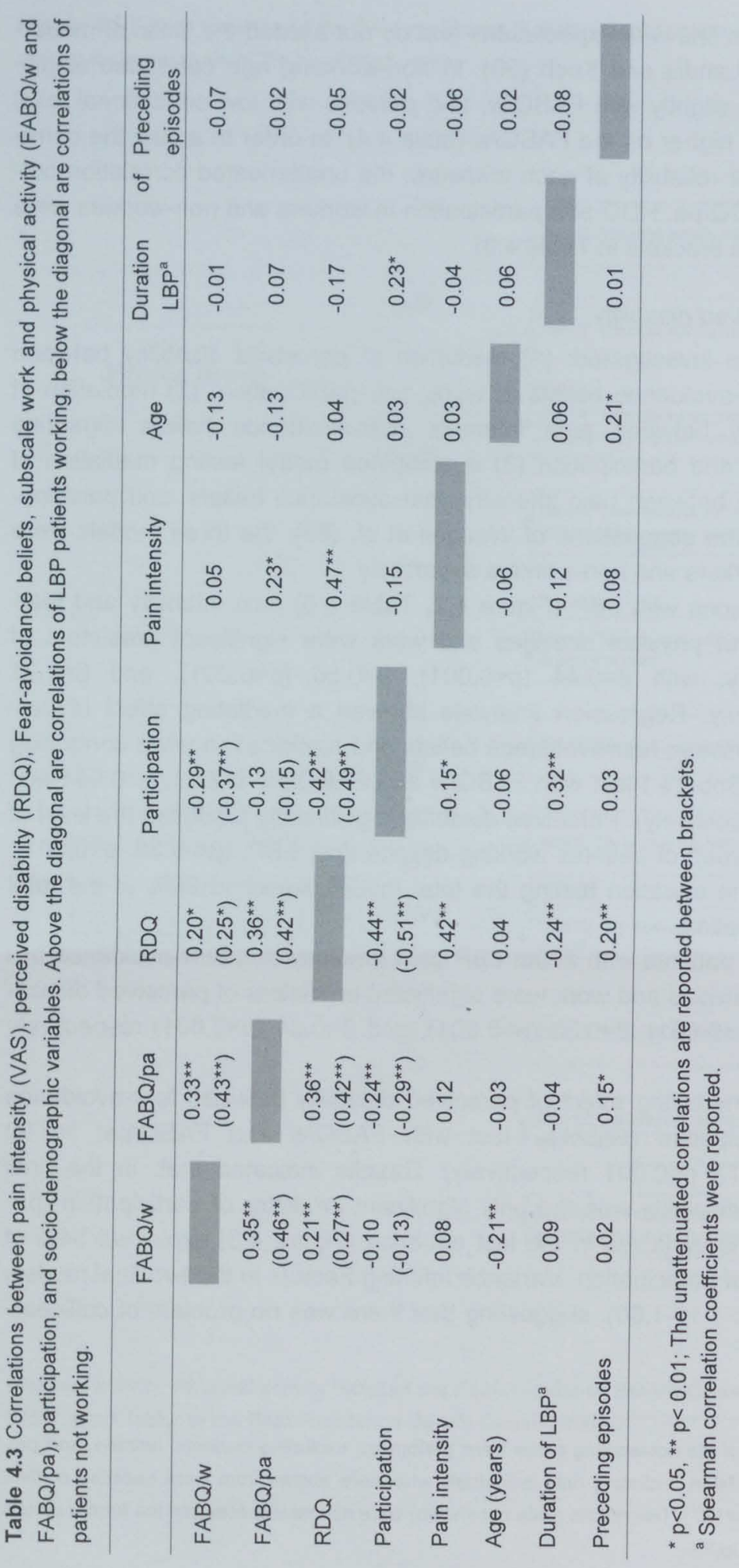


Fear-avoidance beliefs, disability and participation in acute low back pain

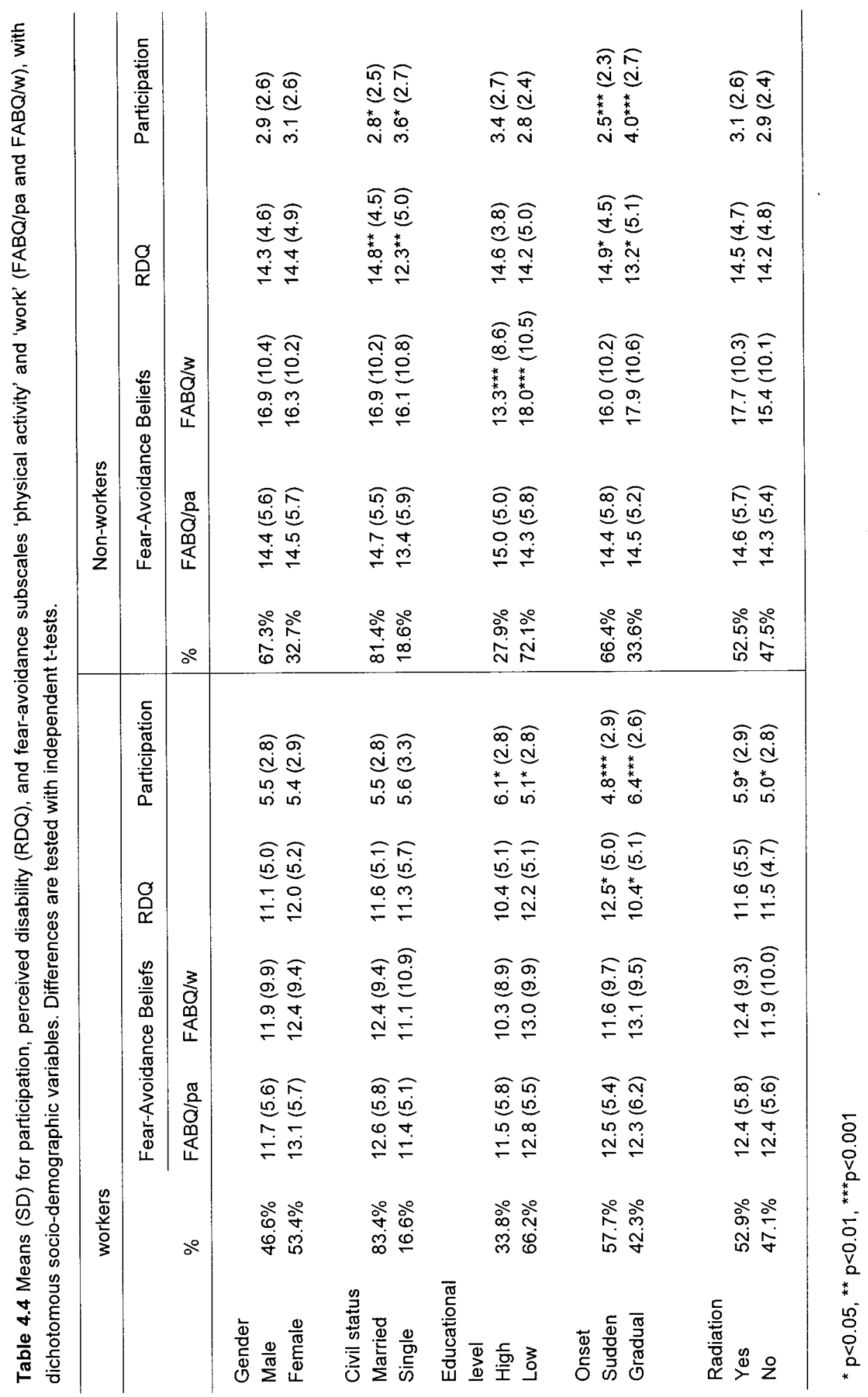


Table 4.5 Hierarchical linear regression analysis of the relationship between participation as dependent variable, and pain intensity, fear-avoidance beliefs, and perceived disability as independent variables, controlling for civil status, preceding episodes, onset, duration of complaints (non-workers), and radiation, educational level, onset, and preceding episodes (workers).

\begin{tabular}{|c|c|c|c|c|c|c|c|c|}
\hline & \multirow[b]{2}{*}{ Dependent } & \multirow{2}{*}{$\begin{array}{l}\text { Work- } \\
\text { ers } \\
\text { Adj. } R^{2}\end{array}$} & \multirow{2}{*}{$\begin{array}{l}\text { Non- } \\
\text { workers }\end{array}$} & \multirow[b]{2}{*}{$\begin{array}{l}\text { Independ- } \\
\text { ents }\end{array}$} & \multirow{2}{*}{$\begin{array}{c}\text { workers } \\
\begin{array}{r}\text { Stand. } \\
\text { beta }\end{array}\end{array}$} & \multirow[b]{2}{*}{$\begin{array}{l}\text { Sign. of } \\
\text { beta }\end{array}$} & \multicolumn{2}{|c|}{ Non-workers } \\
\hline & & & & & & & $\begin{array}{l}\text { Stand. } \\
\text { beta }\end{array}$ & $\begin{array}{l}\text { Sign. of } \\
\text { beta }\end{array}$ \\
\hline & $\begin{array}{l}\text { Perceived } \\
\text { disability } \\
\text { (RDQ) }\end{array}$ & 0.24 & 0.25 & $\begin{array}{l}\text { Pain intensity } \\
\text { (VAS) }\end{array}$ & 0.44 & 0.000 & 0.38 & 0.000 \\
\hline & & 0.09 & 0.17 & FABQ/work & 0.21 & 0.019 & 0.24 & 0.000 \\
\hline & & 0.18 & 0.22 & $\mathrm{FABQ} / \mathrm{pa}$ & 0.36 & 0.000 & 0.33 & 0.000 \\
\hline \multirow[t]{9}{*}{ Step 1} & Participation & 0.15 & 0.24 & Onset & -0.15 & $0 . \overline{101}$ & -0.25 & 0.000 \\
\hline & & & & $\begin{array}{l}\text { Duration of } \\
\text { LBP }\end{array}$ & 0.24 & 0.011 & 0.29 & 0.000 \\
\hline & & & & $\begin{array}{l}\text { Preceding } \\
\text { episodes }\end{array}$ & - & - & 0.06 & 0.862 \\
\hline & & & & Civil status & - & - & -0.10 & 0.117 \\
\hline & & & & Radiation & -0.01 & 0.920 & - & - \\
\hline & & & & $\begin{array}{l}\text { Educational } \\
\text { level }\end{array}$ & 0.17 & 0.057 & - & - \\
\hline & & & & $\begin{array}{l}\text { Pain intensity } \\
\text { (VAS) }\end{array}$ & -0.02 & 0.814 & -0.06 & 0.366 \\
\hline & & & & FABQ/work & -0.20 & 0.032 & -0.06 & 0.354 \\
\hline & & & & $\mathrm{FABQ} / \mathrm{pa}$ & -0.09 & 0.346 & -0.17 & 0.015 \\
\hline \multirow[t]{10}{*}{ Step 2} & Participation & 0.24 & 0.34 & Onset & -0.10 & 0.256 & -0.23 & 0.000 \\
\hline & & & & $\begin{array}{l}\text { Duration of } \\
\text { LBP }\end{array}$ & 0.18 & 0.044 & 0.22 & 0.001 \\
\hline & & & & $\begin{array}{l}\text { Preceding } \\
\text { episodes }\end{array}$ & - & - & 0.12 & 0.064 \\
\hline & & & & Civil status & - & - & -0.06 & 0.372 \\
\hline & & & & Radiation & 0.01 & 0.905 & - & - \\
\hline & & & & $\begin{array}{l}\text { Educational } \\
\text { level }\end{array}$ & 0.15 & 0.086 & - & - \\
\hline & & & & $\begin{array}{l}\text { Pain intensity } \\
\text { (VAS) }\end{array}$ & 0.12 & 0.186 & 0.08 & 0.255 \\
\hline & & & & FABQ/work & -0.17 & 0.062 & -0.01 & 0.872 \\
\hline & & & & $\mathrm{FABQ} / \mathrm{pa}$ & 0.01 & 0.919 & -0.06 & 0.348 \\
\hline & & & & $\mathrm{RDQ}$ & -0.38 & 0.000 & -0.41 & 0.000 \\
\hline
\end{tabular}

FABQ/work: working subscale of the Fear-Avoidance Beliefs Questionnaire; FABQ/pa: physical activities subscale of the Fear-Avoidance Beliefs Questionnaire, RDQ: Roland Disability Questionnaire. 
Figure 4.2 Pain intensity, fear-avoidance beliefs regarding work and physical activities, perceived disability and participation in working persons with acute low back pain.

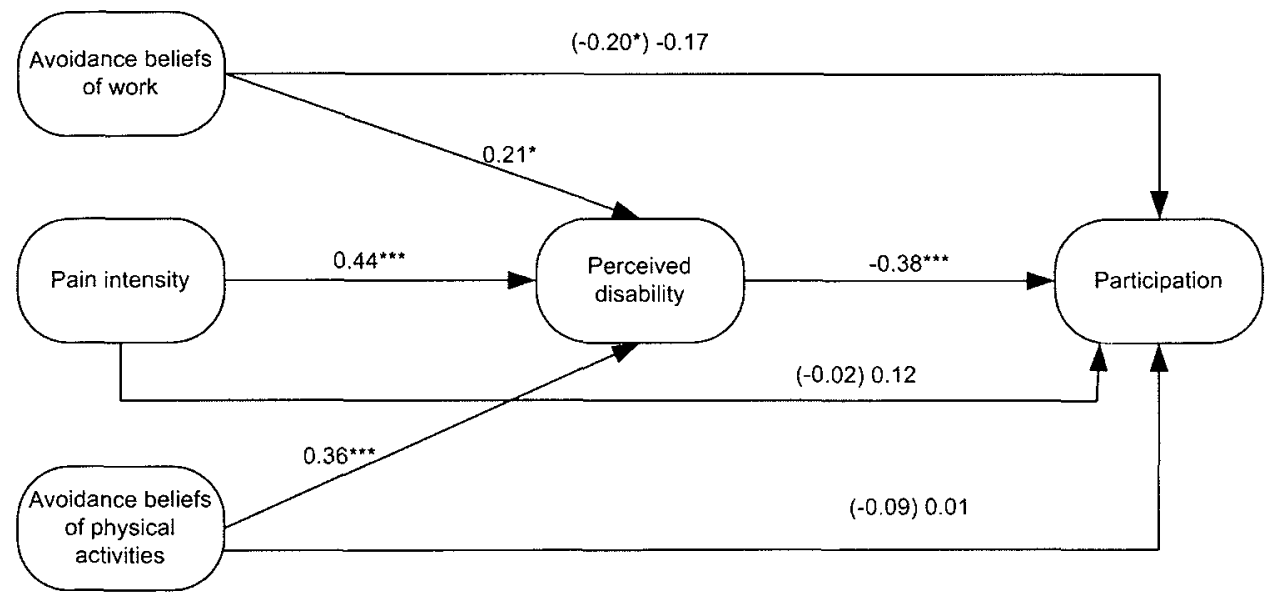

Model showing the mediational effect of perceived disability on the relation of pain intensity and fear-avoidance beliefs about work, and/or physical activity and participation in working persons. (The values in this figure indicate the standardized coefficients as obtained by stepwise hierarchical regression analyses controlling for onset, duration of complaints, radiation and educational level. The numbers on the arrows that run from the first variables directly to the last, control for the mediating variable. The values between brackets are the standardized coefficients of regression analyses without controlling for the mediating variable).

$n=127 ;{ }^{*} p<0.05 ;{ }^{* \star} p<0.01 ;{ }^{* \star \star} p<0.001$

\section{Discussion}

The present study investigated: (1) the factor structure of the $F A B Q$ in a sample of acute LBP patients; (2) the predictive value of fear-avoidance beliefs as measured with the $F A B Q$ for the level of perceived disability and actual participation in this sample of patients with acute low back pain; and (3) the mediation of perceived disability in the association between pain, fear-avoidance beliefs and participation. In investigating the factor structure of the FABQ by means of CFA, two models weretested: a two-factor model (65) and a three-factor model (38). The two-factor model was used for further analyses as this model was slightly better compared to the three-factor model and was most parsimonious. Moreover, the high correlation between the two work-related subscales of the three-factor structure revealed a very close relationship (38), favouring the existence of a one work-factor. Previous studies have supported the reliability and validity of the subscales in the two-factor model $(17,24,48,65)$. In the two-factor model, one item pair had residual correlation. It should be noted that allowing two items to correlate only serves the purpose of improving the model fit and has no consequences for use of the measure in research and clinical settings. The second aim of this study was to investigate 
Figure 4.3 Pain intensity, fear-avoidance beliefs regarding work and physical activities, perceived disability and participation in not-working persons with acute low back pain.

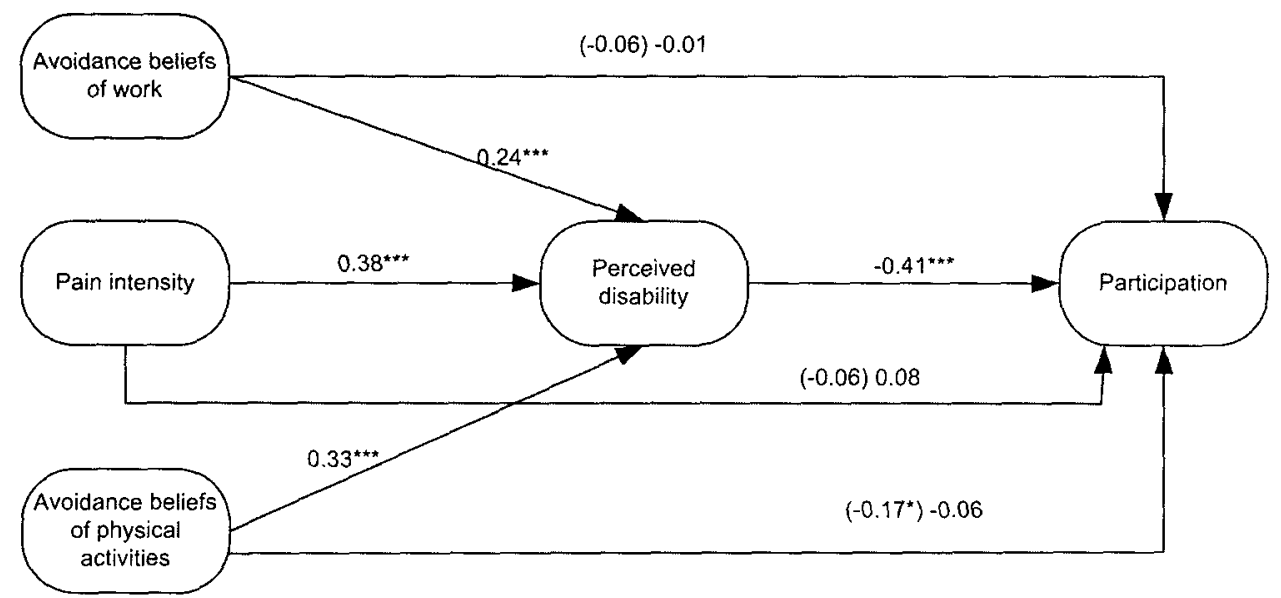

Model showing the mediational effect of perceived disability on the relation of pain intensity and fear-avoidance beliefs about work, and/or physical activity, and participation in not-working persons (The values in this figure indicate the standardized coefficients as obtained by stepwise hierarchical regression analyses controlling for onset, duration of complaints, preceding episodes, and civil status. The numbers on the arrows that run from the first variables directly to the last, control for the mediating variable. The values between brackets are the standardized coefficients of regression analyses without controlling for the mediating variable.)

$n=195 ;{ }^{\star} p<0.05 ;{ }^{\star \star} p<0.01 ;{ }^{\star \star \star} p<0.001$

the associations of fear-avoidance beliefs, self-report perceived disability and participation in daily life activities. As hypothesized and in line with the study by Waddell et al. (65), pain intensity and fear-avoidance beliefs significantly predicted perceived disability in both subgroups. Third, perceived disability, as measured with the RDQ, played a mediating role between pain intensity and participation, and between fear-avoidance beliefs and participation. Both in the working and in the not-working population, self-report perceived disability was the only significant predictive factor of actual participation.

The current study provides a first attempt to investigate the role of fearavoidance beliefs in participation as well as perceived activity levels of patients with acute LBP, divided in sufficiently large samples of workers and a not-workers. In the current study perceived disability and participation were used as outcome measures. The participation measure used in this study comprised work or house holding participation, sport participation, leisure activities, and social or family activities. Thus, participation was placed in a broader social context, which is different from the usual self-report disability measures. Indeed, the results indicated that variables predicting perceived disability differ from the variables predicting 
actual participation. Together with the good internal consistency of both measures and the modest unattenuated correlations between perceived disability and actual participation, it might be suggested that both are measures of different constructs, which refutes the idea that participation is just the inverse of perceived disability. In contrast with measures of functional status, there is a need for validated instruments measuring the participation construct. Our instrument appears reliable and shows high face-validity. It might contribute to a first step in this endeavor, but further investigation of the psychometric properties of the measure is needed. Comparing the results of the current investigation with an earlier study using the TSK as predicting variable, the main result was comparable (47). That is, a mediating effect of self-report perceived disability between pain-related fear and participation. However, the activity avoidance subscale of the TSK was also predictive of participation. In the current study, the FABQ/pa was not directly predictive of participation. This suggests that the TSK and the FABQ measure different constructs of the same pain-related fear concept $(17,48)$.

In the current study no significant correlations were found between pain intensity and fear-avoidance beliefs in the non-working population. In the working group only the $F A B Q / p a$ showed a slight, though significant relationship with the VAS. This is in contrast with the study of Fritz et al.(20) and Fritz and George (19) in a population of acute work-related LBP, who found avoidance beliefs to have a moderate and significant relationship with pain intensity. However, in these studies only persons with work-related LBP were included. In chronic LBP populations the associations between fear-avoidance and pain vary from modest to moderate $(17,23,64)$.

Studies in chronic LBP populations investigating the influence of fearavoidance beliefs and pain intensity on concurrent disability or performance are generally in line with the current study $(1,17,52,65)$. Fritz et al. $(20)$, in their crosssectional analysis of a sample of patients with acute work-related LBP, found pain rating and physical impairment to significantly predict disability, but the FABQ did not reach significance. The difference may be due to the fact that they used a working population who had developed LBP with sufficient magnitude to necessitate modification of their employment duties (20). Beside that, the mean scores on the subscale of the FABQ are much higher than in the current study, which emphasizes the difference in samples, that makes a comparison more hazardous.

Because of the large sample of patients with acute LBP a subdivision in two groups appeared legitimate. In the group of non-workers, the results are in line with the hypotheses. This group existed of students, persons being retired, having disablement payment or persons being on sick leave. The reason for including students, persons being retired, or having disablement payment in the same group as persons with work absenteeism because of their LBP, was because the $\mathrm{FABQ} / \mathrm{w}$ has only been validated for patients who are or have recently been employed (65). Similar secondary analyses were performed including only individuals who were absent from work because of their current LBP episode $(n=137)$. The 
results (data not shown) were almost identical with the former results of the nonworking group. In the working sample, perceived disability significantly predicted participation, whereas fear-avoidance beliefs regarding work were no longer a significant predictor of participation, when controlling for perceived disability. The current study is in line with the study of Waddell et al. (65), who found pain intensity and fear-avoidance beliefs to significantly predict disability in activities of daily living. Work loss (in past year) was significantly predicted by the FABQ/work and the $F A B Q / p a$ did not reach significance. In the current study similar results were found (working group), although a more broadly defined measure of participation than work loss was used. In non-workers, the FABQ/pa was a significant predictor of participation. However, direct comparisons with the Waddell-study are hazardous because of the differences in characteristics of patient samples. This study included patients with acute LBP, divided in workers and non-workers. Waddell et al. included patients with acute, sub-acute and chronic LBP, without a clear division in workers or non-workers. The current study is in contrast with the study of Fritz et al. (20), who found pain intensity and physical impairment to be significantly predictive of disability. However, in their cross-sectional part of the study fear-avoidance beliefs had no significant predictive power regarding disability. The current study shows that in the acute stage of LBP the level of fear-avoidance beliefs may be of value as a screening instrument in patients regardless of their working status.

There are a number of limitations to the current research that need considering. First, the study has a cross-sectional design, and the positive associations found do not permit any causal inferences to be made. Second, the incidence data of patients reporting LBP to general practitioners (GP) from a large patient registry in The Netherlands suggests that more patients, than the 615 in the study, could have been included (53). It is likely that participating GPS and physiotherapists may have failed to include all the referred patients, possibly creating a selection bias. Third, although the main inclusion criterion was having LBP for not longer than four weeks, the population might be biased with chronic cases because it comprised both patients who had never before experienced an episode with LBP and those who had. Although one of the inclusion criteria was having had a period of at least 3 month free of LBP before the current back pain episode, and possible cases of chronicity were excluded from analyses, there is a chance the population is biased with patients already having a chronic condition if the definition of chronic LBP is characterized by an episodic, recurrent course $(34,61,63)$. Fourth, in the absence of a standardized and well-validated measure of participation, we decided to develop a new measure consisting of five items. Although the items showed high face-validity and the preliminary psychometrics of this questionnaire were promising (47), reliability and validity need to be investigated and extended in detail in future studies. Fifth, all measures were self-report questionnaires. Thus, the results may reflect, to some extent, common method variance. The selfreport measures used in the current study to assess functional status, represents 
disability as perceived by the patients rather than actual disability. Although selfreport measures are commonly used and recommended in outcome assessment (10), combining both performance-based and self-report measures of functional status and participation might obtain a more comprehensive picture of disability in patients with LBP (42). Sixth, the results of the non-workers of the current study might be confounded because non-workers might not find the items of the $\mathrm{FABQ}$ /work to be relevant (65). However, a close inspection of the work-related items (e.g. item 10: My work makes or would make my pain worse) reveals that they might be relevant for both workers and non-workers.

As hypothesized the current research corroborated the two-factor structure as found by Waddell et al. (65). In general these subscales, together with pain intensity, significantly predicted perceived disability, which played a mediating role between pain intensity and fear-avoidance beliefs, and participation. Perceived disability significantly predicted the level of actual participation. This means that, in clinical practice, the level of functional status, as measured with the RDQ, may be of value as a screening tool for participation. To prevent restrictions in participation early identification of perceived disabilities is needed and they should be tackled as soon as possible. Perceived disability is a construct that is considered an important clinical outcome in pain management. Improving functional ability can be obtained by modifying one of its major predictors that are both identifiable and malleable. The current study corroborates the finding that in a subgroup of patients, pain-related fear is present early in an episode of LBP, and that it significantly predicts future disability and work-status $(19,20,27,50,65)$. There is accumulating evidence that educational and cognitive-behavioural interventions exist that significantly reduce pain-related fear with improved functional abilities as a result. In contrast, fear-avoidance based treatment might increase disability levels when applied to patients with lower fear-avoidance beliefs (22). Thus, the FABQ may be used as a screening measure. However, caution should be used, because up to date there are no reliable cut-off scores known that may be applied to the individual patient. In case of increased levels of pain-related fear, advice and education aimed at reducing fear-avoidance beliefs and keeping up normal activities should be incorporated early in this way possibly preventing long-lasting disability and hence work absenteeism. Interventions designed to reduce pain-related fear (e.g. exposure in vivo, educational information), or influence avoidance behaviour have been shown to have positive effects on patient's beliefs, functional abilities and work absenteeism due to $\operatorname{LBP}(11,14,16,49,50,55-57,64)$. The results of our study suggest that successful reduction of (perceived) disability will foster increased participation in daily and social life activities. This is in line with existing guidelines of general practitioners and physiotherapists for non-specific LBP in the acute or sub acute phase, that advocate patients to stay active and to reduce rest $(5,9,18,37)$. In persons with increased pain-related fear, the reduction of the maladaptive fear-avoidance beliefs is warranted in order to reduce (perceived) disability. Prospective studies are needed to support the predictive role of pain-related 
fear and the mediating role of (perceived) disability as indicated in our model, in the transition from acute to chronic LBP.

\section{Acknowledgements}

This research was partly supported by the Royal Dutch Physical Therapists Association. We thank the general practitioners and physical therapists for their assistance in including patients. The Netherlands Organization for Health Research and Development (ZonMw), supported participation of Dr. J. Vlaeyen with grant $\mathrm{nr}$. 904-65-090.

We thank the reviewers for their careful reading of the manuscript and their thoughtful comments on earlier drafts. 


\section{References}

1. Al Obaidi,S.M., Nelson,R.M., Al Awadhi,S., and Al Shuwaie,N. The role of anticipation and fear of pain in the persistence of avoidance behavior in patients with chronic low back pain. Spine 2000; $25(9): 1126-1131$.

2. Asmundson,G.J.G., Norton,G.R., and Allerdings,M.D. Fear and avoidance in dysfunctional chronic back pain patients. Pain 1997; 69 (3): 231-236.

3. Asmundson,G.J.G., Norton,P.J., and Norton,G.R. Beyond pain: the role of fear and avoidance in chronicity. Clin Psychol Rev 1999; 19 (1): 97-119.

4. Baron,R.M. and Kenny,D.A. The moderator-mediator variable distinction in social psychological research: conceptual, strategic, and statistical considerations. J Pers Soc Psychol 1986; 51 (6): 1173-1182.

5. Bekkering,G.E., Hendriks,H.J.M., Koes,B.W., Oostendorp,R.A.B., Ostelo,R.W.J.G., Thomassen,J., and Tulder,M.W.v. Dutch physiotherapy guideline for low back pain. Physiotherapy 2003; 89 (2): 82-96.

6. Bergner,M., Bobbitt,R.A., Carter,W.B., and Gilson,B.S. The Sickness Impact Profile: development and final revision of a health status measure. Medical Care 1981; 19 (8): 787-804.

7. Bergner,M., Bobbitt,R.A., Kressel,S., Pollard,W.E., Gilson,B.S., and Morris,J.R. The Sickness Impact Profile: conceptual formulation and methodology for the development of a health status measure. Int J of Health Services 1976; 6 (3): 393-415.

8. Beurskens,A.J.H.M., Vet,H.C.W.d., and Koke,A. Responsiveness of functional status in low back pain: a comparison of different instruments. Pain 1996; 65 71-76.

9. Bigos,S.J., Bowyer,O.R., Braen,G.R., Brown,K.C., Deyo,R.A., and Haldeman,S. Acute Low back Problems in Adults. Clinical practice guideline $\mathrm{nr} 14.1994 ; 14$ 1-25.

10. Bombardier, $\mathrm{C}$. Outcome assessments in the evaluation of treatment of spinal disorders: summary and general recommendations. Spine 2000; 25 (24): 3100-3103.

11. Buchbinder,R., Jolley,D., and Wyatt,M. Population based intervention to change back pain beliefs and disability: three part evaluation. BMJ 2001; 322 (7301): 1516-1520.

12. Buer,N. and Linton,S.J. Fear-avoidance beliefs and catastrophizing: occurrence and risk factor in back pain and ADL in the general population. Pain 2002; 99 (3): 485-491.

13. Burton,A.K., Tillotson,K.M., Main,C.J., and Hollis,S. Psychosocial Predictors of Outcome in Acute and Subchronic Low Back Trouble. Spine 1995; 20 (6): 722-728.

14. Burton,A.K., Waddell,G., Tillotson,K.M., and Summerton,N. Information and advice to patients with back pain can have a positive effect. A randomized controlled trial of a novel educational booklet in primary care. Spine 1999; 24 (23): 2484-2491.

15. Croft,P.R., Papageorgiou,A.C., Ferry,S., Thomas,E., Jayson,M.I.V., and Silman,A.J. Psychologic Distress and Low Back Pain: Evidence from a prospective study in the general population. Spine 1995; 20 (24): 2731-2737.

16. Crombez,G., Eccleston,C., Vlaeyen,J.W.S., Vansteenwegen,D., Lysens,R., and Eelen,P. Exposure to physical movements in low back pain patients: restricted effects of generalization. Health Psychol. 2002; 21 (6): 573-578.

17. Crombez,G., Vlaeyen,J.W.S., Heuts,P.H.T.G., and Lysens,R. Pain-related fear is more disabling than pain itself. Evidence on the role of pain-related fear in chronic back pain disability. Pain 1999; $80(1,2): 329-339$.

18. Faas,A., Chavannes,A.W., Koes,B.W., Hoogen,H.M.M.v.d., Mens,J.M.A., Smeele,L.J.M., Romeijnders,A.C.M., and Laan,J.R.v.d. NHG-Standaard Lage-Rugpijn. Huisarts en Wetenschap 1996; 39 (1): 18-31.

19. Fritz,J.M. and George,S.Z. Identifying psychosocial variables in patients with acute workrelated low back pain: the importance of fear-avoidance beliefs. Phys Ther 2002; 82 (10): 973-983.

20. Fritz,J.M., George,S.Z., and Delitto,A. The role of fear-avoidance beliefs in acute low back pain: relationships with current and future disability and work status. Pain 2001; 94: 7-15.

21. Gatchel,R.J. and Gardea,M.A. Psychosocial issues: their importance in predicting disability, response to treatment, and search for compensation. Neurol Clin 1999; 17 (1): 149-166. 
22. George,S.Z., Fritz,J.M., Bialosky,J.E., and Donald,D.A. The effect of a fear-avoidance-based physical therapy intervention for patients with acute low back pain: results of a randomized clinical trial. Spine 2003; 28 (23): 2551-2560.

23. George,S.Z., Fritz,J.M., and Erhard,R.E. A comparison of fear-avoidance beliefs in patients with lumbar spine pain and cervical spine pain. Spine $2001 ; 26$ (19): 2139-2145.

24. Jacob,T., Baras,M., Zeev,A., and Epstein,L. Low back pain: reliability of a set of pain measurement tools. Arch Phys Med Rehabil. 2001; 82 (6): 735-742.

25. Jensen,M.P. and Karoly,P. Self-report scales and procedures for assessing pain in adults. In Turk,D.C., Melzack,R. (eds) Handbook of Pain Assessment. The Guilford Press, New York. 1992; 135-151.

26. Jöreskog,K.G. and Sörbom,D. LISREL 8.30. 1999;

27. Klenerman,L., Slade,P.D., Stanley,I.M., Pennie,B., Reilly,J.P., Atchison,L.E., Troup, J.D.G., and Rose,M.J. The prediction of chronicity in patients with an acute attack of low back pain in a general practice setting. Spine 1995; 20 (4): 478-484.

28. Kline, $P$. An easy guide to Factor Analysis. 1994

29. Kopec,J.A. and Esdaile,J.M. Functional Disability Scales for back pain. Spine 1995; 20 (17): 1943-1949.

30. Landis,J.R. and Koch,G.G. The measurement of observer agreement for categorical data. Biometrics 1977; 33159-33174.

31. Linton,S.J., Buer,N., Vlaeyen,J.W.S., and Hellsing,A.L. Are fear-avoidance beliefs related to the inception of an episode of back pain? A prospective study. Psychology and Health 2000; 14 1051-1059.

32. McCracken,L.M., Gross,R.T., Aikens,J., and Carnrike,C.L.M. The Assessment of Anxiety and Fear in Persons with Chronic Pain: A Comparison of Instruments. Behav Res Ther 1996; 34 (11/12): 927-933.

33. McCracken,L.M., Zayfert,C., and Gross,R.T. The pain anxiety symptoms scale: development and validation of a scale to measure fear of pain. Pain 1992; $50(-): 67-73$.

34. McGorry,R.W., Webster,B.S., Snook,S.H., and Hsiang,S.M. The relation between pain intensity, disability, and the episodic nature of chronic and recurrent low back pain. Spine 2000; 25 (7): 834-841.

35. McNeil,D.W., Rainwater,A.J., and Al-Jazireh,L. Development of a methodology to measure fear of pain. 1986

36. Moore,J.E., Von Korff,M., Cherkin,D., Saunders,K., and Lorig,K. A randomized trial of a cognitive-behavioral program for enhancing back pain self care in a primary care setting. Pain 2000; 88 (2): 145-153.

37. National Health Committee New Zealand Acute Low Back Pain Guide. 1997; 1-13.

38. Pfingsten,M., Kroner-Herwig,B., Leibing,E, Kronshage,U., and Hildebrandt,J. Validation of the German version of the Fear-Avoidance Beliefs Questionnaire (FABQ). Eur J Pain 2000; 4 (3): 259-266.

39. Picavet,H.S., Vlaeyen,J.W.S., and Schouten,J.S. Pain catastrophizing and kinesiophobia: predictors of chronic low back pain. Am J Epidemiol 2002; 156 (11): 1028-1034.

40. Pincus, T., Burton,A.K., Vogel,S., and Field,A.P. A systematic review of psychological factors as predictors of chronicity/disability in prospective cohorts of low back pain. Spine 2002; 27 (5): E109-E120.

41. Preacher,K.T. and Leonardelli,G.J. Calculation for the Sobel Test. computer program 2001; $1-4$.

42. Reneman,M.F., Jorritsma,W., Schellekens,J.M., and Goeken,L.N. Concurrent validity of questionnaire and performance-based disability measurements in patients with chronic nonspecific low back pain. J Occup Rehabil 2002; 12 (3): 119-129.

43. Roland,M. and Morris, R. A study of the natural history of back pain, Part 1 \& Part 2: RolandMorris Disability Questionnaire. Spine 1983; (8): 141-150.

44. Severeijns,R., van den,H.M., Vlaeyen,J.W.S., and Picavet,H.S. Pain catastrophizing and general health status in a large Dutch community sample. Pain 2002; 99 (1-2): 367-376.

45. Spielberger,C.D., Gorsuch,R.L., Lushene,P.R., Vaggs,P.R., and Jacobs,G.A. Manual for the State-Trait Anxiety Index (Form Y). 1983 
46. Stratford,P.W., Binkley,J.M., and Riddle,D.L. Development and initial validation of the back pain functional scale. Spine 2000; 25 (16): 2095-2102.

47. Swinkels-Meewisse,E.J., Roelofs,J., Verbeek,A.L., Oostendorp,R.A., and Vlaeyen,J.W.S. Fear of movement/(re)injury, disability and participation in acute low back pain. Pain 2003; $105(1-2): 371-379$.

48. Swinkels-Meewisse,E.J., Swinkels,R.A., Verbeek,A.L., Vlaeyen,J.W.S., and Oostendorp,R.A. Psychometric properties of the Tampa Scale for kinesiophobia and the fearavoidance beliefs questionnaire in acute low back pain. Man Ther 2003; 8 (1): 29-36.

49. Symonds,T.L., Burton,A.K., Tillotson,K.M., and Main,C.J. Absence resulting from low back trouble can be reduced by psychosocial intervention at the work place. Spine 1995; 20 (24): 2738-2745.

50. Symonds, T.L., Burton,A.K., Tillotson,K.M., and Main,C.J. Do attitudes and beliefs influence work loss due to low back trouble? Occup Med 1996; 46 (1): 25-32.

51. van den Hout,J.H., Vlaeyen,J.W.S., Houben,R.M., Soeters,A.P., and Peters,M.L. The effects of failure feedback and pain-related fear on pain report, pain tolerance, and pain avoidance in chronic low back pain patients. Pain 2001; 92 (1-2): 247-257.

52. van den Hout,J.H., Vlaeyen,J.W.S., Houben,R.M., Soeters,A.P., and Peters,M.L. The effects of failure feedback and pain-related fear on pain report, pain tolerance, and pain avoidance in chronic low back pain patients. Pain 2001; 92 (1-2): 247-257.

53. Velden,J.V.d., De Bakker,D.H., Claessens,A.A.M.C., and Schellevis,F.G. Een nationale studie naar ziekten en verrichtingen in de huisartsenpraktijk. Basisrapport morbiditeit in de huisartsenpraktijk. 1991;

54. Vendrig,A., Deutz,P., and Vink,I. Nederlandse vertaling en bewerking van de FearAvoidance Beliefs Questionnaire. Ned Tijdschrift voor Pijn en Pijnbestrijding 1998; 18 (1): 11-14.

55. Vlaeyen,J.W.S., de Jong,J., Geilen,M., Heuts,P.H.T.G., and van Breukelen,G. Graded exposure in vivo in the treatment of pain-related fear: a replicated single-case experimental design in four patients with chronic low back pain. Behav Res Ther 2001; 39 (2): 151-166.

56. Vlaeyen,J.W.S., Jong,J.R.d., Geilen,M., Heuts,P.H.T.G., and Breukelen,G.v. The treatment of fear of movement/(re)injury in chronic low back pain: further evidence on the effectiveness of exposure in vivo. Clin J Pain 2002; 18 (4): 251-261.

57. Vlaeyen,J.W.S., Jong,J.R.d., Onghena,P., Kerckhoffs-Hanssen,M., and Kole-Snijders,A.M. Can pain-related fear be reduces? The application of cognitive-behavioural exposure in vivo. Pain Res Manag 2002; 7 (3): 144-153.

58. Vlaeyen,J.W.S., Kole-Snijders,A.M.J., Boeren,R.G.B., and Eek,H.v. Fear of movement/(re)injury in chronic low back pain and its relation to behavioral performance. Pain $1995 ; 62$ 363-372.

59. Vlaeyen,J.W.S., Kole-Snijders,A.M.J., Rotteveel,A.M., Ruesink,R., and Heuts,P.H.T.G. The role of fear of movement/(re)injury in pain disability. J Occup Rehabil 1995; 5 (4): 235-252.

60. Vlaeyen,J.W.S. and Linton,S.J. Fear-avoidance and its consequences in chronic musculoskeletal pain: a state of the art. Pain 2000; 85 (3): 317-332.

61. Von Korff,M. Studying the natural history of back pain. Spine 1994; 19: 2041S-2046S.

62. Von Korff,M., Ormel,J., Keefe,F.J., and Dworkin,S.F. Grading the severity of chronic pain. Pain 1992; 50 133-149.

63. Von Korff,M. and Saunders,K. The Course of Back Pain in Primary Care. Spine 1996; 21 (24): 2833-2839.

64. Vowles,K.E. and Gross,R.T. Work-related beliefs about injury and physical capability for work in individuals with chronic pain. Pain 2003; 101 (3): 291-298.

65. Waddell,G., Newton,M., Henderson,I., Somerville,D., and Main,C.J. A fear avoidance beliefs questionnaire (FABQ) and the role of fear-avoidance beliefs in chronic low back pain and disability. Pain 1993; 52 157-168.

66. World Health Organization. International Classification of Functioning, Disabilities and Health Problems. 2001 



\section{Chapter 5}

\section{Fear of movement/(re)injury, disability and participation in acute low back pain}

Ilse E.J. Swinkels-Meewisse, Jeffrey Roelofs, André L.M. Verbeek, Rob A.B. Oostendorp, Johan W.S. Vlaeyen

\section{Published as:}

Ilse E.J. Swinkels-Meewisse, Jeffrey Roelofs, André L.M. Verbeek, Rob A.B. Oostendorp, Johan W.S. Vlaeyen. Fear of movement/(re)injury, disability and participation in acute low back pain. Pain, 2003; 105 (1-2): 371-379. 


\section{Abstract}

Fear of movement/(re)injury and its associated avoidance behaviour have shown to be strongly associated with functional disability in chronic low back pain. In acute low back pain disability, the role of pain-related fear has received little research attention so far. Measures of pain-related fear such as the Tampa Scale for Kinesiophobia (TSK) are increasingly being used in primary care. The aim of the present study was: (1) to further investigate the factor structure of the TSK in a population of acute LBP patients in primary care by means of a confirmatory factor analysis (CFA); (2) to examine the relationship between fear of movement/(re)injury and disability, as well as participation in daily and social life activities in 615 acute LBP patients seen by general practitioners and physical therapists in primary care settings. (3) to examine whether disability mediates the association between pain-related fear and participation. CFA, and a subsequent explorative factor analysis on the TSK revealed a two-factor model. The factors consisted of items associated with 'harm', and items representing the 'avoidance of activity'. Both constructs were significantly associated with disability and participation. Additionally, and in contrast to what is often observed in chronic pain, disability, and to a lesser degree participation, were also associated with pain intensity. Finally, the association between pain-related fear, pain intensity and participation was indeed mediated by disability. The results suggest that early on in the development of LBP disability, the successful reduction of pain-related fear and disability might foster increased participation in daily and social life activities. 


\section{Introduction}

In the last decade the role of pain-related fear and its associated avoidance behaviour in the development of chronic musculoskeletal pain has received increased scientific attention (for reviews see Asmundson et al. 1999, and Vlaeyen and Linton, $2000(3,40)$ ). These findings can be summarized as follows: 1 . In chronic back pain patients pain-related fear is associated with impaired physical performance $(1,12,16,38)$ and increased self-reported disability $(2,12,39) ; 2$. In the open population, pain-related fear predicts future disability and health status $(7,25,25,27) ; 3$. In acute LBP patients, pain-related fear predicts future occupational disability (13); 4. Educational interventions aimed at reducing negative attitudes and beliefs that mediate avoidance behaviour, reduce LBP related absence from work $(6,24,31)$; 5 . Finally, the reduction of pain-related fear as a result of cognitive-behavioural exposure in vivo, is associated with improved functional abilities $(35,37)$ and increased activity tolerance $(36)$.

Several questionnaires have been developed aimed at measuring specific fear responses in chronic pain patients. The Tampa Scale for Kinesiophobia (TSK) specifically focuses on the fear of movement or (re)injury. So far, the TSK has been shown to be a reliable and valid instrument in chronic back pain patients $(12,38,39)$, and is shown to be strongly associated with measures of functional disability. With respect to the factor structure of the TSK, Vlaeyen et al., (1995b) reported a four-factor solution consisting of the factors Harm, Fear of (re)injury, Importance of exercise, and Activity Avoidance. Clark et al. found a two factor solution with a reduced set of items, consisting of Activity avoidance and Pathological Somatic Focus (10). Geisser et al. successfully replicated this two-factor solution and further support was reported by Goubert et al., who found this twofactor structure to be invariant for both CLBP and fibromyalgia patients $(14,15)$. So far, the psychometric properties of the TSK in acute pain patients are unknown.

The authors of the 'International Classification of Functioning, Disability and Health' (ICF; (44)) recently argued that in health care the focus of attention should stretch beyond activity limitation and disability, and urged clinicians and researchers to include the concept of participation as well. Activity is defined as the capacity of executing an action that is an inherent or intrinsic feature of the person themselves, without the influences of varying environmental factors. Participation is the actual performance of activities in the persons' current environment, encompassing all aspects of the physical, social, and attitudinal world. As such, participation is more than the ability to perform activities, and is likely to be (at least partially) mediated by activity performance. So far, there are no studies that investigated the relationship between pain intensity, pain-related fear, disability and participation in acute LBP patients.

The purpose of this study is threefold: (1) to further investigate the factor structure of the TSK in a population of acute LBP patients by means of CFA; (2) to investigate the relationship between specific pain-related fear, as measured by the 
TSK, disability, and participation in a population of acute LBP patients; (3) to examine whether disability mediates the association between pain-related fear and participation. We hypothesized that: (1) the two factor solution of Clark et al. (1996) can be replicated in a population with acute LBP patients; (2) increased fear of movement/(re)injury would predict a substantial proportion of disability and participation in acute LBP. More specifically, we hypothesized that disability mediates the relation between pain and specific pain-related fear, and participation.

\section{Methods}

\section{STUDY POPULATION}

General practitioners and physiotherapists in the southeast region of The Netherlands between April 1998 and December 2000 recruited 615 individuals who experienced an acute episode of LBP, which in this study is defined as LBP of at most four weeks duration. Inclusion criteria were: aged between 18 and 65 with non-specific LBP independent of radiation, a pain free period of three months preceding the current episode. Criteria for exclusion were: LBP with a specific underlying pathology (e.g. tumours, trauma, infection, inflammatory disorders); presence of malignancies; operations in the lumbar area; or pregnancy.

\section{PROCEDURE}

This study applies a cross-sectional design. During the first consultation for LBP, the general practitioner or physiotherapist requested the patients to participate in the study. After written informed consent was obtained, a set of questionnaires was completed.

\section{MEASURES}

\section{Demographic variables}

A questionnaire was completed covering different socio-demographical variables (i.e. age, gender, education level, sick-leave, and sport activities), and questions regarding the current and/or preceding back pain episodes.

\section{Pain intensity}

A visual analogue scale (VAS) for assessing current pain intensity was used (17), consisting of a horizontal $100 \mathrm{~mm}$ line, with at one end the words "no pain", and at the other end the words "worst imaginable pain".

\section{Pain-related fear measure}

The Dutch version of the Tampa scale for Kinesiophobia (TSK) $(23,38)$ was used. The TSK is a 17-item self-report questionnaire measuring fear of movement or (re) 
injury. Each item is scored on a 4-point Likert scale. Scoring possibilities range from 'strongly disagree' (score=1) to 'strongly agree' (score=4). The scores on items $4,8,12$, and 16 are reverse-scored. Total score ranges from a minimum of 17 points to the maximum of 68 points. Reliability (internal consistency and testretest stability) in a population with acute LBP is 'moderate' to 'substantial' (Cronbach's $\alpha=0.70$ and $\alpha=0.76$; Pearson's $r=0.78$, see (30).

\section{Functional status}

The Dutch version of the Roland Disability Questionnaire (RDQ) $(5,26)$ was used to measure the functional status in LBP. The RDQ is a 24 -items questionnaire with a dichotomous scoring format; yes ( $=$ item is applicable), or no ( $=$ item is not applicable). Total scores can vary from 0 (no disability) to 24 (severe disability). The RDQ is a reliable and valid instrument to measure disability with good responsiveness $(5,20,28)$. For logistic reasons, the RDQ was included halfway the study, and for this reasons functional disability data of only 329 participants are available in this study.

\section{Participation}

Five questions concerning level of participation were scored on an 11-point Likert scale, ranging from zero (no participation) to ten (full participation). The five participation-items comprised items about participation with home activities, work or house holding activities, sport activities, leisure activities, and social or family activities (see appendix). The items are derived from the Chronic Pain Grading Questionnaire (42). The mean of the five scores was used to obtain one participation score. In case a person did not engage in sport activities (i.e. at least weekly participating in any sport), the participation score was obtained by calculating the mean based on the remaining item scores.

\section{STATISTICAL ANALYSES}

The stability of the previously reported factor solutions of the TSK $(10,10,14,39)$ was tested by means of confirmatory factor analyses using LISREL, version 8.30 (18). The weighted least squares algorithm was used to assess the fit of both solutions for which polychoric matrices were used. The goodness-of-fit for the factor solutions was evaluated using multiple criteria: (a) the Root Mean Square Error of Approximation (RMSEA); (b) the Comparative Fit Index (CFI); (c) the Non-Normed Fit Index (NNFI); (d) the Goodness of Fit Index (GFI). For the RMSEA, values below 0.08 are deemed acceptable whereas for $\mathrm{CFI}, \mathrm{NNFI}$, and GFI, values above 0.90 indicate good to very good fit. When the goodness-of-fit of the factor solutions appears to be inadequate, the patients sample is randomly divided into two subsamples. On the first subsample, an exploratory factor analysis (EFA) is conducted on TSK scores. Subsequently, the factor solution obtained from the EFA is then subjected to CFA on patients from the second subsample. Results of the 
factor analyses were integrated in the correlational analysis of TSK, RDQ, VAS, and participation.

The hypothesized mediation, i.e. disability mediating the relation between pain intensity, fear of movement/(re)injury, and participation, was tested. Regression analyses were conducted according to the guidelines provided by Baron and Kenney (4). To establish the mediational model, three succeeding regression equations should meet the following criteria: (1) the independent variables (pain intensity and fear) must affect the mediator (disability), (2) the independent variables (pain intensity and fear) must be shown to affect the dependent variable (participation), and (3) in the third equation the mediating variable (disability) must influence the dependent variable (participation). Mediation is confirmed if, in the third equation, the effect of the independent variables on the dependent variable is substantially less than in the second equation.

\section{Results}

The total number of patients included in the study is 615 . Statistical analyses were performed on 555 cases. 10 cases were dropped because of age (>65 years). 50 cases were excluded from analyses because it concerned cases with more than 10 preceding episodes or a mean duration of preceding episodes of more than 26 weeks and a time interval of less than 26 weeks. There are no statistical differences between the excluded cases and the analysed cases regarding gender $\left\langle 60 \%\right.$ was male; $\left.\chi^{2}=0.087, p=0.77\right)$, pain onset $\left(52,5 \%\right.$ had sudden onset; $\chi^{2}=2.42$, $\mathrm{p}=0.30$ ), or scores on VAS (mean=56.7, $S D=26.9 ; \mathrm{t}=0.06, \mathrm{p}=0.58$ ), TSK (mean=38.1, $S D=6.5 ; t=1,58, p=0.11$ ) and $R D Q$ (mean=12.7, $S D=4.8 ; t=0.57$, $p=0.57$ ). In line with the exclusion criterion by age there was a significant difference concerning age (mean $=48.4, S D=13.2 ; t=3,81, p<0.001$ ).

The group of 555 cases included in the analysis consisted of 233 women $(42 \%)$ and 322 men (58\%) with a mean age of 42.4 years (SD=11.3). 119 patients $(21.4 \%)$ experienced a first-time ever LBP episode, $59.5 \%$ had one to five preceding episodes, and $14.4 \%$ had six to ten preceding episodes in their life. Reliability of the TSK, RDQ and the participation measure in acute LBP, as calculated by the internal consistency, was good with Cronbach's alpha being $0.75,0.87$ and 0.85 respectively. Most items were normally distributed except for four items that were slightly positively skewed (range: $0.085-1.860$ ) and two items that showed some kurtosis (range $-1.089-2.517$ ). However, visual inspection of the normal distributions of these items did not indicate severe deviation from the standard normal distribution.

In investigating the factor structure of the TSK by means of CFA, four models were assessed: (a) the one-factor solution containing all TSK items; (b) the one-factor solution without the four reverse items; (c) the two-factor solution by Clark et al. (1996); and (d), the four-factor model by Vlaeyen et al. (1995b). 
Table 5.1 presents the goodness-of-fit indices for the four tested models. The fit indices for the one-factor solutions, with and without reverse items, were unsatisfactory. This indicates that the TSK items do not appear to represent one latent construct but rather consist of several latent constructs. The two-factor model and the four-factor structure both show a poor fit to the data (table 5.1). Particularly two indices, the CFI and NNFI, showed a poor fit. Taken together, TSK scores from the present sample of acute LBP patients do not substantially fit to the previously reported solutions, originally derived from a sample of chronic LBP patients. Consequently there was a need to further investigate the factor structure of the TSK by means of EFA. This way, a more appropriate factor structure for the present sample of patients could be obtained.

Table 5.1 Goodness-of-fit indices for several TSK factor solutions as obtained by means of confirmatory factor analysis.

\begin{tabular}{|c|c|c|c|c|}
\hline & RMSEA & $\mathrm{CFI}$ & NNFI & GFI \\
\hline \multicolumn{5}{|l|}{$N=544$} \\
\hline One-factor solution & 0.068 & 0.72 & 0.69 & 0.96 \\
\hline One-factor solution without reversed items & 0.067 & 0.83 & 0.80 & 0.97 \\
\hline Four-factor solution (Vlaeyen et al., 1995b) & 0.056 & 0.88 & 0.84 & 0.98 \\
\hline $\begin{array}{l}\text { Two-factor solution without reversed items } \\
\text { (Clark et al., 1996) }\end{array}$ & 0.062 & 0.86 & 0.83 & 0.98 \\
\hline \multicolumn{5}{|l|}{$N=272$} \\
\hline Two-factor solution & 0.076 & 0.80 & 0.77 & 0.95 \\
\hline Two-factor solution (without items $4,8,12$, and 16 ) & 0.053 & 0.93 & 0.91 & 0.97 \\
\hline
\end{tabular}

TSK: Tampa Scale for Kinesiophobia, RMSEA = Root Mean Square Error of Approximation, $\mathrm{CFI}=$ Comparative Fit Index, NNFI = Non-Normed Fit Index, GFI = Goodness of Fit Index.

\section{Exploratory and confirmatory factor analysis}

The total sample $(n=544)$ was randomly divided into two equally sized groups. A principal components analysis with oblique rotation (oblimin) was conducted on TSK data from the first subsample $(n=272)$. Oblique rotation allows factors to be intercorrelated. The Scree test (9) and the eigenvalue $>1$ criterion were used to determine the correct number of factors to retain. Although arbitrarily, only factor loadings of 0.30 and above are interpreted (29).

Both the Scree test and "Eigenvalues $>1$ " method indicated the relative suitability of two or three factors for the TSK. In a three-factor solution, the third factor consisted of three items, of which two reverse-keyed (item 8 and 16) loaded most saliently on this factor, indicating that this factor might be a statistical artefact. A two-factor solution accounting for $32.9 \%$ of the variance, was found most suitable. The two-factor solution indicated that eight items loaded on the first factor. Careful inspection of the content of the items showed that, except for item 5, these items 
appeared to represent 'danger' and 'injury'. Table 5.2 displays the items and factor loadings. Nine items loaded on the second factor, which, except for item 2, appeared to represent 'activity' and 'avoidance of activity'. Three items had secondary loadings. Both factors were somewhat intercorrelated (Pearson $r=0.23$ ).

The two-factor solution obtained by EFA in the present study was further tested by means of CFA on TSK scores of patients from the second subsample. Table 5.1 presents the goodness-of-fit indices. TSK scores from patients in the second subsample do not substantially fit to the two-factor solution as obtained by EFA. All reverse-keyed items (items 4, 8, 12, and 16) loaded poorly (i.e. below 0.05 ) on their corresponding subscales. Goodness-of-fit indices for a two-factor solution without the reverse-keyed items were good to very good (see table 5.1). These results indicate that a two-factor solution shows the best fit if the reversed items are removed. The two factors might be assigned the following labels: (a) 'harm' (TSK-harm, items 3, 5, 6, 9, 11, and 15), reflecting the beliefs that there is something seriously wrong with the body, encompassing both the danger and injury items; (b) 'activity avoidance' (TSK-activity avoidance, items 1, 2, 7, 10, 13, 14 , and 17), indicating the beliefs that avoiding exercise or activities might prevent an increase of pain. The two factors 'harm' and 'activity avoidance' are moderately intercorrelated $\left(r=0.55^{* *}\right.$ ), and the internal consistency is $\alpha=0.74$ and $\alpha=0.68$ respectively.

As displayed in table 5.3, correlations between socio-demographics, TSK subscales, VAS, RDQ, and participation did not exceed the limits of moderate as defined by Landis and Koch (21).

Table 5.3 Means, SD for pain intensity (VAS), age, preceding episodes, pain disability (RDQ), and fear of movement/(re)injury subscales 'harm' and 'activity avoidance' (TSK), and correlation coefficients (Pearson) with continuous socio-demographic variables.

\begin{tabular}{|c|c|c|c|c|c|c|c|}
\hline & \multirow[b]{3}{*}{ Mean } & \multirow[b]{3}{*}{ SD } & \multirow[b]{3}{*}{$N$} & \multicolumn{4}{|c|}{ Pearson's correlation $(r)$} \\
\hline & & & & \multicolumn{3}{|c|}{$\begin{array}{l}\text { Fear of Movement } \\
\text { (TSK) }\end{array}$} & \multirow[b]{2}{*}{ Participation } \\
\hline & & & & 'Harm' & $\begin{array}{l}\text { 'Activity } \\
\text { avoidance' }\end{array}$ & $\mathrm{RDQ}$ & \\
\hline Pain intensity (VAS) & 59.5 & 23.9 & 329 & 0.10 & $0.18^{\star *}$ & $0.45^{\star \star}$ & $-0.16^{\star \star}$ \\
\hline 'Harm' factor (TSK) & 10.5 & 3.7 & 329 & - & $0.57^{* *}$ & $0.30^{\star *}$ & $-0.18^{* *}$ \\
\hline $\begin{array}{l}\text { 'Activity avoidance' } \\
\text { factor (TSK) }\end{array}$ & 16.9 & 4.1 & 329 & - & - & $0.38^{\star \star}$ & $-0.29^{\star *}$ \\
\hline Disability (RDQ) & 13.2 & 5.1 & 329 & - & - & - & $-0.49^{* \star}$ \\
\hline Age (years) & 42.3 & 11.3 & 329 & -0.03 & 0.04 & 0.04 & -0.03 \\
\hline Preceding episodes & 2.8 & 2.7 & 316 & $0.15^{* *}$ & 0.10 & 0.09 & 0.03 \\
\hline $\begin{array}{l}\text { Duration of com- } \\
\text { plaints (weeks) }\end{array}$ & 2.2 & 1.1 & 329 & 0.05 & -0.04 & $-0.24^{* *}$ & $0.30^{* *}$ \\
\hline
\end{tabular}

${ }^{*} p<0.05,{ }^{* \star} p<0.01$ 
Table 5.2 Factor loadings of Tampa Scale for Kinesiophobia items as obtained by means of exploratory factor analysis $(n=272)$.

\begin{tabular}{|c|c|c|c|}
\hline Item & Description & Factor 1 & Factor 2 \\
\hline 11 & $\begin{array}{l}\text { I wouldn't have this much pain if there weren't something potentially } \\
\text { dangerous going on in my body }\end{array}$ & 0.71 & \\
\hline 6 & My accident has put my body at risk for the rest of my life & 0.71 & \\
\hline 3 & My body is telling me I have something dangerously wrong & 0.63 & \\
\hline 9 & I am afraid that I might injure myself accidentally & 0.59 & \\
\hline 5 & People aren't taking my medical condition seriously enough & 0.48 & \\
\hline 15 & $\begin{array}{l}\text { I can't do all the things normal people do because it's too easy for me to } \\
\text { get injured }\end{array}$ & 0.42 & 0.32 \\
\hline 16 & $\begin{array}{l}\text { Even though something is causing me a lot of pain, I don't think it's } \\
\text { actually dangerous }\end{array}$ & 0.25 & \\
\hline 8 & $\begin{array}{l}\text { Just because something aggravates my pain does not mean it is dan- } \\
\text { gerous }\end{array}$ & 0.22 & \\
\hline 14 & $\begin{array}{l}\text { It's really not safe for a person with a condition like mine to be physi- } \\
\text { cally active }\end{array}$ & & 0.66 \\
\hline 12 & $\begin{array}{l}\text { Although my condition is painful, I would be better off if I were physically } \\
\text { active }\end{array}$ & -0.47 & 0.62 \\
\hline 17 & No one should have to exercise when he/she is in pain & & 0.61 \\
\hline 4 & My pain would probably be relieved if I were to exercise & -0.38 & 0.60 \\
\hline 1 & I'm afraid that I might injure myself if I exercise & & 0.48 \\
\hline 10 & $\begin{array}{l}\text { Simply being careful that I do not make any unnecessary movements is } \\
\text { the safest thing I can do to prevent my pain from worsening }\end{array}$ & & 0.42 \\
\hline 2 & If I were to try to overcome it, my pain would increase & & 0.37 \\
\hline 13 & Pain lets me know when to stop exercising so that I don't injure myself & & 0.31 \\
\hline 7 & Pain always means I have injured my body & & 0.30 \\
\hline
\end{tabular}

Mean scores on TSK-harm and TSK-activity avoidance differed significantly between males and females (table 5.4). In order to test for the hypothesized mediational role of disability between pain intensity and fear of movement/(re)injury on the one hand, and participation on the other, regression equations were carried out following the suggestions provided by Baron and Kenney (4). Demographic variables, that showed significant correlations or differences with disability or participation (educational level, duration of complaints, and onset) were controlled for in the regression analyses (see table 5.3 and table 5.4).

In the first equation disability was entered as dependent variable, and pain, TSK-harm, or TSK-activity avoidance were entered as independent variable. In the second analyses, participation was the dependent variable. And lastly, in the third equation, participation was entered as the dependent variable, and disability as the independent variable while controlling for pain intensity and TSK-harm and/or TSK-activity avoidance (table 5.5). In this way three models were investigated: (1) mediation of the RDQ between pain intensity, TSK-harm, and participation; (2) mediation of the RDQ between pain intensity, TSK-activity avoidance, and 
Figure 5.1 Pain intensity, TSK-harm, TSK-activity avoidance, disability and participation in acute low back pain patients.

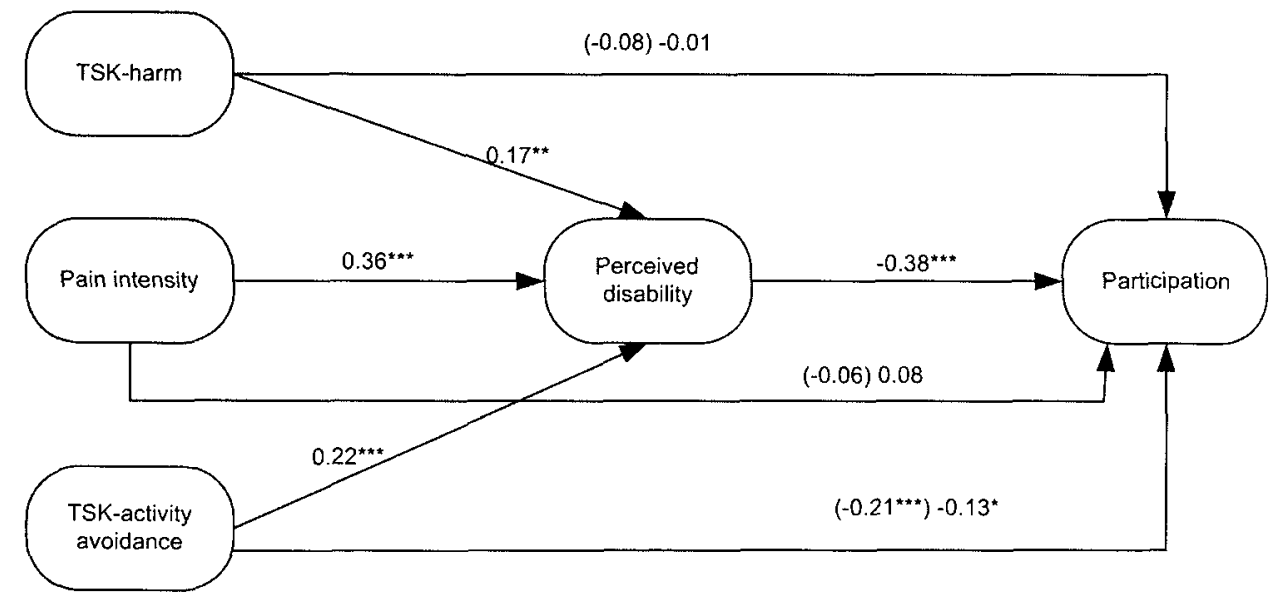

Model showing the mediational effect of disability (Roland Disability Questionnaire; RDQ) on the relation of pain intensity (VAS) and the harm-subscale of the Tampa Scale for Kinesiophobia (TSK-harm), and/or the activity avoidance subscale of the TSK (TSK-activity avoidance) on the one hand, and participation on the other. (The values in this figure indicate the standardized coefficients as obtained by stepwise hierarchical regression analyses controlling for onset, duration of complaints and educational level. The numbers on the arrows that run from the first variables directly to the last, control for the mediating variable. The values between brackets are the standardized coefficients of regression analyses without controlling for the mediating variable.)

${ }^{*} p<0.05 ;{ }^{* *} p<0.01 ;{ }^{* \star *} p<0.001$

participation (3) mediation of the RDQ between pain intensity, TSK-harm, and TSK-activity avoidance on the one hand, and participation on the other hand. Results indicated that, in the final model (Figure 5.1 ), disability significantly predicted participation (Stand. $\beta=-0.38, p<0.001$ ), whereas pain intensity and TSK-harm were no longer significant predictors (Stand. $\beta=0.08$, Stand. $\beta=-0.01$ respectively, $p>0.05$ ). In the regression analysis testing the final model (Figure 5.1), the standardized coefficient of TSK-activity avoidance decreased (from Stand. $\beta=-0.21$, $p<0.001$ to Stand. $\beta=-0.13, p<0.05$ ), but still explained a significant proportion of the variance of the dependent variable (i.e. participation). Variance Inflating Factors were small (1.02-1.60), suggesting that there was no problem of collinearity. The variables in the last equation (Figure 5.1) explained $31 \%$ of the total variance of participation. Summarizing, these results show that: (1) both pain intensity and specific pain-related fear significantly predict disability, and (2) disability plays a mediating role in the association between pain intensity and participation, and the association between fear of movement/(re)injury and participation. 


\section{Discussion}

Applying a cross-sectional design, the present study investigated: (1) the factor structure of the TSK in a sample of acute LBP patients; and (2) the predictive value of fear of movement/(re)injury as measured with the TSK for the level of disability and participation in this sample of patients with acute low back pain. Investigating the factor structure of the TSK by means of CFA, four models were tested: a one- factor model with and without reverse items, a two-factor model without reverse items (10) and a four-factor structure (39). The goodness-of-fit indices indicated inadequate fit of all tested models. Consequently, an EFA was conducted which indicated that a two-factor solution was the most suitable, consisting of a 'harm' and a 'activity avoidance' factor. The second aim of this study was to examine the association between fear of movement/(re)injury, disability and participation in daily life activities. As predicted, both the two subscales harm and activity avoidance, together with pain intensity are found to be significant predictors of disability. In addition, activity avoidance significantly contributes to the prediction of participation. The results of this study also showed that disability, as measured with the RDQ, plays a mediating role between pain intensity and participation, and between pain-related fear and participation.

Four issues regarding the factor analyses need further addressing. First, the current findings generally are in line with similar studies that examined the factor structure of the TSK in chronic back pain patients. In these $(10,14,15)$, a two-factor structure of the TSK also showed the best fit. However, the two factors of the current study consist of not exactly the same items than those of the chronic back pain studies. In contrast to other studies, items 9 , and 15 (reflecting the beliefs of fear of (re)injury) are included in the harm factor. This might mean that these items are important for both acute and chronic LBP patients. Although the content of the items may be more indicative of fear of injury, there clearly is disagreement on the factor structure across samples. Second, the items of the present 'activity avoidance' factor correspond to the factor solution of Clark and colleagues, except item 7 , that loaded on the 'pathological somatic focus' factor. Inspection of the content of this item (i.e.: Pain always means l've injured myself) reveals that it has more in common with the 'harm' and less with the 'activity avoidance' factor. The low loading of this item on 'activity avoidance' $(0.30)$ confirms that caution is needed with this item. Third, the observation that the reverse items do not load substantially on their corresponding subscales may indicate that not all patients are aware that some items are negatively formulated. This is in line with former factor analyses $(10,14,15)$ and the reliability study by Swinkels-Meewisse et al. (30), who found the internal consistency of the total TSK to increase if the reverse-keyed items are deleted. Fourth and last, although there appears to be sufficient evidence supporting the validity of the TSK total score in chronic back pain populations (38), the validity of the harm and activity avoidance subscales of the TSK in acute low back pain patients, needs to be clarified in future studies. 
Table 5.4 Means (SD) for participation, pain disability (RDQ), and fear of movement/(re)injury subscales 'harm' and 'activity avoidance' (TSK), with dichotomous socio-demographic variables.

\begin{tabular}{|c|c|c|c|c|c|}
\hline & percentage & TSK-harm & $\begin{array}{l}\text { TSK-activity } \\
\text { avoidance }\end{array}$ & $\begin{array}{l}\text { Disability } \\
\text { (RDQ) }\end{array}$ & Participation \\
\hline \multicolumn{6}{|l|}{ Gender } \\
\hline Male & $58 \%$ & $11.1^{* *}(3.9)$ & $17.3^{\star}(4.1)$ & $13.2(5.0)$ & $3.8(2.9)$ \\
\hline Female & $42 \%$ & $9.7^{\star \star}(3.4)$ & $16.4^{*}(4.1)$ & $13.2(5.2)$ & $4.3(2.9)$ \\
\hline \multicolumn{6}{|c|}{ Educational level } \\
\hline High & $29.7 \%$ & $10.2(3.4)$ & $16.6(4.0)$ & $12.8(4.9)$ & $4.7^{\star \star}(3.0)$ \\
\hline Low & $70.3 \%$ & $10.7(4.0)$ & $17.1(4.2)$ & $13.4(5.1)$ & $3.7^{* *}(2.8)$ \\
\hline \multicolumn{6}{|c|}{ Sports (Yes/No) } \\
\hline Yes & $53.2 \%$ & $10.6(3.7)$ & $16.9(4.0)$ & $13.1(4.8)$ & $3.8(2.9)$ \\
\hline No & $46.8 \%$ & $10.4(3.8)$ & $16.9(4.1)$ & $13.3(5.4)$ & $4.2(2.9)$ \\
\hline \multicolumn{6}{|c|}{ Civil status } \\
\hline Married & $82.1 \%$ & $10.5(3.8)$ & $17.0(4.2)$ & $13.4(5.0)$ & $4.0(2.9)$ \\
\hline Single & $17.9 \%$ & $10.9(3.9)$ & $16.5(3.8)$ & $12.1(5.1)$ & $4.1(2.9)$ \\
\hline \multicolumn{6}{|c|}{ Radiation } \\
\hline Yes & $53 \%$ & $10.8(4.0)$ & $17.0(4.4)$ & $13.3(5.2)$ & $4.1(3.0)$ \\
\hline No & $47 \%$ & $10.2(3.4)$ & $16.8(3.7)$ & $13.1(5.0)$ & $3.9(2.9)$ \\
\hline \multicolumn{6}{|l|}{ Onset } \\
\hline Sudden & $62.9 \%$ & $10.2(3.6)$ & $16.8(4.0)$ & $14.0^{\star \star \star}(4.8)$ & $3.3^{* * *}(2.8)$ \\
\hline Gradual & $37.1 \%$ & $11.0(4.1)$ & $17.0(4.3)$ & $11.9^{\star \star \star}(5.2)$ & $5.2^{\star \star \star}(2.8)$ \\
\hline
\end{tabular}

${ }^{*} p<0.05,{ }^{* *} p<0.01,{ }^{* * *} p<0.001$

TSK: Tampa Scale for Kinesiophobia, RDQ: Roland Disability Questionnaire.

The current study is the first that investigated the role of fear of movement/(re)injury in participation as well as disability levels of patients with acute LBP. In the current study disability and participation were used as outcome measures. The participation measure used in this study comprised work or house holding participation, sport participation, leisure activities, and social or family activities. Thus, participation was placed in a broader social context, which is different from the usual disability measures. Indeed, variables predicting disability differ from the variables predicting participation. Beside that, the correlation between disability and participation is significant but modest, suggesting that both are measures of different constructs, which refutes the idea that participation is just the inverse of disability. In contrast with disability, there is a need for validated instruments measuring the participation construct. Our instrument appears reliable and valid and might contribute to a first step in this endeavour. 
Table 5.5 Hierarchical linear regression analysis of the relationship between participation as dependent variable, and pain intensity, fear of movement/(re) injury, and disability as independent variables, controlling for onset, duration of complaints and educational level.

\begin{tabular}{|c|c|c|c|c|c|}
\hline & Dependent & Adj. $R^{2}$ & Independents & $\begin{array}{c}\text { Standardized } \\
\text { beta }\end{array}$ & $\begin{array}{l}\text { Significance } \\
\text { of beta }\end{array}$ \\
\hline & \multirow{7}{*}{$\begin{array}{l}\text { Disability } \\
\text { (RDQ) }\end{array}$} & \multirow[t]{7}{*}{0.34} & Onset & 0.11 & 0.029 \\
\hline & & & & & \\
\hline & & & Duration of complaints & -0.19 & 0.000 \\
\hline & & & Educational level & 0.01 & 0.871 \\
\hline & & & TSK-activity avoidance & 0.22 & 0.000 \\
\hline & & & TSK-harm & 0.17 & 0.003 \\
\hline & & & Pain intensity (VAS) & 0.36 & 0.000 \\
\hline \multirow[t]{6}{*}{ Step 1} & \multirow[t]{6}{*}{ Participation } & \multirow[t]{6}{*}{0.22} & Onset & -0.21 & 0.000 \\
\hline & & & Duration of complaints & 0.24 & 0.000 \\
\hline & & & Educational level & 0.13 & 0.011 \\
\hline & & & TSK-activity avoidance & -0.21 & 0.001 \\
\hline & & & TSK-harm & -0.08 & 0.221 \\
\hline & & & Pain intensity (VAS) & -0.06 & 0.279 \\
\hline \multirow[t]{7}{*}{ Step 2} & \multirow[t]{7}{*}{ Participation } & \multirow[t]{7}{*}{0.31} & Onset & -0.17 & 0.001 \\
\hline & & & Duration of complaints & 0.17 & 0.002 \\
\hline & & & Educational level & 0.13 & 0.006 \\
\hline & & & TSK-activity avoidance & -0.13 & 0.027 \\
\hline & & & TSK-harm & -0.01 & 0.839 \\
\hline & & & Pain intensity (VAS) & 0.08 & 0.144 \\
\hline & & & Disability (RDQ) & -0.38 & 0.000 \\
\hline
\end{tabular}

TSK: Tampa Scale for Kinesiophobia, RDQ: Roland Disability Questionnaire.

In line with previous studies in (chronic) LBP the relation between pain intensity and fear of movement/(re)injury is very low $(12,38,39)$. Studies in LBP populations investigating the influence of the TSK and pain intensity on disability, show contrasting results. Vlaeyen et al. $(38,39)$ and Crombez et al. (12) confirm the significant value of the TSK predicting the level of disability. In their studies, pain intensity did not have a significant effect on the prediction of concurrently measured disability. Van den Hout et al. and Fritz et al. however, did not find a significant effect of pain-related fear on baseline measures of disability $(13,16)$. These contrasting results might be caused by differences in study population, e.g. acute versus chronic LBP patients, or patients with or without work absenteeism. It is quite likely that in acute LBP, pain intensity has a greater impact on disability levels as compared to chronic LBP.

There are some limitations in this study that need considering. First, the crosssectional character of this study does not permit causal inferences regarding the 
associations found. Second, 615 patients were included during a two and a half year period. The incidence data of patients reporting LBP to GPs in The Netherlands suggests that more patients could have been included (33). It is likely that participating GPs and physiotherapists may have failed to include all the referred patients, possibly creating a selection bias. Third, the population included in this study was in fact heterogeneous: it comprises both patients who had never before experienced an episode with LBP and those who had. Much discussion exists regarding the definition of chronicity $(22,34)$. Although one of the inclusion criteria was having had a period of at least 3 month free of LBP before the current back pain episode, and possible cases of chronicity were excluded from analyses, there is a chance the population is biased with patients already having a chronic condition if the definition of CLBP is characterized by an episodic, recurrent course $(22,41,43)$. Fourth, in the absence of a standardized and well-validated measure of participation, we decided to develop a new measure consisting of five items (see appendix). Although the preliminary psychometrics of this questionnaire are promising, they need to be replicated in future studies.

The current study found the TSK to consist of two subscales labelled 'harm', and 'activity avoidance'. These subscales, together with pain intensity, significantly predicted disability. Furthermore, participation was significantly predicted by TSKactivity avoidance and disability. Consequently, in clinical practice, the use of the TSK as a screening instrument for the level of disability or participation might be of value. Especially, because there are indications that pain-related fear is present early in an episode of LBP and may be an important indicator of future disability $(13,19)$. Advice and education aimed at reducing pain-related fear should be incorporated early. Interventions designed to reduce pain-related fear (e.g. exposure in vivo, educational information), or influence avoidance behaviour are shown to have positive effects on patient's beliefs, functional abilities and work absenteeism due to $\operatorname{LBP}(6,8,11,24,31,32,35,36)$. The results of our study suggest that successful reduction of functional disability will foster increased participation in daily and social life activities. Prospective studies are needed to support the predictive role of pain-related fear and the mediating role of disability as indicated in our model, in the transition from acute to chronic LBP.

\section{Acknowledgements}

This research was partly supported by the Royal Dutch Physical Therapists Association. We thank the general practitioners and physical therapists for their assistance in including patients. Participation of Dr. J. Vlaeyen was supported by the Netherlands Organization for Health Research and Development (ZONMW), grant nr. 904-65-090. 


\section{Appendix}

Questions concerning participation.

1. To what extent did you perform any activities in or around your home during this episode of low back pain (not being work or household activities)?

No participation

$\begin{array}{lllllllllll}0 & 1 & 2 & 3 & 4 & 5 & 6 & 7 & 8 & 9 & 10\end{array}$

$\begin{array}{lllllllllll}0 & 1 & 2 & 3 & 4 & 5 & 6 & 7 & 8 & 9 & 10\end{array}$

$6 \quad 7$

full normal participation

2. To what extent did you participate in any work and/or household activities during this episode of low back pain?

No participation
$\begin{array}{lll}0 & 1 & 2\end{array}$
$2 \quad 3 \quad 4 \quad 5$
$6 \quad 7$

full normal participation

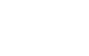

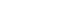

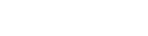




\section{References}

1. Al Obaidi,S.M., Nelson,R.M., Al Awadhi,S., and Al Shuwaie,N. The role of anticipation and fear of pain in the persistence of avoidance behaviour in patients with chronic low back pain. Spine 2000; 25 (9): 1126-1131.

2. Asmundson,G.J.G., Norton,G.R., and Allerdings,M.D. Fear and avoidance in dysfunctional chronic back pain patients. Pain 1997; 69 (3): 231-236.

3. Asmundson,G.J.G., Norton,P.J., and Norton,G.R. Beyond pain: the role of fear and avoidance in chronicity. Clin Psychol Rev 1999; 19 (1): 97-119.

4. Baron,R.M. and Kenny,D.A. The moderator-mediator variable distinction in social psychological research: conceptual, strategic, and statistical considerations. J Pers Soc Psychol 1986; 51 (6): 1173-1182.

5. Beurskens,A.J.H.M., Vet,H.C.W.d., and Koke,A. Responsiveness of functional status in low back pain: a comparison of different instruments. Pain 1996; 65 71-76.

6. Buchbinder,R., Jolley,D., and Wyatt,M. Population based intervention to change back pain beliefs and disability: three part evaluation. BMJ 2001; 322 (7301): 1516-1520.

7. Buer,N. and Linton,S.J. Fear-avoidance beliefs and catastrophizing: occurrence and risk factor in back pain and ADL in the general population. Pain 2002; 99 (3): 485-491.

8. Burton,A.K., Waddell,G., Tillotson,K.M., and Summerton,N. Information and advice to patients with back pain can have a positive effect. A randomized controlled trial of a novel educational booklet in primary care. Spine 1999; 24 (23): 2484-2491.

9. Cattell,R.B. The scientific use of factor analysis in behavioural and life sciences. New York: Plenum Press, 1978

10. Clark,M.E., Kori,S.H., and Brockel,J. Kinesiophopia and chronic pain: psychometric characteristics and factor analysis of the Tampa Scale. Pain Society Abstracts 1996; 15 (77):

11. Crombez,G., Eccleston,C., Vlaeyen,J.W.S., Vansteenwegen,D., Lysens,R., and Eelen,P. Exposure to physical movements in low back pain patients: restricted effects of generalization. Health Psychol 2002; 21 (6): 573-578.

12. Crombez,G., Vlaeyen,J.W.S., Heuts,P.H.T.G., and Lysens,R. Pain-related fear is more disabling than pain itself. Evidence on the role of pain-related fear in chronic back pain disability. Pain 1999; 80 (1,2): 329-339.

13. Fritz,J.M., George,S.Z., and Delitto,A. The role of fear-avoidance beliefs in acute low back pain: relationships with current and future disability and work status. Pain 2001; 94 (1): 7-15.

14. Geisser,M.E., Haig,A.J., and Theisen,M.E. Activity avoidance and function in persons with chronic back pain. J Occup Rehabil 2000; 10 (3): 215-227.

15. Goubert,L., Crombez,G., Van Damme,S., Vlaeyen,J.W.S., Bijttebier,P., and Roelofs,J. Confirmatory factor analysis of the Tampa-Scale for Kinesiophobia: invariant two-factor model across low back pain patients and fibromyalgia patients. Clin J Pain 2004; 20 (2): 103-110.

16. Hout,J.H.C.v.d., Vlaeyen,J.W.S., Houben,R.M., Soeters,A.P., and Peters,M.L. The effects of failure feedback and pain-related fear on pain report, pain tolerance, and pain avoidance in chronic low back pain patients. Pain 2001; 92 (1-2): 247-257.

17. Jensen,M.P. and Karoly,P. Self-report scales and procedures for assessing pain in adults. In Turk,D.C., Melzack, R. (eds) Handbook of Pain Assessment. The Guilford Press, New York. 1992; 135-151.

18. Jöreskog,K.G. and Sörbom,D. LISREL 8.30. 1999

19. Klenerman,L., Slade,P.D., Stanley,I.M., Pennie,B., Reilly,J.P., Atchison,L.E., Troup, J.D.G., and Rose,M.J. The prediction of chronicity in patients with an acute attack of low back pain in a general practice setting. Spine $1995 ; 20$ (4): 478-484.

20. Kopec, J.A. and Esdaile,J.M. Functional Disability Scales for back pain. Spine 1995; 20 (17): 1943-1949.

21. Landis,J.R. and Koch,G.G. The measurement of observer agreement for categorical data. Biometrics 1977; 33159-33174.

22. McGorry,R.W., Webster,B.S., Snook,S.H., and Hsiang,S.M. The relation between pain intensity, disability, and the episodic nature of chronic and recurrent low back pain. Spine 2000; 25 (7): 834-841.

23. Miller,R.P., Kori,S.H., and Todd,D.D. The Tampa Scale. 1991 
24. Moore,J.E., Von Korf,M., Cherkin,D., Saunders,K., and Lorig,K. A randomized trial of a cognitive-behavioural program for enhancing back pain self care in a primary care setting. Pain 2000; 88 (2): 145-153.

25. Picavet,H.S., Vlaeyen,J.W.S., and Schouten,J.S. Pain catastrophizing and kinesiophobia: predictors of chronic low back pain. Am J Epidemiol 2002; 156 (11): 1028-1034.

26. Roland,M. and Morris,R. A study of the natural history of back pain, Part 1 \& Part 2: RolandMorris Disability Questionnaire. Spine 1983; (8): 141-150.

27. Severeijns,R., van den,H.M., Vlaeyen,J.W.S., and Picavet,H.S. Pain catastrophizing and general health status in a large Dutch community sample. Pain 2002; 99 (1-2): 367-376.

28. Stratford,P.W., Binkley,J.M., and Riddle,D.L. Development and initial validation of the back pain functional scale. Spine 2000; 25 (16): 2095-2102.

29. Streiner,D.L. Figuring out factors: the use and misuse of factor analysis. Can J Psychiatry 1994; 39 (3): 135-140.

30. Swinkels-Meewisse,E.J., Swinkels,R.A., Verbeek,A.L., Vlaeyen,J.W.S., and Oostendorp, R.A. Psychometric properties of the Tampa Scale for kinesiophobia and the fear-avoidance beliefs questionnaire in acute low back pain. Man Ther 2003; 8 (1): 29-36.

31. Symonds, T.L., Burton,A.K., Tillotson,K.M., and Main,C.J. Absence resulting from low back trouble can be reduced by psychosocial intervention at the work place. Spine $1995 ; 20$ (24): 2738-2745.

32. Symonds, T.L., Burton,A.K., Tillotson,K.M., and Main,C.J. Do attitudes and beliefs influence work loss due to low back trouble? Occup Med 1996; 46 (1): 25-32.

33. Velden,J.V.d., De Bakker,D.H., Claessens,A.A.M.C., and Schellevis,F.G. Een nationale studie naar ziekten en verrichtingen in de huisartsenpraktijk. Basisrapport morbiditeit in de huisartsenpraktijk. 1991;

34. Verhaak,P.F.M., Kerssens,J.J., Dekker,J., Sorbi,M.J., and Bensing,J.M. Prevalence of chronic benign pain disorder among adults: a review of the literature. Pain 1998; 77 (3): 231-239.

35. Vlaeyen,J.W.S., de Jong,J., Geilen,M., Heuts,P.H.T.G., and van Breukelen,G. Graded exposure in vivo in the treatment of pain-related fear: a replicated single-case experimental design in four patients with chronic low back pain. Behav Res Ther 2001; 39 (2): 151-166.

36. Vlaeyen,J.W.S., Jong,J.R.d., Geilen,M., Heuts,P.H.T.G., and Breukelen,G.v. The treatment of fear of movement/(re)injury in chronic low back pain: further evidence on the effectiveness of exposure in vivo. Clin J Pain 2002; 18 (4): 251-261.

37. Vlaeyen,J.W.S., Jong,J.R.d., Onghena,P., Kerckhoffs-Hanssen,M., and Kole-Snijders, A.M. Can pain-related fear be reduces? The application of cognitive-behavioural exposure in vivo. Pain Res Manag 2002; 7 (3): 144-153.

38. Vlaeyen,J.W.S., Kole-Snijders,A.M.J., Boeren,R.G.B., and Eek,H.v. Fear of movement/ (re)injury in chronic low back pain and its relation to behavioural performance. Pain 1995; 62 363-372.

39. Vlaeyen,J.W.S., Kole-Snijders,A.M.J., Rotteveel,A.M., Ruesink,R., and Heuts,P.H.T.G. The role of fear of movement/(re)injury in pain disability. J Occup Rehabil 1995; 5 (4): 235-252.

40. Vlaeyen,J.W.S. and Linton,S.J. Fear-avoidance and its consequences in chronic musculoskeletal pain: a state of the art. Pain 2000; 85 (3): 317-332.

41. Von Korff,M. Studying the natural history of back pain. Spine 1994; 19 (18S): 2041S-2046S.

42. Von Korff,M., Ormel,J., Keefe,F.J., and Dworkin,S.F. Grading the severity of chronic pain. Pain 1992; 50 133-149.

43. Von Korff,M. and Saunders, K. The Course of Back Pain in Primary Care. Spine 1996; 21 (24): 2833-2839.

44. World Health Organization. International Classification of Functioning, Disabilities and Health Problems. 2001. 
•

- 


\section{Chapter 6}

\section{Fear of movement/(re)injury predicting chronic disabling low back pain: a prospective inception cohort study}

Ilse E.J. Swinkels-Meewisse, Jeffrey Roelofs, Erik G.W. Schouten, André L.M. Verbeek, Rob A.B. Oostendorp, Johan W.S. Vlaeyen

Published as:

Ilse E.J. Swinkels-Meewisse, Jeffrey Roelofs, Erik G.W. Schouten, André L.M. Verbeek, Rob A.B. Oostendorp, Johan W.S. Vlaeyen. Fear of movement/ (re)injury predicting chronic disabling low back pain: a prospective inception cohort study. Spine, 2006; 31 (6): 658-664. 


\section{Abstract}

Study design: Prospective inception cohort study.

Objectives: To investigate prospectively whether pain-related fear predicts future perceived disability and participation in patients with acute LBP.

Summary of background data: There are indications that fear of movement/ (re)injury, as measured by the Tampa Scale for Kinesiophobia (TSK) is present early in an episode of low back pain (LBP) and that it might be a predictor of future perceived disability and participation.

Methods: A cohort of 555 acute LBP patients included by general practitioners and physical therapists in primary care settings were followed for 6 months.

Results: Results indicate that baseline fear of movement/(re)injury was predictive of future perceived disability and to a lesser extent (and together with duration and radiation) of participation.

Conclusions: The results suggest that interventions aimed at reducing pain-related fear in the acute stage of LBP, might prevent restrictions of activity and participation due to pain and might be a way of preventing the transition from acute to chronic LBP. 


\section{Introduction}

The course of low back pain (LBP) seems less favourable than often considered(16). Many factors influencing the clinical course of low back pain, such as physical factors, work-related factors and psychological factors, have been identified $(34,41)$. In LBP, pain-related fear is an example of a psychological factor associated with impaired physical performance and self-reported disability $(1,9,48)$. Pain-related fear causes avoidance of activity, depriving the patient of the necessary feedback concerning the state of his low back. Most studies concerning painrelated fear have used a cross-sectional design or used samples with chronic pain patients. A questionnaire developed to measure a specific aspect of pain-related fear, such as fear of movement/(re)injury, is the Tampa Scale for Kinesiophobia (29) (TSK). In a cross-sectional study investigating fear of movement/(re)injury as a predicting factor of perceived disability and participation by using the TSK (29), Swinkels-Meewisse et al. found pain-related fear to be predictive of both perceived disability and participation in a sample of acute LBP patients (39). However, estimates of recovery or identification of prognostic factors can only be obtained from inception cohort studies. There is a need for prospective studies to further examine the role of fear of movement or (re)injury in the transition from acute to disabling chronic LBP $(34,39)$.

The World Health Organization advocates the use of the International Classification of Functioning, Disability and Health in clinical practice (55) (ICF). The importance of participation, in addition to activity limitation was emphasized. In the ICF, activity is defined as the capacity of executing a task or action that is an inherent or intrinsic feature of the person themselves, without the influences of varying environmental factors (e.g. bending forward). Participation however, is the actual performance of activities in the persons' current environment aimed at engaging in a life situation, (e.g. work: cleaning floors by using a cleaning machine despite limited ability to bend forward). As such, it elicits information about the effects the environment may have on the persons' action. Activity and participation are different constructs with different predictive factors (39).

The aims of the current study are to investigate, using a prospective design, whether pain-related fear predicts future perceived disability and participation. We hypothesized that fear of movement/(re)injury is a substantial and significant predictor in the transition from the acute phase of LBP into the chronic phase.

\section{Materials and Methods}

\section{PARTICIPANTS}

General practitioners (GP) and physiotherapists (PT) in the southeast region of The Netherlands recruited 615 patients experiencing an acute episode of LBP between April 1998 and December 2000. Acute LBP was defined as LBP with a 
maximum duration of four weeks duration and having been free of LBP three month preceding the current episode. Patients were eligible to participate if they met the following criteria: aged between 18 and 65 years, experiencing an episode of non-specific LBP independent of radiation. Criteria for exclusion were: presence of specific LBP (e.g. tumours, trauma, infection, fractures, inflammatory disorders), presence of malignancies, operations in the lumbar area, pregnancy, or inability to read and write.

\section{PROCEDURE}

During their first consultation with the GP or PT, eligible patients were requested to participate in the study. Written informed consent was obtained prior to participation in the study. During the visit with their healthcare provider, patients were requested to complete a set of self-report questionnaires (T1). Six weeks after the onset of LBP, a second set of self-report measures was mailed (T2). Finally, the last set of measures was sent six months after the onset of LBP (T3). If a person did not respond within four days, he or she was contacted by telephone and requested to complete and return the questionnaires within two days. Responses after that time were coded as missing data.

\section{MEASURES}

\section{Socio-demographic variables (T1)}

A questionnaire was completed covering several biographical data (gender, age, civil status, education, occupation, sick leave, health insurance, and sport activities), questions regarding the current LBP episode (duration, radiation, onset, and number of disability-days), and information regarding any preceding episodes of LBP.

\section{Follow-up questionnaire (T2 and T3)}

Covering the status of the current episode of LBP (self-report LBP, radiation, possible pain free period) and current or past interventions.

\section{Current pain intensity (T1, T2, and T3)}

A Visual Analogue Scale (VAS) for current pain was used (19). Validity, reproducibility and responsiveness of the VAS are well established $(10,18,21,54)$.

\section{Pain-related fear (T1, T2, and T3)}

The Dutch version of the Tampa Scale for Kinesiophobia (29)(TSK) was used. The TSK is a 17-item self-report questionnaire measuring fear of movement/ (re)injury. Each item is scored on a 4-point Likert scale. Scoring possibilities range from 'strongly disagree' (score=1) to 'strongly agree' (score=4). The scores on items 4, 8,12 , and 16 are reverse-scored. Reliability and validity of the TSK are moderate 
to good $(15,40,49)$. In acute LBP two subscales have been identified, namely a harm-subscale (TSK-harm, items $3,5,6,9,11$, and 15), reflecting the beliefs that there is something seriously wrong with the body, and an activity avoidancesubscale (TSK-activity avoidance, items 1, 2, 7, 10,13,14, and 17), indicating the beliefs that avoiding exercise or activities might prevent an increase of pain (39).

\section{Functional status (T1, T2, and $T 3$ )}

The Dutch version of the Roland Disability Questionnaire (RDQ; 3,37 ) was used to measure the functional status in LBP. The RDQ is a reliable and valid instrument to measure perceived disability with good responsiveness $(3,24,38)$. For logistic reasons, the RDQ was included halfway the study. For this reason data of functional status of only 337 patients were available in this study.

\section{Participation (T1, T2, and T3)}

Five questions concerning self-report level of participation were scored on an 11point Likert scale, ranging from zero (no participation) to 10 (full participation). The participation-items comprise items about participation with home activities, work or house holding activities, sport activities, leisure activities, and social or family activities. The items are derived from the Chronic Pain Grade Questionnaire (52). The mean of the scores is used to obtain one 'participation' score. In case a person did not engage in sport activities, the participation score was obtained by calculating the mean based on the remaining item scores. The participation items constitute a reliable instrument (39) (Cronbach's alpha was 0.85 ).

\section{STATISTICAL ANALYSES}

Mean scores and standard deviations of outcome measures on T1, T2, and T3 were caiculated. Multilevel analyses were performed, with perceived disability and participation, in succession, used as dependent variables and baseline measures as independent variables, including the baseline score of the dependent one. The repeated measured dependent variables (on T2 and T3) constitute the first level and persons the second. These random intercept models were estimated with the RIGLS-algorithm. The factor "Time" was entered as a dummy variable to represent the measurement moment, which is 0 for T2 and 1 for T3. The calculations were done with the use of MLwiN version 1.10.0007 (35).

\section{Results}

\section{Descriptive statistics}

The total number of participants included in the current study was 615 of which 60 persons were excluded from further follow up(39). Of the remaining 555 individuals, 467 returned the second set of questionnaires ( $16 \%$ missing; $n=88)$. At the end of the study 431 patients $(78 \%)$ returned all three sets of questionnaires. 
There were no significant differences between persons with and without complete follow up on all tested variables, except for age (respondents: age $=43.3$ years; non-respondents: age $=40.0$ years; mean difference: 3.3 years; $p=0.02$ ), and fear of harm (respondents $=10.2$; non-respondents $=11.2$; mean difference: $1.0 ; p=0.01$ ). However, these differences were not clinically relevant. Figure 6.1 and table 6.1 show the number of persons and their characteristics with and without self-report low back pain at baseline and at follow up. The mean age was 42.4 years $(S D=11.3)$. A total of 119 persons $(21.4 \%)$ had a first-time ever LBP episode. The prevalence of LBP at 6 weeks follow up was 53.1\% (248 participants). At 6 months the prevalence rate was $34.8 \%$ (150 participants).

Figure 6.2, and table 6.2 show the decrease in mean pain intensity, disability, and pain-related fear, and the increase of participation in patients with high or low pain-related fear. LBP patients with high pain-related fear are significantly more

Figure 6.1 Flow diagram of the number of persons with and without self-report LBP at the moment of inclusion (T1), at 6 weeks after LBP onset (T2) and 6 month after onset of LBP (T3).

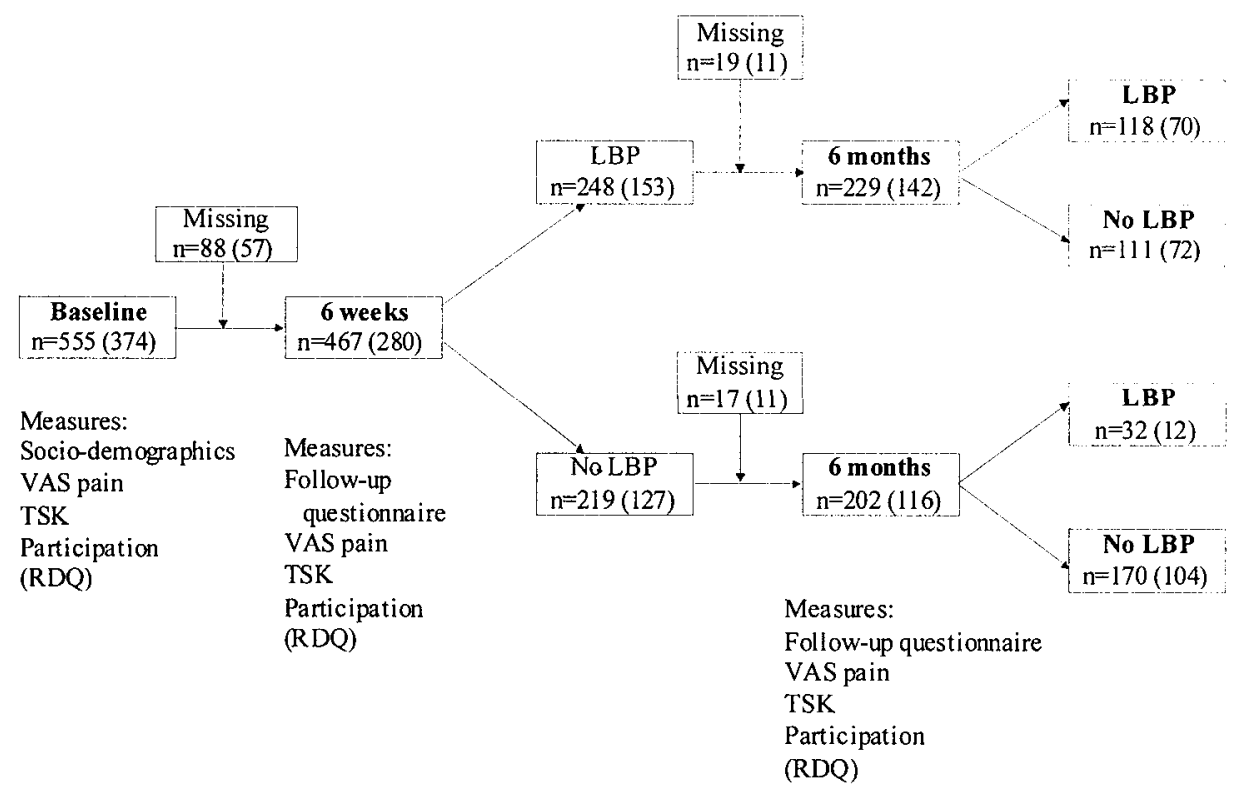

60 patients were dropped from follow-up because of age and possible chronicity. The values between brackets are the number of patients with completed Roland Disability Questionnaire (RDQ). 
Table 6.1 Demographic data of the patients on inclusion (T1), six weeks after onset (T2), and six months after onset (T3).

\begin{tabular}{|c|c|c|c|c|c|}
\hline & $\begin{array}{l}T 1 \\
(n=555)\end{array}$ & $\begin{array}{l}\text { T2 } \\
(n=467)\end{array}$ & & $\begin{array}{l}\text { T3 } \\
(n=431)\end{array}$ & \\
\hline & $\begin{array}{l}\text { LBP } \\
(n=555)\end{array}$ & $\begin{array}{l}\text { LBP } \\
(n=248)\end{array}$ & $\begin{array}{l}\text { Free of LBP } \\
(n=219)\end{array}$ & $\begin{array}{l}\text { LBP } \\
(n=150)\end{array}$ & $\begin{array}{l}\text { Free of LBP } \\
(n=281)\end{array}$ \\
\hline Gender (male) & $58.0 \%$ & $57.3 \%$ & $55.7 \%$ & $57.4 \%$ & $58.0 \%$ \\
\hline $\begin{array}{l}\text { Civil Status (living } \\
\text { alone) }\end{array}$ & $17.7 \%$ & $15.4 \%$ & $17.9 \%$ & $16.2 \%$ & $17.3 \%$ \\
\hline Educational level (high) & $30.7 \%$ & $30.2 \%$ & $34.0 \%$ & $26.4 \%$ & $35.3 \%$ \\
\hline Sick leave ${ }^{1}$ & $46.0 \%$ & $41.8 \%$ & $48.6 \%$ & $47.0 \%$ & $45.3 \%$ \\
\hline Sport activities & $57.0 \%$ & $53.0 \%$ & $60.2 \%$ & $54.8 \%$ & $57.9 \%$ \\
\hline $\begin{array}{l}\text { Duration at } T 1 \\
\text { (<14 days) }\end{array}$ & $63.4 \%$ & $55.2 \%$ & $74.9 \%$ & $55.5 \%$ & $68.8 \%$ \\
\hline radiation & $52.3 \%$ & $57.7 \%$ & - & $56.1 \%$ & - \\
\hline Onset (sudden) & $62.7 \%$ & $53.4 \%$ & $71.9 \%$ & $49.0 \%$ & $67.8 \%$ \\
\hline $\begin{array}{l}\text { Preceding episodes } \\
(>1)\end{array}$ & $77.5 \%$ & $83.1 \%$ & $73.4 \%$ & $86.5 \%$ & $74.7 \%$ \\
\hline
\end{tabular}

${ }^{1}$ Data regarding absence from work were extracted on $\mathrm{T} 1$ only.

Table 6.2 Means and standard deviations (SD) of pain intensity, fear of movement/(re)injury, perceived disability and participation on the first, second, and third measurement time (T1, T2, and T3)

\begin{tabular}{|c|c|c|c|c|c|c|c|c|c|}
\hline & T1 & & & $\mathrm{T} 2$ & & & T3 & & \\
\hline & Mean & SD & $\mathrm{N}$ & Mean & SD & $N$ & Mean & SD & $N$ \\
\hline Pain intensity & 49.8 & 24.3 & 546 & 20.4 & 23.0 & 433 & 15.0 & 22.9 & 420 \\
\hline Fear of movement/(re)injury & 36.4 & 7.7 & 546 & 34.1 & 7.1 & 433 & 34.1 & 7.7 & 414 \\
\hline Fear of harm" & 10.4 & 3.7 & 544 & 9.5 & 3.6 & 433 & 9.6 & 3.8 & 414 \\
\hline Beliefs of activity avoidance ${ }^{\S}$ & 16.7 & 4.1 & 544 & 15.0 & 4.2 & 433 & 14.7 & 4.5 & 414 \\
\hline Perceived disability & 13.2 & 5.1 & 332 & 6.0 & 5.5 & 268 & 4.0 & 5.0 & 269 \\
\hline $\begin{array}{l}\text { Perceived disability, high } \\
\text { fear" }\end{array}$ & 14.5 & 4.2 & 153 & 8.8 & 5.6 & 123 & 6.9 & 5.7 & 111 \\
\hline $\begin{array}{l}\text { Perrceived disability, low } \\
\text { fear" }\end{array}$ & 11.4 & 5.3 & 179 & 3.6 & 4.1 & 145 & 2.1 & 3.3 & 158 \\
\hline Participation & 4.1 & 2.9 & 546 & 5.8 & 2.7 & 424 & 7.9 & 2.4 & 412 \\
\hline Participation, high fear & 3.3 & 2.7 & 267 & 4.8 & 2.6 & 189 & 6.8 & 2.6 & 176 \\
\hline Participation, low fear"* & 4.9 & 3.0 & 279 & 6.6 & 2.5 & 235 & 8.6 & 1.8 & 236 \\
\hline
\end{tabular}

\# As measured with the Harm subscale of the Tampa Scale for Kinesiophobia $\S$ As measured with the Activity Avoidance subscale of the Tampa Scale for Kinesiophobia High fear: TSK score > mean TSK; Low fear: TSK score $\leq$ mean TSK; ${ }^{* *} p<0.001$ 
Figure 6.2a Means of perceived disability at baseline, 6 weeks and 6 months measurement divided in high (i.e. $>$ mean TSK) and low (i.e. $\leq$ mean TSK) pain-related fear.

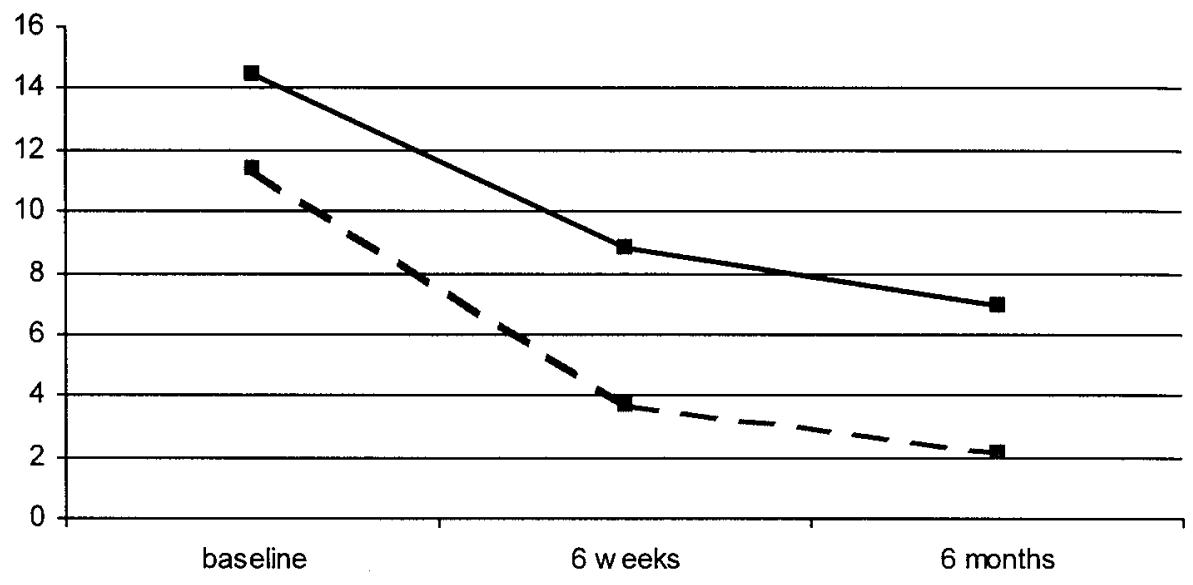

$\longrightarrow$ - perceived disability w ith high pain-related fear

-

Figure 6.2b Means of participation at baseline, 6 weeks and 6 months measurement divided in high (i.e. > mean TSK) and low (i.e. $\leq$ mean TSK) pain-related fear.

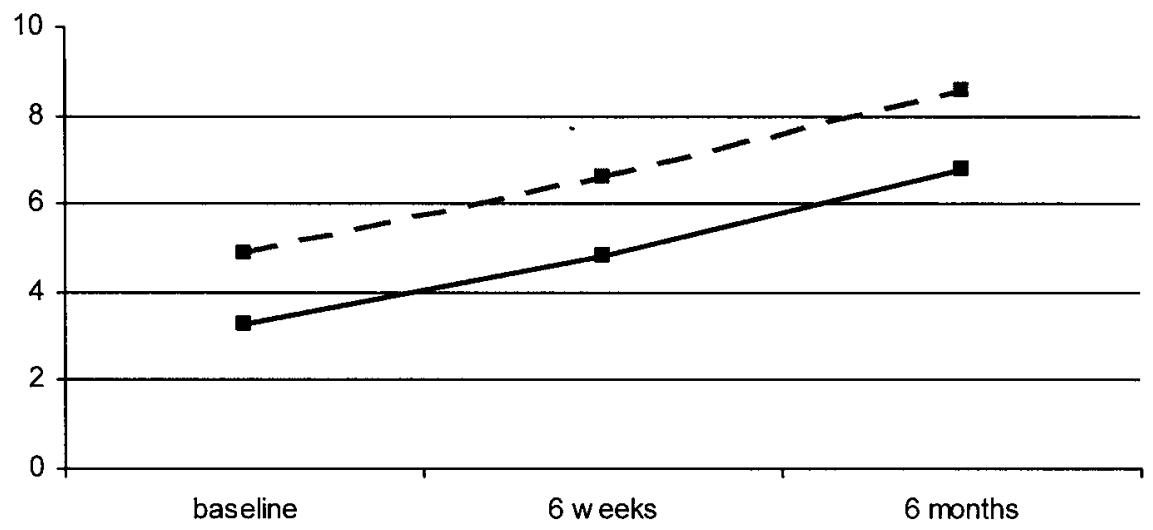

$\longrightarrow$ participation with high pain-related fear

- participation $w$ ith low pain-related fear 
disabled than patients with low fear of movement/(re)injury. A total of 32 individuals, who responded to be free of low back pain at 6 weeks measurement, had a relapse within 6 months. These persons were excluded from the final analyses to be absolutely certain that the data were not confounded by new episodes of LBP.

\section{Prediction of perceived disability and participation}

To examine which variables were predictive of levels of perceived disability and participation, multilevel analyses were performed. Tables 6.3 and 6.4 show the results of the regression analyses with perceived disability and participation as dependent variables respectively. Baseline fear of movement/(re)injury was the most powerful predictor of future perceived disability $(\beta=.23, p<.001)^{2}$. Besides fear of movement/(re)injury, age, duration, radiation, education, sports, and pain intensity contributed significantly to the prediction of follow-up perceived disability (table 6.3). Secondary analyses using the two subscales of the TSK as independent variable yielded comparable results (fear of harm: $\beta=.23, p<.001$; activity avoidance: $\beta=.16, p=, 007)$.

With perceived disability as outcome measure, there were no significant interaction effects among baseline measures of pain intensity, fear of movement/(re)injury, perceived disability, and time (Time*VAS1: $t=.44, p=.66$; Time*fear1: $\mathrm{t}=-.39, \mathrm{p}=.70$; Time* ${ }^{\star} \mathrm{dq} 1: \mathrm{t}=-.35, \mathrm{p}=.73$ ). This means that the prediction of these measures is stable during the follow-up time.

Table 6.3 Final results of the multilevel analyses with perceived disability as dependent variable.

\begin{tabular}{lcrrr}
\hline Independents & Standardized Beta & SE & t-value & p-value \\
\hline Age & .11 & .054 & 2.11 & .036 \\
Gender & -.02 & .051 & -.43 & .669 \\
Civil status & -.02 & .053 & -.41 & .685 \\
Education & .00 & .051 & .02 & .983 \\
Sport & -.10 & .050 & -1.97 & .050 \\
Duration & .15 & .055 & 2.73 & .007 \\
Radiation & .10 & .051 & 2.05 & .041 \\
Onset & -.07 & .054 & -1.29 & .198 \\
Preceding episodes & .10 & .052 & 1.96 & .052 \\
Baseline disability & .06 & .063 & 1.01 & .316 \\
Baseline pain intensity & .12 & .056 & 2.13 & .034 \\
Baseline fear of & .23 & .057 & 4.06 & $<.001$ \\
movement/(re)injury & $(.25)$ & $(.052)$ & $(4.89)$ & $(<.001)$ \\
\hline
\end{tabular}

The values between brackets are the results when baseline disability is not controlled for.

2 The relative risk (RR) of prolonged disability between patients with initial high or low fear of movement/(re)injury based on quartile scores of TSK was calculated. The RR was 1.54 (95\% Cl; 1.07-2.23), meaning that high fearful LBP patients are 1.54 times more at risk of prolonged disability than low fearful patients. 
With participation as outcome measure and controlling for baseline participation, fear of movement/(re)injury, pain intensity, education, duration, and radiation all showed comparable predictive power in predicting future participation (table 6.4).

Replacing in the equation the TSK total scores for the subscales "harm" or "activity avoidance" yielded comparable results. However, duration and radiation increased a little in predictive power $(\beta=-0.12, p=.002 ; \beta=-0.13, p=.001$ respectively). With participation as dependent variable, there was a significant interaction between baseline participation and Time $(t=-6.02, p<.001)$ for which was also controlled.

Summarizing these results show that fear of movement/(re)injury significantly predicted future perceived disability and together with several episode specific and demographic variables contributed to the prediction of future participation.

Table 6.4 Final results of the multilevel analyses with participation as dependent variable.

\begin{tabular}{|c|c|c|c|c|}
\hline Independents & Standardized Beta & SE & t-value & p-value \\
\hline Age & -.05 & .039 & -1.24 & .216 \\
\hline Gender & .05 & .038 & 1.23 & .220 \\
\hline Civil status & .06 & .039 & 1.51 & .132 \\
\hline Education & .10 & .039 & 2.57 & .011 \\
\hline Sport & .07 & .038 & 1.96 & .050 \\
\hline Duration & -.12 & .040 & -3.02 & .003 \\
\hline Radiation & -.12 & .037 & -3.29 & .001 \\
\hline Onset & .04 & .040 & 1.02 & .307 \\
\hline Preceding episodes & -.03 & .038 & -.881 & .379 \\
\hline Baseline pain intensity & -.09 & .039 & -2.41 & .016 \\
\hline Baseline fear of & -.10 & .039 & -2.55 & .011 \\
\hline movement/(re)injury & $(-.15)$ & $(.039)$ & $(-3.82)$ & $(<.001)$ \\
\hline Baseline participation & .35 & .049 & 7.12 & $<.001$ \\
\hline Time*baseline participation & -.29 & .048 & -6.02 & $<.001$ \\
\hline
\end{tabular}

The values between brackets are the results when baseline participation is not controlled for.

\section{Discussion}

To our knowledge, the present study is the first to examine prospectively the influence of fear of movement/(re)injury on the prediction of perceived disability and participation in a sample of acute LBP patients. Generally, the findings are in line with both cross-sectional $(9,39,49)$ and prospective investigations $(12,13,23,25)$ showing a close association between pain-related fear and perceived disability. Fear of movement/(re)injury was the most powerful predictor of future disability, even more powerful than baseline pain intensity. This is consistent with the study by Fritz et al. using a sample of patients with acute work-related LBP (12). In addition to perceived disability, the current study also included a measure of participation as dependent variable. Both variables (i.e., perceived disability and participa- 
tion) were predicted by a different set of independent variables, supporting the conceptual difference between perceived disability and participation $(39,55)$.

Education was a significant predictor for participation, but not for perceived disability. High educated persons may have higher work satisfaction $(17,41)$ or easier access to social activities than lower educated individuals, leading to a higher participation score. In predicting future perceived disability, the "harm" scale was more powerful than the "activity avoidance" subscale of the TSK. This corroborates the findings of previous studies using chronic pain samples, in which beliefs of danger expectancy or fear of (re)injury were positively associated with avoidance behaviour or disability $(8,9,48)$. This means that fear of harm is present early and consistently in a pain episode.

There are indications in the literature that pain-related fear is a predictive factor of the development of back pain problems $(25,33)$. Secondary analyses showed that the estimates of fear of movement/(re)injury were comparable irrespective of controlling for the baseline scores of the outcome measures. This result confirms that the effect of pain-related fear is associated with a prospective effect and was not realized prior to the baseline measurement.

Of further interest is that the clinical course of LBP in the current study is in accordance with recent prognostic studies showing that LBP does not always resolve itself when ignored $(16,31,51)$. Between six weeks and six months, the mean values of most of the measures used did not show much improvement. For example, Pengel et al. (32) found measures of pain and disability to decrease rapidly the first four weeks, but after three month there was no further decline in pain or disability, which might mean that a more chronic state of LBP was obtained.

Although this study used a large inception cohort and included both disability and participation as outcome measures, there are some limitations to the present study that need considering. First, the population included was quite heterogeneous, consisting of patients with and without previous episodes of LBP. If the definition of chronicity is characterized by an episodic, recurrent course (53), the sample might have been over represented with persons already having a chronic condition. However, the chance of including chronic cases was reduced by two main inclusion criteria: (1) having LBP for four weeks at most; and (2) having had a period of at least 3 month free of LBP before the current episode. Besides that, all susceptible cases of chronicity were excluded from further analyses. Second, the time-intervals are not of the same length. The time-intervals were chosen based on existing guidelines differentiating between acute, sub acute and chronic LBP. The six weeks measurement was chosen because of the sub acute phase of LBP $(2,11)$ and because the study by Klenerman et al.(23) showed that no recovery was found after 2 month of LBP. The six months measurement was chosen because literature suggests that pain and disability do not show any further decline after six months, which might be defined as a chronic state of back pain $(23,32)$. However, this depends on the definition of chronic LBP over which there is still 
much discussion $(11,43,50)$. The method of analyses used in this study allows variable time-intervals and it does not affect the results. Third, in the absence of a standardized and well-validated measure of participation, a new measure was developed consisting of five items (39). Reliability (39), as calculated with Cronbach's alpha was good ( $\alpha=0.85$ ). However, the significant interaction effect between baseline participation and time might be due to a reduced stability of the participation measure. Although face-validity was accomplished, the preliminary psychometrics of this new measure need to be further validated in future studies assessing in detail reliability and validity. Fourth, the measures used in the current study were all self-report measures and the results may thus reflect some shared method variance. Functional status was assessed by the RDQ, measuring disability as perceived by the patients, which is a commonly used and recommended outcome measure (5). However, combining both performance-based and selfreport measures of functional status and participation might obtain a more comprehensive picture of disability in patients with LBP (36). Fifth, the estimates of the various equations are quite low resulting in a low overall percentage of explained variance. This confirms that the prognosis of LBP depends on many, multidimensional, and interrelated factors $(26,42)$.

What are the clinical implications of these results? The present investigation found baseline fear of movement/(re)injury to be most powerful in predicting six months outcome of LBP. Besides pain-related fear, also pain-intensity and some demographic and episode specific variables were significantly related to follow-up LBP problems. This means that preventive actions should be focused on the reduction of both pain-related fear and pain, and fear of harm in particular. The TSK may be used as a useful screening tool for measuring pain-related fear in the early stage of LBP. Other reliable and valid screening questionnaires also exist that include items focusing on pain-related fear (26). Particularly, in the case of elevated scores, specific interventions may be considered in order to prevent perceived disability and restrictions in participation to develop, in this way possibly preventing a transition into a chronic, disabling pain condition $(14,22)$. Reassurance and the advice to return to normal activities as quickly possible, which are incorporated in national guidelines concerning $\operatorname{LBP}(2,4,28)$ may not be sufficient for patients reporting increased levels of pain-related fear $(20,44)$. Instead fear reduction techniques should be considered, and usually range from brief educational sessions $(6,7,30)$ to more intensive cognitive-behavioural approaches $(27,45-47)$. Our study corroborates the suggestion that successful reduction of fear of movement/(re)injury fosters increased activities and participation in daily and social life activities of patients with back pain. 


\section{Acknowledgements}

This research was partly supported by the Royal Dutch Physical Therapists Association. We thank the general practitioners and physical therapists for their assistance in including patients. The Netherlands Organization for Health Research and Development (ZonMw), supported participation of Dr. J. Vlaeyen with grant $\mathrm{nr}$. 904-65-090. 


\section{References}

1. Al Obaidi,S.M., Nelson,R.M., Al Awadhi,S., and Al Shuwaie,N. The role of anticipation and fear of pain in the persistence of avoidance behavior in patients with chronic low back pain. Spine 2000; 25 (9): 1126-1131.

2. Bekkering,G.E., Hendriks, H.J.M., Koes,B.W., Oostendorp,R.A.B., Ostelo,R.W.J.G., Thomassen,J., and Tulder,M.W.v. Dutch physiotherapy guideline for low back pain. Physiotherapy 2003; 89 (2): 82-96

3. Beurskens,A.J.H.M., Vet,H.C.W.d., and Koke,A. Responsiveness of functional status in low back pain: a comparison of different instruments. Pain 1996; 65 71-76.

4. Bigos,S.J., Bowyer,O.R., Braen,G.R., Brown,K.C., Deyo,R.A., and Haldeman,S. Acute Low back Problems in Adults. Clinical practice guideline nr 14. 1994; 14 1-25.

5. Bombardier,C. Outcome assessments in the evaluation of treatment of spinal disorders: summary and general recommendations. Spine 2000; 25 (24): 3100-3103.

6. Buchbinder,R., Jolley,D., and Wyatt,M. Population based intervention to change back pain beliefs and disability: three part evaluation. BMJ 2001; 322 (7301): 1516-1520

7. Burton,A.K., Waddell,G., Tillotson,K.M., and Summerton,N. Information and advice to patients with back pain can have a positive effect. A randomized controlled trial of a novel educational booklet in primary care. Spine 1999; 24 (23): 2484-2491.

8. Cipher,D.J. and Fernandez,E. Expectancy variables predicting tolerance and avoidance of pain in chronic pain patients. Behav Res Ther 1997; 35 (5): 437-444.

9. Crombez,G., Vlaeyen,J.W.S., Heuts,P.H.T.G., and Lysens,R. Pain-related fear is more disabling than pain itself. Evidence on the role of pain-related fear in chronic back pain disability. Pain 1999; $80(1,2)$ : 329-339.

10. Downie,W.W., Leatham,P.A., Rhind,V.M., Wright,V., Branco,J.A., and Anderson,J.A. Studies with pain rating scales. Annals of the Rheumatic Diseases 1978; 37 378-381.

11. Frank,J.W., Brooker,A., DeMaio,S.E., Kerr,M.S., Maetzel,A., Shannon,H.S., Sullivan,T.J., Norman,R.W., and Wells,R.P. Disability resulting from occupational low back pain. PART II: What do we know about secondary prevention? A review of the scientific evidence on prevention after disability begins. Spine 1996; 21 (24): 2918-2929.

12. Fritz,J.M. and George,S.Z. Identifying psychosocial variables in patients with acute workrelated low back pain: the importance of fear-avoidance beliefs. Phys Ther 2002; $82(10)$ : 973-983.

13. Fritz,J.M., George,S.Z., and Delitto,A. The role of fear-avoidance beliefs in acute low back pain: relationships with current and future disability and work status. Pain 2001; 94 (1): 7-15.

14. George,S.Z., Fritz,J.M., Bialosky,J.E., and Donald,D.A. The effect of a fear-avoidance-based physical therapy intervention for patients with acute low back pain: results of a randomized clinical trial. Spine 2003; 28 (23): 2551-2560.

15. Goubert,L., Crombez,G., Van Damme,S., Vlaeyen,J.W.S., Bijttebier,P., and Roelofs,J. Confirmatory factor analysis of the Tampa Scale for Kinesiophobia: invariant two-factor model across low back pain patients and fibromyalgia patients. Clin J Pain 2004;

16. Hestbaek,L., Leboeuf-Yde,C., and Manniche,C. Low back pain: what is the long-term course? A review of studies of general patient populations. Eur Spine J 2003; 12 (2): 149165.

17. Hoogendoorn,W.E., van Poppel,M.N., Bongers,P.M., Koes,B.W., and Bouter,L.M. Systematic review of psychosocial factors at work and private life as risk factors for back pain. Spine 2000; 25 (16): 2114-2125.

18. Jensen,M., Chen,C., and Brugger,A. Postsurgical pain outcome assessment. Pain 2002; 99 (1-2): 101-

19. Jensen,M.P. and Karoly,P. Self-report scales and procedures for assessing pain in adults. In Turk,D.C., Melzack,R. (eds) Handbook of Pain Assessment. The Guilford Press, New York. 1992; 135-151.

20. Keen,S., Dowell,A.C., Hurst,K., Klaber Moffett,J.A., Tovey,P., and Williams,R. Individuals with low back pain: how do they view physical activity? Fam Pract 1999; 16 (1): 39-45.

21. Kelly,A.M. The minimum clinically significant difference in visual analogue scale pain score does not differ with severity of pain. Emerg Med J 2001; 18 (3): 205-207. 
22. Klaber Moffett,J.A., Carr,J., and Howarth,E. High fear-avoiders of physical activity benefit from an exercise program for patients with back pain. Spine $2004 ; 29$ (11): 1167-1172.

23. Klenerman,L., Slade,P.D., Stanley,I.M., Pennie,B., Reilly,J.P., Atchison,L.E., Troup, J.D.G., and Rose,M.J. The prediction of chronicity in patients with an acute attack of low back pain in a general practice setting. Spine $1995 ; 20$ (4): 478-484.

24. Kopec,J.A. and Esdaile,J.M. Functional Disability Scales for back pain. Spine 1995; 20 (17): 1943-1949.

25. Linton,S.J., Buer,N., Vlaeyen,J.W.S., and Hellsing,A.L. Are fear-avoidance beliefs related to the inception of an episode of back pain? A prospective study. Psychology and Health 2000; 14 1051-1059.

26. Linton, S.J. and Hallden, K. Can we screen for problematic back pain? A screening questionnaire for predicting outcome in acute and subacute back pain. Clin J Pain 1998; 14 (3): 209215.

27. Linton,S.J., Overmeer,T., Janson,M., Vlaeyen,J.W.S., and de Jong,J. Graded in vivo exposure treatment for fear-avoidant pain patients with functional disability: a case study. Cognitive Behaviour Therapy 2002; 31 49-58.

28. Maher,C., Latimer,J., and Refshauge,K. Prescription of activity for low back pain: What works? Australian Physiotherapy 1999; 45 121-132.

29. Miller,R.P., Kori,S.H., and Todd,D.D. The Tampa Scale. 1991

30. Moore,J.E., Von Korf,M., Cherkin,D., Saunders,K., and Lorig,K. A randomized trial of a cognitive-behavioral program for enhancing back pain self care in a primary care setting. Pain 2000; 88 (2): 145-153.

31. Papageorgiou,A.C., Croft,P.R., Thomas,E., Ferry,S., Jayson,M.I., and Silman,A.J. Influence of previous pain experience on the episode incidence of low back pain: results from the South Manchester Back Pain Study. Pain 1996; 66 (2-3): 181-185.

32. Pengel,L.H., Herbert,R.D., Maher,C.G., and Refshauge,K.M. Acute low back pain: systematic review of its prognosis. BMJ 2003; $327(7410): 323-327$.

33. Picavet,H.S., Vlaeyen,J.W.S., and Schouten,J.S. Pain catastrophizing and kinesiophobia: predictors of chronic low back pain. Am J Epidemiol. 2002; 156 (11): 1028-1034.

34. Pincus, T., Burton,A.K., Vogel,S., and Field,A.P. A systematic review of psychological factors as predictors of chronicity/disability in prospective cohorts of low back pain. Spine $2002 ; 27$ (5): E109-E120.

35. Rasbach,J., Browne,W., Goldstein,H., Yang,M., Plewis,l., Healy,M., Woodhouse,G., Draper,D., Langford,l., and Lewis,T. A user's guide to MLwiN. Version 2.1d for use with MLwiN 1.10. 2002;

36. Reneman,M.F., Jorritsma,W., Schellekens,J.M., and Goeken,L.N. Concurrent validity of questionnaire and performance-based disability measurements in patients with chronic nonspecific low back pain. J Occup Rehabil 2002; 12 (3): 119-129.

37. Roland,M. and Morris, R. A study of the natural history of back pain, Part 1 \& Part 2: RolandMorris Disability Questionnaire. Spine 1983; (8): 141-150.

38. Stratford,P.W., Binkley,J.M., and Riddle,D.L. Development and initial validation of the back pain functional scale. Spine $2000 ; 25$ (16): 2095-2102.

39. Swinkels-Meewisse,E.J., Roelofs,J., Verbeek,A.L., Oostendorp,R.A., and Vlaeyen,J.W.S. Fear of movement/(re)injury, disability and participation in acute low back pain. Pain 2003; $105(1-2): 371-379$.

40. Swinkels-Meewisse,E.J., Swinkels,R.A., Verbeek,A.L., Vlaeyen,J.W.S., and Oostendorp, R.A. Psychometric properties of the Tampa Scale for kinesiophobia and the fear-avoidance beliefs questionnaire in acute low back pain. Man Ther 2003; 8 (1): 29-36.

41. Thomas,E., Silman,A.J., Croft,P.R., Papageorgiou,A.C., Jayson,M.I., and Macfarlane,G.J. Predicting who develops chronic low back pain in primary care: a prospective study. BMJ 1999; 318 (7199): 1662-1667.

42. Turk,D.C. The role of demographic and psychosocial factors in transition from acute to chronic pain. 1997; 1 (12): 185-214.

43. Verhaak,P.F.M., Kerssens,J.J., Dekker,J., Sorbi,M.J., and Bensing,J.M. Prevalence of chronic benign pain disorder among adults: a review of the literature. Pain 1998; 77 (3): 231239. 
44. Vlaeyen,J.W.S. Fear in Musculoskeletal Pain. 2003; 24: 631-650.

45. Vlaeyen,J.W.S., de Jong,J., Geilen,M., Heuts,P.H.T.G., and van Breukelen,G. Graded exposure in vivo in the treatment of pain-related fear: a replicated single-case experimental design in four patients with chronic low back pain. Behav Res Ther 2001; 39 (2): 151-166.

46. Vlaeyen,J.W.S., Jong,J.R.d., Geilen,M., Heuts,P.H.T.G., and Breukelen,G.v. The treatment of fear of movement/(re)injury in chronic low back pain: further evidence on the effectiveness of exposure in vivo. Clin J Pain 2002; 18 (4): 251-261.

47. Vlaeyen,J.W.S., Jong,J.R.d., Onghena,P., Kerckhoffs-Hanssen,M., and Kole-Snijders, A.M. Can pain-related fear be reduces? The application of cognitive-behavioural exposure in vivo. Pain Res Manag 2002; 7 (3): 144-153.

48. Vlaeyen,J.W.S., Kole-Snijders,A.M.J., Boeren,R.G.B., and Eek,H.v. Fear of movement/(re)injury in chronic low back pain and its relation to behavioral performance. Pain $1995 ; 62$ 363-372.

49. Vlaeyen,J.W.S., Kole-Snijders,A.M.J., Rotteveel,A.M., Ruesink,R., and Heuts,P.H.T.G. The role of fear of movement/(re)injury in pain disability. J Occup Rehabil 1995; 5 (4): 235-252.

50. Von Korff,M. Point of view. Spine 2000; 25 (7): 840-841.

51. Von Korff,M., Deyo,R.A., Cherkin,D.C., and Barlow,W. Back pain in primary care. Outcomes at 1 year. Spine 1993; 18 (7): 855-862.

52. Von Korff,M., Ormel,J., Keefe,F.J., and Dworkin,S.F. Grading the severity of chronic pain. Pain 1992; 50 133-149.

53. Von Korff,M. and Saunders,K. The Course of Back Pain in Primary Care. Spine 1996; 21 (24): 2833-2839.

54. Wewers,M.E. and Lowe,N.K. A critical review of visual analogue scales in the measurement of clinical phenomena. Res Nurs Health 1990; 13 (4): 227-236.

55. World Health Organization. International Classification of Functioning, Disabilities and Health Problems. 2001. 


\section{Chapter 7}

\section{Acute low back pain: pain-related fear and pain catastrophizing influence physical performance and perceived disability}

Ilse E.J. Swinkels-Meewisse, Jeffrey Roelofs, Rob A.B. Oostendorp, André L.M. Verbeek, Johan W.S. Vlaeyen

\section{Published as}

Ilse E.J. Swinkels-Meewisse, Jeffrey Roelofs, Rob A.B. Oostendorp, André L.M. Verbeek, Johan W.S. Vlaeyen. Acute low back pain: pain-related fear and pain catastrophizing influence physical performance and perceived disability. Pain, 2006 ; 120 (1-2): 36-43. 


\begin{abstract}
Pain-related fear and pain catastrophizing are associated with disability and actual performance in chronic pain patients. In acute low back pain (LBP), little is known about the prediction of actual performance or perceived disability by pain-related fear and pain catastrophizing. This experimental, cross-sectional study aimed at examining whether pain-related fear and pain catastrophizing were associated with actual performance and perceived disability. 96 individuals with an episode of acute LBP performed a dynamic lifting task to measure actual performance. Total lifting time was used as outcome measure. The results show that pain-related fear, as measured with the Tampa Scale for Kinesiophobia, was the strongest predictor of this physical task. Using the Roland Disability Questionnaire as a measure of perceived disability, both pain-related fear and pain catastrophizing, as measured with the Pain Catastrophizing Scale, were significantly predictive of perceived disability and more strongly than pain intensity was. The results of the current study suggest that pain-related fear is an important factor influencing daily activities in individuals suffering an episode of acute LBP. The study results have important clinical implications, especially in the development of preventive strategies for chronic LBP.
\end{abstract}




\section{Introduction}

In the past decades, disability due to low back pain (LBP) has become an increasing socio-economic problem $(22,50)$. The individual and societal impact of chronic LBP and the knowledge that LBP has a less favourable natural course than formally believed $(13,26)$, has made the prevention of chronicity a major issue in public health decision making. The influence of psychological factors seems increasingly important in the transition from acute to chronic $\operatorname{LBP}(6,18,19,21,29,60)$. In particular, pain-related fear and pain catastrophizing are believed to be important factors for disability. A number of studies have shown that pain-related fear is a strong predictor of self-reported disability in both acute and chronic LBP $(8,9,19,35,43,44,56,58)$. Several studies support the notion that in patients with chronic LBP pain-related fear is significantly associated with restricted physical performance $(1,8,10,55)$. However, the influence of pain-related fear as a predictor of poor physical performance in acute LBP has yet to be investigated.

Pain catastrophizing refers to an exaggerated negative interpretation of pain, which might occur during actual or anticipated pain experience (40). Pain catastrophizing is shown to be associated with increased levels of pain intensity and disability in chronic pain population as well as in the open population $(4,27,28,33$, $34,38,42,46,47)$. There is some evidence to suggest that pain catastrophizing influences disability via pain-related fear as presented in a cognitive-behavioural model of chronic pain $(7,23,25,55)$. Studies investigating cognitive-behavioural interventions attempting to modify pain-related fear and/or catastrophizing are generally in favour of this hypothesis $(36,39,53)$. Research concerning the relation between catastrophizing, pain-related fear and disability has mostly been performed in populations with chronic pain disorders, using perceived disability as the outcome measure. However, to the authors' best knowledge, there are no studies investigating the association between catastrophizing and pain-related fear on the one hand, and physical task performance and perceived disability on the other hand, in a population of patients with an episode of acute LBP. Therefore, the main aim of the current study is to investigate which factors are associated with the performance of a physical task in a sample of persons with an episode of acute LBP. A second goal is to study which factors are associated with more general perceived disability. It is hypothesized that both pain catastrophizing and painrelated fear are stronger predictors of performance and perceived disability than pain severity or socio-demographics.

\section{Methods}

\section{STUDY SAMPLE AND METHODOLOGY}

Between March and December 2004, general practitioners and physiotherapists in the southeast region of The Netherlands recruited 96 individuals experiencing an 
acute episode of LBP. An episode of acute LBP was defined as LBP with a duration of at most four weeks with a pain free period of at least three months preceding the current episode. Inclusion criteria were: age between 18 and 65 with nonspecific LBP independent of radiation. Criteria for exclusion were: illiteracy; specific LBP (e.g. tumours, trauma, infection, inflammatory disorders); presence of malignancies; operations in the lumbar area; or pregnancy. During the first consultation for LBP, the general practitioner or physiotherapist requested the patients to participate in the study. Persons who agreed to participate were contacted within two days to make an appointment. All measurements were performed at the patient's home to ensure ecological validity. During the home visit, the participants signed the informed consent and completed a set of questionnaires in the presence of the researcher. After completion of the questionnaires the physical task was explained to the participant in a standardized way (see physical task). At the end of the visit, patients were given a booklet with information concerning LBP, thanking them for their participation. Participants did not receive incentives in turn for their participation. The Advisory Committee on Ethics of the Maastricht University approved the experimental protocol of this study.

\section{PHYSICAL TASK}

The physical task consisted of lifting a bag with $7 \mathrm{~kg}$ from the floor, on and off a table and on the floor again with a height of approximately 75 centimetres. A maximum of standardization was pursued by using the same bag and explaining the task on a standardized way. Participants were free in the way they performed the lifting task, but the bag had to be lifted with two hands simultaneously, without pauses. The total lifting time (maximum time $=300$ seconds) and the number of lifting bouts were recorded. This physical task was chosen because of its ecological value in daily activities. Both men and women are considered having sufficient experience in performing various lifting tasks in daily life. Furthermore, the task was expected to be sufficiently threatening for individuals with back pain, irrespective of their level of pain-related fear.

\section{MEASURES}

\section{Demographic variables}

A questionnaire was completed covering various socio-demographical characteristics (i.e. age, gender, education level, sick-leave, and sport activities), and questions regarding the current and/or preceding back pain episodes (i.e. duration, radiation, onset, and numbers of preceding episodes).

\section{Pain intensity}

Current pain intensity was measured on a horizontal $100 \mathrm{~mm}$ visual analogue scale (VAS) anchored with the words "no pain", on the left side and "worst imagin- 
able pain", on the right side. Furthermore, maximum and mean pain intensity for the previous two days were measured with a VAS.

\section{Functional status}

A Dutch version of the Roland Disability Questionnaire (RDQ; $(2,32)$ was used to measure the functional status in LBP. The RDQ is a 24-items questionnaire with a dichotomous scoring format; yes ( $=$ item is applicable), or no ( $=$ item is not applicable). Total scores can vary from 0 (no disability) to 24 (severe disability). Reliability and validity of the measure were established $(32,37)$.

\section{Pain-related fear}

A Dutch version of the Tampa scale for Kinesiophobia (TSK; $(24,55)$ was used. The TSK is a 17-item self-report questionnaire measuring fear of movement or (re) injury. Items are scored on a 4-point Likert scale ranging from 'strongly disagree' (score=1) to 'strongly agree' (score=4). Items 4, 8, 12, and 16 are reversibly scored. In a population of acute LBP patients, the TSK exists of two subscales: a harm subscale (TSK-harm, items $3,5,6,9,11$, and 15), reflecting the beliefs that there is something seriously wrong with the body, encompassing both the danger and injury items; and an activity avoidance subscale (TSK-activity avoidance, items $1,2,7,10,13,14$, and 17), indicating the beliefs that avoiding exercise or activities might prevent an increase of pain (44). The reliability of the TSK in a population with an acute LBP episode, as measured with the internal consistency and test-retest stability, varies between $\alpha=0.70$ and $\alpha=0.80$, and $r=0.78$ to 0.79 , respectively (45).

\section{Pain catastrophizing}

A Dutch version of the Pain Catastrophizing Scale (PCS) was used (41). The PCS exists of 13 items and was developed to measure exaggerated negative thoughts that might occur during actual or anticipated pain experience. Items are scored on a 5-points scale ranging from 0 (totally disagree) to 4 (totally agree). Beside the overall scale (range 0-52), three subscales can be obtained: a rumination subscale, a helplessness subscale, and a magnification subscale (48). The Dutch version of the PCS is a valid and reliable measurement instrument (48).

\section{Threat control}

To investigate the threat value of the lifting task, 5 pictures of the Photographs series of Daily Activities (PHODA) were shown (20). These pictures were chosen because in a previous study, they discriminated well between high and low fearful subjects (Peters $M$, unpublished data). According to data from this unpublished previous study, the 5 pictures might arbitrarily be divided in two pictures with highly feared activities $\left(V A S_{\text {threat }} \geq 60\right.$ ), one photograph with a moderately feared activity $\left(40 \leq\right.$ VAS $\left._{\text {threat }}<60\right)$, and two with low feared activities $\left(V^{\prime} S_{\text {threat }}<40\right)$. Patients were asked to score on a $100 \mathrm{~mm}$ VAS how concerned they were that the 
shown activity would (re)injure their back. Furthermore, before actually performing the physical task, the participants were asked to rate their concern of re/injuring their low back regarding the current lifting task on a VAS. It was hypothesized that the physical task would be moderately threatening in persons with an acute episode of LBP.

\section{Statistical analyses}

Zero-order correlations between all measures were calculated. Univariate analysis of variance was used to investigate differences in dichotomous demographical and episode related variables with respect to pain-related fear, pain catastrophizing, perceived disability and lifting time. To investigate the extent to which pain-related fear and pain catastrophizing were associated with physical performance and perceived disability, hierarchical linear regression analyses were performed with lifting time and RDQ score as dependent variables. In the first step demographic variables and pain intensity were entered. In the second step, pain-related fear and pain catastrophizing were independently added. Outliers, defined as an extremely high score on PCS and/or TSK (mean + 2SD) in combination with maximum lifting time (300 sec), were excluded from the sample.

\section{Results}

\section{Descriptive data}

Participants were 96 patients with a new back pain episode. Patients included by physiotherapists or general practitioners did not differ significantly on demographic variables, pain-related fear, pain catastrophizing, or outcome measures. Three participants were excluded from the analyses, one because of age ( $>65$ years), one as a result of improper performance of the lifting task, and one because helshe was an outlier (i.e.: TSK total score $=52$ and lifting time was 300 s). Of the remaining 93 participants, the mean age was 44.8 years $(S D=11.5)$ with $52 \%$ being female $(n=48) .51 .6 \%$ of the participants had a high education (more than 13 years education) and $50.5 \%$ of the patients were engaged in sport activities. Concerning the current LBP episode, the mean duration was 11.6 days ( $S D=7.6)$. Of this sample, $21 \%$ experienced a first episode of LBP, $56 \%$ had experienced $0-7$ preceding episodes, and $23 \%$ had more than 7 preceding episodes of LBP. There were no significant differences between persons with or without previous episodes on lifting time, pain-related fear, pain catastrophizing, perceived disability, or demographic variables. Moreover, $53.8 \%$ of the patients experienced radiating pain in the leg, and in $74.2 \%$ of the cases the LBP had a sudden onset. Table 7.1 shows the means, standard deviations and correlations between disability, current pain intensity, pain-related fear, pain catastrophizing, and lifting time. Both pain catastrophizing and pain-related fear were significantly associated with disability. Lifting time was normally distributed (Kurtosis $=0.66$; Skewness $=-0.35$ ) and corre- 
lated significantly with disability, pain-related fear, and pain catastrophizing, but the associations were modest. Pain intensity was modestly correlated with disability only.

Table 7.1 Mean, standard deviation, and zero-order correlations between current pain intensity, disability, pain catastrophizing, pain-related fear, and lifting time.

\begin{tabular}{llrrrrrr}
\hline & Mean & SD & 1 & 2 & 3 & 4 \\
\hline 1 & Pain intensity (0-100) & 40.1 & 27.7 & & & & \\
2 & Disability (RDQ: 0-24) & 12.3 & 4.7 & $.34^{\star *}$ & & & \\
3 & Pain catastrophizing & 18.8 & 12.0 & .18 & $.48^{\star *}$ & & \\
& $\begin{array}{l}\text { (PCS: 0-52) } \\
4\end{array}$ & & & & & & \\
& Pain-related fear (TSK: $17-$ & 37.4 & 7.3 & .15 & $.43^{\star *}$ & $.44^{\star *}$ & \\
& 68) & & & & & & \\
5 & Lifting time (0-300 sec) & 114.0 & 77.0 & -.19 & $-.35^{* \star}$ & $-.26^{*}$ & $-.27^{\star}$ \\
\hline
\end{tabular}

${ }^{\star} P<0.05 ;{ }^{\star} P_{0}<0.001 ;$ In parenthesis are the minimum and maximum score of the measurement instruments.

There was a significant difference in lifting time between men and women (mean difference: 40.7 secs., $t=-2.57, p=0.012$ ), and between high and low educated individuals (mean difference 33.3 secs., $t=-2.08, p=.041$ ), with men and highly educated persons having longer lifting times. There were no significant differences between dichotomous demographical or episode specific variables, and total scores on pain intensity, pain-related fear, pain catastrophizing, and disability.

\section{Threat control}

The participants scored high (mean $V_{A S} S_{\text {threat }}: 75.6$; SD:23.2), moderate (mean $V S_{\text {threat }}: 41.5$; SD:27.4), and low (mean $V A S_{\text {threat }}: 28.0$; SD:25.5) on the photographs of high, moderate, and low feared activities, respectively. As expected, patients scored moderately (mean $V S_{\text {threat }}: 43.5 ;$ SD:30.7) when asked to rate their concern about the lifting task used in the current study. The mean difference between high and low fearful participants on the VAS $_{\text {threat }}$ of the physical task was $29.0(t=4.49, p<.001)$. From these results, it may be concluded that the chosen physical task was sufficiently threatening and discriminated well between high and low fearful persons in this sample.

\section{Prediction of physical performance}

Hierarchical linear regression analysis with pain intensity, and pain-related fear as independent variables, controlling for the effects of demographic variables, indicated that performance of the physical task (i.e. lifting time) was significantly predicted by pain-related fear $(\beta=-0.27, p=0.021)$. Educational level was the only demographic variable predicting lifting time $(\beta=0.23, p=0.043)$. Regression analysis with pain catastrophizing as independent variable showed that education was 
Table 7.2 Results of hierarchical regression analysis with lifting time as dependent variable and demographic variables, pain intensity and pain-related fear as independent variables.

\begin{tabular}{|c|c|c|}
\hline & Stand. $\beta$ & p-value \\
\hline \multicolumn{3}{|l|}{ Step 1} \\
\hline \multicolumn{3}{|l|}{$R 2=0.09, F=1.87, p=0.071$} \\
\hline Age & 0.09 & 0.410 \\
\hline Gender & 0.17 & 0.148 \\
\hline Sports & -0.03 & 0.799 \\
\hline Duration & -0.14 & 0.243 \\
\hline Radiation & 0.06 & 0.612 \\
\hline Onset & -0.01 & 0.955 \\
\hline Preceding episodes & -0.12 & 0.302 \\
\hline Education & 0.26 & 0.024 \\
\hline Pain intensity (VAS) & -0.23 & 0.047 \\
\hline \multicolumn{3}{|l|}{ Step 2a } \\
\hline \multicolumn{3}{|l|}{$R 2=0.15, F=5.54, p=0.021$} \\
\hline Age & 0.05 & 0.652 \\
\hline Gender & 0.21 & 0.060 \\
\hline Sports & -0.03 & 0.773 \\
\hline Duration & -0.13 & 0.283 \\
\hline Radiation & 0.12 & 0.308 \\
\hline Onset & -0.05 & 0.659 \\
\hline Preceding episodes & -0.05 & 0.692 \\
\hline Education & 0.23 & 0.043 \\
\hline Pain intensity (VAS) & -0.20 & 0.072 \\
\hline Pain-related fear (TSK) & -0.27 & 0.021 \\
\hline \multicolumn{3}{|l|}{ Step $2 b^{\star}$} \\
\hline \multicolumn{3}{|l|}{$R 2=0.18, F=8.33, p=0.005$} \\
\hline Age & 0.05 & 0.673 \\
\hline Gender & 0.20 & 0.075 \\
\hline Sports & -0.03 & 0.775 \\
\hline Duration & -0.11 & 0.333 \\
\hline Radiation & 0.10 & 0.393 \\
\hline Onset & -0.05 & 0.689 \\
\hline Preceding episodes & -0.08 & 0.474 \\
\hline Education & 0.24 & 0.033 \\
\hline Pain intensity (VAS) & -0.18 & 0.106 \\
\hline Pain-related fear (TSK-activity avoidance) & -0.31 & 0.005 \\
\hline
\end{tabular}

'Analysis with TSK-harm in the second step did not yield significant results and was left out of the table. 
the only significant variable associated with lifting time (education: $\beta=0.26,95 \%$ $\mathrm{Cl}=0.03-0.47, \mathrm{p}=0.024$ ). Secondary analyses were performed to investigate the contribution of the subscales of the TSK in the association with lifting. Analysis with TSK-harm or TSK-activity avoidance showed that only TSK-activity avoidance was significantly associated with lifting time $(\beta=-0.31 ; p=0.005)$, increasing the explained variance from $9 \%$ to $17.6 \%(F=8.33, p=0.005)$. Results of the remaining variables were almost identical. Table 7.2 shows the results of the analyses.

\section{Prediction of perceived disability}

Linear regression analysis, controlling for demographic variables, with pain intensity, and pain-related fear as independent variables indicated that perceived disability (i.e. RDQ) was significantly predicted by pain-related fear $(\beta=0.35 ; p=0.003)$ and current pain intensity $(\beta=0.27 ; p=0.012)$. Secondary analyses with TSK-harm and TSK-activity avoidance in the equation showed comparable results (see table 7.3 , step $2 b$ and $2 c$ ). Regression analyses with pain catastrophizing in the equation revealed that both pain catastrophizing $(\beta=0.40 ; p<0.001)$ and pain intensity $(\beta=0.26 ; p=0.012)$ were significantly associated with perceived disability (see table 7.4).

\section{Discussion}

The present experimental study provides a first attempt to examine the role of pain-related fear and pain catastrophizing in the prediction of a physical task in a sample of individuals with an episode of acute LBP. Furthermore, we investigated to what extent pain-related fear and pain catastrophizing were associated with perceived disability. In predicting the performance of a lifting task, pain-related fear, as measured with the Tampa Scale for Kinesiophobia, was the strongest predictor. However, both pain catastrophizing and pain-related fear, together with pain intensity were significantly related to perceived disability. Studies investigating pain catastrophizing or pain-related fear as predictors of performance or perceived disability mostly used chronic pain samples investigating either the influence of catastrophizing or pain-related fear. There are few studies investigating both pain-related fear and pain catastrophizing in the prediction of perceived or actual disability. The study of Crombez et al. (8) studied the role of both pain catastrophizing and pain-related fear (measured with the TSK) with performance as outcome measure. In line with the current study, their results indicated that pain-related fear was a better predictor of performance than were pain intensity or pain catastrophizing. However, the study of Crombez et al. used a small sample of chronic back pain patients $(n=31)$ and the physical task (i.e. lifting a $5.5 \mathrm{~kg}$ bag with the dominant arm and hold it as long as possible) differed from the lifting task used in the present study. Initially, we wanted to replicate the study of Crombez et al. (8) and Vlaeyen et al. (55) using the same task but using a population of acute 
Table 7.3 Results of hierarchical regression analysis with perceived disability as dependent variable and demographic variables, pain intensity and pain-related fear as independent variables.

\begin{tabular}{|c|c|c|}
\hline & Stand. $\beta$ & p-value \\
\hline \multicolumn{3}{|l|}{ Step $1 \quad R^{2}=0.10, F=2.07, p=0.043$} \\
\hline Age & -0.22 & 0.838 \\
\hline Gender & -0.81 & 0.456 \\
\hline Sports & -0.02 & 0.862 \\
\hline Duration & -0.15 & 0.220 \\
\hline Radiation & 0.13 & 0.264 \\
\hline Onset & -0.13 & 0.240 \\
\hline Preceding episodes & 0.14 & 0.207 \\
\hline Education & 0.05 & 0.625 \\
\hline Pain intensity (VAS) & 0.31 & 0.007 \\
\hline \multicolumn{3}{|l|}{ Step 2a $R^{2}=0.20, F=9.8, p=0.003$} \\
\hline Age & 0.03 & 0.763 \\
\hline Gender & -0.14 & 0.173 \\
\hline Sports & 0.01 & 0.893 \\
\hline Duration & -0.17 & 0.147 \\
\hline Radiation & 0.06 & 0.600 \\
\hline Onset & -0.06 & 0.571 \\
\hline Preceding episodes & 0.05 & 0.637 \\
\hline Education & 0.10 & 0.364 \\
\hline Pain intensity (VAS) & 0.27 & 0.012 \\
\hline Pain-related fear (TSK-total) & 0.35 & 0.003 \\
\hline \multicolumn{3}{|l|}{ Step $2 b \quad R^{2}=0.23, F=3.4, p=0.001$} \\
\hline Age & 0.02 & 0.842 \\
\hline Gender & -0.12 & 0.238 \\
\hline Sports & -0.01 & 0.938 \\
\hline Duration & -0.18 & 0.111 \\
\hline Radiation & 0.11 & 0.311 \\
\hline Onset & -0.12 & 0.272 \\
\hline Preceding episodes & 0.09 & 0.411 \\
\hline Education & 0.16 & 0.123 \\
\hline Pain intensity (VAS) & 0.23 & 0.030 \\
\hline Pain-related fear (TSK-activity avoidance) & 0.32 & 0.003 \\
\hline \multicolumn{3}{|l|}{ Step 2c $R^{2}=0.19, F=3.00, p=0.004$} \\
\hline Age & -0.00 & 0.982 \\
\hline Gender & -0.13 & 0.212 \\
\hline Sports & -0.00 & 0.984 \\
\hline Duration & -0.16 & 0.157 \\
\hline Radiation & 0.08 & 0.459 \\
\hline Onset & -0.11 & 0.361 \\
\hline Preceding episodes & -0.00 & 0.987 \\
\hline Education & 0.15 & 0.148 \\
\hline Pain intensity (VAS) & 0.28 & 0.009 \\
\hline Pain-related fear (TSK-harm) & 0.28 & 0.021 \\
\hline
\end{tabular}


Table 7.4 Results of hierarchical regression analysis with perceived disability as dependent variable and demographic variables, pain intensity and pain catastrophizing as independent variables.

\begin{tabular}{lcc}
\hline Independents & Stand. $\beta$ & -value \\
\hline Step 1 & & \\
$\mathrm{R}^{2}=0.10 ; \mathrm{F}=2.07 ; \mathrm{p}=0.043$ & & \\
Age & -0.22 & 0.838 \\
Gender & -0.81 & 0.456 \\
Sports & -0.02 & 0.862 \\
Duration & -0.15 & 0.220 \\
Radiation & 0.13 & 0.264 \\
Onset & -0.13 & 0.240 \\
Preceding episodes & 0.14 & 0.207 \\
Education & 0.05 & 0.625 \\
Pain intensity (VAS) & 0.31 & 0.007 \\
\hline Step 2 & & \\
$\mathrm{R}^{2}=0.23 ;$ F=14.1; $\mathrm{p}<0.001$ & & \\
\hline Age & 0.03 & 0.742 \\
Gender & -0.04 & 0.676 \\
Sports & -0.03 & 0.742 \\
Duration & -0.19 & 0.088 \\
Radiation & 0.04 & 0.696 \\
Onset & -0.10 & 0.353 \\
Preceding episodes & -0.00 & -0.987 \\
Education & 0.09 & 0.393 \\
Pain intensity (VAS) & 0.26 & 0.012 \\
Pain catastrophizing (PCS) & 0.40 & $<0.001$ \\
\hline
\end{tabular}

rather than chronic LBP patients and using a higher sample size. However, the results of a pilot study showed a clear ceiling effect of the lifting time. In addition to the ceiling effect, continually lifting a weight while standing still might be less ecologically valid than a more dynamic task. The current performance task (dynamically lifting a bag from the floor on and of a table) resulted in two possible outcome measures, i.e. number of lifts and lifting time. The authors have chosen lifting time as main performance measure because of the better comparability with previous studies $(8,55)$ and because the data of the number of lifts were skewed.

Generally the results of the current study are in line with investigations using chronic pain patients $(1,5,14,27,31,49,51,55)$ or in the open population (4). Prior studies in a sample of individuals with an episode of acute LBP found pain-related fear to be a significant predictor of perceived (future) disability $(43,44)$. However, these investigations used self-report measures that are susceptible to shared method variance. This might also explain why, in the present investigation, pain catastrophizing significantly predicted perceived disability, whereas it lacked significance in predicting actual performance. Besides that, pain-related fear (resulting in avoidance behaviour) is more proxy to actual performance of a moderately 
feared activity than is pain catastrophizing. Investigating disability using an actual performance measure seems to be more robust. Taking only pain catastrophizing into account, the results of this study are in contradiction with the investigation of Sullivan et al. (38) who found pain catastrophizing to be significantly predictive of performance even after controlling for pain intensity, whereas in the current study neither catastrophizing nor pain intensity were significantly associated with performance. The difference might be accounted for by the difference in methodology and performance task. Sullivan et al. studied healthy sedentary students, inducing muscle soreness by a strenuous repeated lifting task.

Secondary analyses in the current study with the TSK subscales 'harm' and 'activity avoidance' in the equation yielded comparable results with previous studies using these TSK factors $(10,43,44)$. Geisser et al. studied the influence of the TSK subscales on the outcome of two functional tests in a sample of chronic back pain patients. Swinkels-Meewisse et al. investigated the TSK factors as predictors of perceived disability in a population with an episode of acute LBP. From the current study and previous literature one might conclude that the activity avoidance subscale is the strongest predictor of both self reported disability and performance. According to Vlaeyen's cognitive behavioural model $(56,57)$, it is proposed that fear plays a strong role in the initial development of disability whereas activity avoidance plays a significant role in maintaining chronic pain disability. Therefore, one would expect the harm subscale to be significantly related to functional activity in a acute sample, rather than the TSK-activity avoidance. This might raise some questions about the significance of the items on the TSK that measure 'harm'. Although the construct validity of the total TSK was established, the validity of the subscales have yet to be investigated. A possible explanation of the activity avoidance factor being a more powerful predictor of functional activity than the TSK-harm subscale, might be that activity avoidance is more proxy to actual performance than are items regarding possible (re)injury. This means that activity avoidance moderated the association between fear of (re)injury (TSK-harm) and functional activities. However, this hypothesis has yet to be investigated.

In sum, the results of the current study are in line with existing literature concerning pain-related fear showing that pain-related fear is significantly associated with perceived disability and actual performance in chronic pain patients.

There are some limitations in the present study that need considering: First, the cross-sectional character of this study does not permit causal inferences regarding the associations found. To examine causality, one should manipulate pain-related fear and pain catastrophizing to study the effects on performance. Second, the measurements were performed at the patients' home. Although this might have resulted in a loss of standardization, the authors believe that the measurement favours ecological validity. To ensure standardization, each measurement the same bag was used and the task was explained in a standardized way. Participants were blinded for their scores on the physical task. Third, although gender, age, and sports activities were controlled for in the regressions, 
individual differences in muscle strength or body mass index, which likely influence task performance, were not controlled for. This might have influenced the results. Fourth, individuals (i.e. researchers or partners) in contact with patients might have beliefs that impact on the participant, unintentionally effecting performance or completion of questionnaires $(15,16)$. In order to diminish as much as possible interaction with other persons, measurements were performed without any significant others in the neighbourhood, the researchers were blinded for the scores on the questionnaires, and they were asked not to respond to any pain behaviour of the patient, and to give no feedback concerning the beliefs of the patient or the performance of the task. Fifth, the mean current pain intensity seems somewhat low compared with other studies on acute LBP patients $(9,12,44,59)$. This low pain intensity might have caused the non-significant prediction of performance by pain intensity. Viewing the mean maximum pain intensity this relatively low current pain intensity might be the result of the favourable natural course of LBP in the first four weeks after onset (26). Finally, the present study used a single physical task due to logistical reasons. This means that no conclusions can be substantiated concerning overall actual disability (30), but together with the comparable results of studies using various physical tasks in chronic pain patients, the current study might indicate that pain-related fear is associated with actual disability.

The present study supports the finding that pain-related fear, as measured with the TSK, is present early in an episode of $\operatorname{LBP}(4,9,11,44)$ and is a strongly associated with functional status in an acute LBP episode. This is in line with the cognitive-behavioural model of fear of movement/(re)injury (55). This model conceptualises the process of developing chronic disabling pain, ascribing a major role to catastrophic misinterpretations of painful sensations and pain-related fear. In patients with an acute LBP episode the TSK might be used as a screening instrument identifying persons with elevated pain-related fear scores. Fear-reducing information, education or interventions designed to reduce pain-related fear should be incorporated early, possibly preventing long lasting disability. Applying exposure-based interventions such as graded exposure, in individuals with elevated levels of pain-related fear have shown to positively affect patients beliefs and avoidance behaviour, fostering increased activity and possibly preventing the transition to chronic LBP $(3,17,52-54)$. 


\section{Acknowledgements}

We thank the general practitioners and physical therapists for their assistance in including patients. The authors wish to thank Madelon Peters for her permission to use the PHODA data of chronic LBP patients and Raymond Swinkels, Kim Kugler, and Sven Balk for data-collection. Participation of Dr. J. Vlaeyen was supported by the Netherlands Organization for Health Research and Development (ZONMW), grant nr. 904-65-090.

We thank the reviewers for their careful reading of the manuscript and their thoughtful comments on an earlier draft. 


\section{References}

1. Al Obaidi,S.M., Nelson,R.M., Al Awadhi,S., and Al Shuwaie,N. The role of anticipation and fear of pain in the persistence of avoidance behavior in patients with chronic low back pain. Spine 2000; $25(9): 1126-1131$.

2. Beurskens,A.J.H.M., Vet,H.C.W.d., and Koke,A. Responsiveness of functional status in low back pain: a comparison of different instruments. Pain 1996; 65 71-76.

3. Boersma,K., Linton,S., Overmeer,T., Jansson,M., Vlaeyen,J.W.S., and de Jong,J. Lowering fear-avoidance and enhancing function through exposure in vivo. A multiple baseline study across six patients with back pain. Pain 2004; 108 (1-2): 8-16.

4. Buer,N. and Linton, S.J. Fear-avoidance beliefs and catastrophizing: occurrence and risk factor in back pain and ADL in the general population. Pain 2002; 99 (3): 485-491.

5. Burns,J.W., Mullen,J.T., Higdon,L.J., Wei,J.M., and Lansky,D. Validity of the Pain Anxiety Symptoms Scale (PASS): prediction of physical capacity variables. Pain 2000; 84 (2-3): 247252.

6. Croft,P.R., Papageorgiou,A.C., Ferry,S., Thomas,E., Jayson,M.I.V., and Silman,A.J. Psychologic Distress and Low Back Pain: Evidence from a prospective study in the general population. Spine 1995; 20 (24): 2731-2737.

7. Crombez,G., Eccleston,C., Baeyens,F., and Eelen,P. When somatic information threatens, catastrophic thinking enhances attentional interference. Pain 1998; 75 (2-3): 187-198.

8. Crombez,G., Vlaeyen,J.W.S., Heuts,P.H.T.G., and Lysens,R. Pain-related fear is more disabling than pain itself. Evidence on the role of pain-related fear in chronic back pain disability. Pain 1999; 80 (1,2): 329-339.

9. Fritz,J.M. and George,S.Z. Identifying psychosocial variables in patients with acute workrelated low back pain: the importance of fear-avoidance beliefs. Phys Ther 2002; $82(10)$ : 973-983.

10. Geisser,M.E., Haig.A.J., and Theisen,M.E. Activity avoidance and function in persons with chronic back pain. J Occup Rehabil 2000; 10 (3): 215-227.

11. Grotle,M., Vollestad,N.K., Veierod,M.B., and Brox,J.I. Fear-avoidance beliefs and distress in relation to disability in acute and chronic low back pain. Pain 2004; 112 (3): 343-352.

12. Haas,M., Nyiendo,J., and Aickin,M. One-year trend in pain and disability relief recall in acute and chronic ambulatory low back pain patients. Pain 2002; 95 (1-2): 83-91.

13. Hestbaek,L., Leboeuf-Yde,C., Engberg,M., Lauritzen,T., Bruun,N.H., and Manniche,C. The course of low back pain in a general population. Results from a 5 -year prospective study. $J$ Manipulative Physiol Ther. 2003; 26 (4): 213-219.

14. Heuts,P.H.T.G., Vlaeyen,J.W.S., Roelofs,J., de Bie,R.A., Aretz,K., van Weel,C., and van Schayck,O.C. Pain-related fear and daily functioning in patients with osteoarthritis. Pain 2004; 110 (1-2): 228-235.

15. Houben,R.M., Gijsen,A., Peterson,J., de Jong,P.J., and Vlaeyen,J.W.S. Do health care providers' attitudes towards back pain predict their treatment recommendations? Differential predictive validity of implicit and explicit attitude measures. Pain 2005; 114 (3): 491-498.

16. Houben,R.M., Ostelo,R.W., Vlaeyen,J.W.S., Wolters,P.M., Peters,M., and Stomp-van den Berg SG Health care providers' orientations towards common low back pain predict perceived harmfulness of physical activities and recommendations regarding return to normal activity. Eur J Pain 2005; 9 (2): 173-183.

17. Jong,J.R.d., Vlaeyen,J.W.S., Onghena,P., Goossens,M.E., Geilen,M., and Mulder,H. Fear of movement/(re)injury in chronic low back pain: education or exposure in vivo as mediator to fear reduction? Clin J Pain 2005; 21 (1): 9-17.

18. Keefe,F.J., Rumble,M.E., Scipio,C.D., Giordano,L.A., and Perri,L.M. Psychological aspects of persistent pain: Current state of the science. J Pain 2004; 5 (4): 195-211.

19. Klenerman,L., Slade,P.D., Stanley,I.M., Pennie,B., Reilly,J.P., Atchison,L.E., Troup, J.D.G., and Rose,M.J. The prediction of chronicity in patients with an acute attack of low back pain in a general practice setting. Spine 1995; 20 (4): 478-484.

20. Kugler,K., Wijn,J., Geilen,M., Jong,J.d., and Vlaeyen,J.W.S. The Photograph series of daily activities. 1999 
21. Linton,S.J. A review of psychological risk factors in back and neck pain. Spine 2000; 25 (9); 1148-1156.

22. Maniadakis,N. and Gray,A. The economic burden of back pain in the UK. Pain 2000; 84 (1): 95-103.

23. McCracken,L.M. and Gross,R.T. Does anxiety affect coping with chronic pain? Clin J Pain 1993; 9 (4): 253-259.

24. Miller,R.P., Kori,S.H., and Todd,D.D. The Tampa Scale. 1991

25. Murphy,D., Lindsay, S., and Williams,A.C. Chronic low back pain: predictions of pain and relationship to anxiety and avoidance. Behav.Res. Ther 1997; 35 (3): 231-238.

26. Pengel,L.H., Herbert,R.D., Maher,C.G., and Refshauge,K.M. Acute low back pain: systematic review of its prognosis. BMJ 2003; 327 (7410): 323-327.

27. Peters,M.L., Vlaeyen,J.W.S., and Weber,W.E. The joint contribution of physical pathology, pain-related fear and catastrophizing to chronic back pain disability. Pain 2005; $113(1-2)$ : 45-50.

28. Picavet,H.S., Vlaeyen,J.W.S., and Schouten,J.S. Pain catastrophizing and kinesiophobia: predictors of chronic low back pain. Am J Epidemiol 2002; 156 (11): 1028-1034.

29. Pincus, T., Burton,A.K., Vogel,S., and Field,A.P. A systematic review of psychological factors as predictors of chronicity/disability in prospective cohorts of low back pain. Spine 2002; 27 (5): E109-E120.

30. Reneman,M.F., Jorritsma,W., Schellekens,J.M., and Goeken,L.N. Concurrent validity of questionnaire and performance-based disability measurements in patients with chronic nonspecific low back pain. J Occup Rehabil 2002; 12 (3): 119-129.

31. Roelofs,J., Goubert,L., Peters,M.L., Vlaeyen,J.W.S., and Crombez,G. The Tampa Scale for Kinesiophobia: further examination of psychometric properties in patients with chronic low back pain and fibromyalgia. Eur J Pain 2004; 8 (5): 495-502.

32. Roland,M. and Morris, R. A study of the natural history of back pain, Part 1 \& Part 2: RolandMorris Disability Questionnaire. Spine 1983; (8): 141-150.

33. Severeijns,R., van den,H.M., Vlaeyen,J.W.S., and Picavet,H.S. Pain catastrophizing and general health status in a large Dutch community sample. Pain 2002; 99 (1-2): 367-376.

34. Severeijns, R., Vlaeyen,J.W.S., van den Hout,M.A., and Weber,W.E. Pain catastrophizing predicts pain intensity, disability, and psychological distress independent of the level of physical impairment. Clin J Pain 2001; 17 (2): 165-172.

35. Sieben,J.M., Vlaeyen,J.W.S., Tuerlinckx,S., and Portegijs,P.J.M. Pain-related fear in acute low back pain: the first two weeks of a new episode. Eur J of Pain 2002; 6 229-237.

36. Spinhoven,P., Ter Kuile,M., Kole-Snijders,A.M., Hutten,M.M., Den Ouden,D.J., and Vlaeyen,J.W.S. Catastrophizing and internal pain control as mediators of outcome in the multidisciplinary treatment of chronic low kack pain. Eur J Pain 2004; 8 (3): 211-219.

37. Stratford,P.W., Binkley,J.M., and Riddle,D.L. Development and initial validation of the back pain functional scale. Spine 2000; 25 (16): 2095-2102.

38. Sullivan,M.J., Rodgers,W.M., Wilson,P.M., Bell,G.J., Murray,T.C., and Fraser,S.N. An experimental investigation of the relation between catastrophizing and activity intolerance. Pain 2002; 100 (1-2): 47-53.

39. Sullivan,M.J. and Stanish,W.D. Psychologically based occupational rehabilitation: the PainDisability Prevention Program. Clin J Pain 2003; 19 (2): 97-104.

40. Sullivan,M.J., Thorn,B., Haythornthwaite,J.A., Keefe,F., Martin,M., Bradley,L.A., and Lefebvre,J.C. Theoretical perspectives on the relation between catastrophizing and pain. Clin $J$ Pain 2001; 17 (1): 52-64.

41. Sullivan,M.J.L. and Bishop,S.R. The Pain Catastrophizing Scale: Development and validation. Psychol Assess 1995; 7 (4): 524-532.

42. Sullivan,M.J.L., Stanish,W., Waite,H., Sullivan,M., and Tripp,D.A. Catastrophizing, pain, and disability in patients with soft-tissue injuries. Pain 1998; 77 (3): 253-260.

43. Swinkels-Meewisse,E.J., Roelofs,J., Schouten,E.G.W., Verbeek,A.L., Oostendorp,R.A., and Vlaeyen,J.W.S. Fear of movement/(re)injury predicting chronic disabling low back pain: a prospective inception cohort study. Spine 2006; 31 (6): 658-664. 
44. Swinkels-Meewisse,E.J., Roelofs,J., Verbeek,A.L., Oostendorp,R.A., and Vlaeyen,J.W.S. Fear of movement/(re)injury, disability and participation in acute low back pain. Pain 2003; $105(1-2): 371-379$.

45. Swinkels-Meewisse,E.J., Swinkels,R.A., Verbeek,A.L., Vlaeyen,J.W.S., and Oostendorp,R.A. Psychometric properties of the Tampa Scale for kinesiophobia and the fearavoidance beliefs questionnaire in acute low back pain. Man Ther 2003; 8 (1): 29-36.

46. Turner,J.A., Jensen,M.P., and Romano,J.M. Do beliefs, coping, and catastrophizing independently predict functioning in patients with chronic pain? Pain 2000; 85 (1-2): 115-125.

47. Turner,J.A., Jensen,M.P., Warms,C.A., and Cardenas,D.D. Catastrophizing is associated with pain intensity, psychological distress, and pain-related disability among individuals with chronic pain after spinal cord injury. Pain 2002; 98 (1-2): 127-134.

48. Van Damme,S., Crombez,G., Bijttebier,P., Goubert,L., and van Houdenhove,B. A confirmatory factor analysis of the Pain Catastrophizing Scale: invariant factor structure across clinical and non-clinical populations. Pain 2002; 96 (3): 319-324.

49. van den Hout,J.H., Vlaeyen,J.W.S., Houben,R.M., Soeters,A.P., and Peters,M.L. The effects of failure feedback and pain-related fear on pain report, pain tolerance, and pain avoidance in chronic low back pain patients. Pain 2001; 92 (1-2): 247-257.

50. van Tulder,M.W., Koes,B.W., and Bouter,L.M. A cost-of-illness study of back pain in The Netherlands. Pain 1995; 62 (2): 233-240.

51. Verbunt,J.A., Seelen,H.A., Vlaeyen,J.W.S., van der Heijden,G.J., and Knottnerus,J.A. Fear of injury and physical deconditioning in patients with chronic low back pain. Arch Phys Med Rehabil 2003; 84 (8): 1227-1232

52. Vlaeyen,J.W.S., de Jong,J., Geilen,M., Heuts,P.H.T.G., and van Breukelen, G. Graded exposure in vivo in the treatment of pain-related fear: a replicated single-case experimental design in four patients with chronic low back pain. Behav Res Ther 2001; 39 (2): 151-166.

53. Vlaeyen,J.W.S., Jong,J.R.d., Geilen,M., Heuts,P.H.T.G., and Breukelen,G.v. The treatment of fear of movement/(re)injury in chronic low back pain: further evidence on the effectiveness of exposure in vivo. Clin J Pain 2002; 18 (4): 251-261.

54. Vlaeyen,J.W.S., Jong,J.R.d., Onghena,P., Kerckhoffs-Hanssen,M., and Kole-Snijders,A.M. Can pain-related fear be reduces? The application of cognitive-behavioural exposure in vivo. Pain Res Manag 2002; 7 (3): 144-153.

55. Vlaeyen,J.W.S., Kole-Snijders,A.M.J., Boeren,R.G.B., and Eek,H.v. Fear of movement (re)injury in chronic low back pain and its relation to behavioral performance. Pain 1995; 62 363-372.

56. Vlaeyen,J.W.S., Kole-Snijders,A.M.J., Rotteveel,A.M., Ruesink,R., and Heuts,P.H.T.G. The role of fear of movement/(re)injury in pain disability. J Occup Rehabil 1995; 5 (4): 235-252.

57. Vlaeyen,J.W.S. and Linton,S.J. Fear-avoidance and its consequences in chronic musculoskeletal pain: a state of the art. Pain 2000; 85 (3): 317-332.

58. Waddell,G., Newton,M., Henderson,I., Somerville,D., and Main,C.J. A fear avoidance beliefs questionnaire $(F A B Q)$ and the role of fear-avoidance beliefs in chronic low back pain and disability. Pain 1993; 52 157-168.

59. Wand,B.M., Bird,C., McAuley,J.H., Dore,C.J., MacDowell,M., and De Souza,L.H. Early intervention for the management of acute low back pain: a single-blind randomized controlled trial of biopsychosocial education, manual therapy, and exercise. Spine 2004; 29 (21): 2350-2356.

60. Williams,R.A., Pruitt,S.D., Doctor,J.N., Epping-Jordan,J., Wahlgren,D.R., Grant,I., Patterson,T.L., Webster,J.S., Slater,M.A., and Atkinson,J.H. The contribution of job satisfaction to the transition from acute to chronic low back pain. Arch of Physical Med and Rehab. 1998; 79 (4): 366-374. 


$$
\text { • }
$$




\section{Chapter 8}

\section{Prediction of pain by acute low back pain patients: effects of exposure to physical activity}

Ilse E.J. Swinkels-Meewisse, Jeffrey Roelofs, Rob A.B. Oostendorp, André L.M. Verbeek, Johan W.S. Vlaeyen 


\section{Abstract}

Numerous studies have supported the importance of pain-related fear and pain catastrophizing in the maintenance of disability and chronic pain. Generally, fearful chronic low back pain (LBP) patients tend to overpredict pain associated with a subsequent physical task. However, they appear to correct these predictions after repeated exposure to that stimulus, often resulting in increased task performance. Knowledge about the influence of these cognitive and emotional factors on prediction of pain and the effects of exposure in acute back pain is currently lacking. This experimental study aimed at (1) examining the associations between pain expectancies, performance, pain-related fear and pain catastrophizing in acute LBP patients, (2) investigating whether pain-related fear and pain catastrophizing are associated with overprediction of pain, (3) examining whether under- or overpredictions are corrected after repeated exposure and whether this is moderated by pain-related fear or pain catastrophizing, (4) examining the influence of repeated exposure to a moderately threatening physical task on subsequent performance. Results showed that despite a significant main effect of pain catastrophizing, and fear of movement/(re)injury, on lifting time, repeated exposure to the physical lifting task did not result in a better performance. Generally, the results showed an underprediction of pain expectancies. Low catastrophizers corrected their pain prediction more readily than high catastrophizers. No such differences are found between high and low fearful patients. The clinical implications of the findings are discussed.

\section{Perspective}

This article focuses on the effects of pain-related fear and catastrophizing on repeated task performance and pain predictions in an acute LBP sample. This study adds to the development of treatment strategies for acute LBP patients with elevated levels of pain-related fear and catastrophizing. 


\section{Introduction}

Pain and disability improve rapidly the first four weeks of a new episodes of LBP (36), but recurrences are common and the self-limiting feature of LBP seems questionable $(21,22)$. A large body of research exists trying to explain the perpetuation of (low back) pain and associated disability. From a cognitivebehavioural perspective, the fear-avoidance model attempts to explain why and how pain is maintained over time $(58,60)$. This model conceptualises the process of developing chronic disabling pain, ascribing a major role to pain catastrophizing and pain-related fear. When, in the acute phase of (low back) pain, the pain is interpreted as threatening, pain-related fear, or the more specific fear that physical activity will cause (re)injury, may emerge. The resulting avoidance behaviour may deprive the person from the necessary feedback that the anticipated threat does not appear, and that such protective behaviour has paradoxical effects, leading to disability, disuse, and depressed mood. Repeated pain experiences will then fuel the cycle of pain, increasing fear and avoidance behaviour, eventually resulting in and maintaining chronic pain. Numerous studies have supported the importance of the fear-avoidance model in LBP $(26,60)$, occupational back pain $(18,19)$, and in other musculoskeletal disorders as well including neck pain (35), osteoarthritis (23), and knee pain after sports injuries (30). Pain-related fear and pain catastrophizing appear to be associated with increased disability $(4,12,16,27,28,43,49,51$, $53,59)$, impaired physical task performance $(1,12,24,58)$, and future disability and health status $(8,9,38,50)$. Pain-related fear and pain catastrophizing also have a clear link with pain anticipation. More specifically, patients with chronic LBP with high levels of pain-related fear or pain catastrophizing tend to overpredict pain associated with a subsequent task. These overpredictions usually are adjusted towards actual experienced pain intensity after repeated exposure to feared activities $(10,11,20,32)$. Research on pain predictions has mostly been performed in chronic pain samples or in experimental laboratory settings.

Based on the cognitive-behavioural model (60) and in line with the suggestions of Philips (37), a more specific intervention has been developed to systematically reduce pain-related fear. This exposure in vivo with behavioural experiments (55) has shown to be associated with improved functional abilities and increased activity tolerance in high fearful chronic LBP patients $(6,55-57)$. The majority of the studies on pain-related fear and pain catastrophizing were performed with persons with chronic (low back) pain. Little is known concerning the association between pain-related fear, pain catastrophizing and pain predictions and its correction in samples with acute LBP. Some recent studies have shown that pain-related fear is also present in the early stage of LBP, influencing future disability $(15,44,50,51)$ and physical task performance (53).

The aims of the present study are: (1) to examine the associations between performance, pain expectancies, pain-related fear, and pain catastrophizing; (2) to investigate if high fearful persons or high catastrophizers in a sample of acute LBP 


\section{Chapter eight}

patients will overpredict expected pain intensity when exposed to a back stressing movement; (3) to examine whether repeated exposure leads to more correct predictions of pain, and whether this is moderated by the level of pain catastrophizing and pain-related fear; (4) to examine to what extent repeated exposure resulted in a better performance in persons with acute LBP. We hypothesize that: (1) there are significant associations between performance, pain expectancies, pain-related fear, and pain catastrophizing; (2) that more catastrophizing and higher levels of pain-related fear are associated with increased overpredictions of pain associated with the physical task; (3) we expected low catastrophizers or low fearful persons to correct the pain expectancies more rapidly after repeated exposure as compared to high catastrophizers or high fearful persons; and lastly (4) the level of performance will increase with repeated exposure with high pain-related fear or pain catastrophizing.

\section{Methods}

\section{ACUTE BACK PAIN SAMPLE}

Between March and December 2004, participants suffering from LBP were recruited by general practitioners and physiotherapists in the southeast region of The Netherlands. During their first visit with the healthcare provider, patients who experienced an acute episode of LBP were invited to participate in the present study. In this study, acute LBP was defined as LBP with a duration of at most four weeks with a pain free period of at least three months preceding the current episode. Inclusion criteria were: age between 18 and 65 with non-specific LBP independent of radiation. Criteria for exclusion were: illiteracy; specific LBP (e.g. tumours, trauma, infection, inflammatory disorders); presence of malignancies; operations in the lumbar area; or pregnancy. Within two days after consultation with the healthcare provider, individuals who agreed to participate were contacted to make an appointment. All measurements were performed at the patient's home to ensure ecological validity. During the home visit and after written informed consent was obtained, the participants completed a set of questionnaires in the presence of the researcher. Subsequently, the physical task was explained to the participant in a standardized way (see physical task). At the end of the visit, participants were given a booklet with information concerning LBP, thanking them for their participation. Participants did not receive incentives in turn for their participation. The protocol of this study was approved by the Advisory Committee on Ethics of the Maastricht University.

\section{PHYSICAL TASK}

The physical task consisted of lifting a bag with $7 \mathrm{~kg}$ with both hands simultaneously on and off a table with a height of approximately 75 centimetres. This procedure was repeated three times $(T 1, T 2$, and $T 3)$ with a 5 minutes resting pause in 
between. A maximum of standardization was pursued by using the same bag and explaining the task in a standardized way, following written instructions read out loud by the experimenter. The total lifting time was recorded. The maximum time was set at 300 seconds. The task was expected to be sufficiently threatening for individuals with back pain, irrespective of their level of pain-related fear $(24,58)$.

\section{MEASURES}

\section{Demographic variables}

A questionnaire was completed covering various socio-demographical characteristics (i.e. age, gender, education level, sick-leave, and sport activities), and questions regarding the current episode (i.e. duration, onset, radiation, interventions) and/or preceding back pain episodes (i.e. duration, number of preceding episodes, and interventions during previous episodes).

\section{Pain intensity}

Current pain intensity was measured on a horizontal $100 \mathrm{~mm}$ visual analogue scale (VAS) anchored with extremes of "no pain", on the left side and "worst imaginable pain", on the right side. Furthermore, maximum and mean pain intensity of the past two days were measured with a VAS. Before each lifting task patients were asked to rate on a VAS the pain intensity they expected to experience during the lifting movement (expected pain intensity). After completion of the task, patients were asked to rate the actual pain that was experienced (experienced pain intensity). This procedure was repeated three times.

\section{Disability}

LBP disability was assessed using the Dutch version of the Roland Disability Questionnaire (RDQ) $(5,42)$. The RDQ is a 24 -items questionnaire with a dichotomous scoring format; yes ( $=$ item is applicable), or no ( $=$ item is not applicable). Total scores can vary from 0 (no disability) to 24 (severe disability). Reliability and validity of the measure were established $(42,45)$. In this study the internal consistency as calculated with Cronbach's alpha was good (Cronbach's alpha $=0.82$ ).

\section{Pain-related fear}

A Dutch version of the Tampa scale for Kinesiophobia (TSK; $(33,58)$ was used. The TSK is a reliable and valid questionnaire, consisting of 17 statements measuring fear of movement or (re) injury $(41,59)$. Items are scored on a 4-point scale ranging from 'strongly disagree' (score $=1$ ) to 'strongly agree' (score=4). Items 4, 8, 12 , and 16 are reversibly scored. In a population of acute LBP patients, the TSK exists of two subscales: a harm subscale (TSK-harm, items $3,5,6,9,11$, and 15), reflecting the beliefs that there is something seriously wrong with the body, encompassing both the danger and injury items; and an activity avoidance subscale (TSK-activity avoidance, items $1,2,7,10,13,14$, and 17), indicating the beliefs 


\section{Chapter eight}

that avoiding exercise or activities might prevent an increase of pain (51). The reliability and validity of the TSK in a population with acute LBP are satisfactory (52). In the current study the internal consistency was satisfactory (Cronbach's alpha=0.74).

\section{Pain catastrophizing}

A Dutch version of the Pain Catastrophizing Scale (PCS) was used (47). The PCS exists of 13 items and was developed to measure exaggerated negative thoughts that might occur during actual or anticipated pain experience. Items are scored on a 5-points scale ranging from 0 (totally disagree) to 4 (totally agree). The Dutch version of the PCS is a valid and reliable measurement instrument (54). In this investigation, the internal consistency was high, Cronbach's alpha being 0.93 .

\section{THREAT CONTROL}

To examine the threat value of the lifting task, five pictures of the Photographs series of Daily Activities (PHODA) were shown (29). Patients were asked to score on a $100 \mathrm{~mm}$ VAS anchored with the words "no concern at all", on the left side and "highest possible concern", on the right side, how concerned they were that the shown activity would (re)injure their back. These pictures were chosen because in a previous study, they discriminated well between high and low fearful subjects (Peters M, unpublished data). Furthermore, before actually performing the physical task, the participants were asked to rate their concern of re/injuring their low back regarding the current lifting task on a VAS. We hypothesized that the physical task would be moderately threatening in persons with acute LBP.

\section{STATISTICAL ANALYSES}

Descriptive statistics and associations. (Pearson's correlation coefficients) of the measurement instruments and lifting times were computed. To test whether overpredictions are associated with pain-related fear and pain catastrophizing, chi square test was used. The criteria of Rachman and Lopotka $(32,40)$ were used in evaluating pain predictions with the sample divided in high or low fearful participants or catastrophizers using the median split of the PCS $(\mathrm{Me}=16)$ and of the TSK $(\mathrm{Me}=37)$. Oneway ANOVA was used to test the difference of pain prediction between participants scoring high and low on the TSK or the PCS. Repeated Measures ANOVA was used to test the difference between high and low pain catastrophizers or fearful persons concerning the lifting bouts needed to correct pain prediction. The difference between patient's expected and experienced pain on the three lifting bouts were entered as within factor. Fear or catastrophizing dichotomy, gender, and education were entered as between subject factors. Current pain intensity was analysed as a covariate. To test whether repeated exposure resulted in a better performance, repeated Measures Analyses of Variance (ANOVA) with measurement moment as within factor were performed. Pain- 
related fear, pain catastrophizing, age and current pain intensity were analysed as continuous variables. Gender, and education were entered as between subject factors.

Outliers, based on inspection of a scatterplot between lifting time and scores on TSK or PCS and based on inspection of Cook's distance were excluded from the sample. In all analyses we controlled for gender and possible interactions with pain-related fear or pain catastrophizing $(13,14)$. Interactions will only be reported in case of significance.

\section{Results}

\section{Participants characteristics}

96 persons with acute LBP were included in the study. There were no significant differences on demographic variables, pain-related fear, disability or lifting time between participants included by physiotherapists and those referred by general practitioners. Three participants were excluded from the analyses, one because of age (> 65 years), one as a result of improper performance of the lifting task, and one because it was an outlier (scatterplot and Cook's distance). Mean age of the remaining sample was 44.8 years $(S D=11.5)$ with $48 \%$ being male $(n=45)$. About half of the participants $(48.4 \%$ ) had lower education (less than 13 years education) and half of the sample was engaged in sports activities $(50.5 \%)$. The mean duration of the current LBP episode was 11.6 days $(S D=7.6)$ with $21 \%$ experiencing a first time ever episode of LBP. There were no significant differences between persons with or without previous episodes of LBP on lifting time, pain-related fear, perceived disability, or demographic variables. Moreover, $53.8 \%$ of the patients experienced radiating pain in the leg, and in $74.2 \%$ of the cases the LBP had a sudden onset.

All outcome measures were checked for normality. No major deviations were found with regard to kurtosis and skewness. Table 8.1 shows the characteristics and the correlations of the current LBP episode: i.e. current pain intensity, perceived disability, pain catastrophizing, pain-related fear, the mean lifting time of $\mathrm{T} 1$ to $T 3$, and the expected pain of $T 1$ to T3. Lifting times and expected pain intensity on $T 1, T 2$, and $T 3$ were significantly correlated with disability, pain catastrophizing, and pain-related fear, but the associations were modest. Pain intensity was modestly correlated with disability only. Table 8.2 shows the means and standard deviations of expected and experienced pain of the total sample, of high and low fearful persons, and of high and low pain catastrophizers (based on a median split). There were significant differences between high and low scorers on PCS and TSK in expected pain intensity and experienced pain intensity on all measurement times with the exception of high versus low catastrophizers on T1expected pain and high versus low fearful persons on T3-experienced pain (see table 8.2). 


\section{Chapter eight}

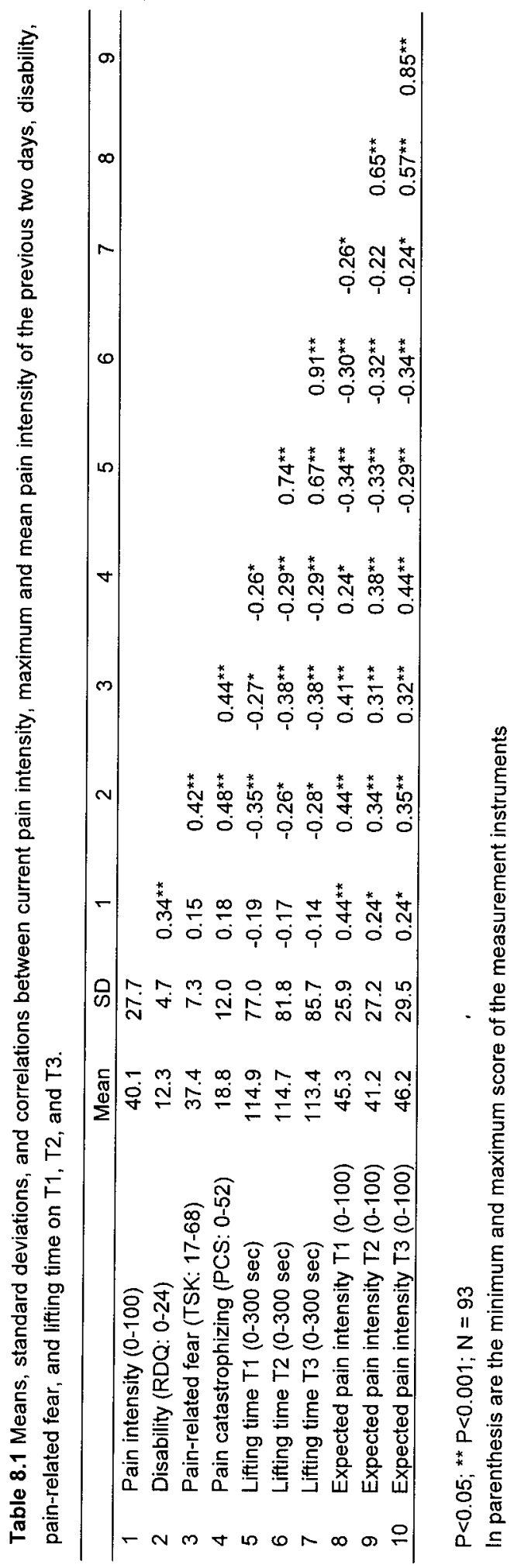


Pain-related fear, catastrophizing and repeated exposure in acute LBP

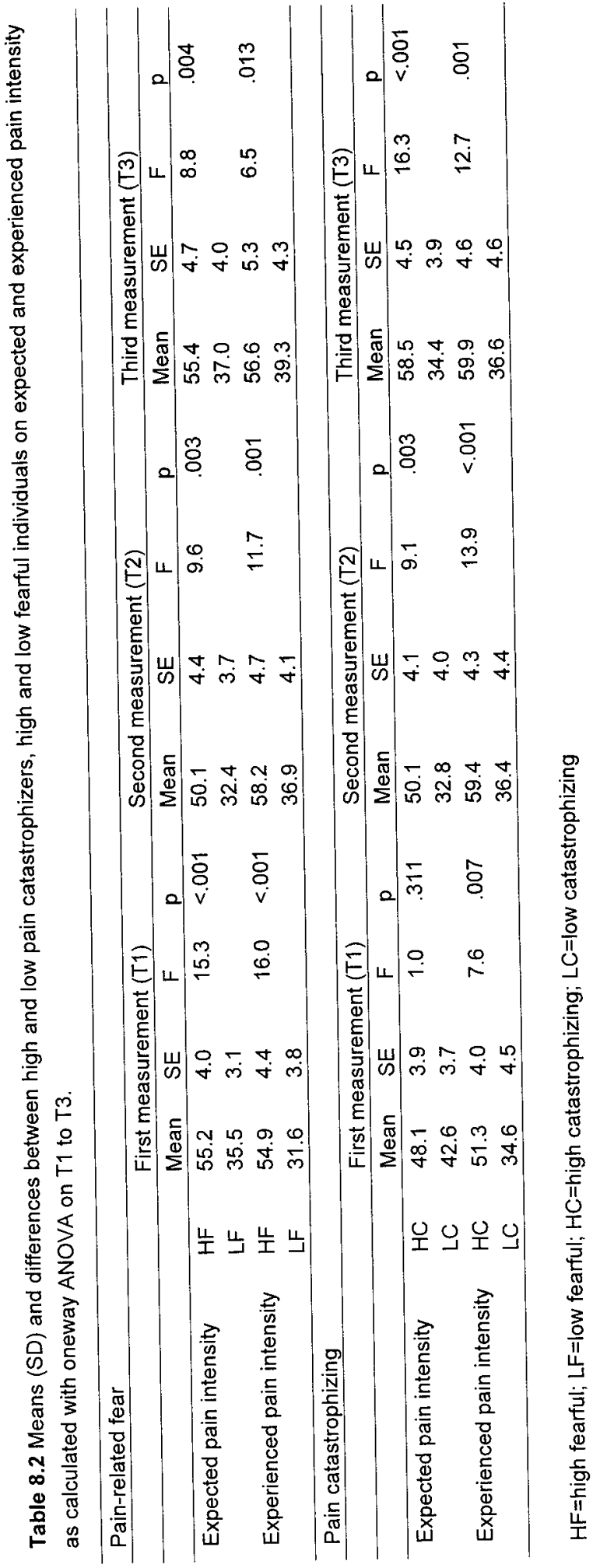


These differences were independent of the current pain intensity of the individuals, because there were no significant differences between high and low scores on TSK or PCS regarding current pain intensity $(p>0.12)$. There was a significant difference in lifting time on T1 only between men and women (mean difference: 40.7, $t=-2.57, p=.012$ ), and between high and low educated individuals (mean difference $33.5, \mathrm{t}=-2.05, \mathrm{p}=.044$ ), with men and highly educated persons having longer lifting times. There were no significant differences between dichotomous demographical or episode specific variables, and total scores on pain intensity, pain-related fear, pain catastrophizing, and disability.

\section{Threat control}

The mean scores on the threat-VAS of the five photographs showing daily activities ranged from $17.0(S D=18.5)$ to $78.3(S D=21.5)$. Participants scored moderately (mean $V S_{\text {threat }}: 43.5 ; S D: 30.7$ ) when asked to rate their concern about the physical task used in the current study. Dividing the sample in high and low fearful persons using the median of the TSK (Me=37), the mean difference on the $V{ }^{\prime} S_{\text {threat }}$ of the physical task was $29.0(t=4.49, p<.001)$. From these results, the conclusion seems justified that the chosen lifting task was sufficiently threatening and discriminated well between high and low fearful persons in this sample.

\section{Experienced versus expected pain}

Evaluating the predictions of pain intensity by applying the criteria of Rachman and Lopotka the percentage of correct predictions increased with the number of trials $(32,40)$. The correct predictions of low catastrophizers or low fearful participants increased from $9.3 \%$ and $8.5 \%$ respectively on the first lifting bout, via $38.1 \%$ for both groups on the second task, to $45.3 \%$ and $43.2 \%$ respectively on the last exposure. High catastrophizers or fearful persons shifted from $16.3 \%$ and $17.9 \%$, to $23.1 \%$ and $24.4 \%$ on the first and last lifting bout, respectively. Figure 8.1 shows the expected and experienced pain of the three measurements divided in high and low fearful persons (figure 8.1a) or high and low catastrophizers (figure 8.1b). Generally, there seemed to be an underprediction of pain, except for T1 where there does not seem to be a consistent trend. Chi-square test was used to test whether overpredictions were associated with high or low fearful individuals or catastrophizers. On T2 there was a significant difference between high and low catastrophizers in the number of patients with overpredictions, correct predictions, and underpredictions $\left(x^{2}=8.7, p=0.034\right) .57 .4 \%, 12.8 \%$, and $14.9 \%$ of the high catastrophizers underpredicted, correctly predicted, and overpredicted pain, respectively. Whereas the percentages for the low catastrophizers were: $34.8 \%$, $34.8 \%$, and $21.7 \%$, respectively. Similar tests with high and low fearful participants did not yield significant results. 
Figure 8.1a Expected and experienced pain of the sample divided in high and low fearful persons on three measurement times (T1-T3)

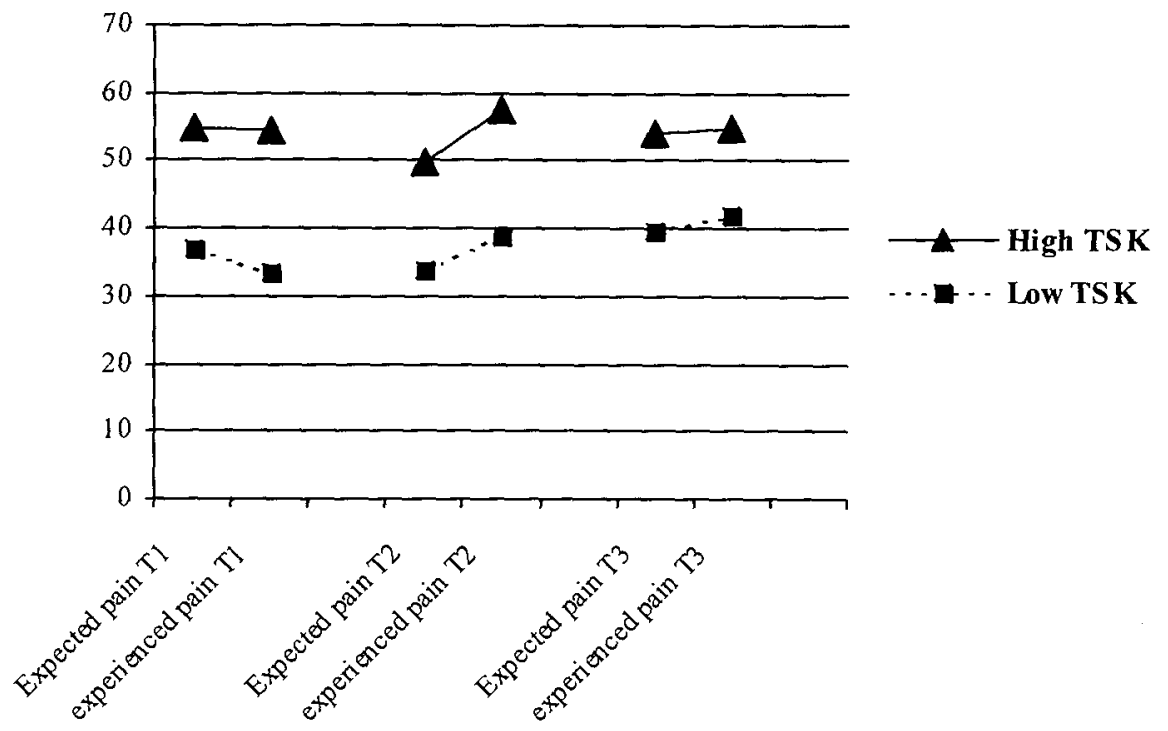

Figure 8.1b Expected and experienced pain of the sample divided in high and low pain catastrophizers on three measurement times (T1-T3)
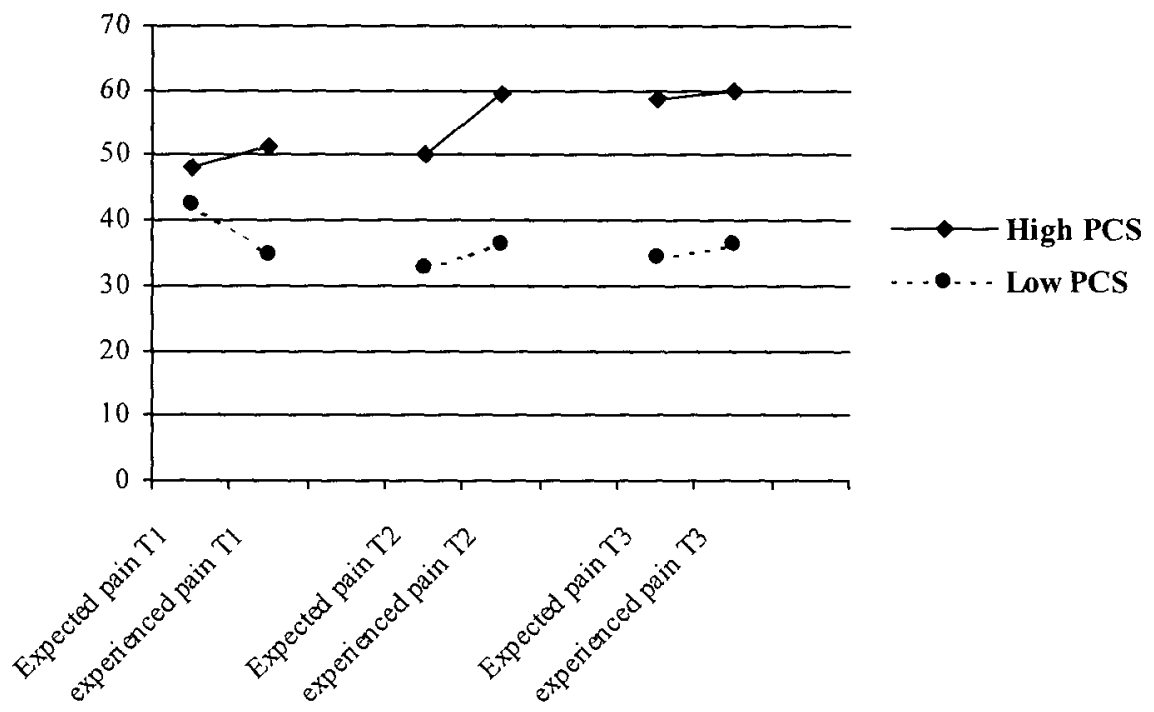


\section{Chapter eight}

A repeated measure ANOVA with the difference between expected and experienced pain on the three lifting times as dependent variable and pain catastrophizing, gender, and education as independent variables revealed a significant interaction between pain catastrophizing and lifting bouts $\left(F=3.4 ; p=0.037 ; \eta^{2}=0.05\right)$, meaning that there is a significant difference in pain correction from T1 to T3 between high and low pain catastrophizers. Low catastrophizers needed one lifting bout to correctly predict pain during subsequent lifting bouts. High catastrophizers needed two lifting bouts to correct their prediction of pain intensity (Figure $8.1 \mathrm{~b}$ ). The analysis was repeated with pain-related fear as the independent variable, and showed no significant interaction effects, meaning that no significant differences exist regarding pain prediction between high and low fearful persons for T1 to T3.

\section{Exposure effect}

Repeated measures ANOVA was performed with the three lifting times as within factor. Gender and education were entered as between subject factors, whereas pain-related fear, pain intensity, and age were analysed as continuous variables. Two variables showed a significant main effect, namely pain-related fear ${ }^{3}(F[1$, $\left.71]=17.2 ; p<0.001 ; \eta^{2}=0.20\right)$ and gender $\left(F[1,71]=6.2 ; p=0.02, n^{2}=0.08\right)$. This means that the more fearful persons are, the shorter they perform these lifting tasks. Men perform the physical task longer than women do, but the effect of gender was less compared to the effect of pain-related fear. The expected interaction between measurement time and pain-related fear was not significant, meaning that there was not a significant effect of fear on the performance of the physical task. None of the other interaction effects reached statistical significance.

Repeated measures ANOVA with pain catastrophizing instead of pain-related fear in the equation showed almost identical results except for the effect of gender, which was not significant. Pain catastrophizing showed a significant main effect $\left(F[1,71]=8.0 ; p=0.006 ; \eta^{2}=0.10\right)$, meaning that the lifting time decreased the higher the level of catastrophizing.

\section{Discussion}

The current experimental study provides a first attempt to examine the associations among pain-related fear and pain catastrophizing, prediction of pain and the effects of repeated exposure to physical activity in patients with acute LBP. The results can be summarized as follows. First, the results of this study did not support the hypothesized overprediction of expected pain intensity. Generally, the results showed an underprediction of pain expectancies, particularly on the second exposure. There was, however, a significant difference in expected and experienced pain between high and low fearful persons and between high and low

\footnotetext{
${ }^{3}$ Secondary analyses with TSK-harm or TSK-activity avoidance showed the same pattern of results, with $F=9.7, p=0.003, \eta^{2}=0.12$, and $F=21.5, p<0.001, \eta^{2}=0.23$ respectively.
} 
pain catastrophizers. Furthermore, high catastrophizers needed more repeated exposures than low catastrophizers to correct their pain prediction, but no such effect was found for low and high fearful patients. Finally, despite a significant main effect of pain catastrophizing and fear of movement/(re)injury on lifting time repeated exposure did not result in a better performance. In other words, patients with low back who catastrophically misinterpret their pain are less active, tend to underpredict their pain, and have difficulties correcting their pain after repeated exposure.

The results concerning the overprediction of expected pain by high fearful participants or high catastrophizers were opposite to our hypothesis. Our hypothesis was based on the cognitive-behavioural model as developed by Vlaeyen et al. (60) in which catastrophic cognitions are presumed to initiate and maintain fear of movement or fear of (re) injury. This fear of movement/(re)injury is caused by anticipated higher pain expectancy or because movements are expected to cause harm to the back. To date, most studies concerning anticipated pain predictions had experimental designs or were performed using samples of patients with chronic pain $(2,10,11,20,32,34,48)$. With the exception of the study of Arnzt and Peters (2), where an underprediction of pain was found in a sample of chronic LBP patients, the results of most studies are in line with the idea that expected pain generally is overpredicted.

Our third hypothesis, concerning the correction of inaccurate prediction of pain, was partially confirmed. In the third lifting bout, the expectancy scores correctly predicted the actual experienced pain. Generally, the existing literature shows that in cases of overprediction of pain, people tend to decrease their prediction but more slowly than in cases of underprediction, in which they tend to increase (39). It has been shown that underpredictions are experienced as being more aversive, needing more correction possibilities $(3,39,40)$. However, our study might be an indication that correction of pain expectancies not only depends on the level of expected pain, but also depends on the level of pain catastrophizing. High catastrophizers needed more times of repeated exposure than low catastrophizers.

Finally, the current study extends the findings in the literature on chronic LBP concerning pain-related fear, pain catastrophizing, and physical performance, in which fearful participants or catastrophizers perform less well during physical tasks $(1,11,12,46,58,60)$. This effect was shown in all three lifting trials. However, a repeated exposure effect could not be demonstrated. It is possible that because they are less active, they have fewer opportunities to calibrate their expectancies against actual pain during the performance. To date, exposure-based treatments in chronic LBP populations showed promising results in decreasing the levels of self-reported disability, pain-related fear, catastrophizing, and, to lesser degree, pain intensity $(6,25,55-57)$. The lack of an exposure effect on physical performance in our acute LBP patients might be explained by the absence of any cognitive education or information, or by the physical task itself. To date, there is only 


\section{Chapter eight}

one study investigating the effect of fear-avoidance-based physical therapy in patients with acute LBP. In that study a combination of fear-avoidance based education and graded activity was used as part of their fear-avoidance-based intervention (17). Comparing graded activity with exposure in vivo intervention in chronic back pain, Vlaeyen et al. (55) found that improvements in disability only occurred during graded exposure. An explanation of the lack of effect in the current study might be that only one physical task was used which was not based on an individualized hierarchy of fear-inducing activities (56). The current physical task was chosen because of its moderate threat value, but was not tailored to the individual participant. The task may have been too threatening for individuals scoring high on pain-related fear or not threatening enough for low fearful persons. Besides that, the participants in our study did not receive any information or education concerning pain-related fear or maladaptive cognitions, nor a behavioural experiment was conducted to challenge these cognitions, which is viewed as an integrated part of exposure-based treatment (55). Finally, the repeated exposure to the physical task may not have resulted in better performances because the assumption that patients correct their expectancies after overpredictions of pain was not met. Maybe the subjects in our study learned that it is safer not to move more in order to prevent pain increases.

What are the clinical implications of our study results? The results support the idea that early screening of psychosocial variables including pain catastrophizing and pain-related fear is warranted. The Örebro Musculoskeletal Pain Screening Questionnaire $(7,31)$ might be a good initial screening, later supplemented with the TSK or the PCS, eventually targeting an intervention. Second, exposure in vivo might be a promising intervention for those patients who display increased levels of pain-related fear or pain-catastrophizing. However, we did not find the hypothesized effect of repeated exposure to a physical task. A number of reasons have been mentioned above. The lack of a clear association between pain-related fear and the overprediction of pain may shed a different light on exposure in acute LBP patients. These patients may have learned something different than fearful patients with chronic LBP who receive a similar exposure treatment.

There are some limitations in the present study that need considering: First, the measurements were performed at the patients' home, which might have resulted in a loss of standardization. However, the authors believe that measuring at the patients' home favours external validity. Furthermore, a maximum of standardization was pursued by using the same bag during all trials, explaining the physical task in a standardized way, and blinding the participants for the scores on all measurement instruments. Second, we included only one physical task which may not have been appropriate for all our subjects, despite the fact that the lifting task chosen was sufficiently threatening and discriminated well between high and low fearful patients. In the future, it may be preferable to better match the physical task to the individual concerns of the patients. 
Despite these limitations, this is the first study to show that in acute LBP pain, and in contrast to chronic LBP, pain-related fear and pain catastrophizing are not associated with the overprediction of pain. In fact, the contrary appears true. Acute LBP patient, and especially those who catastrophize seem to underpredict pain. Before firm conclusions can be drawn about the utility of exposure based interventions in acute LBP, more information is needed about the cognitive processes that guide the protective behaviours of these patients right after the onset of a new episode. Such information is needed to design the most appropriate treatment approach in the acute phase, and will enable us to more effectively prevent the development of chronic LBP later on.

\section{Acknowledgements}

We thank the general practitioners and physical therapists for their assistance in including patients. The authors wish to thank Madelon Peters for her permission to use the PHODA data of chronic LBP patients and Raymond Swinkels, Kim Kugler, and Sven Balk for data-collection. Participation of Dr. J. Vlaeyen was supported by the Netherlands Organization for Health Research and Development (ZONMW), grant nr. 904-65-090. 


\section{References}

1. Al Obaidi,S.M., Nelson,R.M., Al Awadhi,S., and Al Shuwaie,N. The role of anticipation and fear of pain in the persistence of avoidance behaviour in patients with chronic low back pain. Spine 2000; 25 (9): 1126-1131.

2. Arntz,A. and Peters, M. Chronic low back pain and inaccurate predictions of pain: is being too tough a risk factor for the development and maintenance of chronic pain? Behav Res Ther 1995; 33 (1): 49-53.

3. Arntz,A. and van den Hout,M.A. Generalizability of the match/mismatch model of fear. Behav Res Ther 1988; 26 (3): 207-223.

4. Asmundson,G.J.G., Norton,G.R., and Allerdings,M.D. Fear and avoidance in dysfunctional chronic back pain patients. Pain 1997; 69 (3): 231-236.

5. Beurskens,A.J.H.M., Vet,H.C.W.d., and Koke,A. Responsiveness of functional status in low back pain: a comparison of different instruments. Pain 1996; 65 71-76.

6. Boersma,K., Linton,S., Overmeer,T., Jansson,M., Vlaeyen,J.W.S., and de Jong,J. Lowering fear-avoidance and enhancing function through exposure in vivo. A multiple baseline study across six patients with back pain. Pain 2004; 108 (1-2): 8-16.

7. Boersma,K. and Linton,S.J. Screening to Identify Patients at Risk: Profiles of Psychological Risk Factors for Early Intervention. Clin J Pain 2005; 21 (1): 38-43.

8. Buer,N. and Linton,S.J. Fear-avoidance beliefs and catastrophizing: occurrence and risk factor in back pain and ADL in the general population. Pain 2002; 99 (3): 485-491.

9. Burton,A.K., Tillotson,K.M., Main,C.J., and Hollis, S. Psychosocial Predictors of Outcome in Acute and Subchronic Low Back Trouble. Spine 1995; 20 (6): 722-728.

10. Crombez,G., Eccleston,C., Vlaeyen,J.W.S., Vansteenwegen,D., Lysens,R., and Eelen,P. Exposure to physical movements in low back pain patients: restricted effects of generalization. Health Psychol. 2002; 21 (6): 573-578.

11. Crombez,G., Vervaet,L., Lysens,R., Baeyens,F., and Eelen,P. Avoidance and confrontation of painful, back-straining movements in chronic back pain patients. Behav Modif 1998; 22 (1): $62-77$.

12. Crombez,G., Vlaeyen,J.W.S., Heuts,P.H.T.G., and Lysens,R, Pain-related fear is more disabling than pain itself. Evidence on the role of pain-related fear in chronic back pain disability. Pain 1999; $80(1,2): 329-339$.

13. Edwards,R.R., Doleys,D.M., Lowery,D., and Fillingim,R.B. Pain tolerance as a predictor of outcome following multidisciplinary treatment for chronic pain: differential effects as a function of sex. Pain 2003; 106 (3): 419-426.

14. Edwards,R.R., Haythornthwaite,J.A., Sullivan,M.J., and Fillingim,R.B. Catastrophizing as a mediator of sex differences in pain: differential effects for daily pain versus laboratoryinduced pain. Pain 2004; 111 (3): 335-341.

15. Fritz,J.M. and George,S.Z. Identifying psychosocial variables in patients with acute workrelated low back pain: the importance of fear-avoidance beliefs. Phys Ther 2002; $82(10)$ : 973-983.

16. Fritz,J.M., George,S.Z., and Delitto,A. The role of fear-avoidance beliefs in acute low back pain: relationships with current and future disability and work status. Pain 2001; 94 (1): 7-15.

17. George,S.Z., Fritz,J.M., Bialosky,J.E., and Donald,D.A. The effect of a fear-avoidance-based physical therapy intervention for patients with acute low back pain: results of a randomized clinical trial. Spine 2003; 28 (23): 2551-2560.

18. Gheldof,E.L., Vinck,J., Van den Bussche,E., Vlaeyen,J.W.S., Hidding,A., and Crombez,G. Pain and pain-related fear are associated with functional and social disability in an occupational setting: Evidence of mediation by pain-related fear. Eur J Pain 2005;

19. Gheldof,E.L., Vinck,J., Vlaeyen,J.W.S., Hidding,A., and Crombez,G. The differential role of pain, work characteristics and pain-related fear in explaining back pain and sick leave in occupational settings. Pain 2005; $113(1-2): 71-81$.

20. Goubert,L., Francken,G., Crombez,G., Vansteenwegen,D., and Lysens,R. Exposure to physical movement in chronic back pain patients: no evidence for generalization across different movements. Behav Res Ther 2002; 40 (4): 415-429. 
21. Hestbaek,L., Leboeuf-Yde,C., Engberg,M., Lauritzen,T., Bruun,N.H., and Manniche,C. The course of low back pain in a general population. Results from a 5-year prospective study. $J$ Manipulative Physiol Ther 2003; 26 (4): 213-219.

22. Hestbaek,L., Leboeuf-Yde,C., and Manniche,C. Low back pain: what is the long-term course? A review of studies of general patient populations. Eur Spine J 2003; 12 (2): 149165.

23. Heuts,P.H.T.G., Vlaeyen,J.W.S., Roelofs,J., de Bie,R.A., Aretz,K., van Weel,C., and van Schayck,O.C. Pain-related fear and daily functioning in patients with osteoarthritis. Pain 2004; $110(1-2): 228-235$.

24. Hout,J.H.C.v.d., Vlaeyen,J.W.S., Houben,R.M., Soeters,A.P., and Peters,M.L. The effects of failure feedback and pain-related fear on pain report, pain tolerance, and pain avoidance in chronic low back pain patients. Pain 2001; 92 (1-2): 247-257.

25. Jong,J.R.d., Vlaeyen,J.W.S., Onghena,P., Goossens,M.E., Geilen,M., and Mulder,H. Fear of movement/(re)injury in chronic low back pain: education or exposure in vivo as mediator to fear reduction? Clin J Pain 2005; 21 (1): 9-17.

26. Keefe,F.J., Rumble,M.E., Scipio,C.D., Giordano,L.A., and Perri,L.M. Psychological aspects of persistent pain: Current state of the science. J Pain 2004; 5 (4): 195-211.

27. Keefe,F.J., Wallston,K.A., and Caldwell,D.S. Coping with rheumatoid arthritis pain: catastrophising as a maladaptive strategy. Pain 1989; 37 : 51-56.

28. Koes,B.W., Tulder,M.W.v., Ostelo,R.W.J.G., Burton,A.K., and Waddell,G. Clinical guidelines for the management of low back pain in primary care: an international comparison. Spine 2001; 26 (22): 2504-2513.

29. Kugler,K., Wijn,J., Geilen,M., Jong,J.d., and Vlaeyen,J.W.S. The Photograph series of daily activities. 1999

30. Kvist,J., Ek,A., Sporrstedt,K., and Good,L. Fear of re-injury: a hindrance for returning to sports after anterior cruciate ligament reconstruction. Knee Surg Sports Traumatol Arthrosc 2005; 13 (5): 393-397.

31. Linton, S.J. and Hallden,K. Can we screen for problematic back pain? A screening questionnaire for predicting outcome in acute and subacute back pain. Clin J Pain 1998; 14 (3): 209215.

32. McCracken,L.M., Gross,R.T., Sorg,P.J., and Edmands,T.A. Prediction of Pain in Patients with Chronic Low Back Pain: Effects of Inaccurate Prediction and Pain-Related Anxiety. Behav Res Ther 1993; 31 (7): 647-652.

33. Miller,R.P., Kori,S.H., and Todd,D.D. The Tampa Scale. 1991

34. Murphy,D., Lindsay,S., and Williams,A.C. Chronic low back pain: predictions of pain and relationship to anxiety and avoidance. Behav Res Ther 1997; 35 (3): 231-238.

35. Nederhand,M.J., IJzerman,M.J., Hermens,H.J., Turk,D.C., and Zilvold,G. Predictive value of fear avoidance in developing chronic neck pain disability: consequences for clinical decision making. Arch Phys Med Rehabil 2004; 85 (3): 496-501.

36. Pengel,L.H., Herbert,R.D., Maher,C.G., and Refshauge,K.M. Acute low back pain: systematic review of its prognosis. BMJ 2003; 327 (7410): 323-327.

37. Philips,H.C. Avoidance Behaviour and its role in sustaining chronic pain. Behav Res Ther $1987 ; 25$ (4): 273-279.

38. Picavet,H.S., Vlaeyen,J.W.S., and Schouten,J.S. Pain catastrophizing and kinesiophobia: predictors of chronic low back pain. Am J Epidemiol 2002; 156 (11): 1028-1034.

39. Rachman,S. and Arntz,A. The overprediction and underprediction of pain. Clin Psychol Rev $1991 ; 11339-355$

40. Rachman,S. and Lopatka,C. Accurate and inaccurate predictions of pain. Behav Res Ther 1988; 26 (4): 291-296

41. Roelofs,J., Goubert,L., Peters,M.L., Vlaeyen,J.W.S., and Crombez,G. The Tampa Scale for Kinesiophobia: further examination of psychometric properties in patients with chronic low back pain and fibromyalgia. Eur J Pain 2004; 8 (5): 495-502.

42. Roland,M. and Morris,R. A study of the natural history of back pain, Part 1 \& Part 2: RolandMorris Disability Questionnaire. Spine 1983; (8): 141-150. 


\section{Chapter eight}

43. Severeijns,R., Vlaeyen,J.W.S., van den Hout,M.A., and Weber,W.E. Pain catastrophizing predicts pain intensity, disability, and psychological distress independent of the level of physical impairment. Clin J Pain 2001; 17 (2): 165-172.

44. Sieben,J.M., Vlaeyen,J.W.S., Tuerlinckx,S., and Portegijs,P.J.M. Pain-related fear in acute low back pain: the first two weeks of a new episode. Eur J Pain 2002; 6 229-237.

45. Stratford,P.W., Binkley,J.M., and Riddle,D.L. Development and initial validation of the back pain functional scale. Spine 2000; 25 (16): 2095-2102.

46. Sullivan,M.J., Rodgers,W.M., Wilson,P.M., Bell,G.J., Murray,T.C., and Fraser,S.N. An experimental investigation of the relation between catastrophizing and activity intolerance. Pain $2002 ; 100(1-2): 47-53$.

47. Sullivan,M.J.L. and Bishop,S.R. The Pain Catastrophizing Scale: Development and validation. Psychol Assess 1995; 7 (4): 524-532.

48. Sullivan,M.J.L., Rodgers,W.M., and Kirsch,I. Catastrophizing, depression and expectancies for pain and emotional distress. Pain 2001; 91 (1-2): 147-154.

49. Sullivan,M.J.L., Stanish,W., Waite,H., Sullivan,M., and Tripp,D.A. Catastrophizing, pain, and disability in patients with soft-tissue injuries. Pain 1998; 77 (3): 253-260.

50. Swinkels-Meewisse,E.J., Roelofs,J., Schouten,E.G.W., Verbeek,A.L., Oostendorp,R.A., and Vlaeyen,J.W.S. Fear of movement/(re)injury predicting chronic disabling low back pain: a prospective inception cohort study. Spine 2006; 31 (6): 658-664.

51. Swinkels-Meewisse,E.J., Roelofs,J., Verbeek,A.L., Oostendorp,R.A., and Vlaeyen,J.W.S. Fear of movement/(re)injury, disability and participation in acute low back pain. Pain 2003; 105 (1-2): 371-379.

52. Swinkels-Meewisse,E.J., Swinkels,R.A., Verbeek,A.L., Vlaeyen,J.W.S., and Oostendorp, R.A. Psychometric properties of the Tampa Scale for kinesiophobia and the fear-avoidance beliefs questionnaire in acute low back pain. Man Ther 2003; 8 (1): 29-36.

53. Swinkels-Meewisse,I.E., Roelofs,J., Oostendorp,R.A.B., Verbeek,A.L., and Vlaeyen, J.W.S. Acute low back pain: pain-related fear and pain catastrophizing influence physical performance and perceived disability. Pain 2006; 120 (1-2): 36-43.

54. Van Damme,S., Crombez,G., Bijttebier,P., Goubert,L., and van Houdenhove,B. A confirmatory factor analysis of the Pain Catastrophizing Scale: invariant factor structure across clinical and non-clinical populations. Pain 2002; 96 (3): 319-324.

55. Vlaeyen,J.W.S., de Jong,J., Geilen,M., Heuts,P.H.T.G., and van Breukelen,G. Graded exposure in vivo in the treatment of pain-related fear: a replicated single-case experimental design in four patients with chronic low back pain. Behav Res Ther 2001; 39 (2): 151-166.

56. Vlaeyen,J.W.S., Jong,J.R.d., Geilen,M., Heuts,P.H.T.G., and Breukelen,G.v. The treatment of fear of movement/(re)injury in chronic low back pain: further evidence on the effectiveness of exposure in vivo. Clin J Pain 2002; 18 (4): 251-261.

57. Vlaeyen,J.W.S., Jong,J.R.d., Onghena,P., Kerckhoffs-Hanssen,M., and Kole-Snijders,A.M. Can pain-related fear be reduces? The application of cognitive-behavioural exposure in vivo. Pain Res Manag 2002; 7 (3): 144-153.

58. Vlaeyen,J.W.S., Kole-Snijders,A.M.J., Boeren,R.G.B., and Eek,H.v. Fear of movement (re)injury in chronic low back pain and its relation to behavioural performance. Pain 1995; 62 363-372.

59. Vlaeyen,J.W.S., Kole-Snijders,A.M.J., Rotteveel,A.M., Ruesink,R., and Heuts,P.H.T.G. The role of fear of movement/(re)injury in pain disability. J Occup Rehabil 1995; 5 (4): 235-252.

60. Vlaeyen,J.W.S. and Linton,S.J. Fear-avoidance and its consequences in chronic musculoskeletal pain: a state of the art. Pain 2000; 85 (3): 317-332. 


\section{Chapter 9}

General discussion 


\section{Chapter nine}

\section{Introduction}

This chapter presents an overview and integration of the main findings of this thesis. First of all, the main findings of the various studies are briefly summarized. Then, the main results of the thesis will be presented, after which the methodological and clinical considerations are discussed. Finally, this thesis will end with conclusions and a number of recommendations for future research.

\section{Summary of research questions and main results}

The associations between pain-related fear and disability in chronic LBP are well documented. However, less is known concerning these associations in episodes of acute LBP.

This thesis is divided in three sections. The first section concerns the examination of the psychometric properties of the FABQ and TSK in acute back pain. Second, a large inception cohort study was set up to investigate whether pain-related fear in persons with an episode of acute low back pain (LBP) is a prognostic factor of prolonged disability. Cross-sectional relationships between pain-related fear and self-reported disability and participation were also investigated. The third section concerns an experimental study testing the associations among pain-related fear, pain catastrophizing, and actual performance on a physical task in a sample of acute LBP patients.

\section{THE MAIN FINDINGS OF THIS THESIS}

Psychometric investigation

1. In acute back pain, both the Tampa Scale for Kinesiophobia (TSK) and the Fear Avoidance beliefs Questionnaire (FABQ) are reliable questionnaires with good internal consistency and substantial test-retest reliability (chapter 2 ).

2. The Minimal Detectable Change of the TSK was lower than the MDC of the FABQ and equals $18 \%$ of the scale (chapter 3 ). The TSK did not show a floor or ceiling effect whereas the FABQ did.

\section{Inception cohort study}

1. In acute back pain, the TSK consists of two subscales labelled 'harm', and 'activity avoidance'. Both subscales, together with pain intensity, are significantly associated with self-reported disability. The association between pain-related fear, pain intensity and participation is mediated by disability.

2. The two-factor structure of the $F A B Q$, i.e. a work factor and a physical activity factor, was confirmed in a sample of persons experiencing an 
episode of acute LBP. Both subscales of the FABQ, together with pain intensity, were significantly associated with perceived disability. Disability mediated the association between pain intensity and participation, and the association between fear-avoidance beliefs and participation.

3. Fear of movement/(re)injury measured in the first four weeks of an episode of acute LBP is the most powerful predictor of six months outcome of LBP. Besides pain-related fear, also pain-intensity and some demographic and episode specific variables are significantly related to follow-up LBP problems.

1. Among individuals with acute LBP, is fear of movement/(re)injury the strongest predictor of the performance of a lifting task. Both pain catastrophizing and pain-related fear, as measured with the TSK, together with pain intensity are significantly related to perceived disability.

2. High fearful persons and high pain catastrophizers have significantly higher scores on expected and experienced pain than low fearful individuals and low pain catastrophizers. Besides that, high pain catastrophizers need more lifting bouts to correct pain predictions than low catastrophizers.

3. In acute LBP, repeated exposure to a physical lifting task, i.e. three standardized lifting bouts, does not result in a better performance of that specific task.

\section{Psychometric investigation}

A prerequisite for using measurement scales in research or clinical practice is that they are psychometrically sound. Psychometric properties of questionnaires involve the assessment of the reliability, which is important to distinguish persons based on the aspect(s) of the instrument in question, and validity of the questionnaires (17). Clinimetric properties such as responsiveness and sensitivity are equally important (59). Validity and responsiveness of the TSK and FABQ were not investigated further in this thesis. Up to date, the reliability of the TSK was investigated only in chronic LBP populations and the results showed good reliability $(38,73)$. Reliability of the $F A B Q$ and the subscales $F A B Q$-work and $F A B Q-$ physical activity were examined only in chronic LBP $(9,45,72)$. However, since this thesis concerned studies using samples of persons with acute LBP, reliability of TSK and FABQ needed to be established in acute LBP patients. The results of this thesis show that the reliability of both measurement scales in a sample of acute LBP patients is satisfactorily resembling the results of reliability studies in chronic LBP patients. 


\section{Chapter nine}

Evaluating the health status of a patient is of major importance in clinical practice. In view of this, it is imperative that clinicians and researchers have access to measures capable of detecting clinically relevant changes, which is referred to as the responsiveness of a measurement instrument (64). Patients with pain-related fear are often not aware of their fear $(4,34)$ making it very difficult to investigate the responsiveness of pain-related fear measures using a measure of global perceived effect as external criterion (73). However, the current data could well be used to calculate agreement parameters, i.e. the Standard Error of Measurement (SEM) and the minimal detectable change (MDC). Knowing the MDC of a measurement instrument provides the clinician with some grip on whether a patient has improved, deteriorated or remained stable. This is particularly important because some therapeutic interventions, aimed at decreasing pain-related fear, use questionnaires of pain-related fear to evaluate the effect of the intervention $(5,16,66,67)$.

\section{Inception cohort study}

\section{Pain-related fear as a risk factor for (prolonged) disability}

The results of the studies in this thesis imply that pain-related fear is an important factor present early in an episode of LBP influencing the transition from acute to chronic LBP. The results of the current study corroborate previous investigations $(7,23-25,32,36,57)$. However, a recent investigation has found opposite results to the current study. The results of the study of Sieben et al. showed no association of pain-related fear with future disability (56). Although the inclusion criteria (maximum LBP duration of three weeks) and method of the Sieben study and the investigation in this thesis were similar, there are some differences that might explain these opposite results. Sieben et al. excluded persons with acute LBP having a TSK total score above 42 , i.e. highly fearful persons. Our study showed that persons with initial high scores on the TSK (upper quartile; i.e. TSK total scores above 41 ) were 1.54 times more at risk of prolonged disability than were individuals with low initial scores. Besides that, comparison is hampered by the use of different outcome measures. Sieben et al. used a combination of pain intensity, activity limitation and limitation of social participation. The current study used perceived future disability and future participation levels in succession as two dependent outcome variables, because cross-sectional studies had shown that perceived disability mediated the association between pain-related fear and participation. Furthermore, although cross-sectional, the experimental study corroborates the influence of fear of movement/(re)injury on disability, showing that in acute LBP pain-related fear is the strongest predictor associated with actual performance. However, the results and explained variance of the current investigations also indicate that the prognosis of LBP depends on other variables. Throughout this study, demographical variables (e.g. education, age, and sport) 
and episode specific variables (e.g., onset, duration, and radiation) were varying significant factors influencing (future) perceived disability and/or participation. Although this seems consistent with previous literature $(3,19,56,60,63,71)$, evidence regarding the predictive strength of these factors is still a contentious issue (43). Recent systematic reviews have indicated that there are psychological and social factors (e.g. job satisfaction, work environment, depressive mood, and somatization), mentioned in the literature, which are implicated in the transition to chronic LBP $(15,46)$. These factors were not measured in the current study. Furthermore, it has been suggested that the cognitive-behavioural model might be extended with other psychological factors that have not been studied in this investigation, e.g. self efficacy beliefs, and attentional processes $(12,18,20,21,44,53)$. Thus, the influence of these factors was not controlled for, neither their interaction with pain-related fear (61).

A particular strength of the cognitive-behavioural fear-avoidance model is that it may explain how acute pain persists in chronic pain syndromes. The model posits that fear of movement or fear of (re)injury plays a strong role in the initial development of disability whereas the consequent response, that is, activity avoidance, plays a significant role in maintaining chronic pain disability. The current thesis confirmed that the TSK consists of two-factors, namely a harm subscale and an activity avoidance subscale (see chapter 4 ). The harm subscale specifically addresses the beliefs of fear concerning (re)injury, whereas the activity avoidance factor indicates the beliefs that avoidance of activities might prevent an increase of pain. The prospective study (chapter 6 ) showed that indeed baseline fear of harm is a stronger predictor of future perceived disability than are baseline beliefs of activity avoidance as measured with the TSK-activity avoidance subscale. This is in line with an experimental study by Arntz and Claassens, showing a link between harm beliefs and experienced pain (1). Our study shows that harm beliefs also predict disability levels. Fearful LBP patients, misinterpreting their pain as stemming from an injury to their back may avoid activities which they assume will damage their back leading to future disability or long lasting LBP. Cross-sectionally, activity avoidance is more strongly associated with perceived disability and actual performance than are beliefs of harm or fear. This may be due to the fact that avoidance behaviour is more proximal to perceived disability or actual performance. These results suggest that indeed fear is important in the origination of chronic disability due to pain and that beliefs of activity avoidance may be more related to the maintenance of disability. However, such conclusions are still preliminary and there is a bad need for replication studies.

\section{Causes of fear of movement/(re)injury}

If fear of movement/(re)injury is present early in an episode of LBP influencing its course an important question that immediately arises is: What causes this fear of movement/(re)injury? Although there is still little known concerning the acquisition of fear, Rachman suggests that fears can be acquired by three pathways: condi- 
tioning, vicarious exposures and by the transmission of information and instruction (48). A less favourable course of low back pain or a sudden onset of LBP without any biomedical known cause might be sufficiently traumatising to start a process of conditioning by exposure, inducing pain-related fear. Indeed, Crombez et al. found that patients who reported a sudden traumatic onset scored higher on the TSK than persons who reported a more gradual onset of complaints (14). Secondly, LBP is a very common pain syndrome and many experiences from other LBP patients are passed on (e.g. "My brother was your age, and was diagnosed an herniated disc. He was operated, but never got better again.") and/or advises are given (e.g. you should not work, that is bad for your back!"), unintentionally fuelling pain-related fear. Besides that, many misconceptions regarding low back pain exist in persons with LBP as well as in persons free of back pain that influence maladaptive beliefs $(6,26)$. And thirdly, health care providers may positively or negatively influence the fear of a patient by their attitude and beliefs, and by the information, advises and recommendations they provide to patients. Their recommendations reflect personal attitudes of the physicians and physiotherapists as well as factors related to the patients' clinical symptoms $(28,29,37,50-52)$. The shift from the biomedical paradigm (where pain is viewed as an alarm, as a sign that there is something wrong with the body) to the biopsychosocial model started in the sixties, receiving more support after the introduction of the gate-control theory. However, although the biopsychosocial model is gaining acceptance in healthcare provider professions, this does not automatically implicate a change of their attitudes both on the explicit and implicit level (28). Furthermore, special attention should be paid, regarding this issue, to the attitudes of pain patients themselves. Patients still regard pain as a sign of harm or tissue damage (26). Healthcare providers' attitudes might reinforce the deeply rooted beliefs of the patients. In this way, vicarious and informational transmission of fears can even take place in the absence of direct contact with the fear stimuli.

\section{Experimental study}

\section{Pain expectancies and repeated exposure}

Generally, the literature reports that persons with high levels of pain-related fear or pain catastrophizing tend to overpredict pain $(11,13,27,39)$. These overpredictions are adjusted towards actual experienced pain intensity after repeated exposure to feared activities. The study in this thesis generally shows an underprediction of pain (chapter 8). This might mean that the participants showed a tendency to be overoptimistic about the potential pain provocation by the physical task. Arntz and Peters hypothesized that being to tough might be a risk factor for the development and maintenance of chronic LBP (2). Underpredictions are experienced as being more aversive. Generally, underpredictions of pain needed more correction possibilities than overpredictions (49). In the current study, having heightened levels of 
fear of movement/(re)injury or high catastrophizing seemed of more importance in correcting the pain predictions than the anticipation of pain. This might indicate that the threat value of the activities is of more importance.

Based on the cognitive-behavioural model a more specific intervention has been developed to reduce pain-related fear, resulting in less avoidance behaviour: graded exposure in vivo (65). Exposure therapy offers the patient an imposed opportunity to restore synchrony between pain sensation and pain cognitions and has been proven effective in patients with chronic LBP $(5,65-67)$. In our sample of persons with acute LBP repeated exposure to a physical task did not improve performance. Viewing the beneficial effects of graded exposure in persons with chronic LBP, one might conclude that graded exposure is useful only in the chronic stage of LBP. However, recently it has been found that gradually exposing acute LBP patients to activities had positive effects $(25,31,55)$. These effects were found in those patients having (extremely) high levels of pain-related fear. This might mean that the levels of fear in the sample as studied in the current thesis were not high enough to benefit from the exposure. Besides that, the main difference with graded exposure as an intervention opposed to performing an activity multiple times is the fact that there was no hierarchy of activities. Probably, the most important part of the graded exposure treatment is the individual determination of feared activities and their hierarchy (54). The use of merely one activity excludes a hierarchy of activities, which means that the chosen, moderately threatening activity might have been to threatening for our sample. Furthermore, in our study, the assumption that patients correct their expectancies after overpredictions of pain was not met, which may explain why repeated exposure did not result in better performance.

However, the combination of fearful individuals or high catastrophizers having shorter lifting times and generally showing underpredictions of pain in this thesis is contradictory. We have no evident explanation for these results. Future research on this issue may shed more light on possible explanations.

\section{Methodological considerations}

Methodological limitations of the different studies we conducted were already discussed in the earlier chapters. Therefore, this part will focus more specifically on the major strengths and limitations of the total research project.

\section{Patient samples}

The cross-sectional study (chapter 3 ) and prospective study constitute the same patient sample, possibly decreasing the validity of the conclusions. However, in the experimental study (chapter 7), a second sample with the same inclusion criteria was used. This experimental study corroborated the previous two studies, confirming the conclusions. 
In the current thesis two samples of individuals with an episode of acute LBP were investigated. They concern persons who sought help for their back pain, which might mean that they were more concerned regarding their back pain than a group of LBP patients not visiting a healthcare professional. However, the populations at study were clinic based, and constitute LBP patients that primary care clinicians, i.e. general practitioners and physiotherapists, encounter every day. Although the generalization to the total population with LBP is limited, the sample represented a group of individuals that continuously are seen in the every day practice of primary care.

Furthermore, we aimed at including only patients experiencing acute LBP. However, there is a possibility that our sample may include patients already having chronic back pain. Indeed, back pain is characterized by an episodic and recurrent course $(41,69,70)$. In order to increase the likelihood that the included persons suffered an acute episode of LBP, we included only persons with a duration of LBP not longer than 4 weeks and with a pain free episode of at least three months preceding the current episode. Therefore, we are confident that we included patients with episodes of acute back pain rather than chronic pain patients.

\section{Measures}

The measures used in the current studies were all self-report measures and the results may thus reflect some shared method variance. Self-report instruments measure more explicit attitudes, which may diverge from implicitly measured attitudes, having differential predictive power $(28,30,58)$. However, comparing the performance study (chapter 7) with the cross-sectional TSK study (chapter 5) revealed similar results, i.e. the association between pain-related fear and activities.

The TSK and FABQ were not specifically developed for acute LBP patients. However, the results of the factor analyses and reliability study of the questionnaires as performed in the current thesis are similar to the factor analyses and reliability investigations performed in chronic LBP samples. Although this indicates that both measurement instruments can be used both in acute and in chronic LBP samples, this does not preclude a possible conceptual difference between acute and chronic LBP patients.

In the absence of a standardized and well-validated measure of participation, a new measure was developed consisting of five items. Reliability, as calculated with Cronbach's alpha was good $(\alpha=0.85)$. However, the significant interaction effect between baseline participation and time, as found in the prospective study, might be due to a reduced stability of the participation measure. Although facevalidity was accomplished, the preliminary psychometrics of this new measure need to be further validated in future studies assessing in detail reliability and validity. 


\section{Methodology}

Although a prospective design is a minimal prerequisite for investigating causal relationships, conclusions on causal relationships should be drawn with caution. Causal factors are best established under controlled experimental conditions, manipulating the causal variable. The cognitive-behavioural model provides a logical and time sequential explanation, which is essential in studying causal relationships (47). However, because of the circularity of the model, all factors might influence or be causal to each other. This complicates the demonstration of causal relations. The prospective design of chapter 6 of the current thesis together with the theoretical framework and literature confirming this model, provide strong indications of the causality of pain-related fear in provoking activity limitations

Despite these weaknesses, the current studies are notable for several reasons.

First, a particular strength is the relatively large sample size and low percentage of non-responders. There is only one investigation studying fear-avoidance beliefs in acute primary care LBP patients with a large sample size $(n=300)$, but that study suffered from a very large drop-out rate and the instruments used to measure fear-avoidance beliefs were not specifically developed for that purpose and might only be indicative for fear-avoidance beliefs (32).

Second, a further strength of the studies in this thesis is that, although different research designs were used, the results of the studies were similar, corroborating and strengthening the findings. Pain-related fear was significantly associated with levels of activity and/or participation in samples of acute LBP patients, whether or not the design was cross-sectional or prospective and whether or not self-report measures or actual performance was used.

Third, the studies in this thesis use measurement instruments which have specifically been validated for use in samples of LBP patients.

Fourth, the studies in this thesis use a broader measure of participation than is commonly used. Most studies use measures of return to work or days of sick leave. However, participation is a broad construct, consisting of several domains as described in our measure of participation.

Fifth, in clinical practice, it is often hypothesized that disability mediates the association between factors influencing disability and participation level. The current studies are the first that found evidence of this view.

A final strength of the prospective study is the inclusion of a very large sample of acute LBP patients ( $n=555$ ), excluding all susceptible cases of chronic (recurrent) LBP, analysing the total range of TSK scores. 


\section{Implications for clinical practice}

The main research question of this thesis was to investigate pain-related fear as a predictor of chronic disability due to LBP. From the studies in this dissertation it can be concluded that fear of movement/(re)injury plays an important role in acute and future LBP disability. Pain intensity was of secondary importance. In primary care and LBP guidelines, pain relief in acute LBP is one of the most important issues, based on the notion that lowering pain intensity levels will automatically enhance activity levels $(8,10,33,62)$. Furthermore, in all clinical guidelines concerning LBP, early activation is regarded of utmost importance and the recommendation of rest as a treatment option should be reduced (8). However, advising patients with LBP to stay active without examining possible factors that cause the patients' disability might be ineffective. The George et al. study, using a sample of persons with acute LBP, showed that persons with elevated scores on fearavoidance improved after a fear-avoidance based physical therapy intervention, whereas individuals without pain-related fear experienced more disability after such a treatment (25). This emphasizes the importance of a screening procedure for identifying patients with high pain-related fear, before starting a fear reducing intervention. Our study shows that the TSK might be used as a screening tool to identify persons with elevated pain-related fear. The prospective study showed that high fearful LBP patients (i.e. TSK total score above 41) are 1.54 times more at risk of prolonged disability than low fearful patients. However, clear cut-off points are needed before being able to identify persons with acute LBP having increased levels of pain-related fear. In persons with an episode of acute LBP, one might use the sum of the mean and one standard deviation as found in the prospective study of this thesis (mean=36.4; $S D=7.7$ ) as a cut-off point. A score of 44 or higher on the TSK provides a reasonably save threshold defining high fear of movement/ (re)injury.

Especially in primary care, the first visit of a patient with LBP with his/her general practitioner and/or physiotherapist presents a unique opportunity to form a partnership that will enhance treatment results and promote prevention. Providing a logical and simple explanation for the patients' pain and reassurance are of major importance (35). However, this might not be sufficient in LBP patients with elevated pain-related fear. Because pain-related fear is shown to be a prognostic factor of persisting disability special attention should be paid to these fears in that way reducing pain-related fear levels, enhancing global activity levels, and possibly preventing chronic disability to occur (this thesis; $(22,25)$ ). The last study in this thesis indicated that merely performing an activity repeated times does not increase performance time. This might indicate that enhancing activity levels in patients with acute LBP may need more structuring than just advising them to stay active, especially in those patients showing elevated levels of fear of movement(re)injury. In those cases, a fear reducing intervention may be warranted. Graded exposure is an intervention that uses a specific exercise prescription, tailored to 
the patient, combined with education directed at his or her own specific situation and history. It has been shown to reduce pain-related fear and enhance activity levels in chronic LBP patients $(5,65-67)$. In acute LBP patients an adapted version of graded exposure treatment has been studied by Sieben et al. (55). The secondary analyses in their study showed a positive effect on the pain problem in patients with remaining high levels of fear-of movement/(re)injury only, which is in line with the George study. In the Netherlands, physiotherapists have a good opportunity to apply graded exposure in cases with elevated pain-related fear due to time expenditure and their knowledge of activity-based treatment. However, before being able to apply graded exposure to patients, the physiotherapists should follow a special training.

Summarizing, in clinical practice, not all LBP patients benefit from or need specialized treatment strategies. The TSK can be used to identify patients with heightened levels of pain-related fear. In highly fearful persons, a tailored intervention might be more effective in reducing pain-related fear levels and increasing activity levels than is usual care. This might prevent chronic disability to appear.

\section{Conclusions}

The combined studies in this thesis generate strong evidence of the importance of the cognitive-behavioural model and of the value of pain-related fear in the transition of acute LBP to a more chronic stage of LBP. Furthermore, from this study is may be concluded that, in a sample of individuals with an episode of acute LBP, the TSK is a valuable measure to investigate fear of movement/ (re)injury. The experimental part of this thesis shows that acute LBP patients have a tendency to underpredict pain expectancies. Lastly, merely performing a physical task repeated times independent of levels of pain-related fear or of hierarchy of feared activities has no effect on performance, but results in more accurate pain predictions.

\section{Recommendations for future research}

The results of the studies in this thesis support the validity of a part of the cognitive-behavioural model (68) in acute back pain. Future research might build upon this model, further exploring the causality of the factors. For example: 1. Including only persons with a first time ever episode of acute LBP and following them a sufficiently long time; 2 . Prospectively investigating the association between painrelated fear, catastrophizing and disability in persons with acute LBP; 3 . Investigating the effects on disability in persons with an episode of acute LBP when manipulating the level of pain-related fear experimentally. This would facilitate the investigation of causal relationships in the transition from acute to chronic LBP. 
More attention should be paid to procedures to identify patients at risk of becoming chronic LBP patients. The TSK is one measurement instrument that can be used for screening purposes. However, more research is needed investigating the most optimal cut-off point of the TSK before using it as a screening measure in acute LBP patients. A valid method to determine the most optimal cut-off point of the TSK is calculating a Receiver Operating Curve (ROC). The most optimal cutoff point is then defined by the ROC with the largest area under the curve, showing the best sensitivity/specificity ratio. Besides that, more questionnaires exist measuring pain-related fear, e.g. the Fear-Avoidance Beliefs Questionnaire (FABQ (72)), the Fear of Pain Questionnaire (FPQ (42)), and the Pain Anxiety Symptoms Scale (PASS (40)). In our investigation, comparing the TSK and the FABQ, the TSK had slightly better psychometric properties. Although the constructs of the questionnaires overlap, there seems to be a difference. The TSK may be aimed more at measuring a fear of (re)injury, whereas the FABQ measures more a fear of pain directly caused by physical activities or work. Future studies may look in more detail examining the overlap and/or differences in construct between questionnaires measuring pain-related fear and investigating the populations in which to use the various instruments, e.g. acute versus chronic, LBP patients versus neck pain patients, the open population.

In the experimental study of this thesis, patients estimated the expected pain during the performance of the physical task. More attention might be paid to estimations of physical capacities in performing physical tasks. Besides that, investigation of the effects on actual performance of manipulating the estimations of pain and/or physical capacities might provide more insight into the patient's avoidance behaviour.

And last, but definitely not least, prevention of chronicity (and its costeffectiveness) is a major issue in government policy and LBP-research groups. This study shows that pain-related fear is a prognostic factor for future disability in a subgroup of persons with acute LBP. Although exposure-based interventions show promising results, more studies are needed to investigate the effect of these treatments on the prevention of chronic disability. Intervention studies mainly focus on chronic pain samples. Investigations in acute LBP samples are needed, e.g. single case studies with multiple measurements, to examine in more depths the influence of exposure-based treatment on acute LBP problems, and more directing this intervention at acute LBP patients. 


\section{References}

1. Arntz,A. and Claassens,L. The meaning of pain influences its experienced intensity. Pain 2004; 109 (1-2): 20-25.

2. Arntz,A. and Peters,M. Chronic low back pain and inaccurate predictions of pain: is being too tough a risk factor for the development and maintenance of chronic pain? Behav Res Ther 1995; 33 (1): 49-53.

3. Bekkering,G.E., Hendriks,H.J., van Tulder,M.W., Knol,D.L., Simmonds,M.J., Oostendorp, R.A., and Bouter,L.M. Prognostic factors for low back pain in patients referred for physiotherapy: comparing outcomes and varying modelling techniques. Spine $2005 ; 30$ (16): 18811886.

4. Boersma,K. Fear and avoidance in the development of a persistent musculoskeletal pain problem. Implications for secondary prevention. Thesis; 2005

5. Boersma,K., Linton,S., Overmeer,T., Jansson,M., Vlaeyen,J.W.S., and de Jong,J. Lowering fear-avoidance and enhancing function through exposure in vivo. A multiple baseline study across six patients with back pain. Pain 2004; 108 (1-2): 8-16.

6. Buchbinder,R., Jolley,D., and Wyatt,M. Population based intervention to change back pain beliefs and disability: three part evaluation. BMJ 2001; 322 (7301): 1516-1520.

7. Buer,N. and Linton,S.J. Fear-avoidance beliefs and catastrophizing: occurrence and risk factor in back pain and ADL in the general population. Pain 2002; 99 (3): 485-491.

8. Burton,A.K. and Waddell,G. Clinical guidelines in the management of low back pain. Baillieres Clin Rheumatol 1998; 12 (1): 17-35.

9. Chaory,K., Fayad,F., Rannou,F., Lefevre-Colau,M.M., Fermanian,J., Revel,M., and Poiraudeau,S. Validation of the French version of the fear avoidance belief questionnaire. Spine 2004; 29 (8): 908-913.

10. Chavannes,A.W., Mens,J.M.A., Koes,B.W., Lubbers,M.A.I., Ostelo,R.W., Spinnewijn, W.F.M., and Kolenaar,B.G.M. NHG-Standaard Aspecifieke lagerugpijn. Huisarts en Wetenschap 2005; 48 (3): 113-123.

11. Ciccone,D.S. and Just,N. Pain expectancy and work disability in patients with acute and chronic pain: A test of the Fear Avoidance hypothesis. J Pain 2001; 2 (3): 181-194.

12. Crombez,G., Eccleston,C., Baeyens,F., van Houdenhove,B., and van den,B.A. Attention to chronic pain is dependent upon pain-related fear. J Psychosom Res 1999; 47 (5): 403-410.

13. Crombez,G., Eccleston,C., Vlaeyen,J.W.S., Vansteenwegen,D., Lysens,R., and Eelen,P. Exposure to physical movements in low back pain patients: restricted effects of generalization. Health Psychol 2002; 21 (6): 573-578.

14. Crombez,G., Vlaeyen,J.W.S., Heuts,P.H.T.G., and Lysens,R. Pain-related fear is more disabling than pain itself. Evidence on the role of pain-related fear in chronic back pain disability. Pain 1999; 80 (1,2): 329-339.

15. Crook,J., Milner,R., Schultz,I.Z., and Stringer,B. Determinants of occupational disability following a low back injury: a critical review of the literature. J Occup Rehabil 2002; 12 (4): 277-295.

16. de Jong,J.R., Vlaeyen,J.W.S., Onghena,P., Cuypers,C., Hollander,M.D., and Ruijgrok,J. Reduction of pain-related fear in complex regional pain syndrome type I: The application of graded exposure in vivo. Pain 2005; 116 (3): 264-275.

17. de Vet,H.C., Terwee,C.B., and Bouter,L.M. Current challenges in clinimetrics. J Clin Epidemiol 2003; 56 (12): 1137-1141.

18. Denison,E., Asenlof,P., and Lindberg,P. Self-efficacy, fear avoidance, and pain intensity as predictors of disability in subacute and chronic musculoskeletal pain patients in primary health care. Pain 2004; 111 (3): 245-252.

19. Deyo,R.A. and Diehl,A.K. Psychosocial Predictors of Disability in Patients with Low Back Pain. J of Rheumatology 1988; 15 1557-1564.

20. Eccleston, C. and Crombez,G. Pain demands attention: a cognitive-affective model of the interruptive function of pain. Psychol Bull 1999; 125 (3): 356-366.

21. Eccleston, C., Crombez, G., Aldrich, S., and Stannard,C. Attention and somatic awareness in chronic pain. Pain 1997; 72 (1-2): 209-215. 
22. Frank,J.W., Brooker,A., DeMaio,S.E., Kerr,M.S., Maetzel,A., Shannon,H.S., Sullivan,T.J., Norman,R.W., and Wells,R.P. Disability resulting from occupational low back pain. PART II: What do we know about secondary prevention? A review of the scientific evidence on prevention after disability begins. Spine 1996; 21 (24): 2918-2929.

23. Fritz,J.M. and George,S.Z. Identifying psychosocial variables in patients with acute workrelated low back pain: the importance of fear-avoidance beliefs. Phys Ther 2002; 82 (10): 973-983.

24. Fritz,J.M., George,S.Z., and Delitto,A. The role of fear-avoidance beliefs in acute low back pain: relationships with current and future disability and work status. Pain 2001; 94 (1): 7-15.

25. George,S.Z., Fritz,J.M., Bialosky,J.E., and Donald,D.A. The effect of a fear-avoidance-based physical therapy intervention for patients with acute low back pain: results of a randomized clinical trial. Spine 2003; 28 (23): 2551-2560.

26. Goubert,L., Crombez,G., and De,B., I Low back pain, disability and back pain myths in a community sample: prevalence and interrelationships. Eur J Pain 2004; 8 (4): 385-394.

27. Goubert,L., Francken,G., Crombez,G., Vansteenwegen,D., and Lysens,R. Exposure to physical movement in chronic back pain patients: no evidence for generalization across different movements. Behav Res Ther. 2002; 40 (4): 415-429.

28. Houben,R.M., Gijsen,A., Peterson,J., de Jong,P.J., and Vlaeyen,J.W.S. Do health care providers' attitudes towards back pain predict their treatment recommendations? Differential predictive validity of implicit and explicit attitude measures. Pain 2005; 114 (3): 491-498.

29. Houben,R.M., Ostelo,R.W., Vlaeyen,J.W.S., Wolters,P.M., Peters,M., and Stomp-van den Berg SG Health care providers' orientations towards common low back pain predict perceived harmfulness of physical activities and recommendations regarding return to normal activity. Eur J Pain 2005; 9 (2): 173-183.

30. Jong,P.J.d., Hout,M.A.v.d., Rietbroek,H., and Huijding,J. Dissociations between implicit and explicit attitudes toward phobic stimuli. Cogn Emotion 2003; 17 (4): 521-545.

31. Klaber Moffett,J.A., Carr,J., and Howarth,E. High fear-avoiders of physical activity benefit from an exercise program for patients with back pain. Spine 2004; 29 (11): 1167-1172.

32. Klenerman,L., Slade,P.D., Stanley,I.M., Pennie,B., Reilly,J.P., Atchison,L.E., Troup, J.D.G., and Rose,M.J. The prediction of chronicity in patients with an acute attack of low back pain in a general practice setting. Spine 1995; 20 (4): 478-484.

33. Koes,B.W., Sanders,R.J., and Tuut,M.K. CBO-richtlijn voor diagnostiek en behandeling van acute en chronische aspecifieke lage rugklachten. Ned Tijdschr Geneeskd 2004; 148 (7): 310-314.

34. Kori,S.H., Miller,R.P., and Todd,D.D. Kinesophobia: a new view of chronic pain behaviour. Pain Management 1990; (1): 35-43.

35. Linton,S.J. (ed) Understanding pain for better clinical practice. A psychological perspective. 2005: pp. 99-106

36. Linton,S.J., Buer,N., Vlaeyen,J.W.S., and Hellsing,A.L. Are fear-avoidance beliefs related to the inception of an episode of back pain? A prospective study. Psychology and Health 2000; 14: $1051-1059$.

37. Linton,S.J., Vlaeyen,J.W.S., and Ostelo,R. The back pain beliefs of health care providers: are we fear-avoidant? J Occup Rehabil 2002; 12 (4): 223-232.

38. Lundberg,M.K.E., Styf,J., and Carlsson,S.G. A psychometric evaluation of the Tampa Scale for Kinesiophobia - from a physiotherapeutic perspective. Physiotherapy Theory and Practice $2004 ; 20121-133$.

39. McCracken,L.M., Gross,R.T., Sorg,P.J., and Edmands,T.A. Prediction of Pain in Patients with Chronic Low Back Pain: Effects of Inaccurate Prediction and Pain-Related Anxiety. Behav Res Ther 1993; 31 (7): 647-652.

40. McCracken,L.M., Zayfert,C., and Gross,R.T. The pain anxiety symptoms scale: development and validation of a scale to measure fear of pain. Pain 1992; 50: 67-73.

41. McGorry,R.W., Webster,B.S., Snook,S.H., and Hsiang,S.M. The relation between pain intensity, disability, and the episodic nature of chronic and recurrent low back pain. Spine 2000; 25 (7): 834-841.

42. McNeil,D.W., Rainwater,A.J., and Al-Jazireh,L. Development of a methodology to measure fear of pain. 1986; 
43. Nachemson,A.L. and Jonsson,E. (eds) Neck and back pain. The scientific evidence of causes, diagnosis and treatment. Philadelphia: Lippincott Williams and Wilkins, 2000

44. Peters,M.L., Vlaeyen,J.W.S., and Kunnen,A.M. Is pain-related fear a predictor of somatosensory hypervigilance in chronic low back pain patients? Behav Res Ther 2002; 40 (1): 85 103.

45. Pfingsten,M., Kroner-Herwig,B., Leibing,E., Kronshage,U., and Hildebrandt,J. Validation of the German version of the Fear-Avoidance Beliefs Questionnaire (FABQ). Eur J Pain 2000; 4 (3): 259-266.

46. Pincus, T., Burton,A.K., Vogel,S., and Field,A.P. A systematic review of psychological factors as predictors of chronicity/disability in prospective cohorts of low back pain. Spine 2002; 27 (5): E109-E120.

47. Portney,L.G. and Watkins,M.P.Foundations of clinical research. Applications to practice. Appleton and Lange, 2000

48. Rachman,S. Human fears: A Three Systems Analysis. Scand J Behav Ther 1978; 7237 245.

49. Rachman,S. and Arntz,A. The overprediction and underprediction of pain. Clin Psychol Rev 1991; 11 339-355.

50. Rainville,J., Bagnall,D., and Phalen,L. Health care providers' attitudes and beliefs about functional impairments and chronic back pain. Clin J Pain 1995; 11 (4): 287-295.

51. Rainville,J., Carlson,N., Polatin,P., Gatchel,R.J., and Indahl,A. Exploration of physicians' recommendations for activities in chronic low back pain. Spine 2000; 25 (17): 2210-2220.

52. Rainville,J., Pransky,G., Indahl,A., and Mayer,E.K. The physician as disability advisor for patients with musculoskeletal complaints. Spine 2005; 30 (22): 2579-2584.

53. Roelofs, J., Peters,M.L., Zeegers,M.P., and Vlaeyen,J.W.S. The modified Stroop paradigm as a measure of selective attention towards pain-related stimuli among chronic pain patients: a meta-analysis. Eur J Pain 2002; 6 (4): 273-281.

54. Sieben,J.B., Verbunt,J.A., Jong,J.d., and Vlaeyen,J.W.S. Fear of movement / (re)injury in musculoskeletal pain disorders. In Simmonds, $M($ ed): Measuring and managing patients. In press.

55. Sieben,J.M. Pain-related fear in acute low back pain: towards understanding and prevention of chronicity. Thesis 2005

56. Sieben,J.M., Vlaeyen,J.W.S., Portegijs,P.J., Verbunt,J.A., Riet-Rutgers,S., Kester,A.D., Von Korff,M., Arntz,A., and Andre,K.J. A longitudinal study on the predictive validity of the fearavoidance model in low back pain. Pain 2005; 117 (1-2): 162-170.

57. Sieben,J.M., Vlaeyen,J.W.S., TuerlinckX,S., and Portegijs,P.J.M. Pain-related fear in acute low back pain: the first two weeks of a new episode. Eur J of Pain 2002; 6 229-237.

58. Spalding,L.R. and Hardin,C.D. Unconscious unease and self-handicapping: behavioral consequences of individual differences in implicit and explicit self-esteem. Psycol Sci 1999; $10535-539$.

59. Streiner,D.L. and Norman,G.R. Health Status Measurement Scales. A practical guide to their development and use. Oxford: Oxford University Press, 2003

60. Tulder,M.W.v. and Koes,B.W. Evidence-based handelen bij lage rugpijn. Epidemiologie, preventie, diagnostiek, behandeling en richtlijnen. Bohn Stafleu Van Loghum, 2004

61. Turk,D.C. The role of demographic and psychosocial factors in transition from acute to chronic pain. In Jensen,T.S., Turner,J.A., Wiesenfeld,Z. (eds): Progress in pain research and management. Seattle: IASP, 1997; pp. 185-214

62. Turner,J.A., LeResche,L., Von Korff,M., and Ehrlich,K. Back pain in primary care. Patient characteristics, content of initial visit, and short-term outcomes. Spine 1998; 23 (4): 463-469.

63. Valat,J.P., Goupille,P., and Vedere,V. Low back pain: risk factors for chronicity. Rev.Rhum.Engl.Ed 1997; 64 (3): 189-194.

64. Vet,H.C.W.d., Terwee,C.B., and Bouter,L.M. Current challenges in clinimetrics. J Clin Epidemiol 2003; 56 (12): 1137-1141.

65. Vlaeyen,J.W.S., de Jong,J., Geilen,M., Heuts,P.H.T.G., and van Breukelen,G. Graded exposure in vivo in the treatment of pain-related fear: a replicated single-case experimental design in four patients with chronic low back pain. Behav Res Ther 2001; 39 (2): 151-166. 


\section{Chapter nine}

66. Vlaeyen,J.W.S., Jong,J.R.d., Geilen,M., Heuts,P.H.T.G., and Breukelen,G.v. The treatment of fear of movement/(re)injury in chronic low back pain: further evidence on the effectiveness of exposure in vivo. Clin J Pain 2002; 18 (4); 251-261.

67. Vlaeyen,J.W.S., Jong,J.R.d., Onghena,P., Kerckhoffs-Hanssen,M., and Kole-Snijders, A.M. Can pain-related fear be reduces? The application of cognitive-behavioural exposure in vivo. Pain Res Manag 2002; 7 (3): 144-153.

68. Vlaeyen,J.W.S. and Linton,S.J. Fear-avoidance and its consequences in chronic musculoskeletal pain: a state of the art. Pain 2000; 85 (3): 317-332.

69. Von Korff,M. Studying the natural history of back pain. Spine 1994; 19 (18S): 2041S-2046S.

70. Von Korff,M. and Saunders,K. The Course of Back Pain in Primary Care. Spine 1996; 21 (24): 2833-2839.

71. Waddell,G. The back pain revolution. Edinburgh: Churchill Livingstone, 1998

72. Waddell,G., Newton,M., Henderson,I., Somerville,D., and Main,C.J. A fear avoidance beliefs questionnaire (FABQ) and the role of fear-avoidance beliefs in chronic low back pain and disability. Pain 1993; 52 157-168.

73. Woby,S.R., Roach,N.K., Urmston,M., and Watson,P.J. Psychometric properties of the TSK11: A shortened version of the Tampa Scale for Kinesiophobia. Pain 2005; 117 (1-2): 137144. 
Summary 


\section{Summary}

Non-specific low back pain (LBP) is an unpleasant benign syndrome, with life-time prevalence ratings varying between $60 \%-90 \%$ in the general population. Although the natural course of LBP is favourable, a relatively small group of individuals will experience persisting limitations of activities caused by their LBP. The societal costs of LBP are immense and $75 \%-90 \%$ of these costs (in the Netherlands: $\$ 4.9$ billions) are accounted for by persons that have developed a more chronic stage of LBP. The high personal burden and societal costs justifies the development of strategies that prevent chronic LBP. Until the seventies, the majority of research concerning LBP was aimed at identifying biomedical causes of (chronic) LBP and its related disability. With the advent of the gate-control theory and the discovery that cognitive and affective factors might modulate nociceptive information, a more biopsychosocial approach to chronic pain and disability became accepted. Stimulated by these new insights and paradigm shift, behavioural scientists developed cognitive-behavioural models of (chronic) pain. According to one of these models, pain catastrophizing plays a crucial role in the interpretation of pain, causing painrelated fear. The subsequent safety behaviour (e.g. avoidance behaviour and hypervigilance) may, in the long term, have a paradoxical effect, increasing pain and fear instead of reducing it. The avoidance behaviour particularly concerns activities, which the individual interprets as threatening, damaging to the back, or increasing the pain problem. This avoidance of activities, caused by fear of movement, may result in increased disability, disuse and depressive feelings. The last decennium, research concerning pain-related fear and avoidance behaviour in LBP has primarily been directed at the question why pain persists and hardly at the role of pain-related fear in the transition of acute LBP to a more chronic stage of back pain. Besides that, little is known regarding the role of pain catastrophizing and its relation with (expected) pain and disability in persons experiencing an episode of acute LBP. This thesis provides the initial impetus to answering some of the questions that exist concerning the role of pain-related fear and pain catastrophizing in persons experiencing an acute LBP episode.

Chapter 1 provides a general introduction, in which characteristic features, epidemiological data, and societal context of LBP are discussed. Besides that, the cognitive-behavioural model, pain-related fear, and pain catastrophizing are introduced and the literature regarding these factors is briefly reported.

In chapters 2 and 3 some of the psychometric properties of the Tampa Scale for Kinesiophobia (TSK) and the Fear-Avoidance Beliefs Questionnaire (FABQ) in persons with acute LBP were investigated. The TSK was developed to measure fear of movement/(re)injury in persons with LBP. Test-retest stability and internal consistency of the TSK were satisfactory. The FABQ measures fear-avoidance beliefs of LBP patients (i.e. the beliefs that avoidance of activities is the most op- 
timal way of preventing the pain to increase). The FABQ is divided in two subscales, a physical activity scale and a work scale. Both subscales showed moderate to good reliability. Viewing the agreement parameters as found in the second study concerning psychometric qualities of both measurement instruments, it may be concluded that the TSK was slightly superior to the FABQ. This is caused by the smaller Standard Error of Measurement, a smaller Minimal Detectable Change, and the absence of floor or ceiling effects.

Chapter 4 described a cross-sectional investigation in which the influence of fearavoidance beliefs on perceived disability and participation, as measured with the $F A B Q$, was examined as well as the factor structure of the $F A B Q$ in a sample of acute LBP patients. The two-factor model of the FABQ (i.e., physical activity scale and work scale) as originally found by Waddell et al. was replicated. Next, the association of the two FABQ-factors with perceived disability and participation was examined in a working sample and a non-working population. The two subscales were significantly associated with perceived disability and participation, although there were small differences between the associations in the two samples. Lastly, it was demonstrated that perceived disability mediates the association between fear-avoidance beliefs and participation.

Chapter 5 presents the results of a cross-sectional study investigating the factor structure of the TSK and the associations of the TSK and its subscales with perceived disability and participation. A two-factor model of the TSK was obtained, which was highly comparable to the two-factor model found in chronic pain populations. The factors were labelled 'harm' (i.e., reflecting the beliefs that there is something seriously wrong with the body), and 'activity avoidance' (i.e., indicating the beliefs that avoiding exercise or activities might prevent an increase of pain). Both constructs were substantially and significantly associated with disability and participation. Finally, it could be demonstrated that the association between painrelated fear, pain intensity, and participation was mediated by disability.

Chapter 6 concerned a prospective study of the hypothesized role of pain-related fear in the transition of acute LBP into a more chronic, disabling stage. According to the cognitive-behavioural model, patients with elevated baseline pain-related fear were expected to have higher levels of future disability and more limitations in future participation than persons with low baseline levels of fear. A cohort of 555 acute LBP patients included by general practitioners and physical therapists in primary care settings was followed for six months. The results indicated that baseline fear of movement/(re)injury was predictive of future perceived disability and to a lesser extent of participation. It was concluded that pain-related fear is present early in an episode of acute LBP influencing its course. Interventions aimed at reducing pain-related fear in the acute stage of LBP, might prevent restrictions of activity and participation thereby preventing acute pain to become chronic LBP. 
The studies in chapters two to six used self-report measures of disability and participation as outcome measures. In chapter 7 , an experimental study is described studying the hypothesis whether pain-related fear in acute LBP patients is associated with reduced physical performance, which might be an indication of flight and avoidance behaviour. Research questions concerned the association of pain catastrophizing and pain-related fear with actual performance and perceived disability. 96 persons with acute LBP performed a dynamic lifting task after completing measures of pain intensity, pain-related fear, pain catastrophizing, and perceived disability. Using lifting time as outcome measure, pain-related fear was the strongest predictor of the physical task. Both pain-related fear and pain catastrophizing were significantly predictive of perceived disability (Roland Disability Questionnaire), even more strongly than pain intensity was.

Chapter 8 provided an extension of the experimental investigation described in chapter 7. Persons with acute LBP were requested to perform the lifting task three times with a pause of five minutes in between. Furthermore, they were asked to report the expected pain before and the experienced pain after the task. In this way, the effects of pain-related fear and pain catastrophizing on repeated task exposure and on pain predictions were examined in an acute LBP sample. We hypothesized that (1) there would be a positive association between catastrophizing and pain-related fear, and overpredictions of pain; (2) that these pain predictions would be corrected more rapidly by low fearful persons or low catastrophizers as compared to high catastrophizers or high fearful persons; and lastly, (3) the level of performance would increase with repeated exposure. Generally, the results showed an underprediction of pain expectancies. Low catastrophizers, but not low fearful patients, corrected their pain prediction after one lifting bout. High catastrophizers needed two lifting bouts to predict their expected pain accurately. Furthermore, repeated performance of the physical lifting task did not result in a better performance. However, there was a significant main effect of pain catastrophizing and pain-related fear on lifting time.

Chapter 9 and the final chapter of this thesis provided a brief summary of the main results from the thesis as well as a general discussion of the findings.. Some strengths and weaknesses of the studies were discussed. Clinical implications and final conclusions of this thesis were given. Lastly, recommendations for future research were discussed. 
Samenvatting 


\section{Inleiding}

A-specifieke lage-rugpijn (LRP) is een onaangename maar vaak voorkomende klacht. $60 \%$ tot $90 \%$ van de mensen maken wel eens een acute rugpijn episode mee in zijn of haar leven. Hoewel het natuurlijk beloop van LRP gunstig is, blijft een relatief kleine groep langdurig beperkt vanwege rugpijn. De maatschappelijke kosten van deze chronische rugpijn zijn immens en bedragen ca. $75-90 \%$ van de totale kosten die voor rugpijn worden gemaakt (in Nederland is dat ongeveer $€ 4,9$ miljard). De grote persoonlijke problemen en de hoge maatschappelijke kosten benadrukken het belang van de preventie van chronische LRP. Tot de jaren zeventig lag het zwaartepunt van het onderzoek betreffende LRP op het detecteren van biomedische oorzaken van (chronische) LRP en de daarmee samenhangende beperkingen in de uitvoering van dagelijkse activiteiten. Onder meer door de introductie van de gate-control theorie, en de ontdekking dat de transmissie van nociceptieve informatie gemoduleerd kan worden door cognitieve en affectieve factoren, werd chronische pijn in toenemende mate bestudeerd vanuit een biopsychosociaal perspectief. Geholpen en gestimuleerd door deze paradigma shift, hebben een aantal gedragswetenschappers het vrees-vermijdings model ontwikkeld. In dit model wordt een belangrijke rol weggelegd voor de catastrofale interpretatie van pijn, die vervolgens leidt tot pijngerelateerde vrees. De daarop volgende veiligheidsgedragingen (vermijdingsgedrag en hypervigilantie) hebben op lange termijn een paradoxaal effect. In plaats van het reduceren van pijn houden deze gedragingen de vrees en pijn in stand. Het vermijdingsgedrag betreft vooral activiteiten die door het individu als bedreigend worden geïnterpreteerd, als zijnde schadelijk voor de rug, of waarvan hij verwacht dat deze de pijn zal doen toenemen. Het door deze bewegingsvrees veroorzaakte vermijden van activiteiten kan uiteindelijk leiden tot een verhoogde mate van beperkingen in activiteiten, eventueel zelfs leidend tot een deconditionerings syndroom en depressieve gevoelens.

Het onderzoek naar vrees en vermijding bij rugpijn heeft zich het afgelopen decennium voornamelijk gericht op de in stand houding van chronische pijn, en nauwelijks op de rol van pijngerelateerde vrees in het ontstaan van chronische LRP. Ook is er tot op heden weinig bekend over de rol van catastroferen en de relaties met (verwachte) pijn en beperkingen in activiteiten bij mensen met een episode van acute LRP. Dit proefschrift is een eerste aanzet tot het beantwoorden van de vragen naar de rol van pijngerelateerde vrees, en catastroferen bij mensen met een episode van acute LRP.

Hoofdstuk 1 geeft een algemene introductie waarin de typische kenmerken van rugpijn en de maatschappelijk context worden verduidelijkt. Tevens wordt het cognitief-gedragsmatig model, pijngerelateerde vrees en pijn catastroferen geïntroduceerd. 
In hoofdstuk 2 en 3 worden enkele van de psychometrische eigenschappen van de Tampa Schaal voor Kinesiofobie (TSK) en de Fear-Avoidance Beliefs Questionnaire (FABQ) onderzocht in een steekproef van personen met acute LRP. De TSK is ontwikkeld om vrees voor beweging en/of letsel bij personen met LRP te meten. De test-hertest betrouwbaarheid en de interne consistentie van de TSK zijn voldoende gebleken. De FABQ geeft een indruk van de mate waarin personen geloven dat het vermijden van activiteiten de beste manier is om geen toename van pijn te krijgen. Ze bestaat uit twee subschalen, een activiteiten subschaal en een werk subschaal. Beide subschalen zijn matig tot goed betrouwbaar. Wanneer we kijken naar de parameters voor overeenkomst (agreement) zoals gevonden in de tweede studie betreffende de psychometrische eigenschappen van de TSK en de FABQ, dan mogen we concluderen dat de TSK iets superieur is aan de FABQ. Dit wordt veroorzaakt door de kleinere Standard Error of Measurement (standaard meetfout), een kleinere Minimal Detectable Change (minimaal detecteerbare verandering) en het afwezig zijn van grond of plafond effecten.

Hoofdstuk 4 beschrijft een cross-sectioneel onderzoek naar de invloed van pijngerelateerde vrees, zoals gemeten door de FABQ, op ervaren beperkingen in activiteiten en participatie. Tevens werd onderzocht of de originele factor structuur bevestigd kon worden in een steekproef van patiënten met acute rugpijn. De resultaten van een confirmatieve factor analyse bevestigen het bestaan van een 'werk' factor en een 'fysieke activiteiten' factor binnen de FABQ. Er bestaan significante relaties tussen beide factoren en ervaren beperkingen in activiteiten en participatie zoals onderzocht binnen een werkende en niet-werkende groep personen met acute LRP. Er bestonden kleine verschillen tussen de associaties van de betreffende factoren in de verschillende steekproeven. Tenslotte kon worden aangetoond dat de relatie tussen pijn-gerelateerde vrees en participatie gemedieerd wordt door ervaren beperkingen in de uitvoering van dagelijkse activiteiten.

Hoofdstuk 5 presenteert de resultaten van een cross-sectioneel onderzoek naar de factor structuur van de TSK en de associaties van de TSK, en eventuele subschalen, met ervaren beperkingen en participatie. Er werd een twee-factor structuur gevonden die, hoewel verschillend, sterk leek op de factor structuur zoals gevonden in populaties met chronische pijn. De factoren werden als volgt benoemd: 'harm' (letsel) wat de overtuiging van de persoon weergeeft dat er iets ernstigs met de rug aan de hand is; en 'activity avoidance' (activiteiten vermijden) wat aangeeft dat de persoon denkt dat het vermijden van bepaalde activiteiten een toename van pijn voorkomt. Beide factoren zijn significant geassocieerd met het niveau van activiteiten en participatie. Tot slot kon worden aangetoond dat de relatie tussen pijngerelateerde vrees en pijn intensiteit enerzijds en participatie anderzijds wordt gemedieerd door beperkingen in activiteiten. 
Hoofdstuk 6 betreft een prospectieve studie naar de rol van pijngerelateerde vrees in de overgang van acute LRP naar een meer chronisch stadium van beperkende rugklachten. Volgens het cognitief-gedragsmatig model zouden patiënten met een verhoogd niveau van pijngerelateerde vrees in de acute fase meer beperkingen ervaren in de loop der tijd (i.c. zes maanden), dan personen met een laag beginniveau van angst. Een cohort van 555 patiënten met LRP geïncludeerd door huisartsen en fysiotherapeuten in de eerstelijns gezondheidszorg werden gedurende 6 maanden gevolgd. De resultaten laten zien dat vrees voor beweging/letsel zoals in de begin situatie gemeten predictief is voor de, ervaren beperkingen in activiteiten en in mindere mate ook voor participatie gemeten zes maanden later Er kon worden geconcludeerd dat pijngerelateerde vrees vroegtijdig tijdens een episode van LRP aanwezig is en het beloop van de rugklachten beïnvloedt. Specifieke behandelstrategieën in het vroegtijdig stadium van een rugklacht, gericht op reductie van deze vrees, zouden toekomstige beperkingen in activiteiten en/of participatie kunnen verminderen en zo mogelijk het ontstaan van chronische LRP kunnen voorkomen.

De studies in hoofdstukken $2 \mathrm{t} / \mathrm{m} 6$ zijn gebaseerd op uitsluitend zelf-rapportage. In hoofdstuk 7 wordt in een experimentele studie de vraag onderzocht of pijngerelateerde vrees bij patiënten met acute pijn geassocieerd is met verminderde fysieke performantie als indicatie voor vlucht- en vermijdingsgedrag. De onderzoeksvragen concentreerden zich in eerste instantie op het aantonen van een associatie tussen catastroferen, pijngerelateerde angst enerzijds en performantie en ervaren beperkingen in activiteiten anderzijds. 96 personen met acute LRP werden gevraagd een dynamische tiltaak uit te voeren, nadat ze verschillende vragenlijsten voor pijn intensiteit, pijngerelateerde angst, pijn catastroferen en beperkingen in activiteiten hadden ingevuld. Pijngerelateerde vrees was de sterkste voorspeller voor het uitvoeren van de tiltaak, waarbij tiltijd werd aangehouden als uitkomstmaat. Namen we ervaren beperkingen in activiteiten als uitkomstmaat (Roland Disability Questionnaire), dan waren zowel pijngerelateerde vrees als catastroferen significant geassocieerd met ervaren beperkingen in activiteiten, zelfs sterker dan de mate van pijn was.

Hoofdstuk 8 vormt een uitbreiding van het onderzoek beschreven in hoofdstuk 7 . Patiënten met acute LRP werden verzocht de tiltaak $3 x$ uit te voeren met een pauze van $5 \mathrm{~min}$. tussen elke taak. Tevens werd hen gevraagd de verwachte pijn voor de taak en de daadwerkelijk ervaren pijn tijdens de uitvoering van de tiltaak respectievelijk voor en na de uitvoering op te schrijven. Op deze wijze wilden we de effecten van pijngerelateerde vrees en catastroferen op het herhaalde blootstelling aan de taak en op de pijn predicties bestuderen in een steekproef van patiënten met acute rugpijn. We verwachtten: (1) dat er een positieve associatie zou zijn tussen pijngerelateerde angst, catastroferen en overschatten van verwachte pijn; (2) dat laag angstigen en laag catastrofeerders verkeerde predicties sneller zou- 
den corrigeren dan hoog angstigen/catastrofeerders; en tenslotte (3) dat de tiltijd zou toenemen naarmate de patiënten vaker hadden getild; Over het algemeen genomen verwachtten de patiënten minder pijn dan ze daadwerkelijk ervoeren. Laag catastrofeerders en niet laag angstigen, hadden slechts een keer tillen nodig om de verwachte pijn juist te voorspellen. Hoog catastrofeerders daarentegen hadden tweemaal tillen nodig. Het herhaald uitvoeren van de fysieke taak resulteerde niet in een langere uitvoering van deze taak. Maar er was wel een significant hoofdeffect van catastroferen en pijngerelateerde angst op tiltijd.

Hoofdstuk 9 en het laatste hoofdstuk van deze dissertatie geeft een korte samenvatting en een algemene discussie van de belangrijkste resultaten. De sterke en minder sterke aspecten van de studies worden in hoofdlijnen besproken. Tevens wordt aandacht besteed aan de klinische implicaties van dit onderzoek en worden conclusies geformuleerd. Tenslotte worden een aantal aanbevelingen voor toekomstig onderzoek gedaan. 


$$
\text { . }
$$


DANKWOORD 


\section{DANKWOORD}

Zeven jaar geleden begon dit onderzoek als afstudeerproject aan de Vrije Universiteit van Brussel. Als iemand toen had gezegd dat het zou leiden tot een promotie, had ik hem/haar absoluut niet geloofd. Desalniettemin leest $u$ nu de resultaten van zeven jaar verdieping in het fenomeen vrees bij lage rugpijn. Het waren leerzame jaren, zeker niet alleen op mijn vakgebied. Het waren leuke jaren. Onderzoek doen is ongelooflijk interessant en leuk en opent steeds weer nieuwe perspectieven. Hoewel ik dit promotie onderzoek als extraneus heb verricht en het lijkt alsof je het in je eentje doet, is dat ver buiten de waarheid. In de afgelopen zeven jaar zijn en waren er heel veel personen die me hebben geholpen en gesteund. Ik wil bij voorbaat iedereen die me van nabij, in mijn omgeving of van veraf heeft geholpen, gesteund, een zetje de goede richting heeft gegeven of anderszins, heel hartelijk danken. Zonder jullie steun en begrip had ik dit nooit voor elkaar gekregen: Dank jullie. Uiteraard zijn er een aantal personen die ik uitgebreider wil bedanken.

Johan, jij bijt de spits af. Toen ik in Israël vroeg of je me wilde helpen bij het onderzoek waar ik al mee begonnen was, antwoordde je positief, maar met de kanttekening dat je niet ruim in je tijd zat. Heel langzaam aan werd je er steeds meer bij betrokken. Uiteindelijk ben je eerste promotor geworden. Dat doet me ongelooflijk plezier, want jouw inzet is cruciaal geweest om tot dit eindresultaat te komen. De bijeenkomsten die we hadden waren voor mij altijd een stimulans. Jouw kennis, rust, enthousiasme, positieve, opbouwende kritiek, maar vooral jouw vertrouwen in mij waren een enorme steun en hebben tot dit mooie resultaat geleid.

Rob, toen ik in 1998 begon met dit onderzoek als afstudeerproject voor de opleiding Manuele Therapie aan de faculteit Geneeskunde en Farmacie van de Vrije Universiteit Brussel, was jij daar hoogleraar. Ik studeerde af op een klein deel van dit onderzoek en had toen absoluut niet in de gaten dat het zo'n grootschalig project was. Jij zag dat wel en vroeg me al snel of ik eens wilde nadenken over een promotie-traject. $\mathrm{Nu}$, acht jaar later, is het dan zover. Het boekje is klaar, de artikelen geschreven en de meeste gepubliceerd. Dank je voor jouw aanzet en inzet. Als jij er niet over was begonnen, was ik er nooit aan begonnen.

André, jouw bescheidenheid siert je. Gedurende het project zei je steeds dat je net zoveel leerde als ik. Ik betwijfel dat. Steeds was je bereid om naar Maastricht te komen. Je was vaak langer onderweg dan dat je daar was. Tijdens die bijeenkomsten was je ook vaak bescheiden, maar je opmerkingen sneden altijd hout. Jouw positieve reacties en complimenten hebben ertoe bijgedragen dat ik met veel plezier terugkijk op de afgelopen jaren en in het bijzonder op onze bijeenkomsten. 
Jeffrey, als laatste van mijn promotie-team. Bijna vanaf het begin ben je betrokken geweest bij mijn promotie-perikelen. Je was, aanvankelijk, officieel geen copromotor, maar officieus was je dat wel degelijk. Je was mijn steun en toeverlaat. Ik kan hier eerlijk schrijven dat het zonder jou niets was geworden. Je kennis van analyse technieken, van de Engelse taal, maar vooral je inhoudelijke kennis maakten dat je voor mij de vraagbaak was die ik broodnodig had. Maar, het meest belangrijke nog, je stond altijd voor me klaar en het was je nooit teveel. Het doet me plezier dat je ook officieel mijn co-promotor bent geworden. Je inzet en bijdrage rechtvaardigen dit absoluut.

Bij patiënt gebonden onderzoek vormt het includeren van die personen die voldoen aan de juiste criteria een groot probleem. Mijn "probleem" werd opgelost door de persoonlijke en geheel onbaatzuchtige inzet van een groot aantal fysiotherapeuten en huisartsen. Zonder hen en hun ideële inzet was dit onderzoek nooit geworden wat het uiteindelijk geworden is. Velen hebben jarenlang patiënten met acute lage rugpijn geïncludeerd. Dank jullie.

Dank ook aan al die mensen, gelukkig voor mij, helaas voor hen, met acute lage rugpijn. Zitten is vaak zo pijnlijk bij rugpijn en dan toch al die vragenlijsten invullen of zelfs een zware tas tillen. Ruim 700 mensen hebben aan dit onderzoek meegedaan. Hun pijn en moeite is niet voor niets geweest.

De combinatie van klinisch werk en onderzoek maakt dat er veel flexibiliteit van collegae wordt gevergd. Carine, Corinne, Maartje en Merijn, dank jullie voor het steeds weer luisterend oor hebben voor mijn verhalen, voor het begrip hebben en vaak ook gerust stellen. Met twee promovendi in een praktijk zullen jullie er zeker onder te lijden hebben gehad.

Eric, Wendy en Willem, als vrijwillig assistent aan de VUB gaven jullie me alle vrijheid om "nee" te zeggen als het me eens niet uitkwam. Er zijn niet veel collegae die dat zo makkelijk zouden opvangen. Ik vond het fijn met jullie samen te werken en heb veel van jullie geleerd. Wendy, ik mis onze lange gesprekken in de auto op weg naar Brussel.

In de afgelopen jaren, waarin je de dagen vaak te vol propt met werk, studie, of onderzoek, doe je soms vriendschappen tekort. Het is geweldig om te ervaren hoe vrienden meeleven en accepteren dat je soms even geen of minder tijd hebt, maar je ook geweldig weten te stimuleren. Jan en Annelies, jullie zitten in dezelfde situatie als Raymond en ik. Annelies, jij was de eerste. Jan, zet hem op, we bewaren het beste gewoon voor het laatst. Ria en Ton, Dineke en Sibbe, jullie zijn geweldige vrienden, die altijd voor me klaarstaan, dank jullie. 
Ik besef dat ik toch een beetje een vreemde eend in de bijt was bij het Departement Medische, Klinische en Experimentele Psychologie (DMKEP) van de Universiteit Maastricht en bij het interfacultaire onderzoeksinstituut Experimentele Psychopathologie (EPP). Dit leidde echter veeleer tot prettige en waardevolle discussies dan tot vragen. Het is geweldig zoals iedereen bij DMKEP voor me klaar stond als ik hulp nodig had, met name Eric, die me hielp met de GEE-analyses en natuurlijk alle anderen.

De volgende personen wil ik bedanken voor hun inzet, hulp dan wel nuttige discussies: Judith, het was verhelderend om met jou van gedachten te kunnen wisselen; Kim en Sven, fijn dat jullie meehielpen bij de metingen voor het experimenteel onderzoek; Raymond, jouw uitleg en kennis van SEM's, MCD's, MIC's etc. was helder en onontbeerlijk voor me, dank daarvoor.

Ouders steunen en stimuleren hun kinderen zoveel mogelijk om zich te ontwikkelen. Mijn ouders waren niet anders en ze waren trots op ieder behaald resultaat. Het is jammer dat mijn moeder het niet meer mag meemaken. Pap, mama zou hartstikke blij en zenuwachtig zijn geweest. In gedachten is ze bij ons. Dank jullie voor jullie belangstelling en steun al die jaren.

Ook mijn lieve schoonouders wil ik bedanken. Mam, eindelijk is het dan zover. $U$ leefde zo met ons mee. Dank u voor uw morele steun en liefde. Pap zou het geweldig hebben gevonden; twee van zijn kinderen gepromoveerd.

En als laatsten van de familie; Carla, Yvonne en Conny, jullie zijn fijne zussen die net zo blij waren als ik wanneer er weer een manuscript was aangenomen. Ik zie uit naar onze volgende zussendag.

Rest mij nog de personen te bedanken die me het meest dierbaar zijn: Raymond, Mendy en Koen.

Mendy en Koen, jullie weten niet bèter of Raymond en ik waren aan het werk, zaten achter de computer of waren anderszins bezig. Ik weet zeker dat jullie dat niet altijd even leuk hebben gevonden. $\mathrm{Nu}$, het tweede en laatste boekje is af. Dank voor jullie geduld en enthousiasme, jullie zijn onmisbare schatten. Op naar Afrika.

Raymond, dit dankwoord kan nooit genoeg zijn. Je had meer geloof in mijn kunnen dan ikzelf. Je steunde me niet alleen moreel, maar ook daadwerkelijk met het onderzoek. Je stimuleerde me en we hebben oneindig veel gepraat over fysiotherapie en onderzoek. Promoveren is niet het belangrijkste op de wereld, maar aan het einde van zo'n project lijkt het er wel op. Weet dat jij het belangrijkste bent voor mij. Dank voor jouw onvoorwaardelijke steun en liefde. 
ABOUT THE AUTHOR 


\section{ABOUT THE AUTHOR}

Ilse Swinkels was born on December 19, 1957 in Raamsdonk, the Netherlands. She obtained her Gymnasium diploma in 1976 at the Mensia de Mendoza Lyceum in Breda. She then started her physiotherapy study at the College of Physiotherapy (in Breda) and graduated in 1980. She worked five years as a physiotherapist in various private practices in primary healthcare setting. From 1986 to 1994 she was a fulltime housewife after which she resumed working as a physiotherapist. She combined work with her study Manual Therapy, which she started in 1995 at the Free University in Brussels, Belgium, where she graduated in 1999. Her master's thesis focused on the reliability of two measures of pain-related fear as part of an extensive cohort study. During the period from 1998 to 2005, she carried out the studies included in this thesis, from 2003 as a non-resident researcher at the Department of Medical, Clinical, and Experimental Psychology at Maastricht University. For the purpose of her thesis' studies she attended a Postgraduate Epidemiology Programme at the Institute for Research in Extramural Medicine of the Free University Amsterdam (2000-2001). Furthermore, besides working as a physiotherapist (1994-), she was an assistant professor at the Department of Experimental Anatomy and Manual Therapy at the Free University Brussels (20012005), non-resident teacher Evidence Based Practice at College of Physiotherapy Amsterdam (2002-2003), and is a member of the editorial board of Stimulus, a Dutch physiotherapy journal (2003-). 


\section{PUBLICATIONS}


Swinkels-Meewisse,E.J., Roelofs,J., Schouten,E.G.W., Verbeek,A.L., Oostendorp, R.A., and Vlaeyen,J.W.S. Fear of movement/(re)injury predicting chronic disabling low back pain: a prospective inception cohort study. Spine 2006; 31 (6): 658-664.

\section{Swinkels RAHM, Bouter LM, Oostendorp RAB, Swinkels-Meewisse EJCM,}

Dijkstra PU, Vet HCW de. Construct validity of impairment measures in rheumatic disorders: Which Constructs are selected for validation? A systematic review. Clin Exp Rheum 2006; 24 (1): 93-102.

Swinkels-Meewisse,I.E., Roelofs,J., Oostendorp,R.A.B., Verbeek,A.L., and Vlaeyen,J.W.S. Acute low back pain: pain-related fear and pain catastrophizing influence physical performance and perceived disability. Pain 2006; 120 (1-2): 3643.

Swinkels-Meewisse,I.E., Roelofs,J., Verbeek,A.L., Oostendorp,R.A., and Vlaeyen, J.W. Fear-avoidance beliefs, disability, and participation in workers and non-workers with acute low back pain. Clin J Pain 2006; 22 (1): 45-54.

Swinkels-Meewisse,E.J.C.M. Pijn-gerelateerde angst bij patiënten met acute lage-rugpijn. Jaarboek Fysiotherapie Kinesitherapie. Houten.: Bohn Staffleu van Loghum, 2004: pp. 218-231.

Swinkels-Meewisse,E.J., Roelofs,J., Swinkels,R.A., Verbeek,A.L., Vlaeyen,J.W.S., and Oostendorp,R.A. Statistics and pain-related fear measures in acute low back pain. Man. Ther. 2004; 9 (1): 47-48.

Swinkels-Meewisse,E.J., Swinkels,R.A., Verbeek,A.L., Vlaeyen,J.W.S., and Oostendorp,R.A. Psychometric properties of the Tampa Scale for kinesiophobia and the fear-avoidance beliefs questionnaire in acute low back pain. Man.Ther. 2003; 8 (1): 29-36.

Swinkels-Meewisse,E.J., Roelofs,J., Verbeek,A.L., Oostendorp,R.A., and Vlaeyen, J.W.S. Fear of movement/(re)injury, disability and participation in acute low back pain. Pain 2003; 105 (1-2): 371-379.

Swinkels-Meewisse,E.J. Klinimetrie; De Tampa schaal voor Kinesiofobie. Stimulus 2003; 22 (4): 284-299. 
Swinkels,R.A.H.M. and Swinkels-Meewisse,E.J.C.M. Klinische diagnostiek van zwangerschapsgerelateerde lage-rugpijn in de fysiotherapiepraktijk. Jaarboek Fysiotherapie Kinesitherapie. Houten: Bohn Staffleu van Loghum, 2002: pp. 228243.

Barbaix E, Meewisse EJCM, Janssens V, Van Roy P. "Observation d'un muscle surneméraire de la nuque: le muscle rhomboïde de l'atlas". Bulletin "De l'Association des morphologistes". 1998; 82 (257): 19-20. 